\title{
Identifizierung und Charakterisierung der Hüllproteine von pflanzlichen COP Vesikeln
}

\author{
Dissertation \\ zur Erlangung des Doktorgrades \\ der Mathematisch-Naturwissenschaftlichen Fakultäten \\ der Georg-August-Universität zu Göttingen
}

vorgelegt von

Ali Movafeghi

aus Tabriz/Iran

Göttingen 2000 
Referent:

Korreferent:

Tag der mündlichen Prüfung:
Prof. D.G. Robinson

Prof. H.-W. Heldt

02.11.2000 
Abkürzungen und Symbole .....................................................................................................

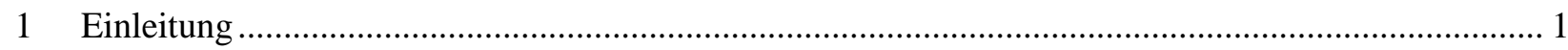

1.1 Das endoplasmatische Retikulum: Anfang des sekretorischen Weges, ............................. 1

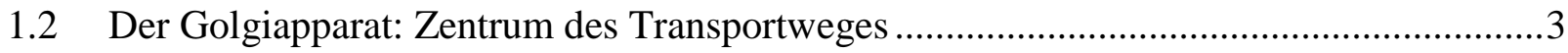

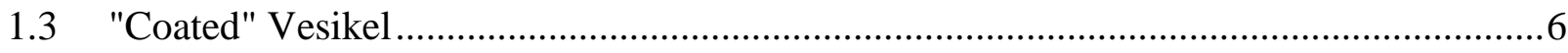

1.3 .1 Clathrin-"coated" Vesikel .......................................................................................

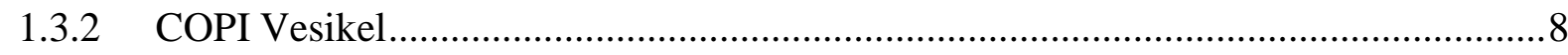

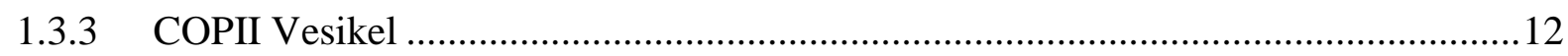

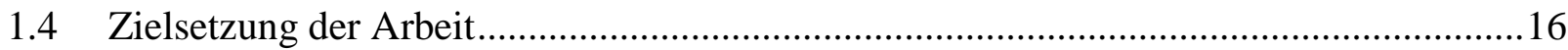

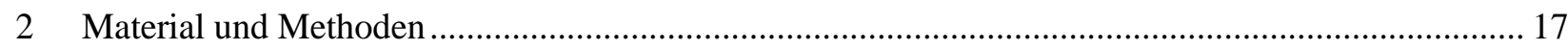

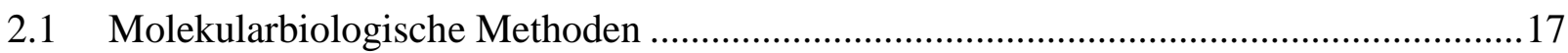

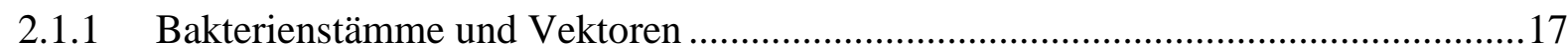

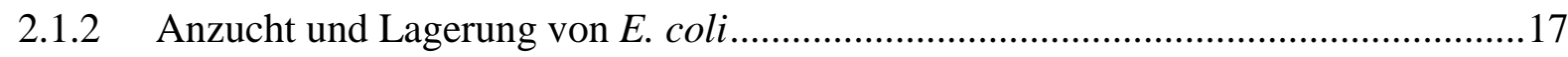

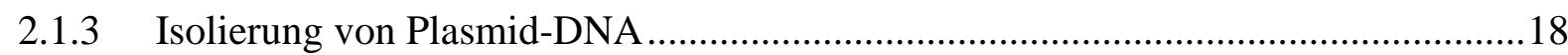

2.1.3.1 Isolierung im kleinen Maßstab (Mini-Präparation) .............................................. 18

2.1.3.2 Isolierung im mittleren Maßstab (Midi-Präparation) ............................................. 19

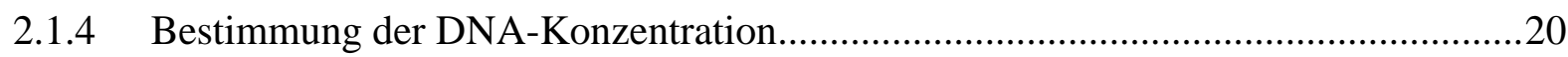

$2.1 .5 \quad$ Fragmentierung von DNA mit Restriktionsendonukleasen ......................................20

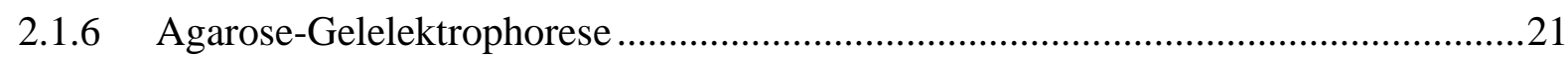

2.1 .7 Isolierung von DNA aus Agarose-Gelen, .................................................................22

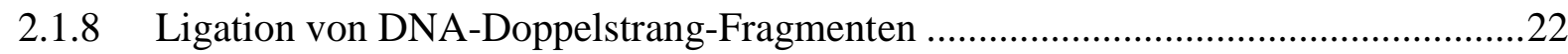

2.1 .9 Transformation von E. coli mit Plasmid-DNA .....................................................23

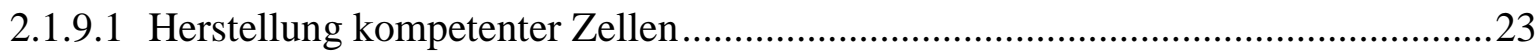

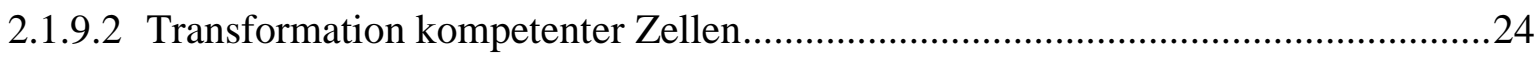

2.1 .10 Identifizierung und Sequenzierung von EST-cDNA-Klonen ..................................24

2.1.11 Expression und Aufreinigung der GST-Fusionsproteine und Antikörperherstellung 24

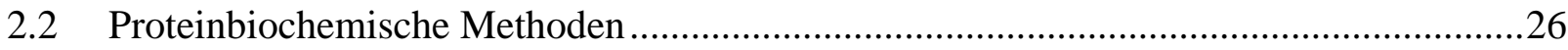

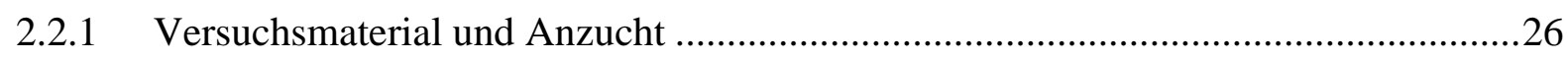

2.2 .2 Präparation von Cytosol und mikrosomalen Membranen .........................................28

2.2 .3 Aufarbeitung cytosolischer Proteine ......................................................................29

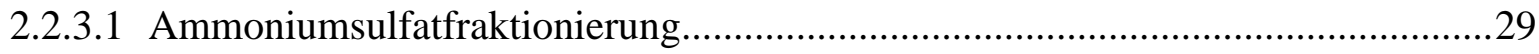

2.2.3.2 Trennung cytosolischer Proteine durch Gelfiltration............................................. 31

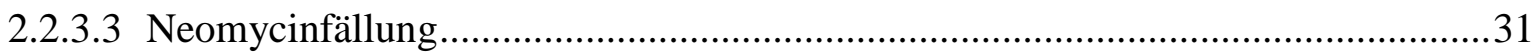

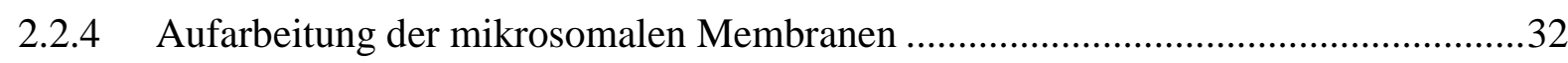

2.2.4.1 Trennung mikrosomaler Membranen mit der Gelfiltrationschromatographie.........32

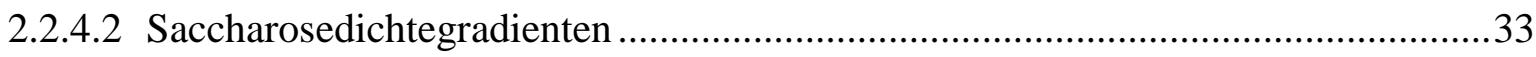

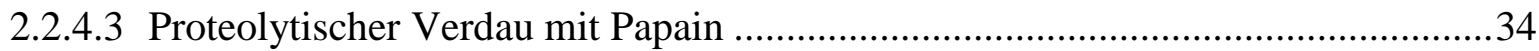

2.2.4.4 Membranbehandlung mit verschiedenen Reagenzien,..........................................35

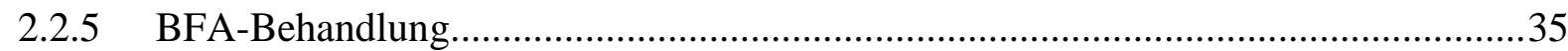

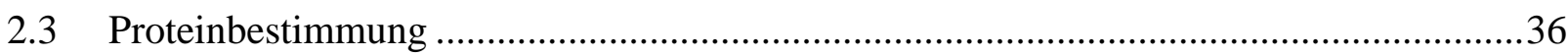




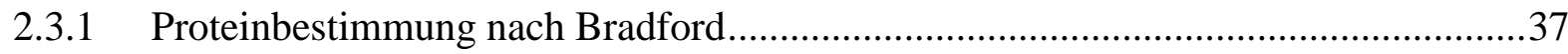

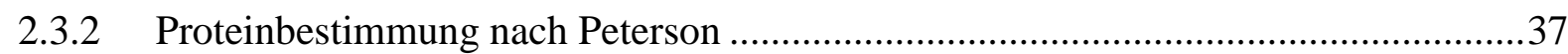

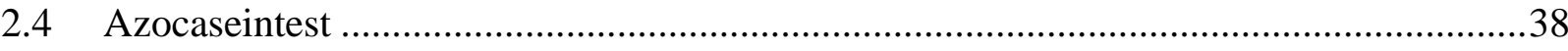

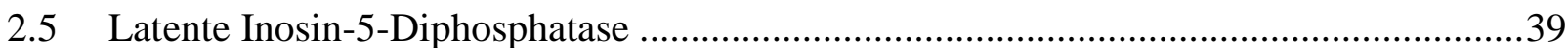

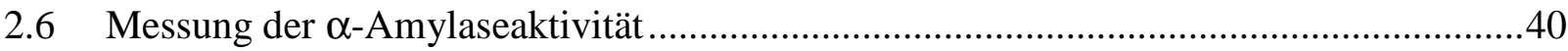

2.7 Antikörperaufreinigung über eine Protein A-Sepharosesäule ..........................................41

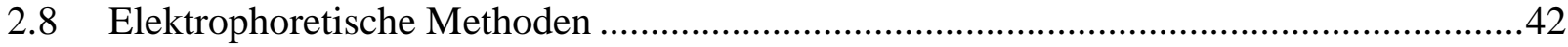

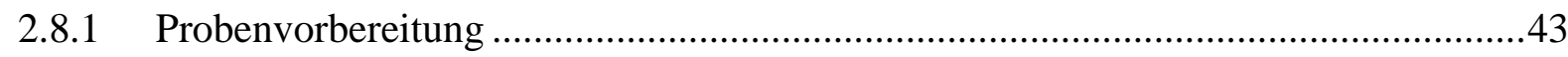

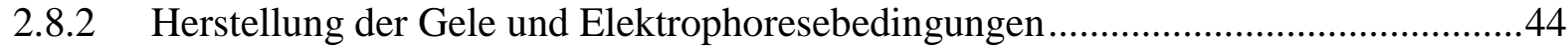

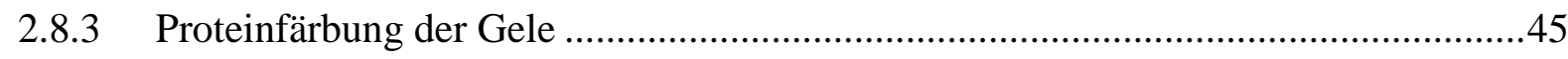

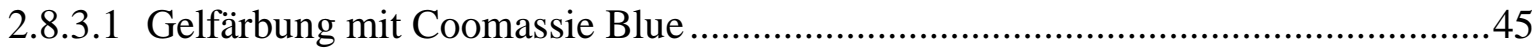

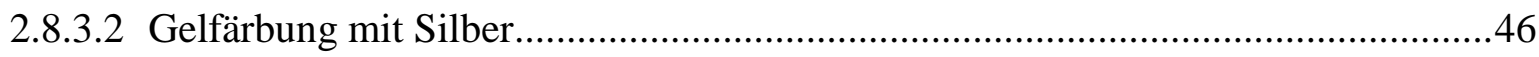

2.8 .4 Elution von Proteinen aus Polyacrylamidgelen ....................................................47

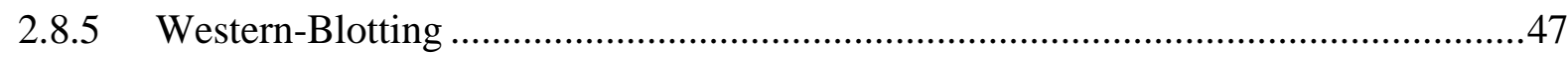

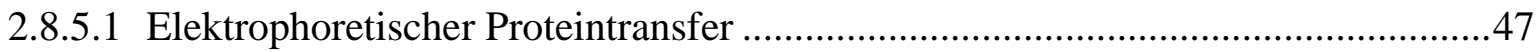

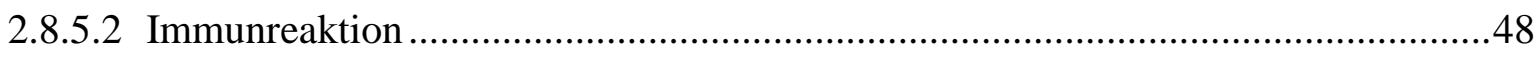

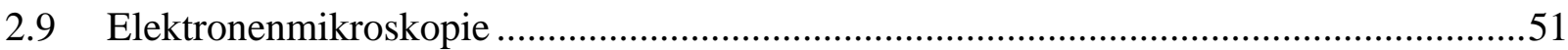

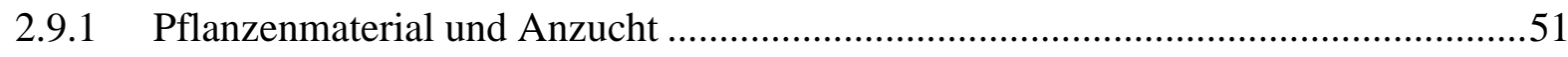

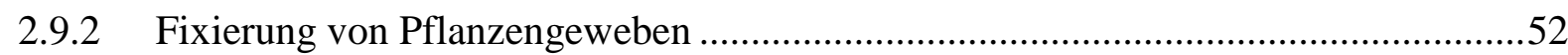

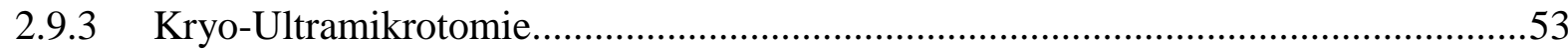

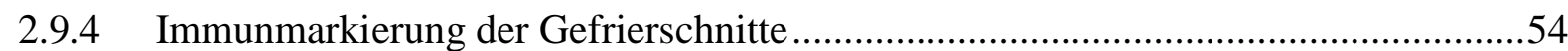

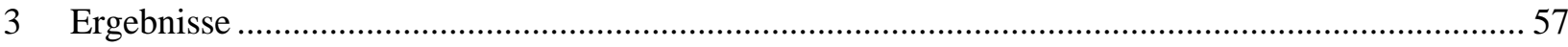

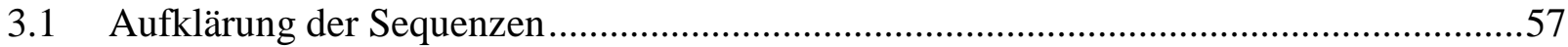

3.1.1 Die Sequenz der $\gamma$-COP-cDNA und die Klonierungsstrategie...................................57

3.1.2 Die Sequenz der AtSec23-cDNA und die Klonierungsstrategie................................62

3.2 Lokalisierung von At $\gamma$-COP und AtSec23p in den Cytosol- und Membranfraktionen ....66

3.3 Charakterisierung von At $\gamma$-COP und AtSec23p aus dem Cytosol ....................................67

3.3.1 Ammoniumsulfatfällung von At $\gamma$-COP und AtSec 23p............................................68

3.3.2 At $\gamma$-COP und AtSec23p als Bestandteile von Proteinkomplexen ...............................70

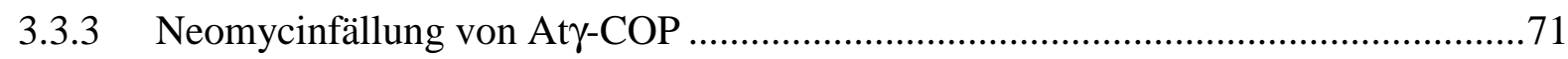

3.4 Membranassoziation von At $\gamma$-COP und AtSec23p..................................................... 72

3.4.1 At $\gamma$-COP und AtSec23p als periphere Membranproteine.......................................72

3.4.2 Beeinträchtigung der Membranbindung von At $\gamma$-COP und AtSec $23 p$ durch niedrige

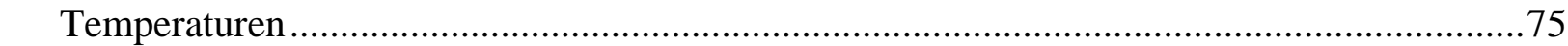

3.4.3 Einfluss von BFA auf die membrangebundenen At $\gamma$-COP und AtArf1p ..................77

3.4.4 Gelfiltrationschromatographie der mikrosomalen Membranen..................................78

3.4.5 Membrangebundene At $\gamma$-COP und AtSec23p in Saccharosedichtegradienten..........80

3.5 Lokalisierung der COPI-Hüllproteine in Wurzelspitzenzellen............................................84

3.6 Lokalisierung von AtSec21p in Zellen von Erbsenkotyledonen ....................................89 
3.7 Elektronenmikroskopischer Nachweis für den Rücktransport von Proteinen aus dem cis-

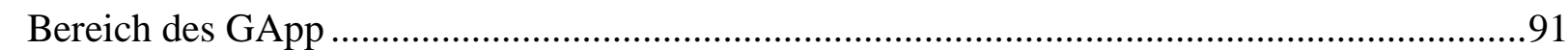

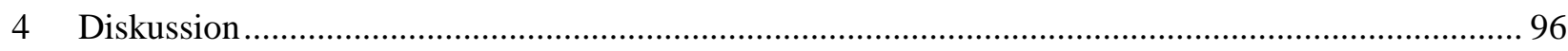

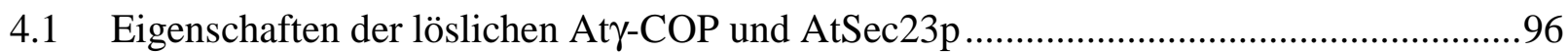

4.2 Physiologische Bedeutung der Membranbindung von At $\gamma$-COP und AtSec23p.............99

4.2.1 At $\gamma$-COP und AtSec23p an Membranen des GApp, des ER und der COP Vesikel. 100

4.2 .2 Verhinderung der Fusion von ER und GApp durch das Coatomer........................... 103

4.2 .3 COPI Vesikel im $c i s$-Bereich des GApp von Pflanzenzellen...................................105

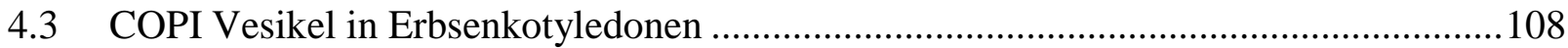

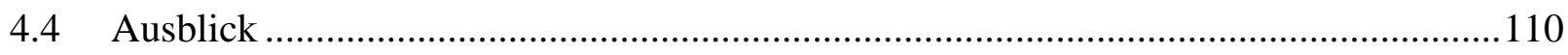

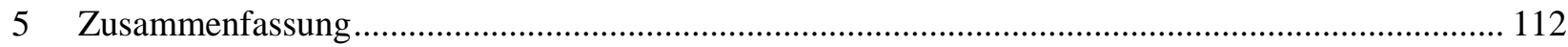

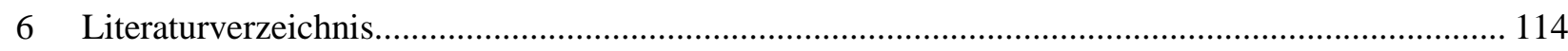

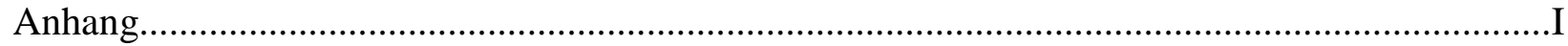




\section{Abkürzungen und Symbole}

${ }^{\circ} \mathrm{C}$

2,4-D

A

Abb.

ADP

AP

Arf

ATP

BFA

BiP

bp

BP-80

BSA

$\mathrm{CCV}$

$\mathrm{CHC}$

COP

DOC

DTT

DV

DXE

$\mathrm{E}$

E64

EDTA

ER

ERGIC

EST

FPLC

$\mathrm{g}$

GApp

GEF

$\mathrm{g}_{\max }$

GMP-PNP

GST

GTP

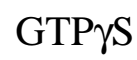

Grad Celsius

2,4-Dichlorphenoxyessigsäure

Ampere

Abbildung

Adenosindiphosphat

Adaptorkomplex

ADP-Ribosylierungsfaktor

Adenosintriphosphat

Brefeldin A

Bindungsprotein

Basenpaare

Bindungsprotein von $80 \mathrm{kDa}$

Rinderserumalbumin

Clathrin-"coated" Vesikel

schwere Ketten des Clathrins

"coat protein"

Desoxycholat

Dithiothreitol

Dense Vesikel

Asparaginsäure - beliebige Aminosäure - Glutaminsäure

Einstein

trans-Epoxysuccinyl-L-Leucylamido-(4-Guanido)-Butan

Ethylendiamintetraessigsäure

endoplasmatisches Retikulum

"ER-Golgi intermediate compartment"

"expressed sequence tagged site"

"fast protein liquid chromatography"

Gramm

Golgiapparat

Guaninnukleotid Austauschfaktor

maximale Erdbeschleunigung

5'-Guanylyl-Imidodiphosphat

Glutathion-S-Transferase

Guanosintriphosphat

Guanosin-5'-O-(3-thiotriphosphat) 
$\mathrm{h}$

H/KDEL

$\mathrm{H}^{+}$-ATPase

$\mathrm{H}_{2} \mathrm{O}$ bidest.

Hepes

HSP

IDPase

IPTG

Kap.

$\mathrm{kDa}$

KKXX

KTC

1

LMW

$\mathrm{M}$

Mes

$\min$

$\mathrm{mM}$

Mops

MPR

$\mathrm{NADH}$

ng

$\mathrm{nm}$

NPIR

p.a.

PBS

PCR

PLD

PM

PM-ATPase

PMSF

PSV

RGP

RT

$\mathrm{s}$

SDS-PAGE

SNARE
Stunde

Histidin/Lysin - Asparaginsäure - Glutaminsäure - Leucin

Protonen-ATPase

zweifach destilliertes Wasser

2,4-(2-Hydroxyethyl)-Piperazinyl-1-Ethansulfonsäure

Hitzeschockprotein

Inosin-5-Diphosphatase

Isopropyl- $\beta$-D-thiogalactopyranosid

Kapitel

Kilodalton

Lysin - Lysin - zwei beliebige Aminosäuren

Kalium-Tartrat-Karbonat-Reagenz

Liter

Marker für niedrige Molekularmassen

Molar

2-Morpholinoethansulfonsäure

Minute

Millimolar

3-Morpholinopropansulfonsäure

Mannose-6-Phosphat-Rezeptor

Nikotinamiddinkleotid (reduzierte Form)

Nanogramm

Nanometer

Asparagin-Prolin-Isoleucin-Arginin

pro analysi

Phosphat-gepufferte Kochsalzlösung

"partially coated reticulum"

Phospholipase D

Plasmamembran(en)

Plasmamembran- $\mathrm{H}^{+}$-ATPase

Phenylmethylsulfonylfluorid

Proteinspeichervakuole(n)

"reversibly glycosylated protein"

Raumtemperatur

Sekunde

Natriumdodecylsulfat-Polyacrylamidgelelektrophorese

SNAP-Rezeptor 
TBS

TCA

TEMED

TGN

Tris

Tween 20

U

Upm

$\mathrm{V}$

$\mathrm{v} / \mathrm{v}$

$\mathrm{v} / \mathrm{w}$

V-ATPase

$\mathrm{w} / \mathrm{w}$
Tris-gepufferte Kochsalzlösung

Trichloressigsäure

$\mathrm{N}, \mathrm{N}, \mathrm{N}$ ',N'-Tetramethylendiamin

trans-Golgi-Netzwerk

Tris(hydroxymethyl)aminoethan

Polyoxyethylensorbitanmonolaurat

Unit

Umdrehungen pro Minute

Volt

Volumen zu Volumen

Volumen zu Gewicht

vakuoläre $\mathrm{H}^{+}$-ATPase

Gewicht zu Gewicht 


\section{Einleitung}

Alle eukaryotischen Zellen sind durch Membranen in einzelne Kompartimente unterteilt, die spezifische Aufgaben wahrnehmen. Dabei ist jedes Kompartiment durch zahlreiche Proteine charakterisiert, die für seine Struktur und biochemische Aktivität entscheidend sind. Die Synthese, Sortierung und der korrekte Transport dieser Proteine zu ihren Zielorganellen sind sehr komplexe Vorgänge und müssen genau reguliert werden. Die Aufklärung des biosynthetischen Proteintransports steht seit den sechziger Jahren im Mittelpunkt zahlreicher zellbiologischer Untersuchungen.

Mit Ausnahme der Proteine, die in den Mitochondrien und Plastiden gebildet werden, erfolgt die Proteinsynthese an Ribosomen, die frei im Cytosol oder an Membranen des rauhen endoplasmatischen Retikulums (ER) gebunden vorliegen. Für die Sekretion bestimmte, lysosomale und vakuoläre Proteine sowie residente Proteine des Endomembransystems werden in das ER transportiert und als "sekretorische Proteine" zusammengefasst (Gilmore, 1993; Vitale und Denecke, 1999). Der Transportweg dieser Proteine wird auch als "sekretorischer Transportweg" bezeichnet (Chrispeels, 1991; Gomord und Faye, 1996). Verschiedene transitorische Vesikel verbinden die beteiligten Organellen miteinander und bringen die Proteine zu ihrem Zielkompartiment.

\subsection{Das endoplasmatische Retikulum: Anfang des sekretorischen Weges}

Das ER liegt als ein komplexes Netzwerk in eukaryotischen Zellen vor. Seine unterschiedlichen Domänen unterscheiden sich hinsichtlich ihrer Proteinausstattung und Funktion (Staehelin, 1997). Im Elektronenmikroskop lassen sich glatte Bereiche und von Ribosomen besetzte rauhe Gebiete, an welchen die Proteinbiosynthese stattfindet, unterscheiden. Da das ER eine wichtige Rolle bei der Biosynthese sekretorischer Proteine und ihrem Eingang ins Membransystem spielt, wird es auch als "Tor zum sekretorischen Weg" bezeichnet (Vitale und Denecke, 1999). Der Transport sekretorischer Proteine mit einer Molekularmasse über $8 \mathrm{kDa}$ in das ER ist mit ihrer Translation gekoppelt und heißt deswegen cotranslational (Rapoport et al., 1996). Die Biosynthese dieser Proteine beginnt zunächst an freien Ribosomen. Durch Bindung einer meist aminoterminalen, hydrophoben Signalsequenz an einen Signalerkennungspartikel (SRP), der wiederum an einen Rezeptor (sogenanntes "docking protein") der Zielmembran bindet, wird der Präprotein-SRP-Komplex zum ER dirigiert (Andrews und Johnson, 1996; Rapoport et al., 1996). Nach der Dissoziation des Komplexes wird die Biosynthese der Proteine fortgesetzt, wobei die noch ungefaltete Polypeptidkette durch eine Pore mit einem Durchmesser von 4-6 nm in das Lumen des ER sekretiert wird (Hamman et al., 1997). Das aminoterminale Signalpeptid löslicher Proteine wird dabei cotranslational durch eine Endopeptidase entfernt (Evans et al., 1986; Walter 
und Johnson, 1994). Proteine, die eine kleinere Molekularmasse als $8 \mathrm{kDa}$ haben, werden posttranslational und unabhängig vom SRP in das ER hinein transportiert (Klappa et al., 1994; Panzner et al., 1995). Membranproteine werden entweder aufgrund einer Stopp-TransferSequenz, die die Translokation am carboxyterminalen Bereich der Proteine blockiert, oder mit Hilfe der Signal-Anker-Sequenzen als transmembrane Domänen in der Membran verankert (Spiess, 1995; Wahlberg und Spiess, 1997).

Der Transport, die Sortierung und die Modifikationen sekretorischer Proteine werden ebenfalls durch spezifische Signale in der Sequenz oder der Struktur der entstehenden Polypeptide festgelegt. Bereits im Lumen des ER erfolgen erste Modifikationen wie die Ausbildung von Disulfidbrücken, die N-Glykosylierung, Faltung und Oligomerisierung unter der Mitwirkung der molekularen Chaperone. Den Chaperonen wird die Funktion einer Qualitätskontrolle im ER zugeschrieben (Hammons und Helenius, 1995; Kopito, 1997). Sie erleichtern und steuern die Faltung und Oligomerisierung der Polypeptide und verhindern den Weitertransport fehlerhaft gefalteter Proteine (Hartl, 1996; Ellis und Hartl, 1999). Zu den bekanntesten Vertretern der löslichen Chaperone im ER zählen das Bindungsprotein (BiP), Calreticulin und die Proteindisulfidisomerase (PDI) (Denecke, 1996; Galili et al., 1998). Molekulare Chaperone können auch als membrangebundene Proteine vorkommen. Das beste Beispiel dafür ist Calnexin, dem eine wichtige Funktion an der Faltung der Glykoproteine in Zusammenarbeit mit BiP und Calreticulin zugeschrieben wird (Tatu und Helenius, 1997; Molinari und Helenius, 2000).

Der nächste Schritt im sekretorischen Weg ist der Proteintransport vom ER zum Golgi-Apparat (GApp), der von speziellen COPII Vesikeln ermöglicht wird (siehe Kap. 1.3.3). Dabei müssen Proteine, die ihre Funktion im ER erfüllen, in diesem Kompartiment zurück gehalten werden. Das kann prinzipiell sowohl durch eine Verhinderung des Austritts aus dem ER als auch durch einen selektiven Rücktransport erklärt werden (Gomord et. al., 1999; Pagny et al., 1999, 2000). Trotz der Unstimmigkeiten über den selektiven Export aus dem ER (siehe Kap. 1.3.3), wird für ER-residente lösliche Proteine im Allgemeinen ein selektiver Rücktransport aus dem GApp angenommen (Teasdale und Jackson, 1996; Gomord et. al., 1999). Zu diesem Zweck besitzen lösliche ER-residente Proteine in der Regel ein carboxyterminales Tetrapeptid (Denecke et al., 1992), die sogenannte KDEL- (in Säuger- und Pflanzenzellen; Munro und Pelham, 1987) oder HDEL-Sequenz (in Hefen- und Pflanzenzellen; Pelham, 1988), das als Retentionssignal fungiert. Am cis-Golgi wird diese Sequenz von einem Rezeptor gebunden, der mit seinem Liganden zum ER zurückgebracht wird (Lewis und Pelham, 1990; Griffiths et al., 1994). Residente ERMembranproteine in Hefe und Säugetieren besitzen ebenfalls spezifische Signale wie das diLysin-Motiv (KKXX oder KXKXX), das deren Rücktransport zum ER vermittelt (Jackson et al., 1993; Townsley und Pelham, 1994). Da dieses Motiv auch in der $\Omega-3$ Desaturase von Arabidopsis nachgewiesen wurde, liegt die Vermutung nahe, dass das di-Lysin-Motiv in eukaryotischen Zellen konserviert ist (Arondel et al., 1992). An dem selektiven Rücktransport der 
löslichen und membrangebundenen Proteine zum ER sind COPI Vesikel beteiligt, deren Hülle anders als die der COPII Vesikel aufgebaut ist (siehe Kap. 1.3.2).

\subsection{Der Golgiapparat: Zentrum des Transportweges}

Der GApp nimmt eine zentrale Position im sekretorischen Transportweg ein (Rothman, 1994; Hawes und Satiat-Jeunemaitre, 1996). In tierischen Zellen besteht der GApp aus einem Komplex von miteinander verbundenen Zisternenstapeln und ist oft in der Nähe des Zellkerns zu finden (Rambourg und Clermont, 1997; Farquhar und Palade, 1998). Dagegen ist der GApp in Pflanzenzellen als Gesamtheit aller Dictyosomen im ganzen Cytoplasma verteilt (Robinson, 1985; Staehelin und Moore, 1995; Andreeva et al., 1998). Pflanzliche Zellen können sehr große Mengen von Golgistapeln pro Zelle enthalten (z. B. 300-600 in Maiswurzelspitzen) (Mollenhauer und Morré, 1994; Hawes und Satiat-Jeunemaitre, 1996; Driouich und Staehelin, 1997). Jedes Dictyosom besteht aus einem Stapel Zisternen, an deren Rändern kleinere Vesikel abknospen. Die Zahl der Zisternen pro Golgistapel liegt meist zwischen 5 und 7, kann in einigen Algen jedoch wesentlich höhere Werte erreichen (Becker und Melkonian, 1996). Diese Zahl variiert ebenso wie die Anzahl der Dictyosomen einer Zelle in Zusammenhang mit den physiologischen Bedingungen, dem Entwicklungsstadium und der Funktion der Zelle (Andreeva et al., 1998).

Im Golgistapel werden cis-, median- und trans-Bereich unterschieden, welchen verschiedene Funktionen zugeordnet werden (Rothman und Orci, 1992; Mollenhauer und Morré, 1994). Am cis-Bereich sind die Lumen der Zisternen weit und der Abstand zwischen ihnen ist gering. Im Gegensatz dazu haben die Zisternen am trans-Bereich ein schmales Lumen und weisen einen größeren Abstand voneinander auf (Robinson und Kristen, 1982). Zwischen den Zisternen sind gelegentlich sogenannte interzisternale Filamente zu erkennen, deren Dichte vom cis-Bereich zum trans-Bereich zunimmt. Sie dienen der zusätzlichen Verankerung integraler Membranproteine und halten die Zisternen eines Golgistapels zusammen (Cluett und Brown, 1992; Staehelin und Moore, 1995). Dem trans-Bereich benachbart befindet sich ein tubuläres, verzweigtes Membransystem, auf dem im Elektronenmikroskop Clathrin-Gitter erkennbar sind. Es wird in tierischen Zellen trans-Golgi-Netzwerk (TGN) (Griffiths und Simons, 1986) und in Pflanzenzellen "partially coated reticulum" (PCR) (Pesacreta und Lucas, 1984, 1985) genannt. Das PCR der Pflanzen ist vermutlich dem TGN in tierischen Zellen analog (Hillmer et al., 1988). In tierischen Zellen wurde auch ein "ER-Golgi intermediate compartment" (ERGIC) nachgewiesen (Schweitzer und Hauri, 1992; Pelham, 1995), das oft mit der cis-Zisterne assoziiert und wahrscheinlich dem cis-Golgi-Netzwerk (CGN) äquivalent ist (Teasdale und Jackson, 1996). Dieses Kompartiment zeichnet sich durch ein Protein von 53 kDa (ERGIC-53) aus (Farquhar und Hauri, 1997). Die Existenz von ERGIC oder eines Äquivalents von ERGIC-53 konnte in Pflanzenzellen bislang nicht nachgewiesen werden. 
Wichtigste Funktionen des GApp sind die Sortierung und Glykosylierung von Proteinen. Nverknüpfte Oligosaccharide von im ER entstandenen Glykoproteinen werden beim Transport durch den GApp unter der Mitwirkung von Glykosidasen und Glykosyl-Transferasen stufenweise modifiziert (Colley, 1997; Füllekrug und Nilsson 1998). Während die ersten Reaktionen im GApp der tierischen und pflanzlichen Zellen gleich sind, werden durch weitere Reaktionen organismusspezifische N-gebundene Oligoglykane aufgebaut. Bei Pflanzen enthalten diese Moleküle keine Sialinsäure als terminale Reste, sondern $\alpha-1,4$-Fucose und $\beta-1,3-$ Galactose. Außerdem haben sie einen hohen Gehalt an immunogener $\alpha$-1,3-Fucose und/oder $\beta$-1,2-Xylose (Lerouge et al., 1998; Rayon et al., 1998). Da die entstehenden Moleküle stärker als ihre Vorläufer verzweigt sind und zusätzliche Zuckerreste enthalten, werden sie komplexe Glykoproteine genannt (Sturm et al., 1987). Außer der Fortsetzung der N-Glykosylierung findet im GApp die ganze O-Glykosylierung statt. Dabei werden Zuckerreste einzeln - nicht en bloc wie im ER - auf Serin- und Tyrosinreste (bei Pflanzenzellen zusätzlich auf Hydroxyprolinreste) übertragen (Driouich und Staehelin, 1997). Die entstehenden Oligoglykane sind vermutlich weniger verzweigt als die komplexen Oligoglykane und bestehen vorwiegend aus Arabinose und Galactose (Staehelin und Moore, 1995). Eine weitere Funktion des GApp in Pflanzenzellen ist die Synthese der Zellwandpolysaccharide (mit Ausnahme von Zellulose). Daher enthält der GApp in Pflanzen eine größere Menge von Glykosyl-Transferasen (Driouich und Staehelin, 1997; Robinson und Hinz, 1999). Obwohl die an der Herstellung der Zellwandpolysaccharide beteiligten Enzyme teilweise identifiziert und charakterisiert worden sind, konnte bisher keines von ihnen aus Pflanzen isoliert und gereinigt werden (Hanna et al., 1991; Bruyant-Vannier et al., 1996; Baydoun und Brett, 1997).

Für den Transport zwischen cis- und trans-Bereich eines Dictyosomes werden zwei Modelle diskutiert. Nach dem klassischen Reifungsmodell, das vor allem aufgrund von Beobachtungen an Algen entwickelt wurde (Morré, 1987; Melkonian et al., 1991), entstehen im cis-Bereich neue Zisternen durch Fusion transitorischer Vesikel, die vom ER stammen (Mollenhauer und Morré, 1991). Jede einzelne Zisterne unterliegt einem Reifungsprozess und gelangt im Laufe ihrer Entwicklung zum trans-GApp, wo sie sich vom Stapel ablöst. Während dieses Durchwanderns wird transportiertes Material gemäß der Position im Stapel modifiziert. Im Gegensatz zu diesem Modell wird nach dem "vesicle shuttle"-Modell sowohl der anterograde als auch der retrograde intra-Golgi-Transport von Vesikeln ohne Clathrin-Hülle vermittelt (Farquhar und Palade, 1981; Balch et al., 1984; Orci et al., 1989). Dieses Modell konnte mit der Entdeckung der COPI Vesikel in Säugetieren (Orci et al., 1986; Malhotra et al., 1989) und Hefe (Hosobuchi et al., 1992; Duden et al., 1994) und der Aufklärung ihrer Funktion am intra-Golgi-Transport und am Transport vom GApp zum ER weiter unterstützt werden (Rothman und Wieland, 1996; Orci et al., 1998; Nickel und Brüger, 1999). Die Zisternenreifung wurde aber auch von neueren Untersuchungen bestätigt (Becker et al., 1995; Glick et al., 1997; Bonfanti et al., 1998). Dabei konnte gezeigt werden, dass 
bestimmte Makromoleküle (wie Schuppenplatten von Algen, Prokollagen und Kaseinaggregate) wegen ihrer Größe in den kleinen COPI Vesikeln nicht vorkommen können. Aus diesen Gründen gehen viele Arbeitsgruppen davon aus, dass beide Mechanismen zusammenwirken, wobei parallel zur Reifung der Zisternen der anterograde und der retrograde Transport durch COPI Vesikel stattfinden sollen (Bannykh und Balch, 1997; Gaynor und Emr, 1997; Mironov et al., 1997). An dem anterograden und dem retrograden Vesikeltransport sind zwei unterschiedliche Populationen von COPI Vesikeln beteiligt (Orci et al., 1997). Diese Populationen werden als COPI-a und COPI-r (von anterograd und retrograd) bezeichnet und können auf der Basis ihrer Frachtmoleküle voneinander unterschieden werden (Lowe und Kreis, 1998).

Das TGN stellt die zentrale Sortierungsstelle für lysosomale, vakuoläre, zu sezernierende und Plasmamembranproteine dar (Griffiths und Simons, 1986; Rothman und Orci, 1992; Traub und Kornfeld, 1997). Lösliche Proteine, die keine besonderen Signale aufweisen, gelangen von dort zur Zelloberfläche. Dieser Transportweg wird als "default pathway" bezeichnet (Pfeffer und Rothman, 1987; Denecke et al., 1990). Im Gegensatz dazu werden Proteine, die für das lytische Kompartiment bestimmt sind, aufgrund eines spezifischen Signals am TGN in Vesikel mit einer clathrinhaltigen Hülle (Clathrin-"coated" Vesikel = CCV) sortiert (siehe Kap. 1.3.1). In Säugetierzellen fungieren Mannose-6-Phosphat-Reste bei einem Großteil lysosomaler saurer Hydrolasen als Sortierungssignal. Diese werden von einem integralen Membranprotein am TGN dem Mannose-6-Phosphat-Rezeptor (MPR) gebunden (Kornfeld, 1992; Braulke, 1996). Mannose-6-Phosphat-Reste spielen bei der Zielsteuerung zur lytischen Vakuole in Pflanzen dagegen keine Rolle. Die Sortierung der vakuolären Proteine in Pflanzenzellen erfolgt entweder durch dreidimensionale Muster in der gefalteten Polypeptidkette ("signal patches") oder aufgrund bestimmter Aminosäuresequenzen an aminoterminalen oder carboxyterminalen Propeptiden sowie im Mittelbereich der reifen Proteine (Chrispeels, 1991; Neuhaus, 1996; Neuhaus und Rogers, 1998; Matsuoka and Neuhaus; 1999). Eine Consensus-Sequenz scheinen einige aminoterminale Sortierungssignale in Form einer NPIR-Sequenz aufzuweisen. Diese Sequenz bindet mit hoher Affinität an ein integrales Membranprotein mit einer Molekularmasse von $80 \mathrm{kDa}$ (BP-80) aus CCVs. Dieses Protein wurde zuerst aus Erbsenkotyledonen isoliert und ist wahrscheinlich der Sortierungsrezeptor für pflanzliche, vakuoläre Hydrolasen (Kirsch et al., 1994, 1996). Homologe zu BP-80, die wahrscheinlich die gleiche Rolle bei der Proteinsortierung spielen, wurden jetzt auch in anderen Pflanzen identifiziert (Paris und Rogers, 1996; Ahmed et al., 1997; Paris et al., 1997; Shimada et al., 1997; Jiang und Rogers, 1999; Miller et al., 1999). Kürzlich konnte aber gezeigt werden, dass BP-80 nicht nur die aminoterminale NPIR-Sequenz sondern auch carboxyterminale Motive anderer Liganden bindet (Cao et al., 2000). Der MPR der Säugetiere bindet über ein tyrosinhaltiges Motiv in der cytoplasmatischen Domäne an die Proteinhülle der CCVs. Dieses Motiv konnte in BP-80 ebenfalls nachgewiesen werden. Weiterhin bindet das BP-80 an Untereinheiten der Proteinhülle der CCVs aus Säugetieren (Sanderfoot et al., 
1998). Deshalb scheint die Zielsteuerung von vakuolären Proteinen in Pflanzenzellen und lysosomalen Hydrolasen in Säugetieren trotz vieler Unterschiede, grundlegend ähnlich zu sein.

\section{3 "Coated" Vesikel}

Viele charakterisierte Transportvesikel besitzen eine Proteinhülle auf ihrer Oberfläche und werden als sogenannte "coated" Vesikel bezeichnet (Robinson et al., 1998). Nach Untersuchungen in Hefe und Säugetieren werden sie in zwei Hauptklassen unterteilt. Zu der ersten Klasse gehören vier Typen von Vesikeln, die gemeinsam als Clathrin-"coated" Vesikel (CCV) definiert werden und deren Proteinhülle aus Clathrin und Adaptorkomplexen aufgebaut wird. Die zweite Klasse umfasst die COP Vesikel. Zwei Arten von COP Vesikeln (COPI und COPII Vesikel) sind in Hefe und Säugetieren identifiziert worden. Sie wurden aber bis zu Beginn der vorliegenden Arbeit in Pflanzenzellen nicht nachgewiesen. Diese Vesikel unterscheiden sich grundlegend in ihrer Größe, ihrem Inhalt und der Struktur ihrer Proteinhülle von den CCVs (Scales et al., 2000). Sowohl bei CCVs als auch bei COP Vesikeln sind die Hüllstrukturen für die Abknospung, die Selektion der Inhaltsproteine und die Regulation einer Fusion mit anderen Membranen von Bedeutung (Schmid und Damke, 1995; Robinson, 1997).

Für die Steuerung der Vesikel zu den richtigen Zielorganellen sind typische, in allen Eukaryoten vorkommende Membranproteine, die sogenannten SNAREs ("SNAP-receptor") verantwortlich (Söllner et al., 1993; Weber et al., 1998). Es existiert jeweils ein SNARE-Paar: eines in der Vesikelmembran, das v-SNARE, und eines in der Zielmembran ("target"), das t-SNARE. Bei "coated" Vesikeln ist die Wechselwirkung zwischen den SNAREs erst nach Dissoziation der Proteinhülle möglich (Tanigawa et al., 1993; Lowe und Kreis, 1998). Die Funktion der SNAREs wird durch andere Proteine wie Rab-GTPasen (Homologe zu Ypt-GTPasen in Hefe) und myosinähnliche "docking"-Faktoren reguliert (Schimmöller et al., 1998; Pfeffer, 1999). An der Fusion der Vesikel sind auch cytosolische Faktoren wie NSF (N-Ethyl-Maleimide-sensitiver Faktor) und SNAPs ("soluble NSF-attachment Proteins") beteiligt (Goda und Pfeffer, 1991; Whiteheart et al., 1992). Die Fusion wird durch die Interaktion des v-SNARE mit dem t-SNARE eingeleitet. Nach der Anlagerung von SNAP und NSF an den SNARE-Komplex erfolgt die Fusion. Nach der Membranfusion führt eine von NSF katalysierte ATP-Hydrolyse zur Freisetzung von SNAPs und NSF vom Komplex und zur Dissoziation des t-SNARE vom vSNARE (Whiteheart et al., 1994; Pfeffer, 1996; Matveeva und Whiteheart, 1998). Seit Entdeckung der pflanzlichen Homologe von t-SNAREs (Bassham et al., 1995; Conceição et al., 1997; Sanderfoot et al., 1999) und NSF (Hugueney et. al., 1995) wird vermutet, dass die Sortierung der Vesikel zum Zielkompartiment und die anschließende Membranfusion der Vesikel mit ihrem Zielkompartiment auch in diesen eukaryotischen Zellen nach dem gleichen Prinzip abläuft (Sanderfoot und Raikhel, 1999). 


\subsubsection{Clathrin-"coated" Vesikel}

CCVs vermitteln in tierischen Zellen die rezeptorgekoppelte Endozytose und den Transport lysosomaler, saurer Hydrolasen aus dem TGN (Robinson, 1994; Schekman und Orci, 1996). In Hefe wurden bislang CCVs in situ nicht gesehen, obwohl ihre Beteiligung sowohl an der rezeptorgekoppelten Endozytose als auch an der Sortierung von Proteinen am TGN angenommen wird (Payne et al., 1988; Seeger und Payne, 1992; Chu et al., 1996, 1999; Huang et al., 1997). In Pflanzenzellen sind sie am Transport vakuolärer Proteine (Harley und Beevers, 1989; Hoh et al., 1991; Robinson und Hinz, 1997) und wahrscheinlich auch an endozytotischen Prozessen beteiligt. Hierfür sprechen "clathrin-coated pits" an der Plasmamembran (PM), in deren unmittelbarer Nähe CCVs zu finden sind (Hawes et al., 1995; Robinson, 1996).

CCVs, deren Durchmesser meist 70-100 nm beträgt, sind durch ihre charakteristische Hülle gekennzeichnet. Diese Hülle enthält vor allem die in sogenannten Triskelien angeordneten Ketten des Clathrins sowie spezifische Adaptorproteine, die zwischen den Triskelien und der Membran liegen (Robinson, 1996). Das Triskelion ist eine dreibeinige Struktur, wobei jedes Bein aus je einer schweren Kette ("clathrin heavy chain" = CHC) und einer leichten Kette ("clathrin light chain" = CLC) zusammengesetzt ist. Die hochkonservierte CHC ist in Pflanzenzellen (Robinson und Depta, 1988) und in Hefe (Mueller und Branton, 1984) mit 190 kDa um 10 kDa schwerer als die tierischer CCVs. In Rinderhirn wurden zwei CLCs $\left(\mathrm{CLC}_{\mathrm{a}}\right.$ und $\left.\mathrm{CLC}_{\mathrm{b}}\right)$ mit einer Molekularmasse von 36 und $33 \mathrm{kDa}$ identifiziert, die zu $60 \%$ identisch sind. Im Gegensatz zu Säugetieren besitzt Hefe nur eine CLC von $38 \mathrm{kDa}$, deren Aminosäure-Identität zur Säuger-CLC ${ }_{\mathrm{a}}$ nur $16 \%$ und zur CLC b $_{1} 18 \%$ beträgt (Silveira et al., 1990). In Pflanzen werden Proteine von 45 und $52 \mathrm{kDa}$ aus Zucchinihypokotylen und von 40 bis $50 \mathrm{kDa}$ aus Erbsenkotyledonen als CLCs beschrieben (Lin et al., 1992; Demmer et al., 1993). Als mögliche Funktion wird den CLCs eine Beteiligung an der Regulation der Zusammenlagerung (Ungewickell und Ungewickell, 1991; Ybe et al., 1998) und der Dissoziation der Triskelien zugesprochen (Schmid et al., 1984).

Die Bildung von CCVs beginnt mit der Ansammlung von Rezeptor-Liganden-Komplexen in bestimmten Bereichen der Donormembranen. Diese Ansammlung wird durch spezifische Adaptorkomplexe (AP-Komplexe) vermittelt (Robinson et al., 1998; Hirst und Robinson 1998). Bisher sind vier verschiedene AP-Komplexe beschrieben worden, die gemäß der Reihenfolge ihrer Entdeckung als AP-1-, AP-2-, AP-3- und AP-4-Komplex bezeichnet werden. Der AP-1Komplex wurde am TGN und an frühen Endosomen lokalisiert (Ahle et al., 1988; Le Borgne et al., 1996). Der AP-2-Komplex wurde hauptsächlich an der PM, aber auch an Endosomen und Lysosomen gefunden (Pearse und Robinson, 1990; Traub et al., 1996). Kürzlich konnte der AP3-Komplex am TGN und/oder in einem post-Golgi-Kompartiment identifiziert werden (Simpson et al., 1997; Dell'Angelica, 1997). Dieser AP-Komplex konnte zwar mit Clathrin kolokalisiert werden (Dell'Angelica, 1998), aber es wurde auch ein AP-3 vermittelter, clathrinunabhängiger 
Transport beschrieben (Vowels und Payne, 1998). Der zuletzt entdeckte AP-4-Komplex wurde am TGN oder einem diesem nahestehenden Kompartiment nachgewiesen und scheint mit Clathrin nicht assoziiert zu sein (Dell'Angelica et al., 1999; Hirst et al., 1999). In molekularbiologischen Arbeiten wurden cDNA-Klone aus Pflanzen isoliert, deren abgeleitete Proteine Homologien zu Bestandteilen tierischer AP-Komplexe zeigen (Maldonado-Mendoza und Nessler, 1996, 1997; Happel et al., 1997; Roca et al., 1998; Schledzewski et al., 1999). Die AP-Komplexe sind Heterotetramere und binden an die cytoplasmatische Domäne der Rezeptoren. An die Adaptoren (mit Ausnahme von AP-4) lagern sich cytoplasmatische Triskelien an und ermöglichen dadurch die Abknospung von CCVs (Robinson, 1996). Durch die Aktivität einer "uncoating"-ATPase, die eine Dissoziation der Triskelien ermöglicht, verlieren die CCVs kurz nach dem Abschnüren ihre Hüllstruktur und können so mit ihrem Zielkompartiment fusionieren (Ungewickell, 1985; Ungewickell et al., 1995).

\subsubsection{COPI Vesikel}

COPI Vesikel sind an dem selektiven Transport von Proteinen im GApp und vom GApp zum ER beteiligt. Sie wurden durch elektronenmikroskopische Untersuchungen an isolierten Dictyosomen aus "chinese hamster ovary"-Zellen (CHO-Zellen) entdeckt (Orci et al., 1986). In Säugetieren sind sie mit einem Durchmesser von 70-80 nm kleiner als CCVs und ihre Proteinhülle hat eine Dicke von $10 \mathrm{~nm}$. Der Bildungsort der COPI Vesikel befindet sich im Gegensatz zu den CCVs nicht am TGN, sondern an den seitlichen Enden der Zisternen. Obwohl sie überwiegend am cisBereich der Dictyosomen nachgewiesen werden können, knospen sie von allen Zisternen eines Dictyosomes ab (Oprins et al., 1993; Orci et al., 1997). COPI Vesikel wurden erstmals isoliert, nachdem gereinigte Dictyosomen aus Kaninchenleber mit cytosolischen Proteinen in Gegenwart von GTP $\gamma$ S - ein nicht hydrolysierbarer Analog von GTP - inkubiert worden waren (Malhotra et al., 1989). In den isolierten Vesikeln wurde Albumin, ein Sekretprotein aus Hepatocyten, nachgewiesen. Dadurch konnte die Beteiligung dieser Vesikel am sekretorischen Transportweg in Säugetieren gezeigt werden. Diese Vesikel und ihre Bestandteile konnten aber bis zu Beginn der vorliegenden Arbeit in Pflanzen nicht identifiziert werden.

Die Proteinhülle der COPI Vesikel setzt sich aus dem ADP-Ribosylierungsfaktor (Arf) und dem Coatomer zusammen. Das Coatomer besteht aus sieben Untereinheiten, die bei Säugetieren als $\alpha-, \beta-, \beta-, \gamma-, \delta-, \varepsilon-$ und $\zeta$-COP bezeichnet werden. Sie assoziieren im Cytosol posttranslational in 1-2 $\mathrm{h}$ miteinander und bilden das Coatomer (Lowe und Kreis, 1996; Schekman und Orci, 1996). Ihre Homologe in Hefe sind Produkte von bestimmten Sec (von "secretion") und Ret (von "retrieval") Genen (siehe Tabelle 1.1), die alle mit Hilfe der defekten Mutanten an dem Transport zwischen ER und Golgi identifiziert wurden (Harter, 1999). Drei COPs zeigen strukturelle Homologien zu den Adaptinmolekülen der CCVs ( $\beta$-COP zu $\beta$-/ $\beta$-Adaptin, $\delta$-COP zu $\mu$ - 
Adaptin, und $\zeta$-COP zu $\delta$-Adaptin). Dennoch wurde bisher keine funktionelle Ähnlichkeit zwischen Coatomer und Adaptorkomplexen nachgewiesen (Harter, 1999). Eine andere Homologie zu bestimmten Membranproteinen zeigen $\alpha$-COP und $\beta$ '-COP durch WD-40 Sequenzen in ihren aminoterminalen Domänen (Neer et al., 1994). WD-40 Sequenzen bestehen aus 40 Aminosäuren und haben Asparaginsäure und Tryptophan als Motivende. Sie sind sowohl aus der $\beta$-Untereinheit der trimeren GTP-bindenden Proteine (G-Proteine) als auch aus den Untereinheiten von anderen oligomeren Proteinkomplexen bekannt und haben eine Funktion in der Protein-Protein- oder einer Protein-Membran-Wechselwirkung. Die Funktion der WD-40 Sequenzen beim Coatomer ist jedoch noch nicht geklärt.

Durch Behandlung mit hohen Salzkonzentrationen und dem Reagenz Dimetyl Maleic Anhydrid (DMMA) wurde die Wechselwirkung zwischen Untereinheiten des Coatomers untersucht. Damit konnten ein $\alpha / \beta^{\prime} / \varepsilon$-COP Trimer, ein $\beta / \delta$-COP Dimer und ein $\gamma / \zeta$-COP Dimer identifiziert werden (Lowe und Kreis, 1995; Pavel et al., 1998). Mit anderen Methoden wurde außer dem $\alpha / \beta^{\prime} / \varepsilon$-COP Trimer ein weiteres $\beta / \gamma / \zeta$-COP Trimer nachgewiesen. Dabei ist es nicht klar, wie $\delta$-COP mit beiden Subkomplexen assoziiert (Fiedler et al., 1996). Nach dem Entfernen von Salz oder Einstellung des pH-Wertes auf 6,5 (für DMMA modifizierte COPs) können alle Untereinheiten des Coatomers schnell wieder assoziieren.

Tabelle 1.1: Hüllproteine der COPI Vesikel und ihre Eigenschaften (Lowe und Kreis, 1998; Harter, 1999).

\begin{tabular}{|l|l|l|l|l|}
\hline $\begin{array}{l}\text { Protein in } \\
\text { Säugetieren }\end{array}$ & $\begin{array}{l}\text { Homologe } \\
\text { in Hefe }\end{array}$ & $\begin{array}{l}\mathbf{M}_{\mathbf{r}} \\
(\mathrm{kDa})\end{array}$ & Eigenschaften & bindende Proteine \\
\hline$\alpha$-COP & Ret1p & 135 & repetitive WD-40 Sequenzen & $\beta$-COP, $\varepsilon$-COP \\
\hline$\beta$-COP & Sec26p & 107 & homolog zu $\beta$-/ $\beta$-Adaptin & $\delta$-COP, Arf1p \\
\hline$\beta$-COP & Sec27p & 102 & repetitive WD-40 Sequenzen & $\alpha$-COP \\
\hline$\gamma$-COP & Sec21p & 98 & & $\zeta$-COP, Arf1p, p23, KKXX \\
\hline$\delta$-COP & Ret2p & 57 & homolog zu $\mu$-Adaptin & $\beta$-COP \\
\hline$\varepsilon$-COP & Sec28p & 36 & & $\alpha$-COP \\
\hline$\zeta$-COP & $\operatorname{Ret3p}$ & 21 & homolog zu $\delta$-Adaptin & $\gamma$-COP \\
\hline Arf1p & Arf1/2/3p & 21 & kleine GTPase & $\beta$-COP, $\gamma$-COP \\
\hline
\end{tabular}


Die Bildung von COPI Vesikeln wird durch Bindung von Arf1p an die Donormembran eingeleitet (Ostermann et al., 1993; Donaldson und Klausner, 1994). Arf1p ist eine Nmyristolierte GTPase und liegt im Cytosol als Arf1p-GDP vor. Durch den Austausch von GDP gegen GTP, der von einem oder mehreren membrangebundenen GDP-GTP-Austauschfaktoren (GEFs) katalysiert wird, bindet Arf1p mit seiner N-myristolierten Domäne an die Membran (Serafini et al., 1991; Kahn et al., 1992). Als spezifische GEFs für Arf1p sind in Hefe Gea1p, Gea2p und Sec7p identifiziert worden (Peyroche et al., 1996). Gea1p und Gea2p zeigen in der Mitte ihrer Struktur bei etwa 200 Aminosäuren Homologie zu einer funktionellen Domäne von Sec7p und sind deshalb gemeinsam als Sec7-Domäne-Familie bekannt. Mit Hilfe dieser Domäne binden sie an Arf1p-GDP und ermöglichen den GDP-GTP-Austausch. Brefeldin A (BFA), ein toxischer Metabolit aus Pilzen, stabilisiert in Hefe den Arf-GDP-Sec7-Domäne-Komplex und hemmt damit die Freisetzung von GDP (Peyroche et al., 1999). Dadurch werden der GDP-GTPAustausch, die Rekrutierung des Coatomers und infolgedessen die Bildung der COPI Vesikel verhindert (Orci et al., 1991; Donaldson et al., 1992; Helms und Rothman, 1992).

Bei der Rekrutierung des Coatomers wird eine Doppelfunktion für Arf1p postuliert. Einerseits wurde eine direkte Wechselwirkung zwischen Arflp und $\beta$-COP in in vitro isolierten Vesikeln nachgewiesen (Zhao et al., 1997). Es wird vermutet, dass diese Bindung von $\beta$-COP an das membrangebundene Arf1p die Anlagerung des Coatomers an die Membran ermöglicht. Andererseits wurde gezeigt, dass die Phospholipase D (PLD) in den Golgimembranen von Arf1pGTP aktiviert wird (Brown et al., 1993). Aktivierte PLD katalysiert die Bildung von Phosphatidinsäure und Cholin aus Phosphatidylcholin und führt zur negativen Ladung bestimmter Regionen der Membran. Das Coatomer kann nun rekrutiert werden, da es an negativ geladene Membrane bindet (Ktistakis et al., 1996). Andere Mitglieder der Arf-Familie spielen bei der Anlagerung der AP-Komplexe an ihre Donormembran eine Rolle. Dabei wird ebenfalls die vergleichbare Funktion der Arf-Proteine bei der Aktivierung der PLD vermutet (Robinson und Kreis, 1992; West et al., 1997).

In der Membran der COPI Vesikel wurden zwei Gruppen von Proteinen entdeckt, die mit ihren cytosolischen, carboxyterminalen Domänen an das Coatomer binden. Die erste Gruppe umfasst Proteine, die ein di-Lysin-Motiv besitzen und als Frachtmoleküle der COPI Vesikel vom GApp zum ER gebracht werden (siehe Kap. 1.1) (Cosson und Letourneur, 1994; Tisdale et al., 1997). Während durch Experimente mit isolierten Untereinheiten des Coatomers eine Arf1punabhängige Wechselwirkung des trimeren $\alpha / \beta^{\prime} / \varepsilon$-COP Komplexes mit di-Lysin-Motiven gezeigt werden konnte (Lowe und Kreis, 1995), konnte bei Bindungsstudien mit dem intakten Coatomer $\gamma$-COP als Bindungsprotein für das di-Lysin-Signal identifiziert werden (Harter et al., 1996). Möglicherweise reagiert zuerst die $\alpha / \beta^{\prime} / \varepsilon$-COP Untereinheit mit dem di-Lysin-Motiv und dadurch ändert das Coatomer seine Konformation so, dass $\gamma$-COP mit diesem Motiv interagiert. Jedenfalls 
wird die Membranassoziation des Coatomers durch die Bindung an das di-Lysin-Motiv stabilisiert (Lowe und Kreis, 1998).

Der zweiten Klasse von Membranproteinen gehören p23 und p24 aus der p24-Familie an, die in COPI Vesikeln im Vergleich zum GApp 20-fach angereichert werden (Stamnes et al., 1995; Sohn et al., 1996). Die Mitglieder der p24-Familie sind meist am Transport zwischen ER und GApp beteiligt (Nickel et al., 1997; Blum et al., 1999; Marzioch et al., 1999). Diese Proteine besitzen ein carboxyterminales di-Phenylalanin oder di-Lysin Motiv, die eine Funktion bei der Bindung des Coatomers haben. Das di-Phenylalanin Motiv bindet wie das di-Lysin Motiv an die $\gamma$-COPUntereinheit des nativen Coatomers (siehe Abb. 1.1) (Fiedler et al., 1996; Harter und Wieland, 1998). Der trimeren $\beta / \gamma / \zeta$-COP Untereinheit des Coatomers kann möglicherweise auch eine Funktion bei der Einleitung dieser Bindung zugeschrieben werden (Lowe und Kreis, 1995, 1998; Harter, 1999). Mit der Bindung des Coatomers an die cytoplasmatische Domäne der p24-Proteine wird die spezifische Polymerisation des Coatomers induziert (Reinhard et al., 1999; Weidler et al., 2000). Es wird vermutet, dass durch diese Polymerisation die Konformation der gebundenen Coatomerkomplexe geändert und die mechanische Kraft für die Membranwölbung erzeugt wird (Bremser et al., 1999; Harter, 1999; Reinhard et al., 1999). Die luminale Domäne der p24Proteine hat eine coiled-coil Region, die wahrscheinlich durch die Bindung an Fracht-Moleküle deren Sortierung ermöglicht (Schimmöller et al., 1995; Fiedler et al., 1996). Sowohl gleiche als auch unterschiedliche Proteine der p24-Familie (z. B. p23 und p24 in Säugetieren) assoziieren in dieser Region und bauen einen heterotetrameren Komplex auf (Gommel et al., 1999; Marzioch et al., 1999; Ciufo und Boyd, 2000). Die Bedeutung dieser Proteine im Proteintransport scheint in den verschiedenen Gruppen der Eukaryoten unterschiedlich zu sein: Während der Verlust der p24-Proteine durch Mutation in Säugetieren letal ist (Denzel et al., 2000), können die entsprechenden Mutanten von Saccharomyces cerevisiae weiterleben (Springer et al., 2000). So bleibt die Diskussion um die Notwendigkeit der Funktion der p24-Proteine im sekretorischen Weg verschiedener Eukaryoten weiterhin offen (siehe auch Kap. 1.3.3).

Die Fusion der COPI Vesikel mit ihrer Zielmembran kann erst nach der Dissoziation der Proteinhülle stattfinden (Lowe und Kreis, 1998; Wieland und Harter, 1999). Die Voraussetzung für diesen Prozeß ist die Hydrolyse des gebundenen GTP von Arf1p unter Beteiligung membrangebundener und cytosolischer Faktoren (Tanigawa et al., 1993; Randazzo und Kahn, 1994; Kahn et al., 1996; Randazzo, 1997). Die GTP-Hydrolyse führt zur Konformationsänderung von Arf1p und zur Freisetzung der Proteinhülle (Kahn und Gilman, 1986; Serafini et al., 1991). Nach der Dissoziation der Proteinhülle liegen Coatomer und Arf1p-GDP im Cytosol zur Bildung der COPI Vesikel vor (Serafini et al., 1991). Durch den Einsatz nicht hydrolisierbarer Analogen von GTP, wie GTPYS, wird aufgrund der blockierten GTP-Hydrolyse die Dissoziation der Hülle gehemmt (Melançon et al., 1987). So können in vitro COPI Vesikel mit einer stabilen Proteinhülle induziert und isoliert werden (Malhotra et al., 1989). 


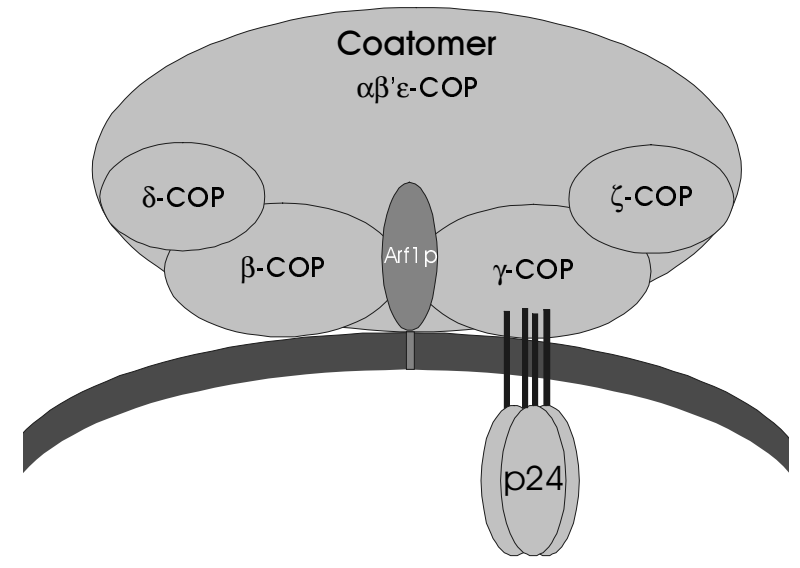

Abbildung 1.1: Schematische Darstellung vom Aufbau der Proteinhülle der COPI Vesikel nach Wieland und Harter (1999).

\subsubsection{COPII Vesikel}

COPII Vesikel vermitteln den anterograden Transport vom ER zum GApp. Obwohl sie im Elektronenmikroskop eine ähnliche Struktur wie COPI Vesikel aufweisen, unterscheiden sie sich von diesen in der Zusammensetzung ihrer Hüllproteine sowie der Frachtmoleküle (Barlowe et al., 1994; Scales et al., 1997, 2000). Die Hülle dieser Vesikel ist aus der GTPase Sar1p und zwei heterodimeren Proteinkomplexen, dem Sec23- und dem Sec13-Komplex, aufgebaut. Der Sec23Komplex mit einer Molekularmasse von $400 \mathrm{kDa}$ besteht aus zwei Untereinheiten Sec24p und Sec23p (Hicke et al., 1992). Der Sec13-Komplex hat eine Molekularmasse von $700 \mathrm{kDa}$ und wird aus Sec13p und Sec31p gebildet (Tabelle 1.2) (Pryer et al., 1993; Salama et al., 1993, 1997). Diese Untereinheiten besitzen wie $\alpha$-COP und $\beta$ '-COP repetitive WD-40 Sequenzen, die möglicherweise eine Funktion in der Protein-Protein- oder Protein-Membran-Wechselwirkung haben (siehe Kap. 1.3.2) (Barlowe, 1998). Außer Sar1p, das eine Homologie zu Proteinen der Arf-Familie zeigt, sind keine homologen Proteine zu anderen Bestandteilen der Proteinhülle der COPII Vesikel bekannt. Sar1p ist das einzige Protein der COPII-Hülle, dessen homologes Protein in Pflanzen identifiziert und charakterisiert wurde (Bar-Peled und Raikhel, 1997). 
Tabelle 1.2: Hüllproteine von COPII Vesikeln und ihre Eigenschaften (Barlowe, 1995, 1998; Wieland und Harter, 1999)

\begin{tabular}{|l|l|r|l|l|}
\hline natives Protein & Untereinheit & $\begin{array}{r}\mathbf{M}_{\mathbf{r}} \\
(\mathrm{kDa})\end{array}$ & Eigenschaften & bindende Proteine \\
\hline $\begin{array}{l}\text { Sec23 Komplex } \\
(400 \mathrm{kDa})\end{array}$ & Sec23p & 85 & Sar1p aktivierendes Protein & Bos1p, Bet1p \\
\cline { 2 - 5 } & Sec24p & 105 & & \\
\hline $\begin{array}{l}\text { Sec13 Komplex } \\
(700 \mathrm{kDa})\end{array}$ & $\operatorname{Sec} 13 \mathrm{p}$ & 34 & repetitive WD-40 Sequenzen & \\
\cline { 2 - 5 } & Sec31p & 150 & repetitive WD-40 Sequenzen & \\
\hline Sar1p & & 21 & kleine GTPase & Bos1p \\
\hline
\end{tabular}

Die Bildung der COPII Vesikel beginnt mit der Anlagerung von Sar1p-GTP an die ER-Membran. Sar1p liegt wie Arf1p als GTPase-GDP im Cytosol vor und kann nach dem Austausch von GDP gegen GTP an die Membran binden (Nakano und Muramatsu, 1989). Sec12p, ein integrales Glykoprotein des ER, katalysiert als GEF (siehe Kap. 1.3.2) diese Austauschreaktion (Nakano et al., 1988; d'Enfert et al., 1991; Barlowe und Schekman, 1993). Damit wird die Bindung vom Sec23-Komplex an das membrangebundene Sar1p-GTP eingeleitet. Der Sec13-Komplex bindet erst nach der Anlagerung des Sec23-Komplexes an die ER-Membran. Die Bildung der Proteinhülle der COPII Vesikel an der Donormembran wird als analog zur Zusammenlagerung der AP-Komplexe und des Clathrins bei CCVs betrachtet (siehe Kap. 1.3.1). Dabei wird der Sec23-Komplex mit den AP-Komplexen und der Sec13-Komplex, der zuletzt an die Membran bindet, mit Clathrin verglichen (Barlowe, 1998; Pagano et al., 1999). Zwei weitere Proteine, die eine Funktion bei der in vivo Bildung der COPII Vesikel haben, sind Sec16p und Sed4p (Espenshade et al., 1995; Gimeno et al., 1995). Sec16p wurde an der Membran des ER und an COPII Vesikeln nachgewiesen. Es bindet direkt an Sec23p, Sec24p und Sec31p und ermöglicht den Zusammenbau der Proteinhülle (Gimeno et al., 1996; Shaywitz et al., 1997). Sed4p, das eine 45\%-ige Aminosäureidentität zu Sec12p besitzt (Gimeno et al., 1995), unterstützt durch direkte Wechselwirkung mit Sec16p dessen Funktion bei der Vesikelbildung (Barlowe, 1998).

Die bekanntesten Vertreter der löslichen Fracht der COPII Vesikel sind die Invertase der Hefe und das Albumin der Säugetiere. Zu den membrangebundenen Frachtmolekülen gehören Gap1p ("general amino acid permease") in Hefe und VSV-G ("vesicular stomatitis virus glycoprotein") in infizierten Säugetierzellen. Der Mechanismus des Frachtexports aus dem ER ist noch nicht endgültig aufgeklärt. Es konnte in den achtziger Jahren gezeigt werden, dass Proteine, die kein besonderes Signal besitzen, automatisch über transitorische Vesikel vom ER zum GApp ("bulk flow") gelangen (Wieland et al., 1987; Pelham, 1989). Jedoch deuten neuere Untersuchungen darauf hin, dass bei der Bildung der COPII Vesikel die Fracht selektiv aufgenommen wird. 
Sekretorische Proteine sowie membrangebundene v-SNARE Proteine (Sec22p, Bos1p und Bet1p) werden in COPII Vesikeln im Vergleich zum ER angereichert (Balch et al., 1994; Rexach et al., 1994; Bednarek et al., 1995; Campbell und Schekman, 1997). Außerdem kommen ERresidente Proteine wie Kar2p (das homologe Protein zu BiP in Hefe), Sec61p und Shr3p in in vitro induzierten COPII Vesikeln nicht vor (Rexach et al., 1994; Kuehn et al., 1998). In der cytoplasmatischen Domäne von VSV-G und einer Reihe von Membranproteinen der COPII Vesikel wurde eine DXE-Sequenz entdeckt (Nishimura und Balch, 1997). Ohne diese Sequenz wird VSV-G etwa $80 \%$ langsamer in COPII Vesikel sortiert. Da die DXE-Sequenz selbst keine Rolle bei der Faltung und Oligomerisation der VSV-G Moleküle spielt, hat sie möglicherweise eine direkte Funktion bei der effektiven Proteinsortierung (Nishimura und Balch, 1997). Unabhängig davon wurde gezeigt, dass die Rekrutierung von Sar1p und vom Sec23-Komplex die Voraussetzung für den selektiven Eintritt von membrangebundenen Proteinen wie VSV-G in COPII Vesikel ist (Aridor et al., 1998; Kuehn et al., 1998). Eine Wechselwirkung zwischen VSVG und dem Sec23 Komplex bzw. Sec23p wurde ebenfalls nachgewiesen (Aridor et al., 1998, 1999). Vergleichbar zu diesen Daten konnte eine Sarlp- und GTP-abhängige Interaktion zwischen Bet1p sowie Bos1p und Sec23p gezeigt werden (Springer und Schekman, 1998). Daher spielt der Sec23-Komplex möglicherweise eine Rolle bei der Sortierung der Frachtmoleküle. Es wurde kürzlich gezeigt, dass Frachtmoleküle in vivo und in vitro Einfluss auf die Rekrutierung der Proteinhülle und infolgedessen auf die Bildung der COPII Vesikel haben (Aridor et al., 1999). Wenn unter physiologischen Bedingungen die richtige Faltung der Frachtmoleküle verhindert wird, wird VSV-G im ER angesammelt und die Bildung der COPII Vesikel verlangsamt. Das zeigt, dass der Proteinexport aus dem ER mit dessen Funktion - besonders im Hinblick auf die Tätigkeit der molekularen Chaperone - zusammenhängt (Aridor et al., 1999).

Die lösliche Fracht wird vermutlich auch durch eine indirekte Wechselwirkung mit der Proteinhülle selektiert (Kuehn et al., 1998; Wieland und Harter, 1999). Dafür sind integrale Membranproteine, die sowohl eine cytoplasmatische als auch eine luminale Domäne aufweisen, notwendig, um die Verbindung zwischen der Hülle und den löslichen Frachtmolekülen herzustellen. Die möglichen Kandidaten dafür sind p24-Proteine, die sowohl in COPI Vesikeln als auch in COPII Vesikeln als heterotetramere Membranproteine vorkommen (siehe Kap. 1.3.2). Ihre luminale Domäne kann theoretisch durch Oligomerisation verschiedener Mitglieder dieser Familie variable Kombinationen für die Bindung der unterschiedlichen, löslichen Frachtmoleküle anbieten (Stamnes et al., 1995; Dominguez et al., 1998; Marzioch et al., 1999). Für die HefeProteine Emp24p und Erv25p, die homolog zu p24 und p23 aus Säugetieren sind, wurde eine Funktion bei der Proteinsortierung in die COPII Vesikel nachgewiesen. Wenn diese Proteine durch Mutationen fehlen, werden einige sekretorische Proteine langsamer aus dem ER zum GApp transportiert (Schimmöller et al., 1995; Belden und Barlowe, 1996) und bestimmte ERresidente Proteine wie Kar2p sekretiert (Springer et al., 2000). Obwohl die Wechselwirkung der 
cytoplasmatischen Domänen der p24-Proteine mit dem Sec23-Komplex inzwischen nachgewiesen wurde (Dominguez et al., 1998), konnte die mögliche Interaktion zwischen ihrer luminalen Domäne und der löslichen Fracht bisher nicht gezeigt werden. Aufgrund ihrer Rolle bei der Exportverhinderung der ER-residenten Proteine, wird für sie eine negative Steuerung des Proteintransports angenommen (Elrod-Erickson und Kaiser, 1996; Springer et al., 2000). Dabei scheinen sie an die COPII-Hülle zu binden und dadurch indirekt als Platzhalter den Eintritt der anderen Proteine in die COPII Vesikel zu beschränken (Springer et al., 2000).

Da die v-SNARE-Proteine von der COPII-Hülle bedeckt werden (siehe Abb. 1.2), können COPII Vesikel wie COPI Vesikel erst nach der Dissoziation der Proteinhülle unter Beteiligung der SNARE-Proteine mit ihrer Zielmembran fusionieren (Schekman und Orci, 1996). Nach dem Abknospen wird die GTPase-Aktivität des Sar1p von dem in der Hülle enthaltenen Sec23p stimuliert (Yoshihisa et al., 1993). Daher sind im Gegensatz zu den COPI Vesikeln keine cytosolischen Proteine zum Ablösen der Proteinhülle von den COPII Vesikeln notwendig (Barlowe et al., 1994; Aridor et al., 1998). Das Ersetzen von GTP durch GTP S oder GMP-PNP bei der in vitro Induktion der COPII Vesikel führt aufgrund der Hemmung der GTP-Hydrolyse zur Ansammlung von Vesikeln mit stabiler Proteinhülle, deren Eigenschaften weiter untersucht werden können (Barlowe et al., 1994; Oka und Nakano, 1994).

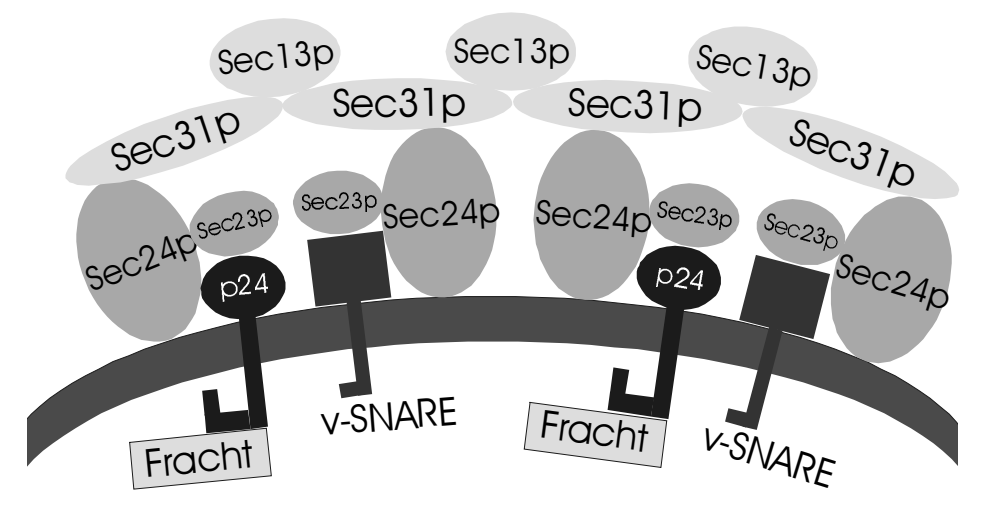

Abbildung 1.2: Schematische Darstellung der Struktur der Proteinhülle der COPII Vesikel nach Schekman und Orci (1996). 


\subsection{Zielsetzung der Arbeit}

$\mathrm{Zu}$ Beginn der vorliegenden Arbeit gab es keine Hinweise auf die Existenz von COP Vesikeln in Pflanzenzellen, obwohl ihre Beteiligung am Proteintransport in Pflanzen- wie in Hefe- und Säugetierzellen angenommen wurde. Der erste Schritt bei den Untersuchungen des Transportweges zwischen ER und GApp in Pflanzenzellen war daher die Identifizierung und Charakterisierung dieser Vesikel sowie der Bestandteile ihrer Proteinhülle. Mit molekularbiologischen Methoden sollten zwei rekombinante Proteine gewonnen werden, die Homologien zu Hüllproteinen von COPI und COPII Vesikeln von Hefe und Säugetieren aufweisen. Gegen diese Proteine sollten Antikörper gerichtet werden, mit deren Hilfe durch biochemische Methoden die Hüllproteine der pflanzlichen COP Vesikel identifiziert und charakterisiert werden. Als Schwerpunkt wurde dabei die Untersuchung der Eigenschaften der löslichen bzw. membrangebundenen Proteine und ihrer Funktion im sekretorischen Transportweg in Pflanzenzellen festgelegt. Durch Immunmarkierungen und Elektronenmikroskopie sollten pflanzliche COP Vesikel und ihre Frachtmoleküle in situ lokalisiert werden, um neue Erkenntnisse über das Proteinrecycling zwischen ER und GApp in Pflanzenzellen zu gewinnen. 


\section{Material und Methoden}

\subsection{Molekularbiologische Methoden}

\subsubsection{Bakterienstämme und Vektoren}

Im Rahmen dieser Arbeit wurden folgende Stämme von Escherichia coli (E. coli) verwendet:

\begin{tabular}{|c|c|c|}
\hline Stamm & Genotyp & Quelle \\
\hline DH5 $\alpha$ & $\begin{array}{l}\text { supE44 } \Delta l a c \mathrm{U} 169 \text { ( } \phi 80 \text { lacZAM15) hsdR17 recA1 } \\
\text { endA1 gyrA96 thi-1 relA1 }\end{array}$ & Hanahan, 1983 \\
\hline BL-21 & hsdS gal ( $\lambda$ cIts857 ind1 Sam7 nin5 lacUV5-T7 gene 1) & Studier und Moffatt, 1986 \\
\hline
\end{tabular}

pGEX-4T-3 (Pharmacia, Freiburg, BRD), der ein Ampicillin-Resistenzgen enthält, wurde als Expressionsvektor benutzt. Mittels der pGEX-Vektoren werden Fusionsproteine hergestellt, die Glutathion-S-Transferase (GST) in ihrer Struktur enthalten. Mit Hilfe von GST können diese Fusionsproteine durch Affinitäts-Chromatographie gereinigt werden (Smith und Johnson, 1988).

\subsubsection{Anzucht und Lagerung von $E$. coli}

Lösungen:

Ampicillin-Stammlösung: $\quad 50 \mathrm{mg} / \mathrm{ml}$ Ampicillin in $\mathrm{H}_{2} \mathrm{O}$ bidest., sterilfiltriert

Luria-Bertani-Medium: $\quad 10 \mathrm{~g} / \mathrm{l} \mathrm{NaCl}$

(LB-Medium)

$5 \mathrm{~g} / \mathrm{l} \mathrm{Hefeextrakt}$

$10 \mathrm{~g} / \mathrm{l}$ Trypton in $\mathrm{H}_{2} \mathrm{O}$ bidest.

$\mathrm{pH}$ 7,0 mit $\mathrm{NaOH}$ eingestellt und autoklaviert

LB Amp $_{\text {-Medium: }} \quad 100 \mu \mathrm{g} / \mathrm{ml}$ Ampicillin in LB-Medium

Ampicillin wurde nach dem Autoklavieren und Abkühlen auf $50{ }^{\circ} \mathrm{C}$ gegebenenfalls zugesetzt. Zum Gießen von Agarplatten wurde $1 \%$ (w/v) Agar vor dem Autoklavieren hinzugegeben. 
Sofern nicht anders beschrieben, wurden die E. coli-Flüssigkulturen bei $37^{\circ} \mathrm{C}$ und $220 \mathrm{Upm}$ auf einem Schüttelinkubator angezogen. Auf Agarplatten ausgestrichen, wurden über Nacht im Brutschrank bei $37^{\circ} \mathrm{C}$ inkubiert.

Um die E. coli-Zellen für längere Zeit aufbewahren zu können, wurden Glycerin-Stammkulturen angelegt, wobei $1 \mathrm{ml}$ Flüssigkultur mit $0,5 \mathrm{ml}$ 98\%-igen (v/v) Glycerin vermischt und bei $-80{ }^{\circ} \mathrm{C}$ gelagert wurde.

\subsubsection{Isolierung von Plasmid-DNA}

Sämtliche hier aufgeführten Verfahren zur Aufreinigung von Plamid-DNA basieren auf dem Prinzip einer alkalischen Lyse der Bakterienzellen in Gegenwart von SDS (Sambrook et al., 1989), bei der die bakterielle genomische DNA sowie die Proteine denaturiert werden und somit durch Zentrifugation entfernt werden können. Auf die alkalische Lyse folgt dann eine Isopropanol-Fällung der Plasmid-DNA aus dem verbleibenden Überstand.

\subsubsection{Isolierung im kleinen Maßstab (Mini-Präparation)}

Diese Aufreinigungsmethode wurde zur Isolierung von kleineren Mengen DNA (bis zu $5 \mu \mathrm{g} / \mathrm{ml}$ Kultur) für analytische Zwecke verwendet.

\section{Lösungen:}

Lösung A:

$25 \mathrm{mM}$ Tris/HCl, $\mathrm{pH} 8,0$

$50 \mathrm{mM}$ Glucose

10 mM EDTA, pH 8,0

Lösung B:

$200 \mathrm{mM} \mathrm{NaOH}$

$1 \%(w / v)$ SDS

Lösung C:

$60 \mathrm{ml} 5 \mathrm{M}$ Kaliumacetat

$11,5 \mathrm{ml}$ Eisessig

28,5 ml steriles $\mathrm{H}_{2} \mathrm{O}$ bidest.

Resuspendierungspuffer: $\quad 10 \mathrm{mM}$ Tris/ $\mathrm{HCl}, \mathrm{pH} 8,0$

$1 \%$ (v/v) DNase-freie RNase (Boehringer Mannheim) 
1,5 ml einer Übernachtkultur von E. coli wurden für $30 \mathrm{~s}$ bei $20.800 \mathrm{~g}_{\max }$ (Eppendorf 5417C) zentrifugiert, der Überstand abgesaugt und das Sediment in $100 \mu l$ Lösung A resuspendiert. Nun erfolgte die alkalische Lyse durch Zugabe von $200 \mu$ l Lösung B, mehrmaliges Invertieren und 5minütige Inkubation auf Eis. Die Proteine und chromosomale DNA wurden durch Zugabe von $150 \mu$ l eiskalter Lösung $C$ und einer 10-minütigen Inkubation auf Eis ausgefällt und durch eine 10-minütige Zentrifugation bei $20.800 \mathrm{~g}_{\max }$ und $4{ }^{\circ} \mathrm{C}$ (Eppendorf 5417C) sedimentiert. Danach wurden $400 \mu \mathrm{l}$ des Überstandes mit $200 \mu \mathrm{l}$ Isopropanol gemischt und für 15 min bei $20.800 \mathrm{~g}_{\max }$ und $4{ }^{\circ} \mathrm{C}$ (Eppendorf 5417C) zentrifugiert. Die präzipitierte Plasmid-DNA wurde in $70 \%$ (v/v) Ethanol gewaschen und anschließend 15 min bei RT trocknen gelassen, bevor sie in $20 \mu \mathrm{l}$ Resuspendierungspuffer aufgenommen wurde.

\subsubsection{Isolierung im mittleren Maßstab (Midi-Präparation)}

Zur Aufreinigung von Plasmid-DNA in Mengen von 50-100 $\mu \mathrm{g}$ und für Arbeiten mit hochreiner Plasmid-DNA, z. B. für eine Sequenzierung wurde das "Plasmid-Midi-Kit" (Qiagen, Hilden, BRD) verwendet. Die jeweilige Präparation wurde nach Angaben des Herstellers unter Verwendung der mitgelieferten Puffer durchgeführt.

\section{Lösungen:}

Puffer P1: $\quad 50 \mathrm{mM}$ Tris/HCl, $\mathrm{pH} 8,0$

$10 \mathrm{mM}$ EDTA

$10 \mu \mathrm{g} / \mathrm{ml}$ RNase $\mathrm{A}$ in $\mathrm{H}_{2} \mathrm{O}$ bidest.

Puffer P2: $\quad 200 \mathrm{mM} \mathrm{NaOH}$

$1 \%$ (w/v) SDS in $\mathrm{H}_{2} \mathrm{O}$ bidest.

Puffer P3: $\quad 3$ M Kaliumacetat, $\quad$ pH 5,5

in $\mathrm{H}_{2} \mathrm{O}$ bidest.

Puffer QBT: $\quad 50 \mathrm{mM}$ Mops, $\mathrm{pH} \mathrm{7,0}$

$750 \mathrm{mM} \mathrm{NaCl}$

$15 \%$ (v/v) Isopropanol

$0,15 \%$ Triton $\mathrm{X}-100$ in $\mathrm{H}_{2} \mathrm{O}$ bidest. 
$\begin{array}{ll}\text { Puffer QC: } & 50 \mathrm{mM} \text { Mops, } \mathrm{pH} \mathrm{7,0} \\ & 750 \mathrm{mM} \mathrm{NaCl} \\ & 15 \% \text { Isopropanol in } \mathrm{H}_{2} \mathrm{O} \text { bidest. }\end{array}$

Puffer QF: $\quad 50 \mathrm{mM}$ Tris/HCl, $\mathrm{pH} \mathrm{8,5}$

$1,25 \mathrm{M} \mathrm{NaCl}$

$15 \%$ Isopropanol in $\mathrm{H}_{2} \mathrm{O}$ bidest.

TE:

$10 \mathrm{mM}$ Tris/HCl, $\mathrm{pH} 8,0$

$1 \mathrm{mM}$ EDTA in $\mathrm{H}_{2} \mathrm{O}$ bidest.

Als Ausgangsmenge wurden hierfür $100 \mathrm{ml}$ einer Übernachtkultur von E. coli für $10 \mathrm{~min}$ bei $5.000 \mathrm{~g}_{\max }$ und $4{ }^{\circ} \mathrm{C}$ (Sorvall RC-5B, Rotor GS3) zentrifugiert. Die Zellen wurden in $4 \mathrm{ml}$ Puffer P1 resuspendiert und durch Zugabe von $4 \mathrm{ml}$ Puffer P2 für $5 \mathrm{~min}$ bei RT lysiert. Dem Ansatz wurden anschließend $4 \mathrm{ml}$ Puffer P3 zugesetzt und dabei die Proteine mit anhaftender chromosomaler DNA für $10 \mathrm{~min}$ auf Eis gefällt. Nach einer 30-minütigen Zentrifugation bei $30.000 \mathrm{~g}_{\max }$ und $4{ }^{\circ} \mathrm{C}$ (Sorvall RC-5B, Rotor GS3) wurde der Überstand auf eine Qiagen-tip 100 Säule aufgetragen, die vorher mit Puffer QBT äquilibriert worden war. Die Säule wurde mit $20 \mathrm{ml}$ Puffer QC gewaschen und die DNA mit $5 \mathrm{ml}$ Puffer QF eluiert. Das Eluat wurde mit $3,5 \mathrm{ml}$ Isopropanol versetzt und $30 \mathrm{~min}$ bei $15.000 \mathrm{~g}_{\max }$ und $4{ }^{\circ} \mathrm{C}$ (Eppendorf $5417 \mathrm{C}$ ) zentrifugiert. Die präzipitierte DNA wurde mit 70\%-igem Ethanol gewaschen, 15 min bei RT getrocknet und schließlich in $50 \mu \mathrm{H} \mathrm{H}_{2} \mathrm{O}$ bidest. oder TE gelöst.

\subsubsection{Bestimmung der DNA-Konzentration}

Die Konzentration von DNA in sterilem $\mathrm{H}_{2} \mathrm{O}$ bidest. wurde photometrisch durch Messung der Lichtabsorption bei $260 \mathrm{~nm}$ in Quarzküvetten bestimmt. Eine DNA-Konzentration von $50 \mu \mathrm{g} / \mathrm{ml}$ für doppelsträngige DNA und $20 \mu \mathrm{g} / \mathrm{ml}$ für Oligonukleotide entspricht dabei einer OD von 1 bei $260 \mathrm{~nm}$. Da aromatische Aminosäuren und Phenol Licht der Wellenlänge $280 \mathrm{~nm}$ absorbieren, wurde der Quotient aus $\mathrm{OD}_{260} / \mathrm{OD}_{280}$ als Anhaltspunkt für die Reinheit der DNA gemessen, der zwischen 1,8 und 2,0 liegen sollte (Sambrook et al., 1989).

\subsubsection{Fragmentierung von DNA mit Restriktionsendonukleasen}

Restriktionsendonukleasen wurden zum Schneiden von DNA aus zwei Gründen eingesetzt: entweder um definierte Enden zum Klonieren zu erhalten oder um das Vorhandensein von Schnittstellen zu überprüfen. Die Restriktionsendonukleasen wurden von den Herstellern mit 
passenden Reaktionspuffern und gegebenenfalls mit einer BSA-Stammlösung geliefert. Es wurden 1-5 Units Enzym pro $1 \mu \mathrm{g}$ DNA nach den Angaben der Hersteller eingesetzt und für $2 \mathrm{~h}$ bei $37^{\circ} \mathrm{C}$ inkubiert (ein Unit entspricht der Menge an Restriktionsendonuklease, die benötigt wird, um $1 \mu \mathrm{g} \lambda$-DNA in einer Stunde zu spalten). Die Reaktion wurde durch Zugabe eines zehntel Volumens 10-fach konzentriertem DNA-Probenpuffer beendet und die Fragmente durch Gelelektrophorese getrennt.

\subsubsection{Agarose-Gelelektrophorese}

Die Agarose-Gelelektrophorese wurde zur Trennung und Isolierung von DNA-Fragmenten eingesetzt. Aufgrund der negativen Ladung ihrer Phosphatgruppen bewegt sich DNA im elektrischen Feld zur Anode. Dieses wird bei der Gelelektrophorese ausgenutzt, um die DNAMoleküle nach ihrer Größe zu trennen.

Lösungen:

0,5-fach TBE:

(Tris-borate/EDTA)

DNA-Probenpuffer:

Ethidiumbromid-Stammlösung:
$5,4 \mathrm{~g} / \mathrm{l}$ Tris

2,75 g/l Borsäure

$2 \mathrm{ml} / \mathrm{l}$ 0,5 M EDTA, $\mathrm{pH} 8,0$

in $\mathrm{H}_{2} \mathrm{O}$ bidest.

0,42\% (w/v) Bromphenolblau

$0,42 \%(w / v)$ Xylencyanol FF

$25 \%(w / v)$ Ficoll Typ 400

in $\mathrm{H}_{2} \mathrm{O}$ bidest.

1\%-ige (w/v) Agarosegele wurden für größere Fragmente ab 1.000 bp, 1,5\%-ige (w/v) Agarosegele für Fragmente zwischen 500 bp und 1.000 bp eingesetzt. Zum Gießen der Gele wurde die entsprechende Menge Agarose in 0,5-fachem TBE aufgekocht und nach dem Abkühlen auf etwa $50{ }^{\circ} \mathrm{C}$ in eine Flachbett-Gelform (BlueMarine Flachbett-System 100; Serva, Heidelberg, BRD) gegossen, in die dann ein taschenbildender Kamm gegeben wurde. Nach dem Abkühlen und Erstarren wurde das Gel in einer Elektrophoresekammer mit 0,5-fachem TBE überschichtet. Die aufzutrennenden Proben wurden 1:10 mit dem DNA-Probenpuffer vermischt und in die Geltaschen pipettiert. Das Auftrennen der Proben erfolgte bei einer Spannung von 
$100 \mathrm{~V}$. Nach Beendigung der Elektrophorese wurde das Agarose-Gel für $30 \mathrm{~min}$ in einer Ethidiumbromidlösung mit einer Konzentration von $1 \mu \mathrm{g} / \mathrm{ml}$ inkubiert und danach die DNA mit UV-Licht sichtbar gemacht. Sollten DNA-Fragmente aus einem präparativen Gel isoliert werden, wurde nur längerwelliges UV-Licht $(365 \mathrm{~nm})$ verwendet, um eine Beschädigung der DNAMoleküle zu vermeiden.

Um die Länge der DNA-Fragmente zu bestimmen wurde $\lambda$-DNA, die mit den Restriktionsendonukleasen Eco RI und Hind III gespalten worden war (MBI, St. Leon-Rot, BRD), als Längenstandardsatz verwendet. Der Standardsatz enthält 13 Fragmente, die aus 21.226, 5.148, 4.973, 4.268, 3.530, 2.027, 1.904, 1.584, 1.375, 947, 831, 564 und 125 bp bestehen.

\subsubsection{Isolierung von DNA aus Agarose-Gelen}

Die Isolierung der DNA-Fragmente aus Agarose-Gelen erfolgte unter der Verwendung des "QiaQuick Gel Extraction Kits" und der mitgelieferten Puffer (Qiagen, Hilden, BRD). Gemäß den Angaben des Herstellers wurden Gelstücke, welche die zu isolierende DNA enthielten, mit einem sterilen Skalpell herausgeschnitten, gewogen und pro $100 \mathrm{mg}$ Gel $300 \mu \mathrm{l}$ Puffer QG zugesetzt. Durch 10-minütiges Erhitzen bei $50{ }^{\circ} \mathrm{C}$ wurden die Gelstücke verflüssigt. Dann wurde ein Drittel der verwendeten Menge von Puffer QG Isopropanol hinzupipetiert und auf die QiaQuick-Säule aufgetragen. Die Säule wurde in ein $2 \mathrm{ml}$ fassendes Reaktionsgefäß gehängt und 1 min bei $14.000 g_{\max }$ (Eppendorf 5417C) zentrifugiert. Die Säule wurde mit $500 \mu 1$ Puffer QG und danach mit $750 \mu$ Puffer PE auf gleiche Weise gewaschen und einmal 1 min bei $14.000 \mathrm{~g}_{\max }$ (Eppendorf 5417C) trocken zentrifugiert. Zur Elution wurden $50 \mu 10 \mathrm{mM}$ Tris/HCl, pH 8,0 oder $\mathrm{H}_{2} \mathrm{O}$ bidest. auf die Säule gegeben und für $1 \mathrm{~min}$ wie vorher beschrieben zentrifugiert.

\subsubsection{Ligation von DNA-Doppelstrang-Fragmenten}

Die Ligation dient der Verknüpfung linearisierter DNA-Fragmente. Die dazu eingesetzte T4DNA-Ligase katalysiert die Bildung von intra- oder intermolekularen Phosphodiester-Bindungen zwischen einer freien 5'-Phosphatgruppe und einer freien 3'-Hydroxylgruppe eines DNAStranges. Die jeweilige Ligation wurde unter Verwendung der T4-Phagen-DNA-Ligase und des Ligasepuffers (GibcoBRL, Eggenstein, BRD) durchgeführt. Ein Unit bezeichnet hier die Menge Enzym, die bei $37{ }^{\circ} \mathrm{C}$ in $20 \mathrm{~min} 1 \mathrm{nmol}{ }^{32} \mathrm{PPi}$ in $\left(\gamma / \beta-{ }^{32} \mathrm{P}\right) \mathrm{ATP}$ umwandelt. 
Ligationsansatz: $\quad 0,1-1 \mu \mathrm{g}$ DNA (Vektor und Fragment)

\section{Unit Ligase}

$2 \mu 1$ 5-fach konzentrierte Ligase-Puffer (250 mM Tris/HCl, $\mathrm{pH}$ 7,6; $50 \mathrm{mM}$ $\mathrm{MgCl}_{2} ; 5$ mM ATP; 5 mM DTT; $25 \%$ (w/v) PEG-8000) mit sterilem $\mathrm{H}_{2} \mathrm{O}$ bidest. auf $10 \mu \mathrm{l}$ aufgefüllt

Das molare Verhältnis von Fragment- und Vektor-DNA betrug im Ligationsansatz 3:1. Die Inkubation erfolgte $4 \mathrm{~h}$ bei RT oder $16 \mathrm{~h}$ bei $16^{\circ} \mathrm{C}$. Mit der ligierten DNA wurde anschließend einer der unter Kap. 2.1.1 aufgeführten E. coli-Stämme transformiert.

\subsubsection{Transformation von E. coli mit Plasmid-DNA}

Die Fähigkeit (Kompetenz) von E. coli-Zellen Plasmid-DNA aufzunehmen, lässt sich durch bestimmte Behandlungen erheblich steigern. Eine Möglichkeit ist das Anlegen eines elektrischen Feldes (Elektroporation) (Dower et al., 1988), eine andere die Behandlung mit Calciumchlorid (Cohen et al., 1972). In dieser Arbeit wurden E. coli-Zellen mit $\mathrm{CaCl}_{2}$ vorbehandelt und nachher durch Hitzeschock transformiert.

\subsubsection{Herstellung kompetenter Zellen}

Die Präparation von kompetenten Zellen erfolgte nach der Methode von Hanahan (1985).

Lösungen:

Waschlösung: $\quad 100 \mathrm{mM} \mathrm{RbCl}$

$50 \mathrm{mM} \mathrm{MnCl}{ }_{2}$

$30 \mathrm{mM}$ Kaliumacetat

$10 \mathrm{mM} \mathrm{CaCl}_{2}$

$15 \%(\mathrm{v} / \mathrm{v})$ Glycerin

pH 5,8 mit Essigsäure eingestellt und sterilfiltriert

Lagerungspuffer: $\quad 10 \mathrm{mM}$ Mops/NaOH, $\mathrm{pH}$ 6,8

$10 \mathrm{mM} \mathrm{RbCl}$

$75 \mathrm{mM} \mathrm{CaCl}_{2}$

$15 \%(\mathrm{v} / \mathrm{v})$ Glycerin

frisch angesetzt und sterilfiltriert 
$200 \mathrm{ml}$ LB-Medium (siehe Kap. 2.1.2) wurden mit $2 \mathrm{ml}$ einer Übernachtkultur angeimpft und bei $37{ }^{\circ} \mathrm{C}$ bis zum Erreichen einer $\mathrm{OD}_{600}$ von 0,3 angezogen. Die Kultur wurde $15 \mathrm{~min}$ in Eiswasser unter Schwenken abgekühlt und dann 15 min bei $5.000 \mathrm{~g}_{\max }, 4{ }^{\circ} \mathrm{C}$ (Sorvall RC-5B, Rotor GS3) zentrifugiert. Die Zellen wurden in $20 \mathrm{ml}$ vorgekühlter Waschlösung resuspendiert und unter den gleichen Bedingungen zentrifugiert. Anschließend wurden die Zellen in $4 \mathrm{ml}$ Lagerungspuffer resuspendiert, in $200 \mu \mathrm{l}$ Aliquots mit flüssigem Stickstoff eingefroren und bei $-80{ }^{\circ} \mathrm{C}$ bis zur Verwendung gelagert.

\subsubsection{Transformation kompetenter Zellen}

$200 \mu$ kompetente Zellen wurden auf Eis aufgetaut und mit $1 \mathrm{ng}$ Vektor-DNA bzw. einem Ligationsansatz gemischt. Nach 30-minütiger Inkubation auf Eis erfolgte ein Hitzeschock von 1 min bei $42{ }^{\circ} \mathrm{C}$. Der Ansatz wurde für 2 min auf Eis gestellt und anschließend mit $500 \mu \mathrm{LB}$ Medium vermischt. Die Zellen wurden nun für $30 \mathrm{~min}$ bei $37^{\circ} \mathrm{C}$ und $220 \mathrm{Upm}$ auf einem Schüttelinkubator angezogen und durch eine Zentrifugation bei $5.000 \mathrm{~g}_{\max }$ (Eppendorf 5417C) sedimentiert. Der Überstand wurde bis auf $100 \mu \mathrm{l}$ abgenommen, das Sediment vorsichtig resuspendiert und auf $\mathrm{LB}_{\mathrm{Amp}}$-Platten (siehe Kap. 2.1.2) ausgestrichen.

\subsubsection{Identifizierung und Sequenzierung von EST-cDNA-Klonen}

Zur Suche von Arabidopsis EST-cDNA-Klonen, die Homologien zu bekannten SEC21 und SEC23 von Hefe aufweisen, wurde eine Stichwortsuche in der Datenbank des National Center for Biotechnology Information (NCBI) via Internet unter der folgenden Adresse durchgeführt: http://www.ncbi.nlm.nih.gov/.

Die cDNA Klone wurden vom "Arabidopsis Biological Resource Center (Ohio State University, Columbus, USA)" angefordert und in der Abteilung für Molekulare Genetik des Max-PlanckInstituts für biophysikalische Chemie (Göttingen) sequenzieren gelassen.

Identische und ähnliche Aminosäuren von Proteinmolekülen wurden per Internet unter der folgenden Adresse bestimmt:

http://dot.imgen.bcm.tmc.edu:9331/seq-search/alignment.html.

\subsubsection{Expression und Aufreinigung der GST-Fusionsproteine und Antikörperherstellung}

Die Expression und Aufreinigung der GST-Fusionsproteine erfolgte nach Hakes und Dixon (1992). 
Lösungen:

IPTG-Stammlösung: $\quad 100 \mathrm{mM}$ in $\mathrm{H}_{2} \mathrm{O}$ bidest.

sterilfiltriert und bei $-20{ }^{\circ} \mathrm{C}$ gelagert

PMSF-Stammlösung: $\quad 50 \mathrm{mM}$ in eine 1:1 Mischung

von 2-Propanol p.a. und Ethanol p.a.

Phosphat-gepufferte Salzlösung (PBS):

$150 \mathrm{mM} \mathrm{NaCl}$

$16 \mathrm{mM} \mathrm{Na}_{2} \mathrm{HPO}_{4}$

$4 \mathrm{mM} \mathrm{NaH}_{2} \mathrm{PO}_{4}$

pH 7,3 mit $\mathrm{NaOH}$ eingestellt

PBS-T: $\quad 1 \%(\mathrm{v} / \mathrm{v})$ Triton $\mathrm{X}-100$ in PBS

Waschpuffer: $\quad 50 \mathrm{mM}$ Tris/ $\quad \mathrm{HCl}, \mathrm{pH} 8,0$

Elutionspuffer: $\quad 50 \mathrm{mM}$ Tris/ $\quad \mathrm{HCl}, \mathrm{pH} 8,0$

$10 \mathrm{mM}$ Glutathion

Dialysepuffer: $\quad 10 \mathrm{mM}$ Tris/HCl, $\mathrm{pH} 7,5$

Zunächst wurde von dem E. coli-Klon (Stamm BL-21) mit dem gewünschten Expressionsvektor

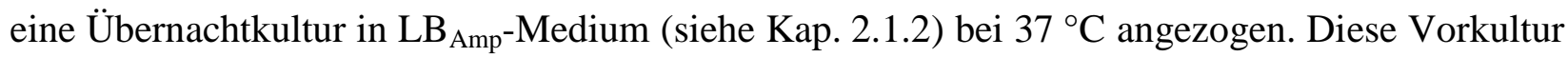
wurde 1:10 im gleichen Medium verdünnt und bei $37^{\circ} \mathrm{C}$ wachsen gelassen bis die $\mathrm{OD}_{600} 0,8$ betrug. Die Expression wurde nach Erreichen der optimalen $\mathrm{OD}_{600}$ durch Zugabe von IPTG (finale Konzentration: 0,2 mM) induziert und für 3 Stunden bei $28^{\circ} \mathrm{C}$ durchgeführt.

Zur schnellen Überprüfung der Expression des Fusionsproteins wurde von der Kultur $1 \mathrm{ml}$ abgenommen, sedimentiert ( $3 \mathrm{~min}$ bei $5.000 \mathrm{~g}_{\max }$, Eppendorf $5417 \mathrm{C}$ ) und in $120 \mu \mathrm{l}$ PBS resuspendiert. Die Zellen wurden dann mit $20 \mu \mathrm{l} 10 \%$ (w/v) SDS, $60 \mu \mathrm{l}$ 4-fach konzentriertem Probenpuffer und $100 \mu \mathrm{l}$ einfachem Probenpuffer gemischt und für 5 min auf $95{ }^{\circ} \mathrm{C}$ erhitzt. Die so aufbereitete Probe wurde als Gesamtzelllysat per SDS-PAGE analysiert (siehe Kap. 2.8).

Die restlichen Zellen wurden durch eine Zentrifugation von $15 \mathrm{~min}$ bei $5.000 \mathrm{~g}_{\max }$ (Sorvall RC 5B, Rotor GS3) im vorgekühlten Rotor geerntet. Die Sedimente wurden in PBS gewaschen und nach erneuter Zentrifugation bei $-80{ }^{\circ} \mathrm{C}$ gelagert. 
Die Sedimente aus $500 \mathrm{ml}$ Kultur wurden in $20 \mathrm{ml}$ eiskaltem PBS-T unter Zusatz von 0,1 \% (v/v) $\beta$-Mercaptoethanol und $0,1 \mathrm{mM}$ PMSF resuspendiert. Die Zellen wurden dann durch Ultraschallbehandlung (Branson Ultrasonic, Danbury, USA) viermal für $30 \mathrm{~s}$ bei $300 \mathrm{~W}$ aufgeschlossen. Anschließend wurden die Zelltrümmer durch eine 20-minütige Zentrifugation bei $12.000 \mathrm{~g}_{\max }$ (Sorvall RC 5B, Rotor HB 4) sedimentiert. Der Überstand wurde mit $500 \mu \mathrm{l}$ in PBST gewaschener Glutathion-Sepharose (Pharmacia, Freiburg, BRD) auf einem Drehrad für 30 min bei $4{ }^{\circ} \mathrm{C}$ geschwenkt. Die Glutathion-Sepharose mit den gebundenen GST-Fusionsproteinen wurde durch eine Leersäule abfiltriert und zunächst mit $30 \mathrm{ml}$ Puffer PBS-T und anschließend mit $20 \mathrm{ml}$ Waschpuffer gewaschen. Die GST-Fusionsproteine wurden mit $2 \mathrm{ml}$ Elutionspuffer eluiert.

Das GST-Fusionsprotein wurde nach der SDS-PAGE und anschließender Coomassiefärbung aus dem SDS-Gel eluiert (siehe Kap. 2.8.4). Es wurde dreimal gegen 11 Dialysepuffer dialysiert und nach dem Lyophilisieren als Antigen zur Immunisierung eines Kaninchens (Eurogentec, Seraing, Belgien) eingesetzt. Dort wurde das Kaninchen viermal (dreimal im Abstand von 14 Tagen und das letzte Mal nach 29 Tagen) mit je $100 \mu \mathrm{g}$ Antigen immunisiert. Nacheinander wurden dem Kaninchen folgende Proben entnommen: einige Milliliter Präimmunserum vor der Immunisierung, das erste Immunserum 38 Tage nach der ersten Immunisierung zur Kontrolle der Immunantwort, eine größere Menge Serum 66 Tage nach der ersten Immunisierung und etwa $40 \mathrm{ml}$ Serum aus der finalen Blutung 80 Tage nach der ersten Immunisierung.

\subsection{Proteinbiochemische Methoden}

\subsubsection{Versuchsmaterial und Anzucht}

Alle folgenden Medien wurden nach dem Ansetzen autoklaviert. Zum Gießen von Agarplatten wurde $0,8 \%(w / v)$ Agar vor dem Autoklavieren hinzugegeben.

Medien:

Gamborgs B5-Medium:

3,86 g Gamborgs B5-Salz inklusive Vitaminen (Sigma, Taufkirchen, BRD)

$20 \mathrm{~g} / \mathrm{l}$ Glucose

$0,5 \mathrm{~g} / \mathrm{l} \mathrm{Mes}$

$0,5 \mathrm{mg} / 1$ 2,4-D

$50 \mu \mathrm{g} / \mathrm{l}$ Kinetin

in $\mathrm{H}_{2} \mathrm{O}$ bidest., pH 5,7 mit $\mathrm{KOH}$ eingestellt 
Murashige und Skoog-Medium: (MS-Medium)
4,3 g/l MS-Salz (Sigma, Taufkirchen, BRD)

$30 \mathrm{~g} / \mathrm{l}$ Saccharose

$0,2 \mathrm{mg} / \mathrm{l} 2,4-\mathrm{D}$

in $\mathrm{H}_{2} \mathrm{O}$ bidest., $\mathrm{pH}$ 5,7 mit $\mathrm{KOH}$ eingestellt

Nach dem Autoklavieren wurden sterile MS-Vitamine aus der Stammlösung (Sigma, Taufkirchen, BRD) zugegeben.

$40 \mathrm{~g} / \mathrm{l}$ Glucose

$10 \mathrm{~g} / \mathrm{l}$ Peptone

in $\mathrm{H}_{2} \mathrm{O}$ bidest., $\mathrm{pH} 5,5$ mit $\mathrm{HCl}$ eingestellt

Der Blumenkohl (Brassica oleracea L. var botrytis) wurde im Gewächshaus im Licht-DunkelRhythmus von $16 \mathrm{~h}$ Licht und $8 \mathrm{~h}$ Dunkel angezogen. 10-15 cm große Infloreszenzen wurden geerntet, von den Strünken befreit und frisch aufgearbeitet. Für die Kältebehandlung wurden Blumenkohlpflanzen über Nacht für $14 \mathrm{~h}$ bei $4{ }^{\circ} \mathrm{C}$ gekühlt und direkt danach homogenisiert.

Für die Herstellung der Arabidopsis-Suspensionskultur wurden Arabidopsis-Samen (Arabidopsis thaliana, var Columbia) auf MS-Platten, die keine Saccharose und 2,4-D enthielten, gelegt und für 10 Tage bei $24{ }^{\circ} \mathrm{C}$ und $16 \mathrm{~h}$ Licht wachsen gelassen. Danach wurden die Blätter der kleinen Pflanzen abgetrennt und in kleinen Stücken auf Gamborgs-Platten verteilt. Nachdem die Kalli dreimal (jeweils 3-4 Wochen Wachstumszeit) auf frische Gamborgs-Platten umgesetzt worden waren, wurde jeweils eine kleine Menge Kallus durch ein Haarsieb gestrichen und in $50 \mathrm{ml}$ Gamborgs-Medium gegeben. Die Zellsuspensionen wurden wöchentlich in frisches GamborgsMedium eingesetzt. Zum Ernten wurden die Suspensionszellen mit Hilfe eines Papierfaltenfilters vom Medium getrennt und sofort in flüssigem Stickstoff eingefroren und bei $-80{ }^{\circ} \mathrm{C}$ gelagert.

Für die Anzucht von Mais (Zea mays L. var mutin) wurden Samen über Nacht in Leitungswasser eingeweicht. Dann wurden sie in abgedeckten Anzuchtschalen auf hochreinem Papier (Nette $\mathrm{GmbH}$, Göttingen, BRD) ausgesät und in einer Klimakammer bei $27^{\circ} \mathrm{C}$ inkubiert. Die Keimlinge wurden täglich gegossen. 2-3 mm lange Wurzelspitzen von 3-4 Tage alten Keimlingen wurden abgetrennt und aufgearbeitet.

Suspensionskultivierte Tabakzellen (Nicotiana tabacum L. Bright Yellow 2: BY2) wurden von Dr. Yuji Moriyasu (School of Food and Nutritional Sciences, Shizuoka University, Shizuoka, Japan) zur Verfügung gestellt. Die Kultivierung der Zellen erfolgte im MS-Medium unter keimarmen Bedingungen. Die Zellen wurden regelmäßig alle sieben Tage subkultiviert. Dafür wurden mit jeweils $2 \mathrm{ml}$ Zellsuspension je $100 \mathrm{ml}$ frisches Nährmedium angeimpft. Die Anzucht erfolgte im Dunkeln auf einem Schüttler bei $27^{\circ} \mathrm{C}$ und $120 \mathrm{Upm}$. 
Hefezellen (Saccharomyces cerevisiae cv Vital Gold) wurden in Sabourauds Glucose-Medium bei $28{ }^{\circ} \mathrm{C}$ in einem Wasserbad für $12 \mathrm{~h}$ gezüchtet (Campbell, 1988). Sie wurden für 15 min bei $5.000 \mathrm{~g}_{\max }$ (Sorvall RC 5B, Rotor SLA-1000) sedimentiert, in $200 \mathrm{ml}$ Homogenisationsmedium (siehe Kap. 2.2.2) resuspendiert und erneut unter gleichen Bedingungen zentrifugiert. Die weitere Aufarbeitung erfolgte mit frisch geernteten Zellen.

Schweinehirn wurde auf dem örtlichen Schlachthof von frisch geschlachteten Tieren entnommen, auf Eis ins Labor transportiert und sofort verarbeitet.

\subsubsection{Präparation von Cytosol und mikrosomalen Membranen}

Um den proteolytischen Abbau gering zu halten, wurden alle Arbeitsschritte, sofern nicht anders angegeben, bei $4{ }^{\circ} \mathrm{C}$ durchgeführt.

Lösungen:

HDKE10-Puffer:

$40 \mathrm{mM}$ Hepes/KOH, pH 8,0

$1 \mathrm{mM}$ DTT

$10 \mathrm{mM} \mathrm{KCl}$

3 mM EDTA

Homogenisationsmedium: $320 \mathrm{mM}$ Saccharose

$2 \mu \mathrm{g} / \mathrm{ml}$ Aprotinin

$0,5 \mu \mathrm{g} / \mathrm{ml}$ Leupeptin

$1 \mu \mathrm{g} / \mathrm{ml}$ Pepstatin

$0,39 \mathrm{mg} / \mathrm{ml}$ o-Phenanthrolin

$1 \mu \mathrm{g} / \mathrm{ml} \mathrm{E}-64$

in HDKE10 Puffer

Die Proteaseinhibitoren wurden vor der Aufarbeitung frisch aus folgenden Stammlösungen zugesetzt:

Aprotinin: $\quad 1 \mathrm{mg} / \mathrm{ml}$ in $\mathrm{H}_{2} \mathrm{O}$ bidest.

Leupeptin: $\quad 1 \mathrm{mg} / \mathrm{ml}$ in $\mathrm{H}_{2} \mathrm{O}$ bidest.

Pepstatin: $\quad 0,7 \mathrm{mg} / \mathrm{ml}$ in $\mathrm{H}_{2} \mathrm{O}$ bidest.

o-Phenanthrolin: $\quad 19,8 \mathrm{mg} / \mathrm{ml}$ in Ethanol p.a.

E-64: $\quad 10 \mathrm{mg} / \mathrm{ml}$ in $50 \%(\mathrm{v} / \mathrm{v})$ Ethanol p.a. in $\mathrm{H}_{2} \mathrm{O}$ bidest. 
Waschlösung: $\quad 250 \mathrm{mM}$ Saccharose in HDKE10-Puffer

25 g Blumenkohlinfloreszenzen, Maiswurzeln oder Arabidopsiszellen wurden jeweils in $25 \mathrm{ml}$ Homogenisationsmedium mit Hilfe eines Waring-Blendors durch drei Impulse von je $15 \mathrm{~s}$ homogenisiert. Das Rohhomogenat wurde durch eine Lage Miracloth (Calbiochem, Bad Soden, BRD) und zwei Lagen Mull filtriert und anschließend $20 \mathrm{~min}$ bei $18.000 \mathrm{~g}_{\max }$ in einem Ausschwingrotor (Sorvall RC 5B, Rotor HB 4) zentrifugiert. Der Überstand wurde abgenommen und für eine weitere Stunde bei $100.000 \mathrm{~g}_{\max }$ in einer Ultrazentrifuge (Kontron, Centrikon T1170; Rotor TFT 50.38) zentrifugiert. Dieser Überstand wurde auf eine zuvor mit HDKE10Puffer äquilibrierten $50 \mathrm{ml}$ großen Sephadex G-25 Gelfiltrationssäule (Pharmacia, Freiburg, BRD) mit einem Durchmesser von 2,5 cm aufgetragen. Bei einer Flussrate von $2 \mathrm{ml} / \mathrm{min}$ wurden die Proteine mit HDKE10-Puffer eluiert (Econo-System FPLC-Anlage, Bio-Rad, München, BRD). Mit Hilfe eines Durchfluss-UV-Monitors konnten die Proteine im Eluat detektiert werden. Der Proteingehalt des Eluats wurde nach der Methode von Bradford bestimmt. Die isolierten cytosolischen Proteine wurden aliquotiert, in flüssigem Stickstoff eingefroren und bei $-80{ }^{\circ} \mathrm{C}$ aufbewahrt.

Das entstandene Membransediment nach der Ultrazentrifugation wurde in $10 \mathrm{ml}$ Waschpuffer aufgenommen und wieder für $1 \mathrm{~h}$ bei $100.000 \mathrm{~g}_{\max }$ pelletiert. Die mikrosomalen Membranen wurden in $1 \mathrm{ml}$ Waschpuffer mit Hilfe eines Glashomogenisators gut resuspendiert. Nach dem Bradfordtest konnte die Membranfraktion in flüssigem Stickstoff eingefroren und bei $-80{ }^{\circ} \mathrm{C}$ gelagert werden.

Die Isolierung cytosolischer Proteinen aus Schweinehirn und Hefezellen erfolgte nach der gleichen Methode, wobei jedoch $25 \mathrm{~g}$ Versuchsmaterial in $50 \mathrm{ml}$ Homogenisationsmedium homogenisiert wurden. Der Aufbruch der Hefezellen erfolgte in einer Zellmühle (Vibrogen, Bühler, Tübingen, BRD) bei $4{ }^{\circ} \mathrm{C}$ durch sechs Impulse von je $30 \mathrm{~s}$ mit einer jeweiligen Pause von $1 \mathrm{~min}$.

\subsubsection{Aufarbeitung cytosolischer Proteine}

Sofern nicht anders angegeben, wurden alle Arbeitsschritte bei $4{ }^{\circ} \mathrm{C}$ durchgeführt, um den proteolytischen Abbau gering zu halten.

\subsubsection{Ammoniumsulfatfraktionierung}

Für diese Aufarbeitung wurde TDKE-Puffer mit höherer KCl-Konzentration verwendet, um die membrangebundenen peripheren Proteine abzulösen und deren Konzentration im Homogenat zu erhöhen. 
Lösungen:

TDKE500-Puffer:

25 mM Tris/HCl, $\mathrm{pH} 8,0$

$1 \mathrm{mM}$ DTT

$500 \mathrm{mM} \mathrm{KCl}$

3 mM EDTA

TDKE150-Puffer:

$25 \mathrm{mM}$ Tris/HCl, $\mathrm{pH}$ 7,5

$1 \mathrm{mM}$ DTT

$150 \mathrm{mM} \mathrm{KCl}$

3 mM EDTA

Homogenisationsmedium: $320 \mathrm{mM}$ Saccharose

$2 \mu \mathrm{g} / \mathrm{ml}$ Aprotinin

$0,5 \mu \mathrm{g} / \mathrm{ml}$ Leupeptin

$1 \mu \mathrm{g} / \mathrm{ml}$ Pepstatin

$0,39 \mathrm{mg} / \mathrm{ml}$ o-Phenanthrolin

$1 \mu \mathrm{g} / \mathrm{ml} \mathrm{E}-64$

in TDKE500-Puffer

$25 \mathrm{~g}$ Blumenkohlinfloreszenzen wurden in $25 \mathrm{ml}$ Homogenisationsmedium mittels eines WaringBlendors durch 3 Impulse von je 15 s homogenisiert. Das Rohhomogenat wurde durch eine Lage Miracloth (Calbiochem, Bad Soden, BRD) und zwei Lagen Mull filtriert und für 20 min bei $18.000 \mathrm{~g}_{\max }$ (Sorvall RC 5B, Rotor HB 4) zentrifugiert. Der Überstand wurde für eine weitere Stunde bei $100.000 \mathrm{~g}_{\max }$ in einer Ultrazentrifuge (Kontron, Centrikon T-1170; Rotor TFT 50.38) zentrifugiert. Der Proteingehalt des entstandenen Cytosols wurde nach der Methode von Bradford bestimmt und danach die Proteinkonzentration mit Homogenisationsmedium auf $5 \mu \mathrm{g} / \mu \mathrm{l}$ verdünnt.

Beim ersten Schritt der Ammoniumsulfatfraktionierung wurden Proteine zunächst durch Zugabe von $20 \%$ (Sättigung) Ammoniumsulfat gefällt. Hierzu wurde über $15 \mathrm{~min}$ fein gemörsertes Ammoniumsulfat in kleinen Portionen unter Rühren zugegeben, die Lösung weitere 15 min bei $4{ }^{\circ} \mathrm{C}$ gerührt und für $20 \mathrm{~min}$ bei $20.000 \mathrm{~g}_{\max }$ (Sorvall RC 5B, Rotor HB 4) zentrifugiert. Das erhaltene Proteinpräzipitat wurde in $1 \mathrm{ml}$ TDKE150-Puffer gelöst, auf eine $2 \mathrm{ml}$ große PD-10 Säule (Pharmacia, Freiburg, BRD) aufgetragen und mit TDKE150-Puffer eluiert. Zum Überstand wurde weiteres Ammoniumsulfat bis zu einer Endkonzentration von 30 \% (Sättigung) zugegeben 
und wie oben beschrieben aufgearbeitet. Insgesamt wurden 7 solche Fällungsschritte durchgeführt, so dass schließlich eine Ammoniumsulfatsättigung von $80 \%$ erreicht wurde. So erhielt man eine Reihe von Proteinfraktionen, die mit steigender Konzentration von Ammoniumsulfat in $10 \%$-Schritten gefällt waren. Die Proteinkonzentration jeder Fraktion wurde nach der Methode von Peterson bestimmt und jeweils $20 \mu \mathrm{g}$ Protein nach einer TCA-Fällung mit Western-Blotting analysiert. Die proteolytische Aktivität jeder Fraktion wurde mittels des Azocaseintests (siehe Kap. 2.4) bestimmt, um die Verteilung der Proteasen in den Ammoniumsulfatfraktionen zu prüfen.

\subsubsection{Trennung cytosolischer Proteine durch Gelfiltration}

Zur Vorbereitung wurde TDKE150-Puffer durch einen 0,2 $\mu \mathrm{m}$ Millipore-Filter steril filtriert. Die Cytosolfraktion von $25 \mathrm{~g}$ Blumenkohlinfloreszenzen wurde wie vorher beschrieben (siehe Kap. 2.2.3.1]) isoliert. Nach der Zentrifugation bei $100.000 \mathrm{~g}_{\max }$ wurde die Proteinkonzentration mit dem Bradfordtest bestimmt und mit Homogenisationsmedium auf $5 \mu \mathrm{g} / \mu \mathrm{l}$ eingestellt. Nun wurde Ammoniumsulfat bis zu einer Konzentration von $40 \%$ (Sättigung) über 20 min zugegeben und die Lösung für weitere 30 min gerührt. Die gefällten Proteine wurden für 20 min bei $20.000 \mathrm{~g}_{\max }$ (Sorvall RC 5B, Rotor HB 4) sedimentiert, in $2 \mathrm{ml}$ TDKE150-Puffer gelöst und auf einer zuvor mit TDKE150-Puffer äquilibrierten $80 \mathrm{ml}$ großen Sepharose CL-6B Gelfiltrationssäule (Sigma, Taufkirchen, BRD) mit einem Durchmesser von $1 \mathrm{~cm}$ aufgetragen. Cytosolische Proteine wurden bei einer Flussrate von $0,1 \mathrm{ml} / \mathrm{min}$ mit TDKE150-Puffer eluiert (Bio-Rad, Econo-System FPLC-Anlage). Durch Messung der Absorption bei $280 \mathrm{~nm}$ wurden die proteinhaltigen Fraktionen (Fraktionen 16-35) identifiziert. Jeweils $100 \mu \mathrm{l}$ dieser $2 \mathrm{ml}$ großen Fraktionen wurden mit TCA gefällt und mit Western-Blotting analysiert.

Die Säule wurde gründlich mit Elutionspuffer gewaschen und zur Aufbewahrung mit $20 \%$ (v/v) Ethanol in $\mathrm{H}_{2} \mathrm{O}$ bidest. äquilibriert.

Als Molekularmassenmarker wurden folgende Proteine mit einer Konzentration von 0,2 mg/ml in TDKE150-Puffer verwendet:

$\begin{array}{ll}\text { Thyroglobulin } & 669 \mathrm{kDa} \\ \text { Apoferritin } & 443 \mathrm{kDa} \\ \beta \text {-Amylase } & 200 \mathrm{kDa} \\ \text { BSA } & 67 \mathrm{kDa}\end{array}$

\subsubsection{Neomycinfällung}

Das Coatomer aus Säugetieren und Hefe kann mit bestimmten aminoglykosierten Antibiotika wie Neomycin präzipitiert werden (Hudson und Draper, 1997). Um diese Eigenschaft des pflanzlichen Coatomers zu prüfen wurde folgender Versuch durchgeführt. 
Resuspendierungspuffer: $\quad 25 \mathrm{mM}$ Tris/ $\mathrm{HCl}, \mathrm{pH} 8,0$

$10 \mathrm{mM} \mathrm{KCl}$

Die cytosolischen Proteine von Blumenkohlinfloreszenzen wurden wie unter 2.2.3.1 beschrieben aufgereinigt und ihre Konzentration auf $5 \mu \mathrm{g} / \mu \mathrm{l}$ eingestellt. Durch Zugabe von $40 \%$ Ammoniumsulfat (Sättigung) erfolgte eine Proteinfällung. Die gefällten Proteine wurden für 20 min bei $20.000 \mathrm{~g}_{\max }$ (Sorvall RC 5B, Rotor HB 4) sedimentiert, in Resuspendierungspuffer gelöst und ihre Konzentration auf $1,5 \mu \mathrm{g} / \mu \mathrm{l}$ eingestellt. $\mathrm{Zu} 1,5 \mathrm{ml}$ großen Aliquots wurde Neomycin (Sigma, Taufkirchen, BRD) bis zu einer finalen Konzentration von 0,05, 0,5, 1, 4 und $10 \mathrm{mM}$ zugegeben. Ein Aliqout ohne Neomycin diente als Kontrolle. Nach einer 20-minütigen Zentrifugation bei $100.000 \mathrm{~g}_{\max }$ (Beckman TL-100, Rotor TLA 100.3) und einer TCA-Fällung wurden die Überstände mit Western-Blotting analysiert.

\subsubsection{Aufarbeitung der mikrosomalen Membranen}

Alle Arbeitsschritte wurden bei $4{ }^{\circ} \mathrm{C}$ durchgeführt.

\subsubsection{Trennung mikrosomaler Membranen mit der Gelfiltrationschromatographie}

Die Aufreinigung der mikrosomalen Membranen von Blumenkohlinfloreszenzen erfolgte wie bei Kap. 2.2.2 beschrieben, wobei jedoch statt HDKE10-Puffer TDKE10-Puffer verwendet wurde.

Lösungen:

TDKE10-Puffer:

$25 \mathrm{mM}$ Tris/HCl, $\mathrm{pH} 8,0$

$1 \mathrm{mM}$ DTT

$10 \mathrm{mM} \mathrm{KCl}$

3 mM EDTA

Homogenisationsmedium: $320 \mathrm{mM}$ Saccharose und Proteaseinhibitoren (siehe Kap. 2.2.2) in TDKE10-Puffer

Kalibrierungslösung: $\quad 0,5 \mathrm{mg} / \mathrm{ml}$ Thyroglobulin in TDKE10-Puffer 
Sättigungslösung: $\quad 10 \mathrm{mg} / \mathrm{ml}$ L- $\alpha$-Lecithin (Typ XV-E; Sigma, Taufkirchen, BRD) in TDKE10-Puffer

$200 \mathrm{mg}$ L- $\alpha$-Lecithin wurden bei RT auf einem Schüttler in $20 \mathrm{ml}$ TDKE10-Puffer vorgelöst und anschließend 10-mal in Intervallen von 30 s mit Ultraschall (Branson Ultrasonic, Danbury, CT, USA) bei $200 \mathrm{~W}$ behandelt. Die Suspension wurde für $20 \mathrm{~min}$ bei $12.000 \mathrm{~g}_{\max }$ zentrifugiert und der Überstand zur Absättigung der Säule verwendet.

Frisch aufgereinigte, mikrosomale Membranen wurden in $2 \mathrm{ml}$ TDKE10-Puffer $\mathrm{pH} 7,0$ resuspendiert. Die Proteinbestimmung wurde nach der Methode von Bradford durchgeführt und eine Membranfraktion mit einem Proteingehalt von $10 \mathrm{mg}$ auf eine $100 \mathrm{ml}$ große Sephacryl S1000 Säule (Durchmesser $2 \mathrm{~cm}$ ) aufgetragen. Die Säule war zuvor mit Thyroglobulin (669 kDa) als Molekularmassenmarker kalibriert, mit $20 \mathrm{ml}$ Sättigungslösung vorgewaschen und mit TDKE10-Puffer pH 7,0 äquilibriert worden. Bei der Elution mit TDKE10-Puffer wurden $3 \mathrm{ml}$ große Fraktionen gesammelt. $200 \mu \mathrm{l}$ der proteinhaltigen Fraktionen wurden mit TCA gefällt und später der Analyse durch Western-Blotting unterzogen.

\subsubsection{Saccharosedichtegradienten}

Verschiedene Zellkompartimente lassen sich wegen ihrer unterschiedlichen Schwebedichte durch Dichtegradientenzentrifugation auftrennen. Durch unterschiedliche Auftrennung in An- und Abwesenheit von Magnesium kann geprüft werden, in welchen Kompartimenten bestimmte Proteine vorkommen (Robinson und Hinz, 2000). Daher wurde die Aufarbeitung mikrosomaler Membranen unter zwei unterschiedlichen Bedingungen durchgeführt.

Für Minus-Magnesium-Bedingungen wurden der TDKE10-Puffer (als Grundmedium) und das Homogenisationsmedium aus Kap. 2.2.4.1 verwendet. Als Grundmedium für Plus-MagnesiumBedingungen wurden in diesen beiden Medien $3 \mathrm{mM}$ EDTA durch $3 \mathrm{mM} \mathrm{MgCl} 2$ ersetzt. Für die Gradienten wurden $20 \%$ (w/w) bzw. $55 \%$ (w/w) Saccharose in dem jeweiligen Grundmedium angesetzt.

Mikrosomale Membranen aus $5 \mathrm{~g}$ Blumenkohlinfloreszenzen wurden jeweils unter Plus- und Minus-Magnesium-Bedingungen frisch aufgearbeitet und anschließend durch eine einstündige Zentrifugation bei $100.000 \mathrm{~g}_{\max }$ (Kontron, Centrikon T-1170; Rotor TST 28.38) auf einem $5 \mathrm{ml}$ großen Saccharosekissen (55\% (w/w) in Grundmedium) gesammelt. Die Membranfraktionen wurden vorsichtig von der Interphase abgenommen, ihr Saccharosegehalt mit Hilfe eines Handrefraktometers (Carl Zeiss, Jena, BRD) bestimmt und durch Zugabe von Grundmedium ein Saccharosegehalt von $15 \%$ (w/w) eingestellt. Diese Fraktionen wurde danach auf $30 \mathrm{ml}$ große 
lineare 20-55\%(w/w) Saccharosedichtegradienten aufgetragen, die mittels eines Gradientenmischers aus 20\%- und 55\%-igen Saccharoselösungen hergestellt worden waren. Nach einer 3-stündigen Zentrifugation in einem Vertikalrotor bei $150.000 \mathrm{~g}_{\max }$ (Kontron, Centrikon T-1170; Rotor TV-850) wurden schließlich 1,5 ml große Fraktionen mit einer peristaltischen Pumpe (ISCO, Modell 183) aufgefangen.

Die Saccharosedichte der Einzelfraktionen wurde mit einem Handrefraktometer (Carl Zeiss, Jena, BRD) und die Proteinkonzentration nach der Methode von Bradford bestimmt. Die Proteine von $100 \mu \mathrm{l}$ jeder Fraktion wurden mit TCA gefällt und die Verteilung der einzelnen Membrankompartimente in den Gradienten mit Western-Blotting analysiert. Zudem wurde durch Messung der latenten Inosin-5-Diphosphatase (siehe Kap. 2.5) die Verteilung des GApp in den Gradienten untersucht.

\title{
2.2.4.3 Proteolytischer Verdau mit Papain
}

Frische mikrosomale Membranen aus Blumenkohlinfloreszenzen wurden in Abwesenheit von Magnesium (siehe Kap. 2.2.4.2) aufgereinigt. Nach der einstündigen Zentrifugation bei $100.000 \mathrm{~g}_{\max }$ (Kontron, Centrikon T-1170; Rotor TST 28.38) wurden sie vorsichtig in TDKE10Puffer (+/- Triton X-100) resuspendiert. Die Proben mit Detergenz enthielten dabei 0,1\% (v/v) Triton. Der Proteingehalt wurde nach der Methode von Bradford bestimmt und die Proteinkonzentration mit TDKE10-Puffer auf $2 \mu \mathrm{g} / \mu \mathrm{l}$ eingestellt.

$100 \mu \mathrm{l}$ große Fraktionen wurden mit $2 \mu \mathrm{g}$ Papain (Sigma, Taufkirchen, BRD) in TDKE10-Puffer pH 7,0 (+/- Triton X-100) gemischt und für den Verdau für 5, 15 oder 30 min auf Eis inkubiert. Eine Kontrollfraktion wurde ohne Papain für 30 min auf Eis gestellt. Die Verdaureaktion wurde durch Zugabe von $10 \mu \mathrm{g}$ Leupeptin, $50 \mu \mathrm{l}$ heißem, 3-fach konzentriertem SDS-Probenpuffer und 5-minütiges Kochen gestoppt. Die Proteine aus $15 \mu$ jeder Fraktion wurden durch WesternBlotting analysiert.

3-fach konzentrierter SDS-Probenpuffer:

\author{
690 mM Tris/HCl, pH 6,8 \\ $6 \%(\mathrm{w} / \mathrm{v}) \mathrm{SDS}$ \\ $48 \%(\mathrm{v} / \mathrm{v})$ Glycerin \\ $0,15 \%$ (w/v) Bromphenolblau ( $\left.\mathrm{Na}^{+}-\mathrm{Salz}\right)$ \\ $13,5 \%$ (v/v) 2-Mercaptoethanol
}




\subsubsection{Membranbehandlung mit verschiedenen Reagenzien}

Frisch aufgereinigte mikrosomale Membranen aus Blumenkohlinfloreszenzen (siehe Kap.2.2.2) wurden nach der einstündigen Zentrifugation bei $100.000 \mathrm{~g}_{\max }$ in HDKE10-Puffer resuspendiert. Als Referenz wurde ein Teil dieser Fraktion nach dem Bradfordtest für eine spätere WesternBlotting-Analyse in flüssigem Stickstoff eingefroren und bei $-80{ }^{\circ} \mathrm{C}$ aufbewahrt. 9 weitere Membranfraktionen mit einem Proteingehalt von jeweils $5 \mathrm{mg}$ wurden erneut bei $100.000 \mathrm{~g}_{\max }$ pelletiert und anschließend in je 2,5 $\mathrm{ml}$ folgender Lösungen auf Basis des HDKE10-Puffers aufgenommen:

1. Kontrollansatz ohne Zusätze

2. $+0,1 \%$ Triton $X-100$

3. $+1 \%$ Triton $\mathrm{X}-100$

4. + 0,5 M Harnstoff

5. + 2 M Harnstoff

6. $+0,1 \mathrm{M} \mathrm{Na}_{2} \mathrm{CO}_{3}$

7. $+0,25 \mathrm{M} \mathrm{NaCl}$

8. $+0,5 \mathrm{M} \mathrm{NaCl}$

9. $+1 \mathrm{M} \mathrm{NaCl}$

Diese Fraktionen wurden für eine Stunde bei $4{ }^{\circ} \mathrm{C}$ auf einem Drehrad geschwenkt und anschlieBend für eine Stunde bei $100.000 \mathrm{~g}_{\max }$ zentrifugiert. Die Überstände wurden vorsichtig abgenommen, die Sedimente in 2,5 $\mathrm{ml}$ resuspendiert und für beide die Proteinkonzentration nach der Methode von Bradford bestimmt. Je $50 \mu$ d dieser Proben wurden mit Chloroform/Methanol gefällt (siehe Kap. 2.8.1) und für ein Western-Blotting vorbereitet.

\subsubsection{BFA-Behandlung}

Um den Effekt von Brefeldin A (BFA) auf die Membranbindung der Hüllproteine der COP Vesikel zu zeigen, wurden kultivierte Tabakzellen mit diesem toxischen Metabolit aus Pilzen folgendermaßen behandelt.

Lösungen:

Grundmedium: $40 \mathrm{mM}$ Hepes/KOH, pH 7,4

$1 \mathrm{mM}$ DTT

$10 \mathrm{mM} \mathrm{KCl}$ 
$3 \mathrm{mM} \mathrm{MgCl} 2$

Homogenisationsmedium: $\quad 320 \mathrm{mM}$ Saccharose und Proteaseinhibitoren

(siehe Kap. 2.2.2) im Grundmedium

Saccharoselösung:

$20 \%(w / w)$ Saccharose im Grundmedium

BFA-Stammlösung:

$5 \mathrm{mg} / \mathrm{ml}$ BFA (Sigma, Taufkirchen, BRD)

in Dimethylsulfoxid (DMSO)

Der Versuchsansatz erfolgte in $500 \mathrm{ml}$ Erlenmeyerkolben, die jeweils $200 \mathrm{ml}$ vier Tage alte suspensionskultivierte Tabakzellen enthielten. In die 7 Medien wurden $400 \mu \mathrm{l}$ der BFAStammlösung pipettiert (finale Konzentration im Medium $10 \mu \mathrm{g} / \mathrm{ml}$ ) und die Zellen wurden in der Klimakammer weiter geschüttelt. Die Zellen eines Mediums wurden als Kontrolle ohne Zugabe von BFA geerntet. Nach 5, 10, 15, 30, 60, 120 und 300 min wurden die mit BFA behandelten Zellen mit Hilfe eines Büchner-Trichters mit einer Saugflasche auf einen Papierfaltenfilter gesaugt. Sie wurden sofort in flüssigem Stickstoff eingefroren und bei $-80{ }^{\circ} \mathrm{C}$ gelagert.

Für die Isolierung der Membran- und Cytosolfraktion wurden die gefrorenen Tabakzellen zum Aufbruch in flüssigem Stickstoff gemörsert und anschließend in $10 \mathrm{ml} 4{ }^{\circ} \mathrm{C}$ kaltes Homogenisationsmedium überführt. Die Rohhomogenate wurden durch eine Lage Miracloth (Calbiochem, Bad Soden, BRD) und zwei Lagen Mull filtriert und anschließend 15 min bei $5.000 \mathrm{~g}_{\max }$ in einem Ausschwingrotor (Sorvall RC 5B, Rotor HB 4) zentrifugiert. Die Überstände wurden abgenommen und auf $10 \mathrm{ml}$ Saccharoselösung aufgetragen. Durch eine einstündige Zentrifugation bei $100.000 \mathrm{~g}_{\max }$ (Kontron, Centrikon T-1170; Rotor TST 28.38) wurden die Membranen sedimentiert und so von den Cytosolfraktionen, die auf der Saccharoselösung blieben, getrennt. Sie wurden jeweils in $2 \mathrm{ml}$ Homogenisationsmedium resuspendiert. Der Proteingehalt der beiden Membran- und Cytosolfraktionen wurde nach der Methode von Bradford bestimmt. $30 \mu \mathrm{g}$ Protein von jeder Fraktion wurden mit Chloroform/Methanol gefällt (siehe Kap. 2.8.1) und mit Western-Blotting untersucht.

\subsection{Proteinbestimmung}

Die Proteinkonzentration einer Probe wurde entweder nach Bradford (1976) oder nach Peterson (1977) bestimmt. Die Proteinbestimmung nach Bradford wurde als Schnelltest verwendet, während der Proteintest nach Peterson vorgezogen wurde, wenn es auf die Genauigkeit der Messung ankam. 


\subsubsection{Proteinbestimmung nach Bradford}

Die Proteinbestimmung nach Bradford beruht auf einer quantitativen Bindung von Coomassie $\mathrm{G}$ an Argininreste von Polypeptidketten.

Bradford-Reagenz: $\quad 70 \mathrm{mg} / \mathrm{l}$ Coomassie G (Serva, Heidelberg, BRD) $5 \%(\mathrm{v} / \mathrm{v})$ Ethanol p.a.

$8,5 \%$ (v/v) ortho-Phosphorsäure in $\mathrm{H}_{2} \mathrm{O}$ bidest.

Für den Proteintest wurden $50 \mu$ Probe mit $1 \mathrm{ml}$ Bradford-Reagenz versetzt und gut geschüttelt. Innerhalb von 2 min bei RT entwickelte sich ein blauer Farbkomplex, der bei $595 \mathrm{~nm}$ mit Hilfe eines Spektralphotometers (Kontron, Uvikon 810) quantitativ nachgewiesen werden konnte. Alle Proben wurden gegen einen entsprechenden Blindwert gemessen. Mit Hilfe einer Eichkurve von 0-500 $\mu \mathrm{g} \mathrm{BSA} / \mathrm{ml} \mathrm{H}_{2} \mathrm{O}$ bidest. konnte die Proteinkonzentration errechnet werden.

\subsubsection{Proteinbestimmung nach Peterson}

Der quantitative Nachweis von Proteinen nach Peterson stellt eine Erweiterung der Proteinbestimmmung nach Lowry et al. (1951) dar und ist genauer und empfindlicher als die Methode von Bradford. Die Grundlage des Verfahrens ist die Bildung eines Biuret-Komplexes aus $\mathrm{Cu}^{2+}$-Ionen und Peptidbindungen in alkalischen Lösungen, der das Folin-Ciocalteu-PhenolReagenz reduziert, wodurch eine intensive Blaufärbung entsteht.

Lösungen:

$0,15 \%(\mathrm{w} / \mathrm{v})$ Natriumdesoxycholat (DOC)

$72 \%(\mathrm{w} / \mathrm{w})$ Trichloressigsäure (TCA)

$10 \%(\mathrm{w} / \mathrm{v}) \mathrm{SDS}$ in $\mathrm{H}_{2} \mathrm{O}$ bidest.

$0,8 \mathrm{M} \mathrm{NaOH}$

Kupfer-Tartrat-Karbonat-Reagenz (KTC):

Lösung 1: $10 \mathrm{~g} \mathrm{Na}_{2} \mathrm{CO}_{2}$ in $40 \mathrm{ml} \mathrm{H}_{2} \mathrm{O}$ bidest.

Lösung 2: 0,2 $\mathrm{g} \mathrm{K}_{2}$-Tartrat $\left(\mathrm{C}_{4} \mathrm{H}_{4} \mathrm{~K}_{2} \mathrm{O}_{6}\right)$ in $50 \mathrm{ml} \mathrm{H} \mathrm{H}_{2} \mathrm{O}$ bidest.

Lösung 1 und Lösung 2 wurden vereinigt und mit $\mathrm{H}_{2} \mathrm{O}$ bidest. auf $100 \mathrm{ml}$ aufgefüllt. 
Reagenz A: $\quad \mathrm{H}_{2} \mathrm{O}, \mathrm{SDS}, \mathrm{KTC}$ und $\mathrm{NaOH}$ im Verhältnis 4:1:1:1

Die Lösung wurde frisch angesetzt.

Reagenz B: $\quad 16,6 \%(\mathrm{v} / \mathrm{v})$ Folin-Ciocalteau-Phenolreagenz in $\mathrm{H}_{2} \mathrm{O}$ bidest.

10 oder $20 \mu \mathrm{l}$ der Probe wurden mit $\mathrm{H}_{2} \mathrm{O}$ bidest. auf $1 \mathrm{ml}$ aufgefüllt und mit $100 \mu \mathrm{l}$ DOC vermischt. Die Solubilisierung von Membranproteinen wurde nach $10 \mathrm{~min}$ bei RT mit $100 \mu \mathrm{l}$ eiskalter TCA abgestoppt. Durch 15-minütiges Zentrifugieren bei $9.000 \mathrm{~g}_{\max }$ in einer Eppendorfzentrifuge wurden die Proteine sedimentiert. Der Überstand wurde verworfen und die Sedimente bei RT über Kopf getrocknet und in $1 \mathrm{ml}$ Reagenz A resuspendiert. Nach 10-minütiger Inkubation bei Raumtemperatur wurden die Ansätze mit $250 \mu 1$ Reagenz B versetzt. Innerhalb von 30 min entwickelte sich ein blauer Farbkomplex, dessen Bildung auf der Biuret-Reaktion beruht. Die Absorptionsmessung wurde bei $750 \mathrm{~nm}$ gegen Luft an einem Spektralphotometer (Kontron, Uvikon 810) durchgeführt. Eine Eichkurve wurde mit BSA-Mengen zwischen 0 und $20 \mu \mathrm{g}$ in $\mathrm{H}_{2} \mathrm{O}$ bidest. erstellt.

Zur Berechnung wird ein Wert aus dem niedrigen (n) und ein zweiter aus dem hohen Konzentrationsbereich (h) der Eichkurve entnommen. Die Proteinmenge einer Probe errechnet sich aus:

$$
\begin{aligned}
& \mu \mathrm{g} \text { Protein }=\left(\mathrm{A}_{750} \cdot \mathrm{I}\right)^{\mathrm{s}} \\
\mathrm{s} & =\lg (\mathrm{h} / \mathrm{h}): \lg \left(\mathrm{A}_{750}{ }^{\mathrm{h}} / \mathrm{A}_{750}{ }^{\mathrm{n}}\right) \\
\mathrm{I} & =\operatorname{antilg}\left(\lg \mathrm{h} / \mathrm{s}-\lg \mathrm{A}_{750}^{\mathrm{h}}\right) \\
\mathrm{A}_{750} \quad & =\text { Absorption bei } 750 \mathrm{~nm} \\
\mathrm{~h} \quad & =\mu \mathrm{g} \text { Protein der Probe mit hoher Proteinkonzentration } \\
\mathrm{A}_{750}{ }_{\mathrm{h}} & =\text { deren Absorption bei } 750 \text { nm } \\
\mathrm{n}^{\mathrm{n}} & =\mu \mathrm{g} \text { Protein einer Probe mit niedriger Proteinkonzentration } \\
\mathrm{A}_{750} \quad & =\text { deren Absorption bei } 750 \mathrm{~nm}
\end{aligned}
$$

\subsection{Azocaseintest}

Zur Bestimmung der proteolytischen Aktivität von verschiedenen cytosolischen Fraktionen wurde der Azocaseintest, modifiziert nach Gröne (1986), verwendet. Bei diesem Test wird der Probe als künstliches Proteasesubstrat Azocasein zugesetzt, welches durch Proteolyse 
hydrolysiert wird. Die dabei entstehenden farbigen Oligopeptidbruchstücke lassen sich im Gegensatz zu unhydrolysiertem Azocasein nicht mit Perchlorsäure fällen und deshalb im Überstand eines sauren Cytosolpräzipitates photometrisch bestimmen.

\section{Lösungen:}

Grundpuffer (KPP): 100 mM Kaliumphosphatpuffer, pH 7,5

Substratlösung: $\quad 50 \mathrm{mg} / \mathrm{ml}$ Azocasein in $\mathrm{H}_{2} \mathrm{O}$ bidest.

Fällungsreagenz: $\quad 14 \%(\mathrm{v} / \mathrm{v}) \mathrm{HClO}_{4}$

$200 \mu 1$ der cytosolischen Fraktionen wurden mit $200 \mu 1$ KPP und $50 \mu 1$ Azocaseinlösung versetzt und für $2 \mathrm{~h}$ bei $7^{\circ} \mathrm{C}$ inkubiert. Als Blindwertansatz wurden $200 \mu \mathrm{l}$ von einer cytosolischen Fraktion und eine Mischung von $200 \mu \mathrm{K}$ KP und $50 \mu$ l Azocaseinlösung getrennt im Wasserbad inkubiert und am Ende der Inkubationszeit vereinigt. Durch Zugabe von $500 \mu 1$ Perchlorsäure wurde die proteolytische Aktivität abgestoppt. Die Ansätze wurden $10 \mathrm{~min}$ bei $9.000 \mathrm{~g}_{\max }$ sedimentiert und anschließend die Extinktion der Überstände bei $340 \mathrm{~nm}$ in Quarzküvetten gemessen. Ein Unit (U) Azocaseinaseaktivität wurde nach Hamano (1983) berechnet: $1 \mathrm{U}=10^{-2} \times \Delta \mathrm{E}_{340}:($ Zeit $(\min ) \times \mathrm{mg}$ Protein $)$

\subsection{Latente Inosin-5-Diphosphatase}

Die latente Inosin-5-Diphosphatase (IDPase) wird als ein Markerenzym für den GApp angesehen (Nagahashi und Nagahashi, 1982). Da bei der Reaktion dieses Enzyms Phosphat freigesetzt wird, kann die Messung der IDPase-Aktivität nach der Menge des abgespaltenen Phosphats quantitativ nachgewiesen werden (Chen et al., 1956). Die Aktivität jeder Probe wird mit und ohne Zugabe von $0,2 \%$ (v/v) Triton X-100 gemessen und die Differenz aus beiden Werten gebildet.

$\begin{array}{ll}\text { IDPase-Lösung: } \quad & 50 \mathrm{mM} \text { Tris/HCl, } \mathrm{pH} \mathrm{7,0} \\ & 2 \mathrm{mM} \mathrm{MgCl}_{2} \\ & 4 \mathrm{mM} \text { Inosin-5-Diphosphat } \\ & +/-0,2 \%(\mathrm{v} / \mathrm{v}) \text { Triton X-100 }\end{array}$


Farbreagenz:

6 Teile $\mathrm{H}_{2} \mathrm{O}$ bidest.

1 Teil $6 \mathrm{~N} \mathrm{H}_{2} \mathrm{SO}_{4}$

1 Teil 2,5\% (w/v) Ammoniumheptamolybdat

1 Teil $10 \%(w / v)$ Ascorbinsäure

$50 \mu \mathrm{l}$ der Probe wurden mit $50 \mu \mathrm{l}$ der IDPase-Lösung versetzt und für $30 \mathrm{~min}$ bei $37^{\circ} \mathrm{C}$ im Wasserbad inkubiert. Die Reaktion wurde durch Zugabe von $500 \mu 1$ eiskalter $10 \%$-iger (w/w) TCA beendet. Die Ansätze wurden für $1 \mathrm{~h}$ bei $4{ }^{\circ} \mathrm{C}$ gelagert und anschließend bei $9.000 \mathrm{~g}_{\max }$ zentrifugiert. Das freigesetzte anorganische Phosphat befand sich im Überstand, von dem je $100 \mu \mathrm{l}$ für die Phosphatbestimmung eingesetzt wurden. Dazu wurden $900 \mu \mathrm{l}$ frisches Farbreagenz gegeben und für $1 \mathrm{~h}$ bei $37^{\circ} \mathrm{C}$ inkubiert. Die Extinktion bei $820 \mathrm{~nm}$ wurde gemessen und die Berechnung der Phosphatkonzentration erfolgte über eine Eichkurve, die mit 0-200 nM KH${ }_{2} \mathrm{PO}_{4}$ erstellt wurde.

\subsection{Messung der $\alpha$-Amylaseaktivität}

Die Messung der Aktivität der $\alpha$-Amylase (EC 3.2.1.1) erfolgte in Anlehnung an ein von McCleary und Sheehan (1987) entwickeltes Nachweisverfahren, das mit Hilfe des "Cereal $\alpha$ amylase assay" der Firma Megazyme (County Wicklow, Irland) durchgeführt wurde. Das zur Messung der $\alpha$-Amylaseaktivität eingesetzte Substrat p-Nitrophenol-Maltoheptaosid trägt am nicht reduzierenden Ende eine 4,6-O-verknüpfte Benzylidingruppe, so dass seine Hydrolyse durch $\beta$-Amylase, Glucoamylase und $\alpha$-Glucosidase blockiert wird. Nach der Hydrolyse einer $\alpha$ 1,4-glycosidischen Bindung innerhalb des Oligomers durch die $\alpha$-Amylase wird das entstandene p-Nitrophenyl-Maltosaccharid durch Glucoamylase und $\alpha$-Glucosidase in Glucose und pNitrophenol gespalten, wobei die Konzentration des freigesetzten p-Nitrophenols photometrisch bestimmt wird.

Lösungen:

Extraktionspuffer: $\quad 50 \mathrm{mM}$ Maleinsäure

$80 \mathrm{mM} \mathrm{NaOH}$

$50 \mathrm{mM} \mathrm{NaCl}$

$2 \mathrm{mM} \mathrm{CaCl}_{2}$

$0,05 \%(w / v)$ Natriumazid

in $\mathrm{H}_{2} \mathrm{O}$ bidest., $\mathrm{pH} 5,2$ mit $\mathrm{HCl}$ eingestellt 
Substratlösung:

54,5 mg p-Nitrophenol-Maltoheptaosid

$100 \mathrm{U} \alpha$-Glucosidase (bei $\mathrm{pH} 5,2$ )

100 U Glucoamylase (bei pH 5,2)

in $10 \mathrm{ml} \mathrm{H}_{2} \mathrm{O}$ bidest.

Stopplösung: $\quad 1 \%(w / v)$ Trizma base in $\mathrm{H}_{2} \mathrm{O}$ bidest.

Da $\alpha$-Amylase von transformierten Tabakpflanzen ins Anzuchtmedium sekretiert wird, wurden für den Enzymtest $30 \mu \mathrm{l}$ eines 1:10 mit Extraktionspuffer verdünnten Mediums, in dem die Tabakpflanzen angezogen worden waren, in einer Mikrotestplatte vorgelegt. Die so vorbereiteten Proben und die Substratlösung wurden in einem Wasserbad bei $40{ }^{\circ} \mathrm{C}$ für 5 min erwärmt. Der Reaktionsstart erfolgte durch die Zugabe von je $30 \mu$ l der erwärmten Substratlösung zu den vorgewärmten Proben. Nach 30 min wurde die Reaktion durch die Zugabe von je $150 \mu 1$ der Stopplösung abgebrochen. Im Anschluss wurde die Extinktion der Proben mit Hilfe eines Spektralphotometers bei einer Wellenlänge von $405 \mathrm{~nm}$ gemessen. Als Blindwert diente das 1:10 verdünnte Medium. Die Aktivität der $\alpha$-Amylase wurde nach der folgenden Gleichung berechnet.

Aktivität $(\mathrm{Kat} / \mathrm{l})=\mathrm{E}_{405} \times \mathrm{V}_{\text {Ansatz }}: \mathrm{t} \times \varepsilon_{\mathrm{p}-\text { Nitrophenol }} \times \mathrm{d} \times \mathrm{V}_{\text {Aliquot }}$

$\mathrm{E}_{405}=$ Extinktion bei $405 \mathrm{~nm}$

$\mathrm{V}_{\text {Ansatz }}=$ Volumen des gesamten Testansatzes

$\mathrm{V}_{\text {Aliquot }}=$ Volumen der eingesetzten Probe vor der Verdünnung

$\mathrm{t}=$ Reaktionszeit $(1800 \mathrm{~s})$

$\mathrm{d}=$ Schichtdicke der Mikrotiterplatte $(0,74 \mathrm{~cm})$

$\varepsilon_{\mathrm{p}-\mathrm{Nitrophenol}}=$ molarer Extinktionskoeffizient von p-Nitrophenol $\left(17,8 \mathrm{M}^{-1} \mathrm{~cm}^{-1}\right)$

\subsection{Antikörperaufreinigung über eine Protein A-Sepharosesäule}

Um Antikörper aus dem Serum anzureichern, konnte die "low salt" Methode angewendet werden, bei der Antikörper aufgrund ihrer hochaffinen Bindungsstellen für Protein A aufgereinigt werden (Ey et al., 1978). Dazu wurde ein Protokoll zur Aufreinigung von Immunglobulinen über Protein A-Sepharose-Säulen verwendet (Harlow und Lane, 1988).

Lösungen:

Waschlösung: $\quad 10 \mathrm{mM}$ Tris/ $\quad 1 \mathrm{HCl}, \mathrm{pH} 8,0$ 
Elutionspuffer:

$100 \mathrm{mM}$ Glycin/HCl, pH 2,9

Titrationslösung:

$1 \mathrm{M}$ Tris/ $\mathrm{HCl}, \mathrm{pH} 8,0$

Dialysepuffer:

$50 \mathrm{mM}$ Tris/HCl, pH 7,5

$150 \mathrm{mM} \mathrm{NaCl}$

Die Protein A-Sepharose CL-4B (Sigma, Taufkirchen, BRD) als Säulenmaterial mit einer Bindungskapazität von $20 \mathrm{mg}$ humanen $\mathrm{IgG} / \mathrm{ml}$ wurde zunächst für $24 \mathrm{~h}$ in $\mathrm{H}_{2} \mathrm{O}$ bidest. vorgequollen. Die Säule (Durchmesser $1 \mathrm{~cm}$, Säulenvolumen ca. $4 \mathrm{ml}$ ) wurde mit dem 10-fachen Säulenvolumen bei einer Geschwindigkeit von 0,33 ml/min mit dem Econo-System der Firma Bio-Rad (München, BRD) gepackt. Alle Arbeitsschritte wurden bei $4{ }^{\circ} \mathrm{C}$ durchgeführt. Jeweils $3 \mathrm{ml}$ Antiserum wurden für $4 \mathrm{~h}$ mit Hilfe eines geschlossenen Kreislaufsystems (Pumpe von Desaga GmbH, Heidelberg, BRD) bei einer Flussrate von 0,12 ml/min durch das Säulenmaterial gepumpt. Das nicht gebundene Material wurde aufgefangen und die Säule an das Econo-System angeschlossen. Die Säule wurde mit 20-fachem Säulenvolumen Waschpuffer bei einer Geschwindigkeit von $0,30 \mathrm{ml} / \mathrm{min}$ von ungebundenen Proteinen befreit und anschließend bei einer Flussrate von 0,15 ml/min mit dem sauren Elutionspuffer eluiert. Das Eluat wurde in $1 \mathrm{ml}$ großen Portionen fraktioniert, wobei in jedem Röhrchen $100 \mu \mathrm{l}$ der Titrationslösung vorgelegt worden waren, so dass der $\mathrm{pH}-$ Wert der Fraktion durch sanftes Schütteln auf den Neutralpunkt eingestellt werden konnte. Die proteinhaltigen Fraktionen wurden durch Messung der Absorption bei $280 \mathrm{~nm}$ (die optische Dichte 1 entspricht dabei etwa 0,8) identifiziert und vereinigt (meist Fraktionen Nr. 6-8). Die immunglobulinhaltigen Fraktionen wurden über $16 \mathrm{~h}$ bei dreimaligem Pufferwechsel gegen 31 Dialysepuffer dialysiert. Der Proteingehalt wurde nach der Methode von Bradford (siehe Kap. 2.3.1) bestimmt und danach die Proteinkonzentration mit Dialysepuffer auf $1 \mu \mathrm{g} / \mu \mathrm{l}$ verdünnt. Das Dialysat wurde in $200 \mu \mathrm{l}$ Portionen bei $-80{ }^{\circ} \mathrm{C}$ eingefroren. Die Säule wurde gründlich mit Elutionspuffer gewaschen bis die optische Dichte unter 0,05 lag und zur Aufbewahrung mit $20 \%$ (v/v) Ethanol in $\mathrm{H}_{2} \mathrm{O}$ bidest. gespült.

\subsection{Elektrophoretische Methoden}

Zur Auftrennung einzelner Proteine nach ihrer Molekularmasse wurde die SDS-Polyacrylamidgelelektrophorese (SDS-PAGE) mit diskontinuierlichen Gelen (Laemmli, 1970) verwendet. Dabei werden Proteine mit SDS denaturiert, so dass sie überwiegend entfaltet vorliegen. 


\subsubsection{Probenvorbereitung}

Die Probenvorbereitung begann mit einer Fällung aus einem großen Probenvolumen, um die Proben aufzukonzentrieren. Proteine wurden entweder mit TCA oder mit Chloroform/Methanol gefällt.

Bei der TCA-Fällung wurde eine bestimmte Menge der Probe, die $20 \mu \mathrm{g}$ Protein enthielt, mit eiskalter 72\%-iger (w/w) TCA auf eine Endkonzentration von $8 \%(w / v)$ TCA gebracht. Die Fraktion wurde $20 \mathrm{~min}$ bei $9.000 \mathrm{~g}_{\max }$ und $4{ }^{\circ} \mathrm{C}$ zentrifugiert und der Überstand dekantiert. Das Sediment wurde mit $1 \mathrm{ml}$ Ethanol p.a. gewaschen, $10 \mathrm{~min}$ bei $9.000 \mathrm{~g}_{\max }$ zentrifugiert und an der Luft getrocknet.

Die Chloroform/Methanol-Fällung nach Wessel und Flügge (1983) bietet gegenüber den zuvor beschriebenen Methoden den Vorteil, dass sie unempfindlich gegen Salze, Detergenzien und Phospholipide ist. Bei dieser schnellen Methode wurden zu $100 \mu$ l Probe zunächst $400 \mu 1$ Methanol p.a. und nach gründlichem Schütteln $100 \mu$ l Chloroform p.a. gegeben. Nach erneutem Schütteln wurde die Fraktion zur Phasentrennung mit $300 \mu \mathrm{l} \mathrm{H}_{2} \mathrm{O}$ bidest. gemischt und für 1 min bei $9.000 \mathrm{~g}_{\max }$ zentrifugiert. Die obere Phase wurde vorsichtig abgenommen und die untere Chloroform-Phase mit der proteinhaltigen Interphase mit $300 \mu 1$ Methanol versetzt. Nach kurzem Schütteln wurde das Protein durch eine 2-minütige Zentrifugation bei $9.000 \mathrm{~g}_{\max }$ sedimentiert, der Überstand verworfen und das Pellet bei RT getrocknet.

Die gefällten Proteine wurden nach dem Trocknen mit Probenpuffer auf eine Endkonzentration von 1-2 $\mu$ g Protein pro $\mu 1$ Puffer gebracht und für $10 \mathrm{~min}$ bei $60^{\circ} \mathrm{C}$ im Heizblock denaturiert. Nach der Denaturierung wurden die Proben für 15 min geschüttelt, um das Sediment vollständig zu solubilisieren. Nach einer 2-minütigen Zentrifugation bei $9.000 \mathrm{~g}_{\max }$ wurde der Überstand auf das Gel aufgetragen.

Probenpuffer:

$$
\begin{aligned}
& 230 \mathrm{mM} \text { Tris/HCl, pH 6,8 } \\
& 2 \%(\mathrm{w} / \mathrm{v}) \mathrm{SDS} \\
& 36 \%(\mathrm{v} / \mathrm{v}) \text { Glycerin } \\
& 0,05 \%(\mathrm{w} / \mathrm{v}) \text { Bromphenolblau }\left(\mathrm{Na}^{+}-\mathrm{Salz}\right) \\
& 4,5 \%(\mathrm{v} / \mathrm{v}) \text { 2-Mercaptoethanol }
\end{aligned}
$$

Zur Bestimmung der Molekularmassen wurde ein Markersatz für niedrige Molekularmassen ("LMW-Marker") der Firma Pharmacia (Freiburg, BRD), der entsprechend der Herstelleranweisung in Probenpuffer gelöst und für $10 \mathrm{~min}$ bei $60^{\circ} \mathrm{C}$ erhitzt wurde, verwendet. Er enthält folgende Proteine: 


$\begin{array}{ll}\text { Phosphorylase b } & 94 \mathrm{kDa} \\ \text { BSA } & 67 \mathrm{kDa} \\ \text { Ovalbumin } & 43 \mathrm{kDa} \\ \text { Carboanhydrase } & 30 \mathrm{kDa} \\ \text { Sojabohnen-Trypsin-Inhibitor } & 20 \mathrm{kDa} \\ \text { Lactalbumin } & 14 \mathrm{kDa}\end{array}$

\subsubsection{Herstellung der Gele und Elektrophoresebedingungen}

Die verwendeten diskontinuierlichen Polyacrylamidgele setzten sich aus einem 3,75\%-igen Sammelgel und einem 10\%-igen Trenngel zusammen. Die Herstellung der Gele sowie die Gelelektrophorese erfolgte in einem Biometra-Minigelsystem (Größe des Trenngels $80 \times 60 \times 1$ mm, Größe des Sammelgels $80 \times 20 \times 1 \mathrm{~mm}$ ).

\section{Lösungen:}

Ammoniumperoxydisulfatlösung (Ammoniumpersulfatlösung):

$2,4 \%(w / v)$ Ammoniumpersulfat in $\mathrm{H}_{2} \mathrm{O}$ bidest.

Die Lösung wurde jeweils frisch angesetzt.

Acrylamidlösung: $\quad 30 \%(w / w)$ Acrylamid

$0,8 \%$ (w/w) N,N'-Methylenbisacrylamid in $\mathrm{H}_{2} \mathrm{O}$ bidest.

Vor Gebrauch wurde die Lösung filtriert.

Sammelgelpuffer: $\quad$ 0,5 M Tris/HCl, $\mathrm{pH} 6,8$

$0,4 \%$ (w/v) SDS in $\mathrm{H}_{2} \mathrm{O}$ bidest.

Trenngelpuffer: $\quad 1,5 \mathrm{M}$ Tris/HCl, $\mathrm{pH} 8,8$

$0,4 \%$ (w/v) SDS in $\mathrm{H}_{2} \mathrm{O}$ bidest.

Zusammensetzung des Sammelgels (3,75\%-ig):

$0,8 \mathrm{ml}$ Sammelgelpuffer

$0,4 \mathrm{ml}$ Acrylamidlösung

$1,83 \mathrm{ml} \mathrm{H}_{2} \mathrm{O}$ bidest.

2,63 $\mu 1$ TEMED

$133 \mu 1$ Ammoniumpersulfatlösung als Starter der 


\section{Radikalreaktion}

Zusammensetzung des Trenngels (10\%-ig):

2,27 ml Trenngelpuffer

3,04 ml Acrylamidlösung

$3,63 \mathrm{ml} \mathrm{H}_{2} \mathrm{O}$ bidest.

4,4 $\mu 1$ TEMED

$200 \mu$ l Ammoniumpersulfatlösung

Elektrodenpuffer:

0,025 M Tris

0,192 M Glycin

$0,1 \%(\mathrm{v} / \mathrm{v}) \mathrm{SDS}$ in $\mathrm{H}_{2} \mathrm{O}$ bidest.

Vor Zugabe des Ammoniumpersulfats musste das Polymerisationsgemisch mittels einer Wasserstrahlpumpe entgast werden, um den die Polymerisierungsreaktion störenden Sauerstoff zu entfernen. Zunächst wurde das Trenngel zügig zwischen die mit Aceton entfetteten Glasscheiben gegossen und mit 2-Propanol überschichtet, um eine glatte Oberfläche zu erhalten. Nach einer Stunde bei RT konnte das 2-Propanol dekantiert und das Sammelgel auf das auspolymerisierte Trenngel gegossen werden. Die Probentaschen wurden mit einem entsprechenden Kamm geformt. Nach einer weiteren Stunde war das Gel ausgehärtet und gebrauchsfertig.

Die Elektrophoresekammern wurden mit Elektrodenpuffer gefüllt, der Kamm vorsichtig entfernt und die Proben aufgetragen. Sowohl die Konzentrierung der Proteine im Sammelgel als auch ihre Auftrennung im Trenngel erfolgten bei $20 \mathrm{~mA}$.

\subsubsection{Proteinfärbung der Gele}

\subsubsection{Gelfärbung mit Coomassie Blue}

Die Proteinfärbung nach Neuhoff et al. (1985) basiert auf einer Färbung der Argininreste von Peptiden mit Coomassie Blue (Serva Blue, G-250). Dazu färbten die Gele für mindestens $6 \mathrm{~h}$ in einer Neuhofflösung. Die Hintergrundfärbung wurde dann durch ausgiebiges Waschen mit $\mathrm{H}_{2} \mathrm{O}$ so weit wie möglich verringert. 
Neuhofflösung:

$2 \%$ (w/w) Phosphorsäure

$10 \%(\mathrm{w} / \mathrm{w})$ Ammoniumsulfat

$0,1 \%(w / w)$ Coomassie G

Die Lösung wurde vor Gebrauch mit Methanol p.a. im Verhältnis 4:1 (v/v) gemischt.

\subsubsection{Gelfärbung mit Silber}

Die Silberfärbung von Gelen ist sensitiver als die Coomassie Blue-Färbung. Bei dieser Methode lagern sich Silberionen an Proteine an und werden chemisch reduziert, so dass sich analog zur photochemischen Silberreduktion ein bräunliches Präzipitat dort bildet, wo sich Protein befindet.

\section{Lösungen:}

Fixierlösung:

$50 \%(\mathrm{v} / \mathrm{v})$ Methanol p.a.

$12 \%(\mathrm{v} / \mathrm{v})$ Essigsäure

$0,019 \%(\mathrm{v} / \mathrm{v})$ Formaldehyd in $\mathrm{H}_{2} \mathrm{O}$ bidest.

Waschlösung 1:

$50 \%(\mathrm{v} / \mathrm{v})$ Ethanol vergällt in $\mathrm{H}_{2} \mathrm{O}$ bidest.

Imprägnierlösung:

$0,022 \%$ (w/v) $\mathrm{Na}_{2} \mathrm{~S}_{2} \mathrm{O}_{3} .5 \mathrm{H}_{2} \mathrm{O}$ in $\mathrm{H}_{2} \mathrm{O}$ bidest.

Färbelösung:

$0,2 \%(\mathrm{w} / \mathrm{v}) \mathrm{AgNO}_{3}$

$0,028 \%(\mathrm{v} / \mathrm{v})$ Formaldehyd in $\mathrm{H}_{2} \mathrm{O}$ bidest.

Reduzierlösung:

$6 \%$ (w/v) $\mathrm{Na}_{2} \mathrm{CO}_{3}$

$0,019 \%$ Formaldehyd

$4 \mathrm{mg} / \mathrm{l} \mathrm{Na} \mathrm{S}_{2} \mathrm{O}_{3} .5 \mathrm{H}_{2} \mathrm{O}$ in $\mathrm{H}_{2} \mathrm{O}$ bidest.

Stopplösung:

$50 \%(\mathrm{v} / \mathrm{v})$ Methanol p.a.

$12 \%(\mathrm{v} / \mathrm{v})$ Essigsäure in $\mathrm{H}_{2} \mathrm{O}$ bidest.

Waschlösung 2:

$50 \%$ (v/v) Methanol p.a. in $\mathrm{H}_{2} \mathrm{O}$ bidest.

Zur Silberfärbung nach Blum et al. (1987) wurden die Gele mindestens eine Stunde in Fixierlösung aufbewahrt und dreimal für jeweils 20 min mit Waschlösung 1 gewaschen. Nach der 
Imprägnierung für 1 min wurden die Gele dreimal für $20 \mathrm{~s}$ mit $\mathrm{H}_{2} \mathrm{O}$ bidest. gewaschen. Nach der 20-minütigen Färbung, die, um einen möglichst hellen Hintergrund zu erhalten, im Dunkeln stattfand, wurde abermals gründlich mit $\mathrm{H}_{2} \mathrm{O}$ bidest. gewaschen. Die nachfolgende Reduktion des Silbers wurde nach 1-10 min in Abhängigkeit von der Intensität der Färbung abgestoppt. Nach mindestens 20-minütigem Aufenthalt in der Stopplösung wurden die Gele für weitere 20 min mit Waschlösung 2 gewaschen und danach für 20 min in $\mathrm{H}_{2} \mathrm{O}$ bidest. aufgequollen und zur Dokumentation fotografiert.

\subsubsection{Elution von Proteinen aus Polyacrylamidgelen}

Die Elution von Proteinen aus Coomassie-gefärbten SDS-Polyacrylamidgelen wurde mit einem Elektroseparationssystem (Biotrap, Schleicher \& Schüll, Dassel, BRD) durchgeführt. Die Proteinbande mit dem zu eluierenden Protein wurde mit einem sauberen Skalpell aus dem Gel herausgeschnitten und in die dafür vorgesehene Kammer des Systems gegeben. Diese wurde dann in eine mit Elektrophoresepuffer (siehe Kap.2.8.2) gefüllte Flachbettgelkammer (BlueMarine 200; Serva, Heidelberg, BRD) gelegt. Die Elution fand für $24 \mathrm{~h}$ bei $4{ }^{\circ} \mathrm{C}$ bei einer Stromstärke von $50 \mathrm{~mA}$ statt. Die durch das SDS negativ geladenen Proteine wanderten dabei aus dem Gelstuick in Richtung Anode, wo sie in einer von den beiden Spezialfiltern BT1 und BT2 gebildeten Tasche aufgefangen und entnommen werden konnten.

\subsubsection{Western-Blotting}

Um bestimmte Proteine immunologisch nachzuweisen, wurde die Western-Blotting-Technik benutzt. Unter Western-Blotting versteht man den elektrophoretischen Transfer von Proteinen von Polyacrylamidgelen auf Nitrozellulosemembranen (Towbin et al., 1979).

\subsubsection{Elektrophoretischer Proteintransfer}

Der elektrophoretische Transfer wurde entweder in einem Nasskammersystem oder als Schnellblot mit Hilfe eines Halbtrockensystems (Biometra, Göttingen, BRD) durchgeführt.

\section{Lösungen:}

Blotpuffer für das Nasskammersystem:

$25 \mathrm{mM}$ Tris

192 mM Glycin

$20 \%$ (v/v) Methanol p.a. in $\mathrm{H}_{2} \mathrm{O}$ bidest. 
Blotpuffer für das Halbtrockensystem:

$25 \mathrm{mM}$ Tris

$150 \mathrm{mM}$ Glycin

$10 \%$ (v/v) Methanol p.a. in $\mathrm{H}_{2} \mathrm{O}$ bidest.

Färbelösung: $\quad$ 0,2 \% (w/v) Ponceau S (Sigma, Taufkirchen, BRD)

$3 \%(\mathrm{w} / \mathrm{v})$ TCA in $\mathrm{H}_{2} \mathrm{O}$ bidest.

Die Nitrozellulosemembranen (SC 128/0,2 $\mu \mathrm{m}$; Sartorius, Göttingen, BRD) und Filter (Whatman $3 \mathrm{~mm}$ Chromatographiepapier) wurden etwa $30 \mathrm{~min}$ vor Gebrauch in Blotpuffer äquilibriert. Nach Beendigung der Gelelektrophorese wurde das Trenngel für das Nasskammersystem luftblasenfrei auf die Membran gelegt, zwischen je 4 Lagen Filterpapier geschichtet und in die mit Puffer gefüllte Blotkammer gestellt. Bei $70 \mathrm{~mA}$ wurden die Proteine über Nacht aufgrund ihrer negativen Ladung auf die der Anode zugekehrten Membran übertragen. Für den Halbtrockenblot wurden 5 Lagen Whatmanpapier, Trenngel, Nitrozellulosefolie und weitere 5 Lagen Whatmanpapier ebenfalls luftblasenfrei so übereinander geschichtet, dass das Gel der Kathode zugewandt war. Der elektrophoretische Transfer der Proteine erfolgte über 90 min bei $100 \mathrm{~mA}$ pro Minigel. Zur Kontrolle des Proteintransfers wurden die Proteine direkt auf der Nitrozellulosefolie reversibel mit der Färbelösung sichtbar gemacht (Salinovic und Montelaro, 1989). Aufgrund der Reversibilität stört die Färbung den immunologischen Nachweis nicht. Dazu wurde die Nitrozellulosemembran für $30 \mathrm{~s}$ in der Färbelösung geschwenkt und der Hintergrund durch Spülen in $\mathrm{H}_{2} \mathrm{O}$ bidest. entfernt. Die Folie wurde nach der Kontrolle durch schwenken im Waschpuffer (TBS-T) (siehe Kap. 2.8.5.2) entfärbt.

\subsubsection{Immunreaktion}

Bei der Immunreaktion wird das gesuchte Protein mit Hilfe von Antikörpern auf der Nitrozellulosefolie (Blot) sichtbar gemacht.

\section{Lösungen:}

Tris-gepufferte Kochsalzlösung (TBS):

$50 \mathrm{mM}$ Tris/HCl, $\mathrm{pH} 7,5$

$0,9 \%(\mathrm{w} / \mathrm{v}) \mathrm{NaCl}$

in $\mathrm{H}_{2} \mathrm{O}$ bidest.

Waschpuffer (TBS-T): $\quad 0,05 \%(\mathrm{v} / \mathrm{v})$ Tween 20 in TBS 
Blocklösung: $\quad 5 \%(\mathrm{w} / \mathrm{v})$ Magermilchpulver in Waschpuffer

Striplösung: $\quad$ 62,5 $\quad$ mM Tris/HCl, $\quad$ pH 6,7

$100 \mathrm{mM}$ 2-Mercaptoethanol

$2 \%$ (w/v) SDS in $\mathrm{H}_{2} \mathrm{O}$ bidest.

Verwendete Primärantikörper:

Gegen COP Vesikel gerichtete Antikörper:

- polyklonaler Antikörper aus Kaninchen gegen ein Fusionsprotein von Arabidopsis thaliana $\gamma$-COP (Aty-COP) (Movafeghi et al., 1999) (1:2.000 verdünnt)

- polyklonaler Antikörper aus Kaninchen gegen ein Fusionsprotein von Arabidopsis thaliana Sec23 (AtSec23p) (Movafeghi et al., 1999) (1:2.000 verdünnt)

- polyklonaler Antikörper aus Kaninchen gegen ein Fusionsprotein von Arabidopsis thaliana Arf1 (AtArf1p) (1:2.000 verdünnt) (Pimpl et al., 2000)

- polyklonaler Antikörper aus Kaninchen gegen ein Fusionsprotein von Arabidopsis thaliana Sar1 (AtSar1p) (1:2.000 verdünnt) (Pimpl et al., 2000)

- polyklonaler Antikörper aus Kaninchen gegen $\delta$-COP von Zea mays (Zm $\delta$-COP) (1:5.000 verdünnt) (Pimpl et al., 2000)

- polyklonaler Antikörper aus Kaninchen gegen $\varepsilon$-COP von Zea mays (Zmع-COP) (1:10.000 verdünnt) (Pimpl et al., 2000)

- polyklonaler Antikörper aus Kaninchen gegen GST von Schistosoma Japonicum (1:5.000 verdünnt) (von Dr. H.D. Schmitt (Abteilung für Molekulare Genetik des Max-Planck-Instituts für biophysikalische Chemie, Göttingen, BRD) zur Verfügung gestellt)

Gegen sonstige Antigene gerichtete Antikörper:

- polyklonaler Antikörper aus Kaninchen gegen ein Fusionsprotein von BiP (als luminales ER-Protein) aus Nicotiana tabacum (Denecke et al., 1991) (1:8.000 verdünnt)

polyklonaler Antikörper aus Kaninchen gegen ein im trans-GApp lokalisiertes 40 kDa reversibel glykosyliertes Polypeptid (RGP1) aus Pisum sativum (Dhugga et al., 1997) (1:20.000 verdünnt) 
monoklonaler Antikörper aus Maus gegen die 100 kDa Untereinheit der E1/E2-Typ $\mathrm{H}^{+}$-ATPase der Plasmamembran (PM-ATPase) aus Maiskoleoptilen (Fichman et al., 1989; Villalba et al., 1991) (1:1.000 verdünnt)

monoklonaler Antikörper (B1M6) aus Maus gegen $\beta$-Adaptin (Robinson, 1987) (1:500 verdünnt)

Die Primärantikörper wurden jeweils in TBS nach Zusatz von $1 \%$ (w/v) BSA verdünnt. Nach Zugabe von 0,02\% (w/v) Natriumazid konnten sie im Kühlschrank aufbewahrt werden.

Verwendete Sekundärantikörper:

- Meerrettich-Peroxidase gekoppelter Anti-Kaninchen IgG (Sigma, Taufkirchen, BRD)(1:10.000 (v/v) in Waschpuffer verdünnt)

- Meerrettich-Peroxidase-gekoppelter Anti-Maus IgG (Sigma, Taufkirchen, BRD) $(1: 10.000(\mathrm{v} / \mathrm{v})$ in Waschpuffer verdünnt)

Die Transfer-Membran wurde $1 \mathrm{~h}$ in Blocklösung geschwenkt, um unspezifische Bindungskapazitäten der Membran abzusättigen. Nach dreimaligem, 5-minütigem Waschen mit Waschpuffer wurde die Membran für $1 \mathrm{~h}$ bei RT in der Primärantikörperlösung bewegt. Anschließend wurde sie dreimal für 10 min gewaschen und der Blot für $1 \mathrm{~h}$ in dem jeweiligen Sekundärantikörper inkubiert. Nach erneutem Waschen für dreimal 10 min wurde mit Hilfe eines ECL-Kits (Amersham-Buchler, Braunschweig) die an den Sekundärantikörper gekoppelte Meerrettich-Peroxidase detektiert. Dieser auf Chemilumineszenz basierende Test ("enhanced chemiluminescence" = ECL) ist sehr empfindlich und daher auch zum Nachweis sehr geringer Proteinmengen geeignet. Der Blot wurde für $1 \mathrm{~min}$ in Immunnachweisreagenzien (Mischungsverhältnis 1+1) inkubiert, in Klarsichtfolie eingepackt und in Abhängigkeit von der Stärke des Signals für wenige Sekunden bis zu mehreren Stunden auf einem Fotofilm exponiert (Hyperfilm; Amersham-Buchler, Braunschweig). Der Fotofilm wurde 1 min entwickelt, kurz gewässert, für 1 min fixiert und nochmals gewässert. Die Nitrozellulosemembran wurde dreimal 5 min in Waschpuffer gespült und nach dem Trocknen im Kühlschrank aufbewahrt.

Sollte der Blot noch für eine weitere Immunreaktion benutzt werden, wurde er für 5 min in Waschpuffer geschwenkt und für $30 \mathrm{~min}$ bei $50{ }^{\circ} \mathrm{C}$ in einem Schüttelwasserbad mit Striplösung von den Antikörpern befreit. Dann wurde er dreimal für 5 min mit Waschlösung gewaschen und $1 \mathrm{~h}$ mit Blocklösung geblockt, bevor er mit einem anderen Primärantikörper inkubiert wurde. 


\subsection{Elektronenmikroskopie}

Einige Antigene sind bei der Immunelektronenmikroskopie auf Kunststoffschnitten schwer nachzuweisen. Dies liegt zum Teil an den verwendeten Harzen. Dieses Problem kann durch die Tokuyasu-Technik vermieden werden (Tokuyasu, 1980, 1986). Hierbei werden die Zellen lediglich nach einer leichten Fixierung und Infiltration mit Saccharose eingefroren und nicht in Kunststoff eingebettet.

\subsubsection{Pflanzenmaterial und Anzucht}

Murashige und Skoog-Medium (MS-Medium):

4,3 g/l MS-Salz (Sigma, Taufkirchen, BRD)

$0,5 \mathrm{~g} / \mathrm{l}$ myo-Inositol

$0,25 \mathrm{~g} / \mathrm{l} \mathrm{Mes}$

$20 \mathrm{~g} / \mathrm{l} \mathrm{Saccharose}$

in $\mathrm{H}_{2} \mathrm{O}$ bidest., $\mathrm{pH} 5,7$ mit $\mathrm{KOH}$ eingestellt

Nach dem Autoklavieren wurden sterile MS-Vitamine aus der Stammlösung (Sigma, Taufkirchen, BRD) zugegeben.

40-50 Arabidopsis-Samen (Arabidopsis thaliana, var Columbia) wurden für 5 min in $5 \%(\mathrm{v} / \mathrm{v})$ Na-Hypochlorid-Lösung sterilisiert. Nachdem die Samen dreimal mit autoklaviertem $\mathrm{H}_{2} \mathrm{O}$ bidest. gewaschen worden waren, wurden sie für 7 bis 10 Tage in $50 \mathrm{ml}$ Anzuchtmedium auf einem Schüttelinkubator im Licht-Dunkel-Rhythmus von $15 \mathrm{~h}$ Licht und $9 \mathrm{~h}$ Dunkel bei $120 \mathrm{Upm}$ und $24{ }^{\circ} \mathrm{C}$ angezogen.

Maispflanzen (Zea mays L. var mutin) wurden wie vorher unter Kap.2.2.1 beschrieben gezüchtet.

Tabakpflanzen (Nicotiana tabacum L. var SR1 Petit Havanna), die mit einem Genkonstrukt, das für die Synthese der $\alpha$-Amylase mit einer am Carboxyterminus angefügten HDEL-Sequenz versehen war, oder mit dem $\alpha$-Amylasegen transformiert worden waren, wurden von Dr. J. Denecke (Institut für Plant Biotechnologie und Agrikultur der Universität Leeds, Leeds, GB) zur Verfügung gestellt. Die Samen der dritten Generation der transformierten Pflanzen wurden für die elektronenmikroskopischen Untersuchungen verwendet. Die Samen von der gleichen, aber nicht transformierten, Tabakpflanze (Wildtyp) wurden wie transformierte Pflanzen angezogen. Die Samen wurden für 5 min in $5 \%$ (v/v) Na-Hypochlorid-Lösung sterilisiert und dreimal mit autoklaviertem $\mathrm{H}_{2} \mathrm{O}$ bidest. gewaschen. In Zellen einer Mikrotiterplatte wurde jeweils $1 \mathrm{ml}$ MSMedium pipettiert und die Samen einzeln in Zellen verteilt. So konnte die Aktivität der sekretierten $\alpha$-Amylase jeder einzelnen Pflanze gemessen werden. Die Anzucht der Pflanzen 
erfolgte für 7 bis 10 Tage auf einem Schüttler im Licht-Dunkel-Rhythmus von $15 \mathrm{~h}$ Licht und $9 \mathrm{~h}$ Dunkel bei $27{ }^{\circ} \mathrm{C}$ und $120 \mathrm{Upm}$.

Erbsenpflanzen (Pisum sativum L. var Haubners Excellenz) wurden in einem Hydrokultursystem in Klimakammern angezogen. Während der 15-stündigen Lichtperiode betrug die Temperatur $18{ }^{\circ} \mathrm{C}$ und die Lichtstrahlung $250-350 \mu \mathrm{E} \mathrm{m}^{-2} \mathrm{~s}^{-1}$. Während der Dunkelperiode war die Temperatur auf $14^{\circ} \mathrm{C}$ abgesenkt.

\subsubsection{Fixierung von Pflanzengeweben}

Lösungen:

Kaliumphosphatpuffer (KPP):

$100 \mathrm{mM} \mathrm{KH}_{2} \mathrm{PO}_{4}$ $100 \mathrm{mM} \mathrm{K}_{2} \mathrm{HPO}_{4}$

gegeneinander auf $\mathrm{pH}$ 7,4 titriert

Phosphat-gepufferte Salzlösung (PBS): 10 mM KH${ }_{2} \mathrm{PO} 4 / \mathrm{K}_{2} \mathrm{HPO}_{4}, \mathrm{pH} 7,4$ $150 \mathrm{mM} \mathrm{NaCl}$

Glutaraldehyd (GA)-Lösung:

$8 \%(\mathrm{v} / \mathrm{v})$ GA (Polyscience Inc., Warrington, USA) in PBS

Paraformaldehyd (PFA)-Lösung: $\quad 10 \%$ (w/v) PFA (Polyscience Inc., Warrington, USA) in $100 \mathrm{mM} \mathrm{KPP}$

$20 \mathrm{~g}$ Paraformaldehyd wurden mit $90 \mathrm{ml} \mathrm{H} \mathrm{H}_{2} \mathrm{O}$ bidest. unter Rühren für $1 \mathrm{~h}$ bei $60{ }^{\circ} \mathrm{C}$ erwärmt. Danach wurde solange $0,1 \mathrm{M} \mathrm{NaOH}$ zugegeben bis die Lösung klar war. Die Lösung wurde anschließend durch einen Celluloseacetatfilter (Porengröße: 0,45 $\mu \mathrm{m}$ ) filtriert und mit gleichem Volumen $200 \mathrm{mM}$ KPP aufgefüllt, so dass eine Endkonzentration von $10 \%$ (w/v) Paraformaldehyd in $100 \mathrm{mM}$ KPP eingestellt wurde. Die Lagerung erfolgte bei $4{ }^{\circ} \mathrm{C}$.

Fixativ:

$1,5 \%(\mathrm{w} / \mathrm{v})$ PFA

$0,2 \%(\mathrm{v} / \mathrm{v}) \mathrm{GA}$ in KPP

Infiltrationslösung:

2,3 M Saccharose in KPP 
Gelatine:

$10 \%$ (w/v) Gelatine (Dr. Oetker, Veenendaal, BRD)

in $\mathrm{KPP}$ bei $60^{\circ} \mathrm{C}$ gelöst

Von den Arabidopsis-, Tabak- und Mais-Pflanzen wurden 2-3 mm lange Wurzelspitzen abgeschnitten und über Nacht bei $4{ }^{\circ} \mathrm{C}$ in Fixativ inkubiert. Reifende Erbsensamen wurden nach dem Ernten von ihrer Samenschale befreit und von der inneren Seite der Kotyledonen (Durchmesser rund $9 \mathrm{~mm}$ ) wurde eine dünne Scheibe abgetrennt. Sie wurde mit einer Rasierklinge in KPP in kleine Blöcke geschnitten und anschließend wie die Wurzelspitzen über Nacht fixiert. Die fixierten Gewebe wurden stufenweise mit Saccharose infiltriert. Die Proben wurden dazu nacheinander mit in KPP 3:1, 1:1, bzw. 1:3 verdünnter Infiltrationslösung versetzt, für 10 min auf Eis unter Vakuum infiltriert und auf dem Drehrad für $2 \mathrm{~h}$ bei $4{ }^{\circ} \mathrm{C}$ bewegt. Zuletzt wurden sie über Nacht mit der Infiltrationslösung ebenso inkubiert.

Die Wurzelspitzen von Arabidopsis und Tabak wurden dann auf zylinderförmige Gelatineblöcke, die zuvor auf einem Probenhalter aus Kupfer aufgebracht worden waren, aufgesetzt. Die Blöcke wurden für weitere $8 \mathrm{~h}$ mit der Infiltrationslösung inkubiert und anschließend in flüssigem Stickstoff eingefroren und in diesem gelagert.

Die Wurzelspitzen von Mais wurden halbiert, damit sie mit einer flachen Oberfläche auf dem Probenhalter aus Kupfer aufgesetzt werden konnten. Die Kotyledonenblöcke der Erbsen wurden direkt auf den Probenhalter aus Kupfer aufgesetzt. Beide Proben wurden dann in flüssigem Stickstoff eingefroren und bis zur weiteren Verwendung in diesem gelagert.

\subsubsection{Kryo-Ultramikrotomie}

\section{Lösungen:}

Methylcellulose-Lösung:

$2 \%$ (w/w) Methylcellulose (25 centipose; Sigma, Taufkirchen, BRD) in $\mathrm{H}_{2} \mathrm{O}$ bidest.

$2 \mathrm{~g}$ Methylcellulose wurden bis zum lösen in $98 \mathrm{~g} 90{ }^{\circ} \mathrm{C}$ warmem $\mathrm{H}_{2} \mathrm{O}$ bidest. gerührt. Dann wurde die Lösung auf Eis weiter gerührt bis sie eine Temperatur von $10^{\circ} \mathrm{C}$ erreicht hatte. Anschließend wurde die Lösung über Nacht bei $4{ }^{\circ} \mathrm{C}$ gerührt. Nachdem die Lösung 3 Tage lang bei $4{ }^{\circ} \mathrm{C}$ gelagert worden war, wurden durch eine Zentrifugation für $90 \mathrm{~min}$ bei $100.000 \mathrm{~g}_{\max }$ unlösliche Bestandteile abgetrennt. 
Saccharose-Methylcellulose-Lösung: $\quad$ 1,2 M Saccharose

$1 \%(\mathrm{w} / \mathrm{v})$ Methylcellulose

Eine 2\%-ige Methylcellulose-Lösung und eine 2,4 M Saccharose-Lösungen wurden im Verhältnis 1:1 für 30 min bei $4{ }^{\circ} \mathrm{C}$ auf einem Drehrad vermischt.

Sämtliche Schneidevorgänge erfolgten bei $-120^{\circ} \mathrm{C}$ an einem Ultramikrotom (Ultracut, UCT + EM FCS, Leica, Bensheim, BRD). Zunächst wurden die Wurzelspitzen mit einem Glasmesser zu einem Pyramidenstumpf getrimmt. Die Anfertigung der ultradünnen Gefrierschnitte erfolgte dann mit einem Diamantmesser bei einer Messer- und Blocktemperatur von $-120^{\circ} \mathrm{C}$ und einer Schnittgeschwindigkeit von $80 \mathrm{~mm} / \mathrm{s}$ in $70 \mathrm{~nm}$ dicke Schnittbänder. Diese Schnittbänder wurden mit einer Silberdrahtöse, die einen Tropfen Saccharose-Methylcellulose-Lösung enthielt, aufgenommen und anschließend auf ein mit Formvar beschichtetes und kohlebedampftes Nickelgrid gelegt (Liou et al., 1996; Hinz et al., 1999). Die Schnitte wurden bis zur weiteren Verwendung bei $-20{ }^{\circ} \mathrm{C}$ gelagert.

\subsubsection{Immunmarkierung der Gefrierschnitte}

Lösungen:

Gelatine-Platten:

$2 \%(\mathrm{w} / \mathrm{v})$ Gelatine

$0,05 \%(\mathrm{w} / \mathrm{v})$ Natriumazid

in KPP (siehe Kap. 2.9.2)

in Petrischalen mit $3 \mathrm{~cm}$ Durchmesser gegossen

und bei $4{ }^{\circ} \mathrm{C}$ gelagert

Glycin-PBS:

$20 \mathrm{mM}$ Glycin in PBS

Blocklösung:

$1 \%(\mathrm{w} / \mathrm{v}) \mathrm{BSA}$ in PBS

Waschlösung:

$0,1 \%(w / v)$ BSA in PBS

Uranyl-Oxalat-Lösung:

$2 \%$ (w/v) Uranylacetat, $\mathrm{pH} 4,0$

$150 \mathrm{mM}$ Oxalsäure 
Zur Herstellung der Uranyl-Oxalat-Lösung wurden zunächst eine 4\%-ige (w/v) UranylacetatLösung und eine $300 \mathrm{mM}$ Oxalsäure-Lösung hergestellt, die dann im Verhältnis von 1:1 gemischt wurden. Der pH-Wert wurde mit 25\%-iger (w/v) Ammoniumhydroxid-Lösung auf 7,0 eingestellt.

Methylcellulose-Uranylacetat-Lösung:

$$
\begin{aligned}
& 1,8 \%(\mathrm{w} / \mathrm{v}) \text { Methylcellulose } \\
& 0,4 \%(\mathrm{w} / \mathrm{v}) \text { Uranylacetat, } \mathrm{pH} 4,0 \\
& \text { in } \mathrm{H}_{2} \mathrm{O} \text { bidest. }
\end{aligned}
$$

Verwendete Primärantikörper:

Alle Primär-Antikörper wurden über Protein A gereinigt (siehe Kap. 2.7), um die unspezifische Bindung der Antikörper zu vermeiden.

- polyklonaler Antikörper aus Kaninchen gegen ein Fusionsprotein von Arabidopsis thaliana Sec21 (Movafeghi et al., 1999) (1:200 verdünnt)

- polyklonaler Antikörper aus Kaninchen gegen $\delta$-COP von Zea mays (Pimpl et al., 2000) (1:100 verdünnt)

- polyklonaler Antikörper aus Kaninchen gegen $\varepsilon$-COP von Zea mays (Pimpl et al., 2000) (1:200 verdünnt)

- polyklonaler Antikörper aus Kaninchen gegen ein Fusionsprotein von Arabidopsis thaliana Arf1p (Pimpl et al., 2000) (1:500 verdünnt)

- polyklonaler Antikörper aus Kaninchen gegen Calreticulin von Ricinus communis (Coughlan et al., 1997) (1:200 verdünnt)

- polyklonaler Antikörper aus Kaninchen gegen $\alpha$-Amylase von Hordeum vulgare (1:200 verdünnt) (von Dr. B. Svensson (Carlsberg Laboratory, Department of Chemistry, Valby, Dänemark) zur Verfügung gestellt)

Die Primärantikörper wurden jeweils in Blocklösung verdünnt.

Sekundär-Antikörper:

Die sekundären Antikörper waren an $10 \mathrm{~nm}$ kolloidales Gold gebunden. Die aus Ziegen gewonnenen Sekundärantikörper (British BioCell, Cardiff, GB) wurden gemäß der Herstellerangaben 1:30 in Blocklösung verdünnt.

Zunächst musste die Saccharose-Methylcellulose-Schicht von den Grids entfernt werden. Dazu wurden die Grids mit den Schnitten nach unten auf Gelatine-Platten gelegt, leicht angedrückt und für 15 min auf eine $37{ }^{\circ} \mathrm{C}$ warme Heizplatte gestellt, so dass die Gelatine flüssig wurde. In den 
folgenden Wasch- und Inkubationsschritten wurden die Grids, wenn nicht anders angegeben, bei RT mit den Schnitten nach unten auf $50 \mu$ große Tropfen aufgelegt.

1. Waschen:

2. Blocken:

3. Primär-Antikörper:

4. Waschen:

5. Sekundär-Antikörper:

6. Waschen:

7. Waschen:

8. Waschen:

9. Kontrastieren:

10. Waschen:

$$
3 \times 3 \min
$$

$5 \mathrm{~min}$

$1 \mathrm{~h}$

$3 \times 5 \mathrm{~min}$

$1 \mathrm{~h}$

$5 \min$

$3 \times 5 \mathrm{~min}$

$5 \times 2 \min$

$5 \mathrm{~min}$

$2 \times 30 \mathrm{~s}$ mit Glycin-PBS bei $37{ }^{\circ} \mathrm{C}$

mit Blocklösung

mit der jeweiligen Antikörperlösung

mit Waschlösung

auf einem $30 \mu \mathrm{l}$ Tropfen

mit Waschlösung

mit PBS

mit $\mathrm{H}_{2} \mathrm{O}$ bidest.

mit Uranyl-Oxalat-Lösung

mit $\mathrm{H}_{2} \mathrm{O}$ bidest.

Zum Schluss wurden die Grids mit Methylcellulose-Uranylacetat beschichtet. Dazu wurden sie kurz auf einen Tropfen Methylcellulose-Uranylacetat aufgelegt, dann auf einem weiteren Tropfen kreisförmig bewegt, um eine vollständige Benetzung zu gewährleisten und zuletzt auf einem dritten Tropfen für 5 min auf Eis inkubiert. Die Grids wurden mit einer Drahtöse ( $\varnothing$ 3,5 mm) von den Methylcellulose-Uranylacetat-Tropfen genommen und in einem Winkel von $45^{\circ}$ über ein angefeuchtetes Filterpapier gezogen, um überschüssige Lösung abzusaugen und gleichzeitig eine gleichmäßige Methylcellulosebeschichtung zu erhalten. Die Grids wurden in den Ösen für 15 min an der Luft getrocknet und anschließend vor Staub geschützt aufbewahrt. 


\section{Ergebnisse}

Ziel der vorliegenden Arbeit war die Identifizierung und Charakterisierung von Hüllproteinen der pflanzlichen COPI und COPII Vesikel. Da zu Beginn der Arbeit keine Antikörper gegen diese Proteine aus Pflanzen zur Verfügung standen, sollte eine Identifizierung mit Antikörpern durchgeführt werden, die gegen Hüllproteine von COP Vesikeln aus Hefe gerichtet waren. Mit diesen Antikörpern - mit Ausnahme des Antikörpers gegen Sec23p - gab es aber keine spezifischen Kreuzreaktionen in pflanzlichen Cytosolfraktionen aus Blumenkohlinfloreszenzen und kultivierten Suspensionszellen aus Arabidopsis. Der Sec23p-Antikörper reagierte nur schwach mit einem Protein mit einer Molekularmasse von $85 \mathrm{kDa}$. Aus diesem Grund wurden cDNA-Sequenzen aus Arabidopsis in der dbEST-Datenbank des NCBI gesucht (siehe Kap. 2.1.10), deren abgeleiteten Proteine Homologien zu Bestandteilen der Proteinhüllen von COPI und COPII Vesikeln aus Hefe und Säugetieren aufwiesen. Zwei cDNA-Klone wurden dabei identifiziert, deren abgeleiteten Proteine hohe Homologien zu Sec21p (das Homologprotein zu $\gamma$-COP aus Säugetieren) bzw. Sec23p aus Hefe zeigten.

\subsection{Aufklärung der Sequenzen}

\subsubsection{Die Sequenz der $\gamma$-COP-cDNA und die Klonierungsstrategie}

Der $\gamma$-COP-cDNA-Klon 150F14T7 mit der "GenBank Accession" Nummer T75984 (Newman et al., 1994) wurde beim Arabidopsis Biological Resource Centre (Ohio State University, Columbus, USA) bezogen. Die Sequenzierung ergab, dass die cDNA eine Länge von 1565 bp hat und ein Stoppkodon an bp-Position 1362 besitzt (Abb. 3.1). Das von dieser cDNA abgeleitete Polypeptid ( $\left.\mathrm{P}^{*}\right)$ besteht daher aus 454 Aminosäuren. Gegen Ende der vorliegenden Arbeit wurde ein weiteres, vollständiges $\gamma$-COP $\left(\mathrm{P}^{* *}\right)$ aus Arabidopsis veröffentlicht, das von einer genomischen Nukleotidsequenz mit der "GenBank Accession" Nummer AL023094 kodiert wird (siehe Anhang 1). Die Aminosäuresequenzen der beiden Polypeptide wurden miteinander verglichen. Dieser Vergleich zeigte, dass es sich bei dem von der cDNA abgeleiteten Polypeptid $\left(\mathrm{P}^{*}\right)$ um ein $\gamma$-COP-Fragment handelt und es mit den letzten 417 Aminosäuren am Aminoterminus des vollständigen $\gamma$-COP $\left(\mathrm{P}^{* *}\right)$ (unterstrichen in Anhang 1) zu $88 \%$ identisch und zu $89 \%$ ähnlich ist (für die Bestimmung der Identität und Ähnlichkeit von Aminosäuren siehe Kap. 2.1.10). Ein auffälliger Unterschied zwischen beiden Fragmenten ist, dass ein 36Aminosäuren langer Abschnitt im vollständigen $\gamma$-COP $\left(\mathrm{P}^{* *}\right)$ fehlt. Diese Sequenz ist in dem von der cDNA abgeleiteten Polypeptid ( $\left.\mathrm{P}^{*}\right)$ in Position 109-144 vorhanden (unterstrichen in der Abb. 3.1). Abgesehen von dieser Lücke sind beide Fragmente zu $95 \%$ identisch und $96 \%$ ähnlich. 
Interessanterweise zeigt das vollständige $\gamma$-COP $\left(\mathrm{P}^{* *}\right)$ aus Arabidopsis genau in dieser Domäne einen Unterschied zu dem homologen Protein Sec21p aus Hefe, das von einer genomischen Nukleotidsequenz mit der "GenBank Accession" Nummer NC_001146 (Goffeau et al., 1996) abgeleitet wird. Ein Sequenzvergleich von dem vollständigen $\gamma$-COP $\left(\mathrm{P}^{* *}\right)$ aus Arabidopsis mit dem Sec21p aus Hefe ergab $35 \%$ identische und $54 \%$ ähnliche Aminosäuren. In Anhang 1 ist der Vergleich der Aminosäuresequenzen der beiden Proteine inklusive ihrer identischen bzw. ähnlichen Bereiche (schwarz hinterlegt) dargestellt. Der Bereich der letzten 415 Aminosäuren am Aminoterminus des putativen $\gamma$-COP $\left(\mathrm{P}^{* *}\right)$ aus Arabidopsis (unterstrichen in Anhang 1) zeigt zum entsprechenden Bereich von Sec21p aus Hefe 32 \% Identität und 47 \% Ähnlichkeit. Im Vergleich dazu ist das von der $\gamma$-COP-cDNA abgeleitete Polypeptid $\left(\mathrm{P}^{*}\right)$ zu diesem Bereich von Sec21p zu $33 \%$ identisch und zu $49 \%$ ähnlich.

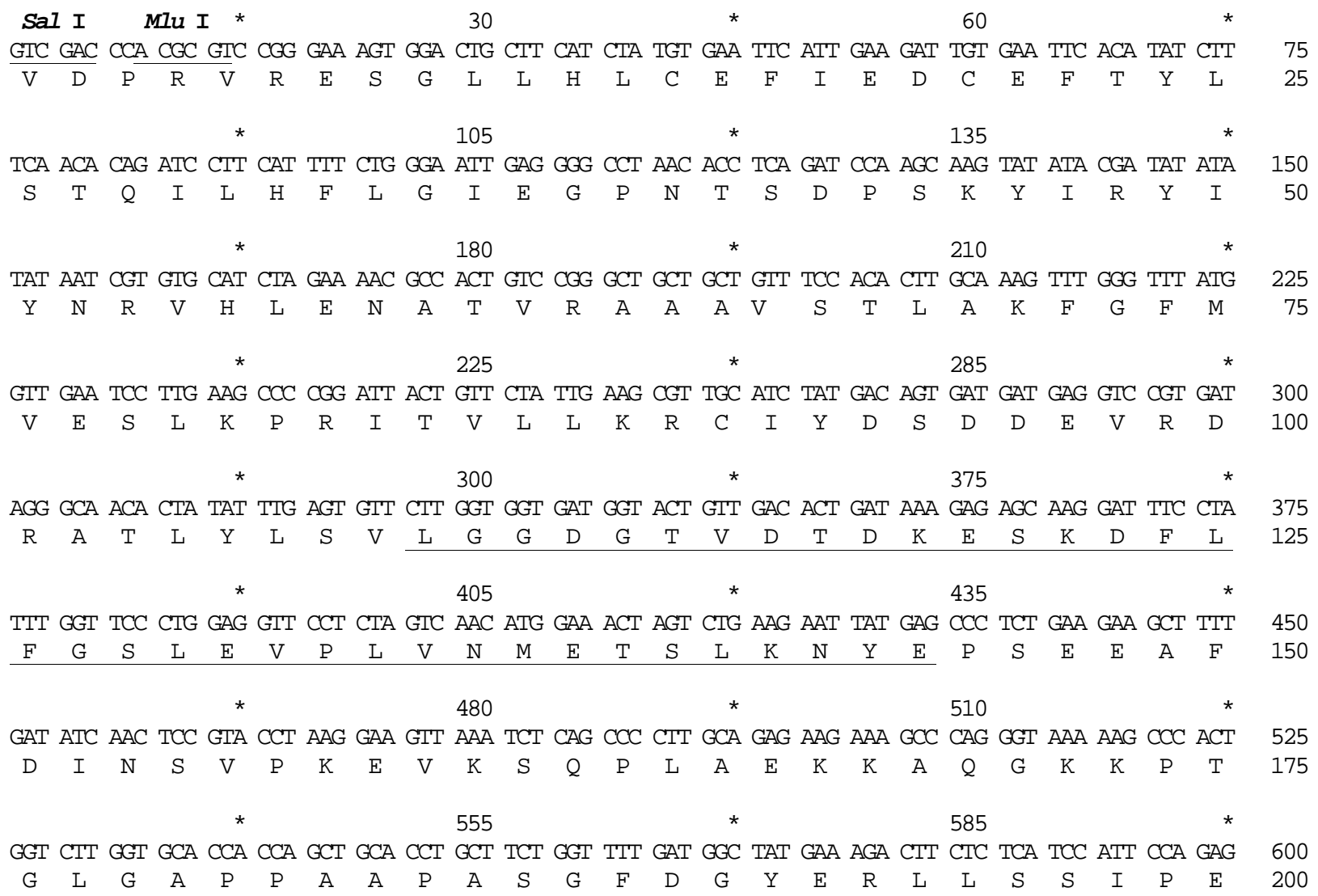

Abb. 3.1: Nukleotidsequenz der cDNA des Klons 150F14T7 mit abgeleiteter Aminosäuresequenz. Der unterstrichene Teil fehlt in der vollständigen $\gamma$-COP-Sequenz aus Arabidopsis (siehe Anhang 1). 
TTT GCC GCC TTT GGA AAA CTT TTC AAG TCT TCT TTA CCT GTG GAG CTA ACT GAA GCA GAA ACA GAA TAC GCT GTC 675 $\begin{array}{llllllllllllllllllllllllllll}\text { F } & \text { A } & \text { A } & \text { F } & \text { G } & \text { K } & \text { L } & \text { F } & \text { K } & \text { S } & \text { S } & \text { L } & \text { P } & \text { V } & \text { E } & \text { L } & \text { T } & \text { E } & \text { A } & \text { E } & \text { T } & \text { E } & \text { Y } & \text { A } & \text { V } & 225\end{array}$ AAT GTT GTT AAG CAT ATC TTT GAC AGT CAT GTG GTG TTT CAG TAC AAC TGC ACT AAC ACA ATA CCA GAG CAG TTG 750 $\begin{array}{lllllllllllllllllllllllllll}\mathrm{N} & \mathrm{V} & \mathrm{V} & \mathrm{K} & \mathrm{H} & \mathrm{I} & \mathrm{F} & \mathrm{D} & \mathrm{S} & \mathrm{H} & \mathrm{V} & \mathrm{V} & \mathrm{F} & \mathrm{Q} & \mathrm{Y} & \mathrm{N} & \mathrm{C} & \mathrm{T} & \mathrm{N} & \mathrm{T} & \mathrm{I} & \mathrm{P} & \mathrm{E} & \mathrm{Q} & \mathrm{L} & 250\end{array}$

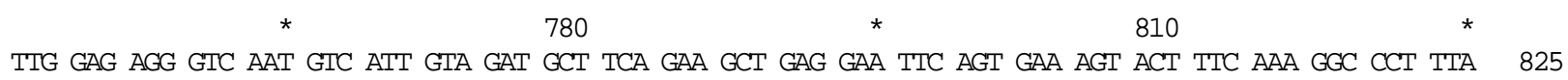
$\begin{array}{llllllllllllllllllllllllll}\mathrm{L} & \mathrm{E} & \mathrm{R} & \mathrm{V} & \mathrm{N} & \mathrm{V} & \mathrm{I} & \mathrm{V} & \mathrm{D} & \mathrm{A} & \mathrm{S} & \mathrm{E} & \mathrm{A} & \mathrm{E} & \mathrm{E} & \mathrm{F} & \mathrm{S} & \mathrm{E} & \mathrm{S} & \mathrm{T} & \mathrm{F} & \mathrm{K} & \mathrm{G} & \mathrm{P} & \mathrm{L} & 275\end{array}$

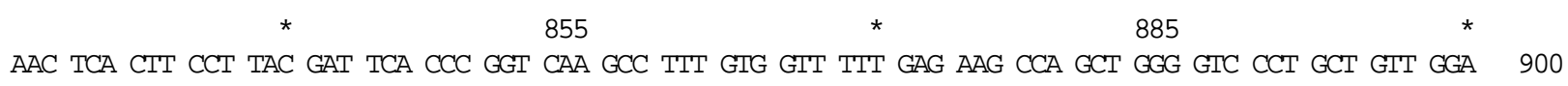
$\begin{array}{lllllllllllllllllllllllllllll}\mathrm{N} & \mathrm{S} & \mathrm{L} & \mathrm{P} & \mathrm{Y} & \mathrm{D} & \mathrm{S} & \mathrm{P} & \mathrm{G} & \mathrm{Q} & \mathrm{A} & \mathrm{F} & \mathrm{V} & \mathrm{V} & \mathrm{F} & \mathrm{E} & \mathrm{K} & \mathrm{P} & \mathrm{A} & \mathrm{G} & \mathrm{V} & \mathrm{P} & \mathrm{A} & \mathrm{V} & \mathrm{G} & 300\end{array}$ AAG TTC TCC AAC ACA TTG ACT TTC GTT GTT AAG GAG GTT GAC CCA AGC ACA GGT GAA GCA GAA GAT GAT GGA GTA 975 $\begin{array}{llllllllllllllllllllllllll}\text { K } & \text { F } & \text { S } & \text { N } & \text { T } & \text { L } & \text { T } & \text { F } & \text { V } & \text { V } & \text { K } & \text { E } & \text { V } & \text { D } & \text { P } & \text { S } & \text { T } & \text { G } & \text { E } & \text { A } & \text { E } & \text { D } & \text { D } & \text { G } & \text { V } & 325\end{array}$

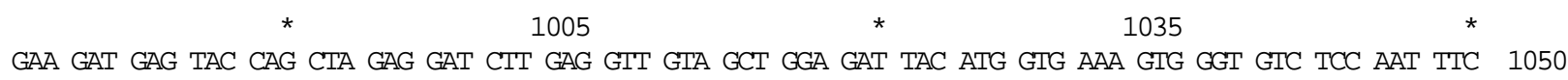
$\begin{array}{llllllllllllllllllllllllllll}E & D & E & Y & Q & L & E & D & L & E & V & V & A & G & D & Y & M & V & K & V & G & V & S & N & F & 350\end{array}$ AGG AAT GCG TGG GAA AGC ATG GAT GAA GAG CGT GTA GAC GAA TAT GGC CTT GGC CAA AGA GAG AGT TTG GGA GAA 1125 $\begin{array}{lllllllllllllllllllllllllll}R & N & A & W & E & S & M & D & E & E & R & V & D & E & Y & G & L & G & Q & R & E & S & L & G & E & 375\end{array}$

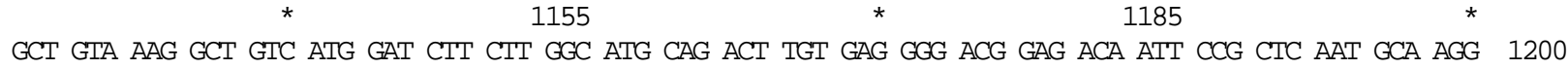
$\begin{array}{lllllllllllllllllllllllllll}\text { A } & \text { V } & \text { K } & \text { A } & V & \text { M } & \text { D } & \text { L } & \text { L } & G & \text { M } & \text { Q } & \text { T } & \text { C } & \text { E } & G & \text { T } & \text { E } & \text { T } & \text { I } & \text { P } & \text { L } & \text { N } & \text { A } & \text { R } & 400\end{array}$ $\begin{array}{ccccc}* & 1230 & * & 1260 & *\end{array}$ $\begin{array}{llllllllllllllllllllllllllll}\mathrm{S} & \mathrm{H} & \mathrm{T} & \mathrm{C} & \mathrm{L} & \mathrm{L} & \mathrm{S} & \mathrm{G} & \text { V } & \text { Y } & \text { I } & \text { G } & \text { N } & \text { V } & \text { K } & \text { V } & \text { L } & \text { V } & \text { R } & \text { A } & \text { Q } & \text { F } & \text { G } & \text { M } & \text { D } & 425\end{array}$

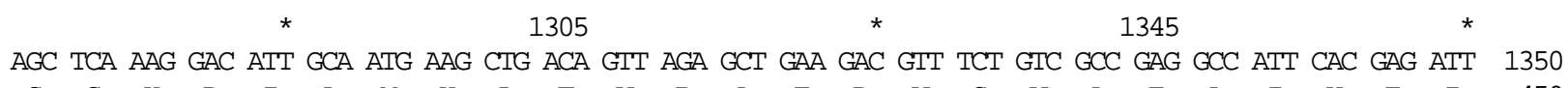
$\begin{array}{lllllllllllllllllllllllllll}\mathrm{S} & \mathrm{S} & \mathrm{K} & \mathrm{D} & \mathrm{I} & \mathrm{A} & \mathrm{M} & \mathrm{K} & \mathrm{L} & \mathrm{T} & \mathrm{V} & \mathrm{R} & \mathrm{A} & \mathrm{E} & \mathrm{D} & \mathrm{V} & \mathrm{S} & \mathrm{V} & \mathrm{A} & \mathrm{E} & \mathrm{A} & \mathrm{I} & \mathrm{H} & \mathrm{E} & \mathrm{I} & 450\end{array}$

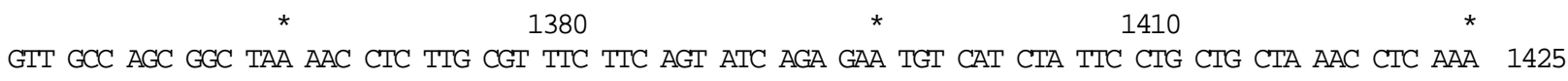
$\mathrm{V} \quad \mathrm{A} \quad \mathrm{S} \quad \mathrm{G} \quad$ * 454

AAT ACA TCA ACT ATT ATA AAT AGC ATA GTA TTA CTT TCT TTC TTT TTT CCT TGC ATT ATT ACT GTC AAA TAC ACT 1500

$\begin{array}{rrrr}* & & & \end{array}$

ATG GAG GTT TTC TTT TTA TTT TAT GAC GGT GCT TTT TGA AAA AAA AAA AAA AAA GGG GCG GCC GC 1565

Abb. 3.1: Fortsetzung. 
Die cDNA war zwischen den Schnittstellen von Sal I und Not I im Vektor $\lambda$ PRL2 einkloniert. Das cDNA-Insert wurde komplett mit Sal I und Not I aus diesem Vektor herausgeschnitten und in dem richtigen Leseraster in den mit Sal I und Not I geöffneten Expressionsvektor pGEX-4T-3 kloniert (siehe Anhang 2). Da die cDNA aus 1565 bp und der Vektor aus 4968 bp bestanden, war das Ligationsprodukt 6533 bp groß. Mit dem Ligationsprodukt wurden zunächst E. coli DH5 $\alpha$ Zellen transformiert. Zur Kontrolle der Klonierung wurde das Konstrukt aus einem positiven Klon isoliert und sequenziert. Nachdem die Sequenzierung die Korrektheit der Klonierung bestätigt hatte, wurden E. coli-Zellen des Expressionsstammes BL-21 mit dem Konstrukt transformiert. Durch Mini-Präparation von Plasmid-DNA und zwei unterschiedlichen Restriktionsverdau-Ansätzen wurde die Korrektheit des Konstrukts in den BL-21-Zellen überprüft. Der erste Verdau wurde mit Sal I und Not I durchgeführt. Die Abb. 3.2 A, Bahn 3 zeigt das 1565 bp große Sal I/Not I-Fragment, das in den 4968 bp großen Expressionsvektor pGEX4T-3 einkloniert war. Da der Expressionsvektor und das cDNA-Insert jeweils eine Schnittstelle für Mlu I hatten (siehe Abb. 3.1 und Anhang 2), wurde dieses Enzym für einen zweiten Verdau verwendet, um ganz sicher zu sein, dass die BL-21-Zellen mit dem richtigen Ligationsprodukt transformiert worden waren. Wenn die Schnittstelle für Sal I als bp-Position 1 definiert wird, ist die erste Schnittstelle für Mlu I (im cDNA-Insert) an bp-Position 8 und die zweite (im Vektor) an bp-Position 4284. Deshalb wurde erwartet, dass durch den Verdau mit Mlu I zwei 4276 und 2257 bp große Fragmente entstehen. Wie Abb. 3.2 A, Bahn 4 zeigt, konnten zwei Fragmente der richtigen Größe nach dem Restriktionsverdau mit Mlu I nachgewiesen werden. Im nächsten Schritt wurde die Expression des GST-Fusionsproteins mit IPTG induziert und das Protein durch eine Glutathion-Sepharose-Säule aufgereinigt (siehe Kap.2.1.11). Das aufgereinigte GSTFusionsprotein wurde nach einer SDS-PAGE mit anschließender Coomassiefärbung aus dem Gel eluiert und in dieser Form direkt als Antigen verwendet. In Abb. 3.2 B ist die Fraktion des aufgereinigten Fusionsproteins nach der SDS-PAGE und der Silberfärbung zu sehen. Das Fusionsprotein zeigte eine apparente Molekularmasse von $81 \mathrm{kDa}$. Dieses Protein wurde von dem gegen Sec21p gerichteten Antikörper nicht erkannt. Der Antikörper gegen GST zeigte aber mit diesem GST-Fusionsprotein eine spezifische Kreuzreaktion (Abb. 3.2B, Bahn 4). Die Immunisierung eines Kaninchens mit dem Fusionsprotein wurde von der Firma Eurogentec (Seraing, Belgien) durchgeführt. Das Immunisierungsprotokoll ist in Kap. 2.1.11 aufgeführt. Das zur Immunisierung verwendete Antigen wurde beim Western-Blotting von dem Antiserum sehr spezifisch erkannt (Abb. 3.2 B, Bahn 5). Das Präimmunserum ergab dagegen in verschiedenen Verdünnungen kein Signal. 


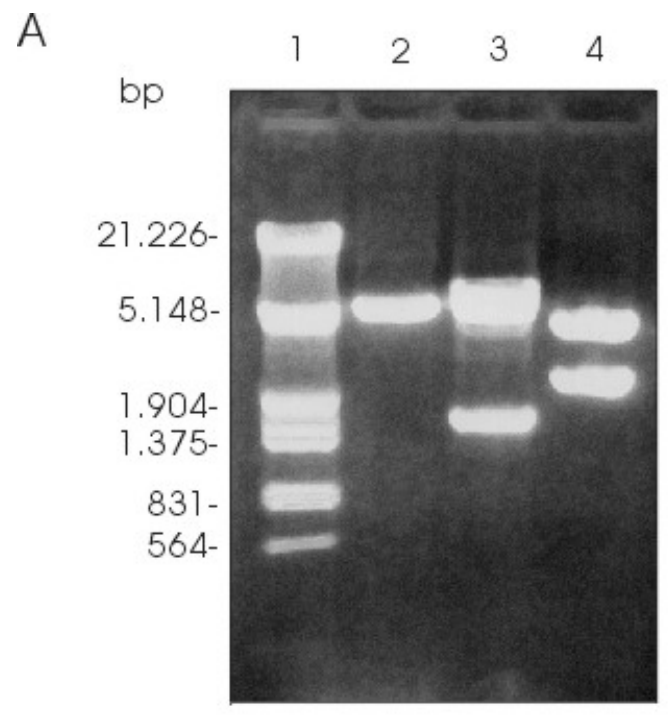

$\mathrm{B}$

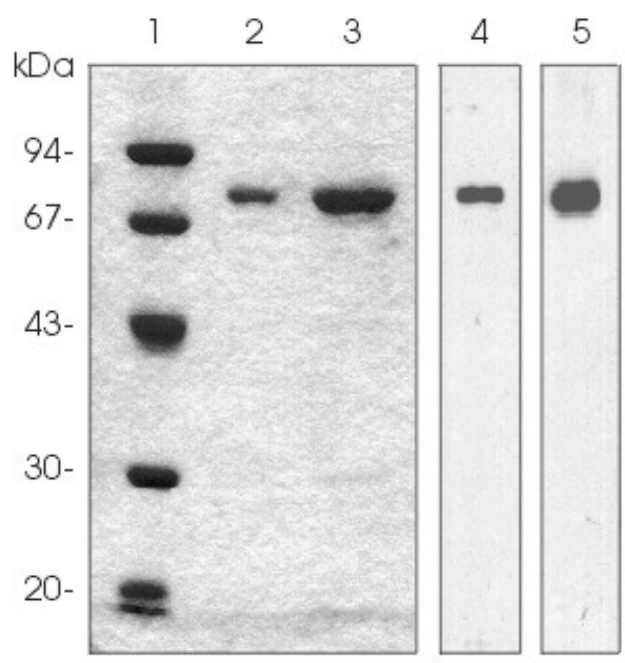

Abb. 3.2: Gewinnung eines Antikörpers gegen $\gamma$-COP aus Arabidopsis.

A) Auftrennung der DNA-Fragmente im Agarosegel. Bahn 1: Längenstandard, Bahn 2: der Expressionsvektor nach der Sal I/Not I-Spaltung, Bahn 3: Sal I/Not I-Spaltungsprodukte des Expressionsvektors nach der Einklonierung der $\gamma$-COP-cDNA, Bahn 4: Mlu ISpaltungsprodukte des Expressionsvektors nach der Einklonierung der $\gamma$-COP-cDNA.

B) SDS-PAGE und Western-Blotting. Bahn 1: Molekularmassenmarker, Bahn 2 und 3: GSTFusionsprotein (Antigen) nach der Aufreinigung im sibergefärbten Acrylamidgel, Bahn 4: die Kreuzreaktion des GST-Fusionsproteins mit dem Antikörper gegen GST, Bahn 5: Kreuzreaktion des GST-Fusionsproteins mit dem gewonnen Antikörper. Pro Bahn wurden $1 \mu \mathrm{g}$ (Bahn 2), $4 \mu \mathrm{g}$ (Bahn 3), 0,2 $\mu \mathrm{g}$ (Bahn 4 und 5) Protein aufgetragen. 


\subsubsection{Die Sequenz der AtSec23-cDNA und die Klonierungsstrategie}

Der AtSec23-cDNA-Klon 34B8T7 mit der "GenBank Accession" Nummer T04245 (Newman et al., 1994) wurde beim Arabidopsis Biological Resource Centre (Ohio State University, Columbus, USA) bestellt. Die Sequenzierung ergab, dass die cDNA eine Länge von 996 bp hat und ein Stoppkodon an bp-Position 702 besitzt (Abb. 3.3). Das von dieser cDNA abgeleitete Polypeptid $\left(\mathrm{P}^{\star}\right)$ besteht daher aus 234 Aminosäuren. Kürzlich wurde ein weiteres, vollständiges Sec23p $\left(\mathrm{P}^{\star \star}\right)$ aus Arabidopsis veröffentlicht (siehe Anhang 3), das von einer genomischen Nukleotidsequenz mit der "GenBank Accession" Nummer AB023036 kodiert wird (Sato et al., 2000). Der Vergleich der Aminosäuresequenz der beiden Polypeptide zeigte, dass es sich bei dem von der cDNA abgeleiteten Polypeptid $\left(\mathrm{P}^{\star}\right)$ um ein Sec23p-Fragment handelt. Dieses Polypeptid ist zu dem Bereich der letzten 234 Aminosäuren am Aminoterminus des vollständigen Sec23p $\left(\mathrm{P}^{\star \star}\right)$ (unterstrichen in Anhang 3) zu $89 \%$ identisch und zu $94 \%$ ähnlich. Ein Sequenzvergleich zwischen dem erwähnten Sec23p ( $\left.\mathrm{P}^{\star \star}\right)$ aus Arabidopsis und dem Sec23p aus Hefe, das von der genomischen DNA mit der "GenBank Accession" Nummer NC_001148 kodiert wird (Goffeau et al., 1996), ergab $41 \%$ identische und $63 \%$ ähnliche Aminosäuren (siehe Anhang (3). Im Vergleich dazu zeigt der Bereich der letzten 234 Aminosäuren am Aminoterminus des putativen Sec23p $\left(\mathrm{P}^{\star \star}\right)$ aus Arabidopsis (unterstrichen in Anhang 3) zum homologen Bereich von Sec23p aus Hefe $49 \%$ Identität und $68 \%$ Ähnlichkeit. Das von der Sec23-cDNA abgeleitete Polypeptid $\left(\mathrm{P}^{\star}\right)$ ist zu diesem Bereich von Sec23p aus Hefe zu $51 \%$ identisch und zu $70 \%$ ähnlich. 
Sal I MZu I * $\quad 30 \quad * \quad 60$

GTC GAC CCA CGC GTG CGG CAA ACA GAG GAG GGA TTT GAT GCA ACT CGG TGG CTA GAT CGG ACT CTC ATT CGT CTG 75

$\begin{array}{lllllllllllllllllllllllllll}\mathrm{V} & \mathrm{D} & \mathrm{P} & \mathrm{R} & \mathrm{V} & \mathrm{R} & \mathrm{E} & \mathrm{T} & \mathrm{E} & \mathrm{E} & \mathrm{G} & \mathrm{F} & \mathrm{D} & \mathrm{A} & \mathrm{T} & \mathrm{R} & \mathrm{W} & \mathrm{I} & \mathrm{D} & \mathrm{R} & \mathrm{T} & \mathrm{I} & \mathrm{I} & \mathrm{R} & 1 & 25\end{array}$ $\begin{array}{ccccc}* & 105 & * & 135 & *\end{array}$ $\begin{array}{lllllllllllllllllllllllllllll}\mathrm{C} & \mathrm{S} & \mathrm{K} & \mathrm{F} & \mathrm{G} & \mathrm{E} & \mathrm{Y} & \mathrm{R} & \mathrm{K} & \mathrm{D} & \mathrm{D} & \mathrm{P} & \mathrm{T} & \mathrm{S} & \mathrm{F} & \mathrm{T} & \mathrm{l} & \mathrm{K} & \mathrm{P} & \mathrm{Y} & \mathrm{I} & \mathrm{T} & \mathrm{l} & \mathrm{F} & \mathrm{P} & 50\end{array}$ CAA TTC ATG TTT AAC CTG AGG CGG TCA CAG TTT GTT CAG GTC TTT AAC AAT AGT CCT GAT GAA ACC GCA TAC TTC 225 $\begin{array}{llllllllllllllllllllllllllll}Q & F & M & F & N & l & R & R & S & Q & F & V & Q & V & F & N & N & S & P & D & E & T & A & Y & F & 75\end{array}$ $\begin{array}{ccccc}* & 255 & * & 285 & * \\ \text { CGC ATG TTG CTA AAC CGG GAA AAC ATT TCA AAT GCA ATT GTC ATG ATC CAA CCT TCT CTG ACG TCA TAT TCA TTC } 300\end{array}$ $\begin{array}{llllllllllllllllllllllllll}R & M & 1 & 1 & N & R & E & N & I & S & N & A & I & V & M & I & Q & P & S & 1 & T & S & Y & S & F & 100\end{array}$

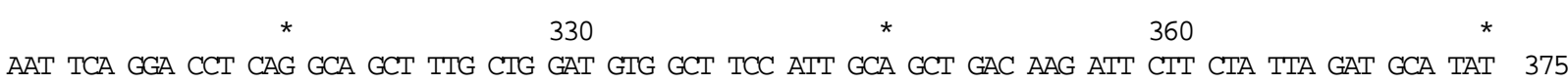
$\begin{array}{lllllllllllllllllllllllllll}\mathrm{N} & \mathrm{S} & \mathrm{G} & \mathrm{P} & \mathrm{Q} & \mathrm{A} & \mathrm{A} & \mathrm{I} & \mathrm{I} & \mathrm{D} & \mathrm{V} & \mathrm{A} & \mathrm{S} & \mathrm{I} & \mathrm{A} & \mathrm{A} & \mathrm{D} & \mathrm{K} & \mathrm{I} & 1 & 1 & 1 & \mathrm{D} & \mathrm{A} & \mathrm{Y} & 125\end{array}$

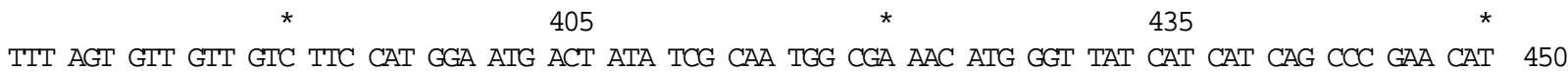
$\begin{array}{llllllllllllllllllllllllllll}F & S & V & V & V & F & H & G & M & T & I & S & Q & W & R & N & M & G & Y & H & H & Q & P & E & H & 150\end{array}$ $\begin{array}{ccccc}* & 480 & * & 510 & *\end{array}$ $\begin{array}{llllllllllllllllllllllllllll}\mathrm{E} & \mathrm{A} & \mathrm{F} & \mathrm{A} & \mathrm{Q} & \mathrm{L} & \mathrm{L} & \mathrm{Q} & \mathrm{A} & \mathrm{P} & \mathrm{Q} & \mathrm{E} & \mathrm{D} & \mathrm{S} & \mathrm{Q} & \mathrm{M} & \mathrm{I} & \mathrm{V} & \mathrm{R} & \mathrm{E} & \mathrm{R} & \mathrm{F} & \mathrm{P} & \mathrm{V} & \mathrm{P} & 175\end{array}$ AGA TTA GTT GTG TGT GAT CAA CAT GGA TCA CAG GCA AGG TTT TTA TTG GCT AAG CTG AAT CCA TCA GCG ACT TAC 600 $\begin{array}{llllllllllllllllllllllllllll}R & \mathrm{~L} & \mathrm{~V} & \mathrm{~V} & \mathrm{C} & \mathrm{D} & \mathrm{Q} & \mathrm{H} & \mathrm{G} & \mathrm{S} & \mathrm{Q} & \mathrm{A} & \mathrm{R} & \mathrm{F} & \mathrm{L} & \mathrm{L} & \mathrm{A} & \mathrm{K} & \mathrm{I} & \mathrm{N} & \mathrm{P} & \mathrm{S} & \mathrm{A} & \mathrm{T} & \mathrm{Y} & 200\end{array}$ AAC AAT GCA AAC GAG ATG TCA GCT GGG TCA GAC ATA ATC TTC ACT GAC GAT GTG AGC CTC CAA GTC TTT ATT GAA 675 $\begin{array}{lllllllllllllllllllllllllll}\mathrm{N} & \mathrm{N} & \mathrm{A} & \mathrm{N} & \mathrm{E} & \mathrm{M} & \mathrm{S} & \mathrm{A} & \mathrm{G} & \mathrm{S} & \mathrm{D} & \mathrm{I} & \mathrm{I} & \mathrm{F} & \mathrm{T} & \mathrm{D} & \mathrm{D} & \mathrm{V} & \mathrm{S} & \mathrm{I} & \mathrm{Q} & \mathrm{V} & \mathrm{F} & \mathrm{I} & \mathrm{E} & 225\end{array}$ $\begin{array}{ccccc}* & 705 & * & 740 & *\end{array}$ $\begin{array}{llllllllllll}\mathrm{H} & \mathrm{I} & \mathrm{Q} & \mathrm{K} & \mathrm{l} & \mathrm{A} & \mathrm{V} & \mathrm{Q} & \mathrm{S} & * & 234\end{array}$

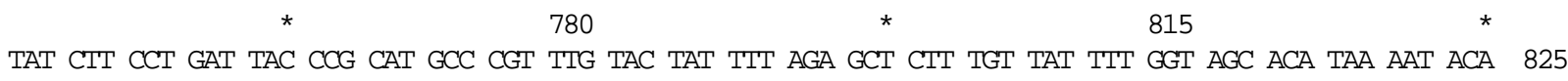
TCA TAG TTG GAA GTC TTT TAT TTG CAT TGG GAT TTG TCT GGA GTA CAG AGA TTT ACT ATT TGC TTC TTC TTT CTT 900 $930 * 065$

TTT TTT TTG GGA TGA AAT CTC TTG TAT GAT TGA TCA ATT ATA TGG TTT GGG TCT GTG GCT TTA GTA AAA AAA AAA 975

\section{* Not I}

AAA AAA AAA AAG GGC GGC CGC 996

Abb. 3.3: Nukleotidsequenz der cDNA des Klons 34B8T7 mit abgeleiteter Aminosäuresequenz. 
Die Sec23-cDNA lag zwischen den Sal I und Not I Schnittstellen des Genbank-Vektors $\lambda$ PRL2 einkloniert vor. Das cDNA-Insert wurde komplett mit Sal I und Not I herausgeschnitten und in den mit Sal I und Not I geöffneten Expressionsvektor pGEX-4T-3 einkloniert (siehe Anhang 2). Mit diesem 5970 bp großen Ligationsprodukt wurden zunächst E. coli DH5 $\alpha$-Zellen transformiert. Durch die Sequenzierung der Plasmid-DNA aus einem positiven Klon wurde die Korrektheit der Klonierung verifiziert. In einem weiteren Schritt wurden E. coli-Zellen des Expressionsstammes BL-21 mit dem Konstrukt transformiert. Durch Mini-Präparation der Plasmid-DNA und zwei unterschiedliche Restriktionsverdau-Ansätze wurde die Korrektheit des Konstrukts in den BL-21-Zellen überprüft. Der erste Verdau wurde mit Sal I und Not I durchgeführt. Abb. 3.4 A zeigt das 1002 bp große Sal I/Not I-Fragment, das in dem Expressionsvektor pGEX-4T-3 einkloniert wurde. Da der Expressionsvektor und das cDNAInsert jeweils eine Schnittstelle für Mlu I hatten (siehe Abb. 3.3 und Anhang 2), wurde ein zweiter Restriktionsverdau mit diesem Enzym durchgeführt. Wenn die Schnittstelle von Sal I als bp-Position 1 definiert wird, ist die erste Schnittstelle für Mlu I (im cDNA-Insert) an bp-Position 8 und die zweite (im Expressionsvektor) an bp-Position 3721. Durch den Verdau wurden, wie erwartet, zwei 3713 und 2257 bp große Fragmente herausgeschnitten (siehe Abb. 3.4A). Die Expression und Reinigung des Fusionsproteins erfolgten wie unter Kap. 3.1.1 beschrieben. In Abb. 3.4 B ist die Fraktion des aufgereinigten Fusionsproteins nach SDS-PAGE und Silberfärbung zu sehen. Das Fusionsprotein zeigte eine apparente Molekularmasse von 63 kDa. Der Antikörper gegen das Sec23p der Hefe sowie der Antikörper gegen GST zeigten eine spezifische Kreuzreaktion mit dem GST-Fusionsprotein. Dieses Protein wurde zur Immunisierung eines Kaninchens verwendet (siehe Kap. 3.1.1). Im Western-Blotting markierte das Antiserum sehr spezifisch das zur Immunisierung verwendete Antigen (Abb. 3.4B). Das Präimmunserum zeigte dagegen in verschiedenen Verdünnungen keine Kreuzreaktion mit dem Fusionsprotein. 

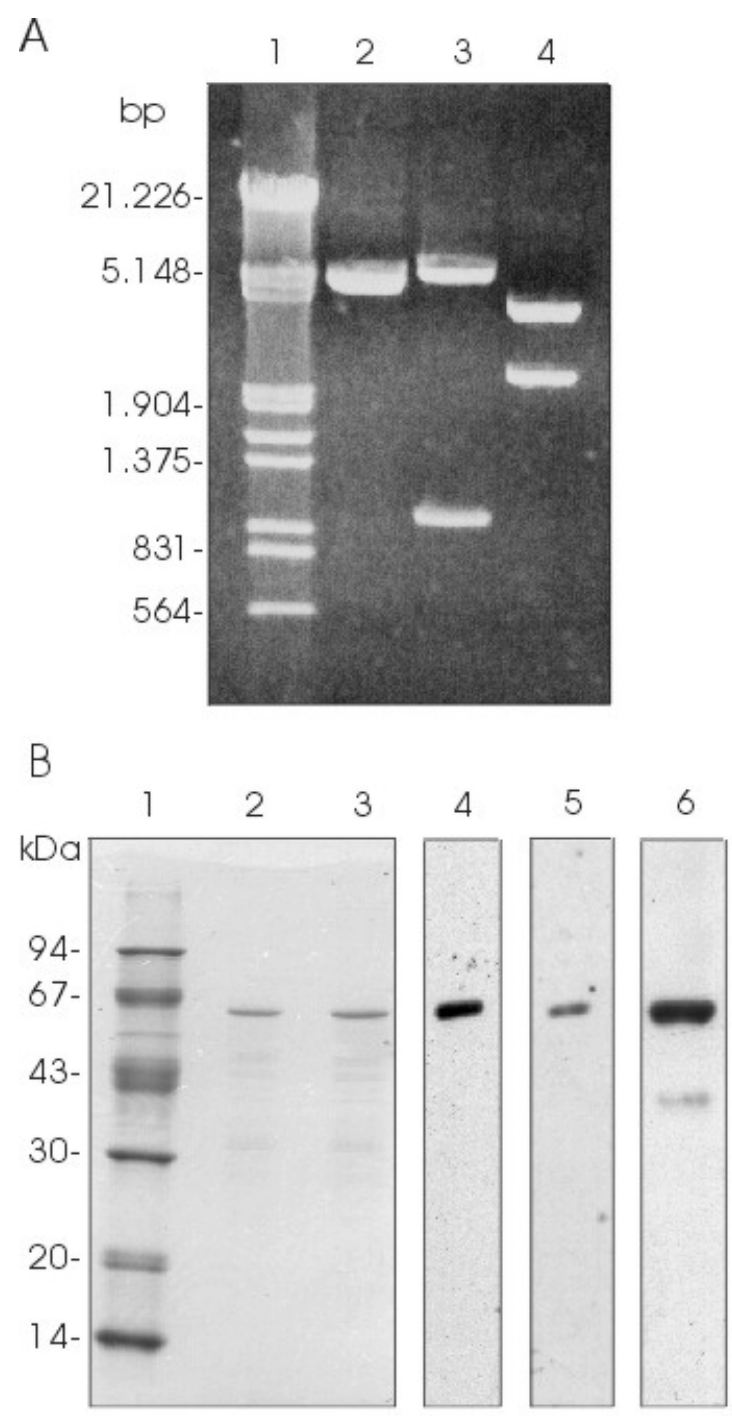

Abb. 3.4: Gewinnung eines Antikörpers gegen Sec23p aus Arabidopsis.

A) Auftrennung der DNA-Fragmente im Agarosegel. Bahn 1: Längenstandard, Bahn 2: der Expressionsvektor nach der Sal I/Not I-Spaltung, Bahn 3: Sal I/Not I-Spaltungsprodukte des Expressionsvektors nach der Einklonierung der AtSec23-cDNA, Bahn 4: Mlu ISpaltugnsprodukte des Expressionsvektors nach der Einklonierung der AtSec23-cDNA.

B) SDS-PAGE und Western-Blotting. Bahn 1: Molekularmassenmarker, Bahn 2 und 3: GSTFusionsprotein (Antigen) nach der Aufreinigung im sibergefärbten Acrylamidgel, Bahn 4: die Kreuzreaktion des GST-Fusionsproteins mit dem Antikörper gegen GST, Bahn 5: Kreuzreaktion des GST-Fusionsproteins mit dem Antikörper gegen Sec23p von Hefe, Bahn 6: Kreuzreaktion des GST-Fusionsprotein mit dem gewonnen Antikörper. Pro Bahn wurden $1 \mu \mathrm{g}$ (Bahn 2), $2 \mu \mathrm{g}$ (Bahn 3), 0,2 $\mu \mathrm{g}$ (Bahn 4, 5 und 6) Protein aufgetragen. 


\subsection{Lokalisierung von At $\gamma-C O P$ und AtSec23p in den Cytosol- und Membranfraktionen}

Um die Kreuzreaktion der hergestellten Antikörper mit homologen Proteinen aus verschiedenen Organismen zu untersuchen, wurden Cytosol und mikrosomale Membranen von Arabidopsis, Blumenkohl, Mais, Hefe und Schweinehirn isoliert (siehe Kap. 2.2.2). Mit diesen Fraktionen wurden dann Western-Blots angefertigt. Durch diese Experimente konnte auch die intrazelluläre

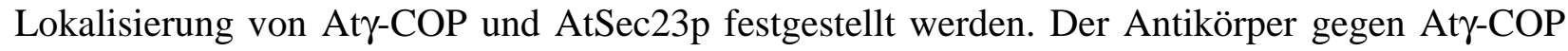
zeigte dabei eine Kreuzreaktion mit einem Protein von $100 \mathrm{kDa}$ in allen Fraktionen aus Pflanzenzellen, wobei die Kreuzreaktion mit dem Cytosol in allen Fällen deutlich stärker ausfiel als die mit den mikrosomalen Membranen (Abb. 3.5). In den Fraktionen aus Hefe und Schweinehirn wurde dagegen kein Protein erkannt.

Bei den Fraktionen aus Arabidopsis, Blumenkohl und Mais zeigte der Antikörper gegen AtSec23p ein ähnliches Verhalten wie der gegen Aty-COP (Abb. 3.5). Ein Protein von 85 kDa wurde sowohl in den cytosolischen als auch in den mikrosomalen Membranfraktionen erkannt, wobei die Kreuzreaktion mit den cytosolischen Fraktionen stärker ausfiel. Im Gegensatz zu dem Antikörper gegen At $\gamma$-COP erkannte dieser Antikörper auch Proteine von Hefe und Schweinehirn. Dabei war die Kreuzreaktion mit dem Protein von $85 \mathrm{kDa}$ in den cytosolischen Fraktionen stärker ausgeprägt. Diese Kreuzreaktion fiel aber im Vergleich zu den pflanzlichen Geweben schwächer aus.

Gegen Ende der vorliegenden Arbeit wurden weitere Antikörper gegen Hüllproteine der pflanzlichen COPI und COPII Vesikel erhältlich. Die Antikörper gegen $\delta$-COP und $\varepsilon$-COP aus Mais wurden von Dr. Saun Coughlan (AG Biotechnology, DuPont Experimental Station, Wilmington, Delaware, USA) und die Antikörper gegen Sar1p und Arf1p aus Arabidopsis von Herrn Peter Pimpl (Abteilung für Strukturelle Zellphysiologie, Albrecht von Haller Institut für Pflanzenwissenschaften der Universität Göttingen, BRD) zur Verfügung gestellt (siehe Kap. 2.8.5.2). Dies ermöglichte einen Vergleich der Verteilung dieser Hüllproteine zwischen

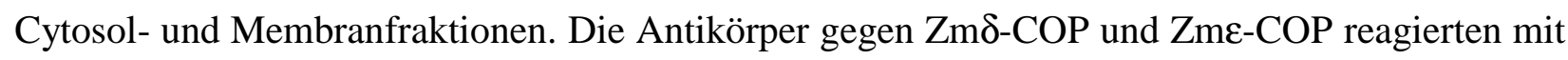
pflanzlichen Proteinen der Molekularmassen $58 \mathrm{kDa}(\delta$-COP) und $31 \mathrm{kDa}(\varepsilon-\mathrm{COP})$ (Abb. 3.5). Es gab jedoch keine Kreuzreaktion mit Proteinen aus Hefe und Schweinehirn. Beide Proteine waren in den Cytosolfraktionen stärker als in den mikrosomalen Membranfraktionen nachweisbar. Die Antikörper gegen die GTPasen der COP Vesikel, AtSar1p und AtArf1p, reagierten nur mit Proteinen aus pflanzlichen Geweben mit Molekularmassen von $22 \mathrm{kDa}$ (AtSar1p) und $20 \mathrm{kDa}$ (AtArf1p) (Abb. 3.5). Im Gegensatz zu den vorgestellten Antikörpern gegen Hüllproteine der COP Vesikel reagierte der Antikörper gegen AtSar1p mit den 
mikrosomalen Membranfraktionen stärker als mit den Cytosolfraktionen. Im Vergleich dazu war die Kreuzreaktion des Antikörpers gegen AtArf1p mit den mikrosomalen Membranfraktionen nur wenig stärker als mit den Cytosolfraktionen ausgeprägt.

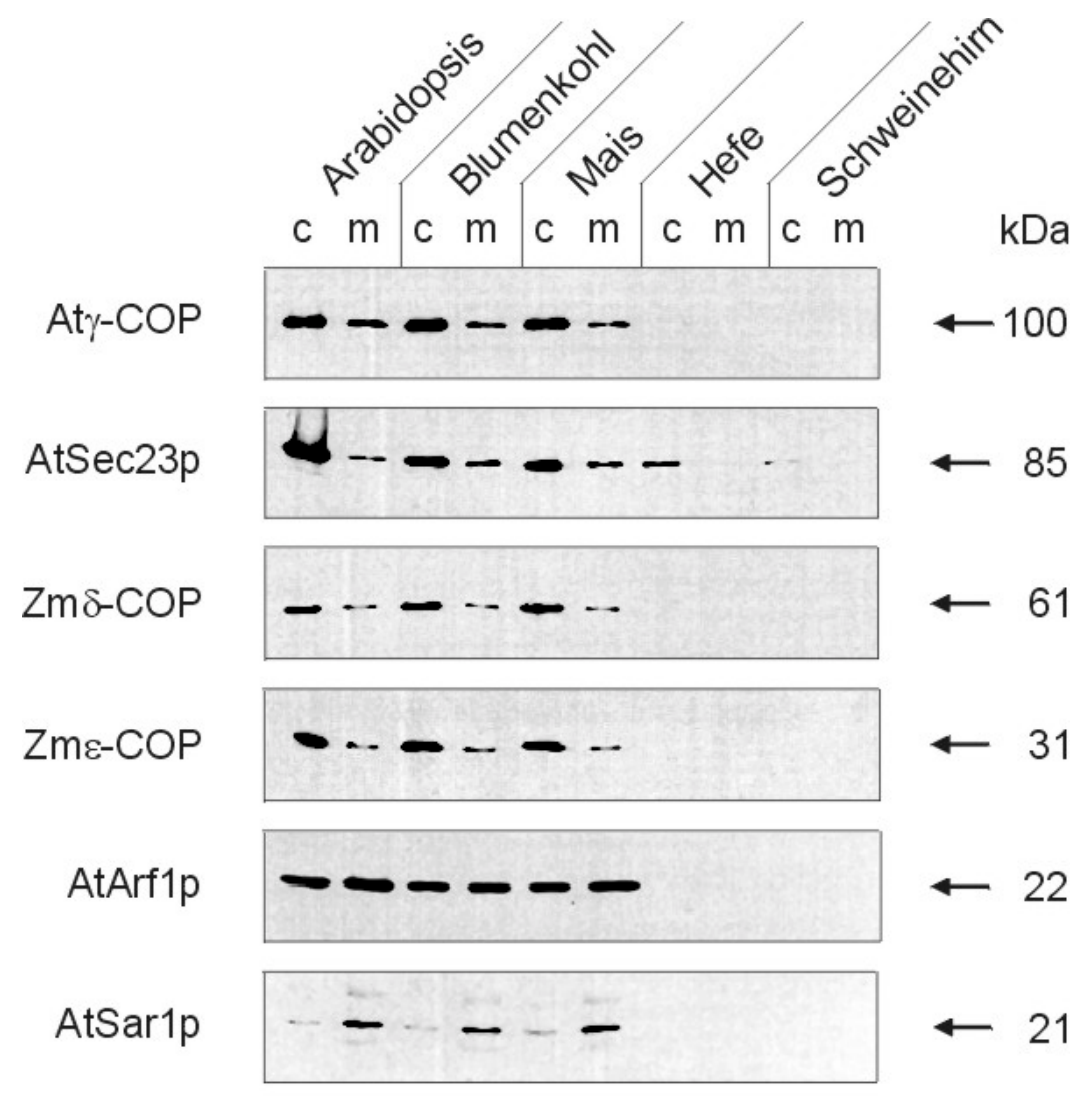

Abb. 3.5: Die Kreuzreaktionen der Antikörper gegen Hüllproteine der pflanzlichen COP Vesikel mit den Cytosol- (c) und Membranfraktionen (m) aus verschiedenen Organismen.

\subsection{Charakterisierung von At $\gamma$-COP und AtSec23p aus dem Cytosol}

Da mit den Antikörpern gegen Aty-COP und AtSec23p gezeigt werden konnte, dass ihre Antigene sowohl gelöst als auch membrangebunden vorkommen, wurde zunächst versucht, diese Proteine aus dem Cytosol zu charakterisieren. Durch die Ammoniumsulfatfällung sollten Fraktionen mit erhöhter At $\gamma$-COP- und AtSec23p-Konzentration gewonnen werden, die möglichst geringe Mengen endogener Proteasen enthalten. In einem weiteren Schritt konnte dann 
erforscht werden, ob beide Proteine, ebenso wie in Hefe und Säugetieren, als Bestandteile der verschiedenen Proteinkomplexe im Cytosol vorliegen.

\subsubsection{Ammoniumsulfatfällung von At $\gamma$-COP und AtSec23p}

Um die Konzentration von At $\gamma-\mathrm{COP}$ und AtSec23p in der cytosolischen Fraktion zu erhöhen und sie von einem großen Teil der endogenen Proteasen $\mathrm{zu}$ trennen (siehe unten), wurde eine Fraktionierung des Cytosols mit Ammoniumsulfat eingesetzt. Für die Isolierung und Konzentrierung von Proteinen ist ihre Fällung mit anorganischen Salzen eine sehr geeignete Methode. Dabei wird Ammoniumsulfat am häufigsten zur Fraktionierung von Proteinen benutzt (Cooper, 1980). In Rohpräparationen mit großem Volumen wird das Salz in trockener Form zugegeben. Beim Lösen des Ammoniumsulfats wird eine große Anzahl von Wassermolekülen pro Ammoniumsulfat-Molekül gebunden. Je mehr Ammoniumsulfat in der Lösung vorhanden ist, desto weniger Wasser steht für die Wechselwirkung mit den Proteinen zur Verfügung. An einem bestimmten Punkt ist nicht mehr genug Wasser vorhanden, um eine Reihe von Proteinen in Lösung zu halten, so dass diese ausfallen. Das Aussalzen kann deswegen als ein DehydratationsProzess bezeichnet werden.

Nach der Fraktionierung der cytosolischen Proteine von Blumenkohlinfloreszenzen (siehe Kap. 2.2.3.1), wurde die Verteilung der Hüllproteine durch Western-Blotting untersucht. Wie Abb. 3.6 zeigt, wurde At -COP mit Ammoniumsulfatkonzentrationen bis $50 \%$ (Sättigung) gefällt, wobei die größte Menge beim Schritt von $30 \%$ zu $40 \%$ Ammoniumsulfat gefällt wurde. Im Vergleich dazu fiel AtSec23p bereits bei $40 \%$ Ammoniumsulfat vollständig aus. Der größte Teil dieses Antigens wurde bei den Schritten von 0 zu $20 \%$ und von 20 bis $30 \%$ Ammoniumsulfat gefällt. Das Verhalten der GTPasen AtSar1p und AtArf1p bei der Ammoniumsulfatfraktionierung war ebenfalls verschieden. AtArflp blieb zum Teil bis zur Zugabe von $60 \%$ Ammoniumsulfat in Lösung, wobei die größte Menge von diesem Protein durch die Erhöhung der Ammoniumsulfatkonzentration von $30 \%$ zu $40 \%$ ausfiel. AtSar1p wurde dagegen durch die Zugabe von $40 \%$ Ammoniumsulfat vollständig präzipitiert.

Ein Problem der Cytosol- und Membranisolierung von Pflanzenmaterial ist die Freisetzung der in der Vakuole vorhandenen Proteasen bei der Homogenisation. Durch ihre Aktivität werden viele lösliche Proteine sowie extrinsische Membranproteine im Laufe der Aufarbeitung abgebaut. Diese proteolytische Aktivität kann durch Zugabe der Proteaseinhibitoren und durch niedrige Temperaturen reduziert, aber nicht vollständig verhindert werden. Die Ammoniumsulfatfraktionierung bietet die Möglichkeit, bei bestimmten Salzkonzentrationen die Proteasen von anderen Proteinen zu trennen. Daher wurde die Aktivität der Proteasen in Ammoniumsulfatfraktionen mit dem Azocaseintest gemessen (siehe Kap. 2.4). Wie man bereits in der Abb. 3.6 sieht, ist diese Aktivität in den ersten drei Fraktionen niedriger als im Cytosol. Erst nach der 
Zugabe von $50 \%$ Ammoniumsulfat wird sie höher als im Cytosol und bei $60 \%$ erreicht sie ihr Maximum. Daher kann mit Zugabe von $30 \%$ und $40 \%$ Ammoniumsulfat eine cytosolische Fraktion aus Blumenkohl gewonnen werden, die im Vergleich zum Cytosol hohe Konzentration der untersuchten Hüllproteine der COPI und COPII Vesikel und weniger Proteasen beinhaltet.

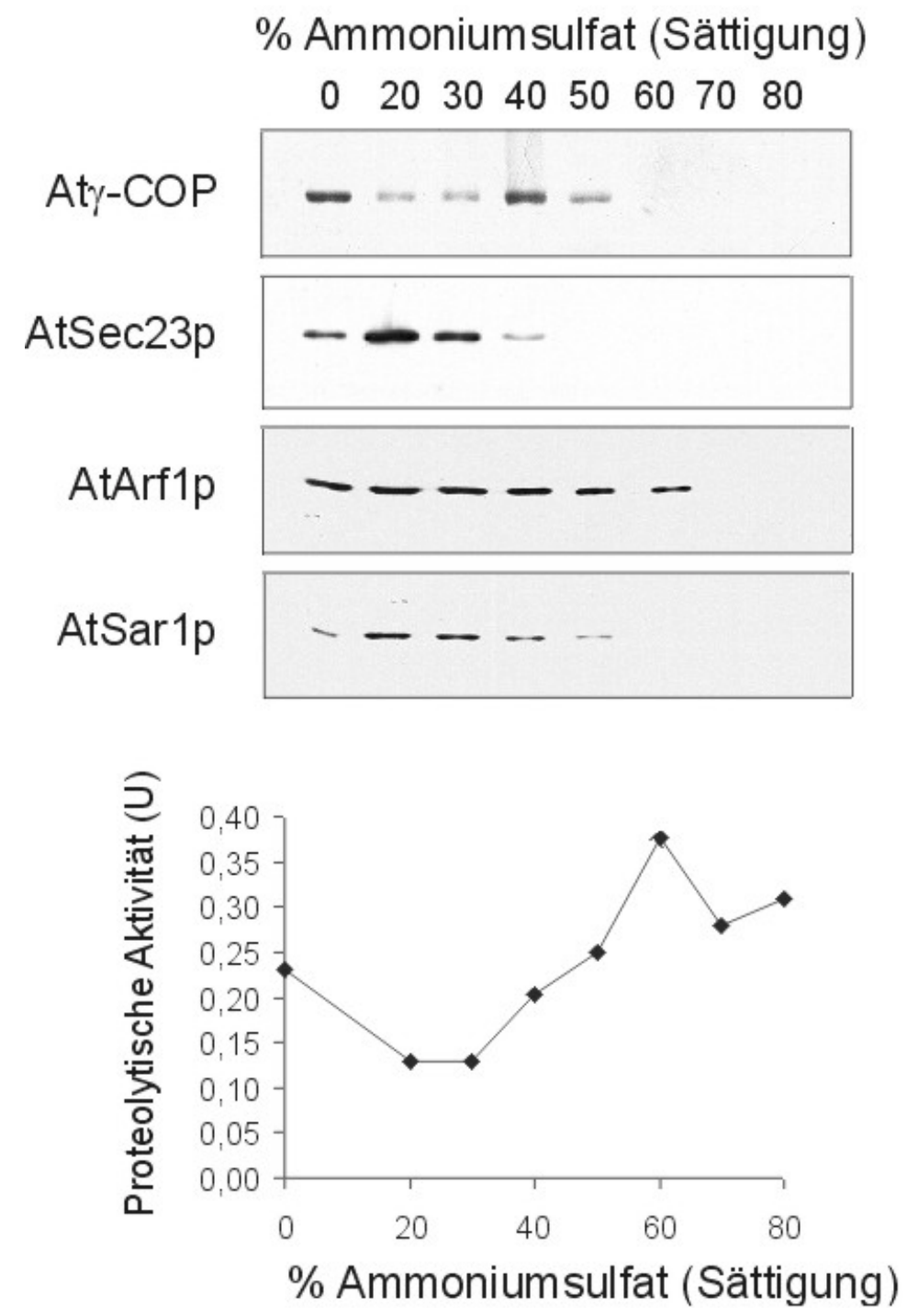

Abb. 3.6: Verteilung von Aty-COP, AtSec23p, AtArf1p und AtSar1p sowie der Proteaseaktivität (auf Basis des Azocaseintests) in Ammoniumsulfatfraktionen des Cytosols aus Blumenkohl. 


\subsubsection{At $\gamma$-COP und AtSec23p als Bestandteile von Proteinkomplexen}

Sec21p und Sec23p in Hefezellen und ihre Homologen in Säugetieren sind Bestandteile von Proteinkomplexen (siehe Kap. 1.3.2 und Kap. 1.3.3). Um zu prüfen, ob At $\gamma$-COP und AtSec23p im Cytosol von Pflanzen isoliert oder in Proteinkomplexen vorkommen, wurde eine Gelfilteration der cytosolischen Proteine aus Blumenkohlinfloreszenzen durchgeführt (siehe Kap. 2.2.3.2). Mit dieser Methode werden Proteine bzw. Proteinkomplexe aufgrund unterschiedlicher Größe getrennt und ihre Größe mit Hilfe der geeigneten Molekularmassenmarker geschätzt. Da vorher gezeigt worden war, dass die meisten At $\gamma$-COP und Atsec23p einer Cytosolfraktion aus Blumenkohl mit $40 \%$ Ammoniumsulfat gefällt werden können und die Proteaseaktivität in dieser Ammoniumsulfatfraktion im Vergleich zum Cytosol deutlich reduziert ist (siehe Kap. 3.3.1), wurde zunächst eine entsprechende Fällung durchgeführt. Die Proteine der so gewonnenen Fraktion wurden entsprechend ihrer Größe durch die Gelfiltration über eine Sepharose CL-6B-Säule aufgetrennt. Diese Säule hat einen Trennbereich von 10-4000 kDa. Die anschließende Western-Blot-Analyse zeigte, dass Aty-COP in den Fraktionen 23 bis 30 eluiert wird (Abb. 3.7). Die größten Antigen-Mengen wurden dabei in den Fraktionen 26 und 27 nachgewiesen. Da Aty-COP trotz seiner Molekularmasse von $100 \mathrm{kDa}$ vor dem Molekularmassenmarker Thyroglobulin $(669 \mathrm{kDa})$ eluiert wurde, deutet dieser Versuch darauf hin, dass dieses Protein ein Bestandteil eines Proteinkomplexes ist, der eine Molekularmasse von etwas über $669 \mathrm{kDa}$ hat. AtSec23p mit einer Molekularmasse von $85 \mathrm{kDa}$ wurde in den Fraktionen 27 bis 34 mit einem Peak bei den Fraktionen 30, 31 und 32 vor der $\beta$-Amylase (200 $\mathrm{kDa}$ ) eluiert. Damit wurde gezeigt, dass AtSec23p auch als Bestandteil eines Proteinkomplexes mit der Molekularmasse von über $200 \mathrm{kDa}$ in der Cytosolfraktion vorkommt. Das Ergebnis dieser Gelfiltrationschromatographie lässt darauf schließen, dass At $\gamma$-COP und AtSec23p im Cytosol als Bestandteile verschiedener Proteinkomplexe vorliegen. 


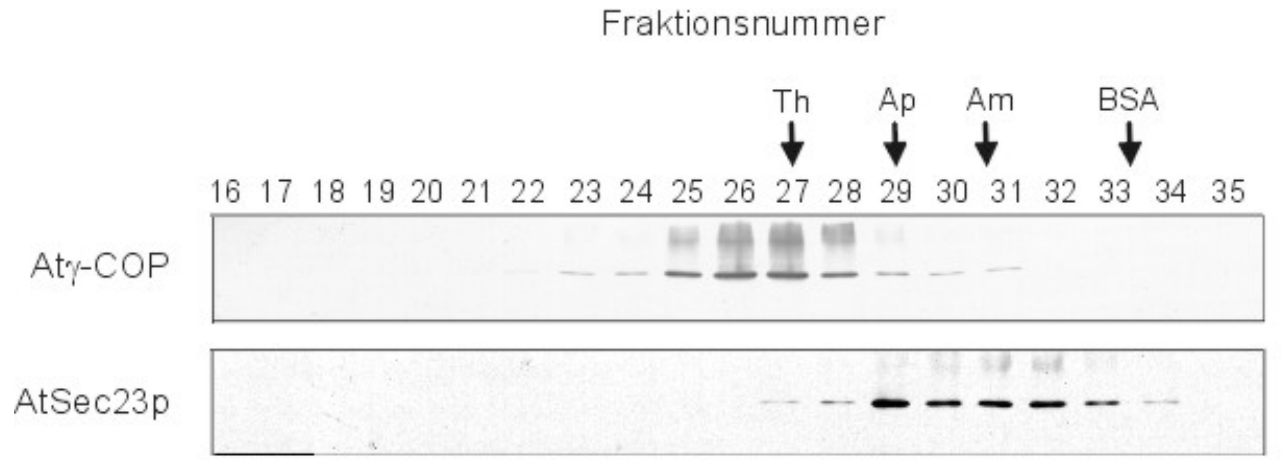

Abb. 3.7: Immunoblots der durch Gelfiltration über eine Sepharose CL-6B-Säule aufgetrennten Cytosolfraktionen. At $\gamma$-COP wird vor Thyroglobulin und AtSec23p vor der $\beta$-Amylase eluiert. Molekularmassenmarker: Th, Thyroglobulin (669 kDa); Ap, Apoferritin (443kDa); Am, $\beta$ Amylase (200 kDa) und BSA (66 kDa).

\subsubsection{Neomycinfällung von At $\gamma-\mathrm{COP}$}

Um zu verifizieren, dass At $\gamma$-COP und AtSec23p als Bestandteile von zwei Proteinkomlexen mit verschiedenen Bindungseigenschaften vorkommen, wurden cytosolische Proteine mit Neomycin gefällt. Bestimmte aminoglykosylierte Antibiotika - wie Neomycin - bilden durch eine direkte Kreuzreaktion mit dem Coatomer aus Säugetieren und Hefe große Aggregate, die durch Zentrifugation aus der löslichen Phase getrennt werden können (Hudson und Draper, 1997). Alle diese Antibiotika besitzen in ihrer Struktur mindestens zwei Paare von benachbarten Aminogruppen, ähnlich wie die Struktur des di-Lysin-Signals, das an das Coatomer bindet. Es ist bekannt, dass das Coatomer aus Säugetieren zwei oder mehr Bindungsstellen für die benachbarten Aminogruppen hat (Hudson und Draper, 1997). Neomycin, das drei Paare von Aminogruppen hat, vernetzt durch Kreuzreaktion mit diesen Bindungsstellen das Coatomer. Um die Wechselwirkung des pflanzlichen Coatomers mit Neomycin zu untersuchen, wurden zu einer mit $40 \%$ Ammoniumsulfat gewonnenen Cytosolfraktion aus Blumenkohl verschiedene Konzentrationen von Neomycin gegeben. Nach der Zentrifugation wurden die Überstände durch Western-Blotting analysiert (siehe Kap.2.2.3.3). At $\gamma$-COP konnte nach Zugabe von 1-10 mM Neomycin in der Cytosolfraktion (Überstand) nicht mehr nachgewiesen werden (Abb. 3.8). Im Vergleich dazu blieb AtSec23p unbeeinflusst von dieser Neomycinkonzentration im Cytosol (Überstand). Da vorher gezeigt worden war, dass At $\gamma$-COP als ein Bestandteil eines Komplexes 
im Cytosol vorkommt (siehe Kap.3.3.2), kann man davon ausgehen, dass in diesem Fall der Proteinkomplex mit Neomycin präzipitiert wird. Dieser Versuch bestätigt das Ergebnis der Gelfiltration, dass At $\gamma$-COP und AtSec23p Bestandteile verschiedener Proteinkomplexe sind.

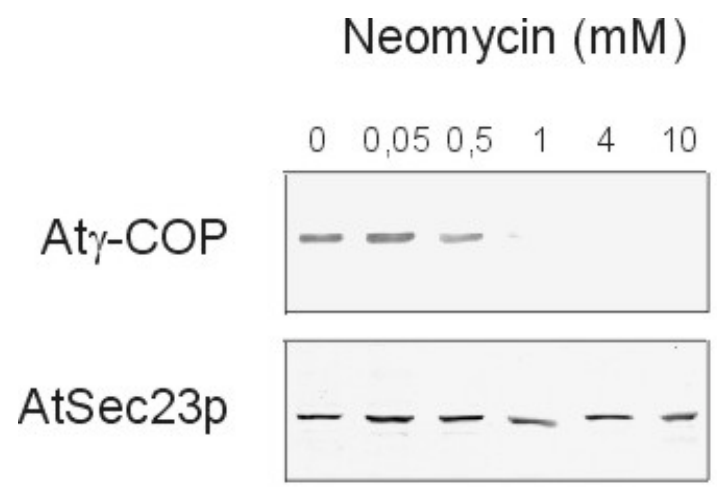

Abb. 3.8: Selektive Fällung von At $\gamma$-COP mit Neomycin. AtSec23p wird von Neomycin nicht präzipitiert.

\subsection{Membranassoziation von At $\gamma$-COP und AtSec23p}

Nachdem die löslichen At $\gamma$-COP und AtSec23p zum Teil charakterisiert worden waren, sollte nun das Membranbindungsverhalten dieser Proteine untersucht werden. Dabei sollte herausgefunden werden, in welcher Form (peripher oder integral) At $\gamma$-COP und AtSec23p mit Membranen assoziiert sind, ob diese Membranbindung spezifisch ist und $\mathrm{zu}$ welchen intrazellulären Kompartimenten diese Membranen gehören.

\subsubsection{At $\gamma$-COP und AtSec23p als periphere Membranproteine}

Um festzustellen, in welcher Weise (peripher oder integral) At $\gamma$-COP und AtSec23p mit Membranen assoziiert sind, wurden zwei Versuche durchgeführt. Zunächst wurden die mikrosomalen Membranen aus Blumenkohl mit Papain behandelt (siehe Kap. 2.2.4.3). Periphere Membranproteine auf der cytosolischen Seite der Membran sind aufgrund ihrer Lokalisation den Proteasen zugänglich und können nach der Behandlung mit Proteasen abgebaut werden (siehe z. B. Nickel et al., 1994; Conceição et al., 1997). Dagegen sind luminale Proteine vor dem proteolytischen Verdau geschützt. Durch Behandlung der Membranen mit Proteasen wie Papain 
und Protinase K kann geklärt werden, in welcher Form Proteine mit Membranen assoziiert sind. Für den Proteaseverdau wurden mikrosomale Membranfraktionen unterschiedlich lange mit der Protease Papain inkubiert. Wie Abb. 3.9 zeigt wurden membranassoziierte At $\gamma$-COP und AtSec23p innerhalb von 30 min vollständig von dem Papain verdaut. Im Gegensatz dazu wurde das luminale ER-Protein BiP, das als Kontrollprotein diente, nur zu einem geringen Anteil abgebaut. Erst durch Zugabe eines Detergenz (0,1\% Triton X-100) wurde dieses Protein für die Protease zugänglich und verdaut. So konnte gezeigt werden, dass der Abbauschutz von BiP tatsächlich auf seine luminale Lokalisation zurückzuführen ist. Die Ergebnisse dieses Versuchs deuten daraufhin, dass At $\gamma$-COP und AtSec23p auf der cytosolischen Seite der Membranen liegen.

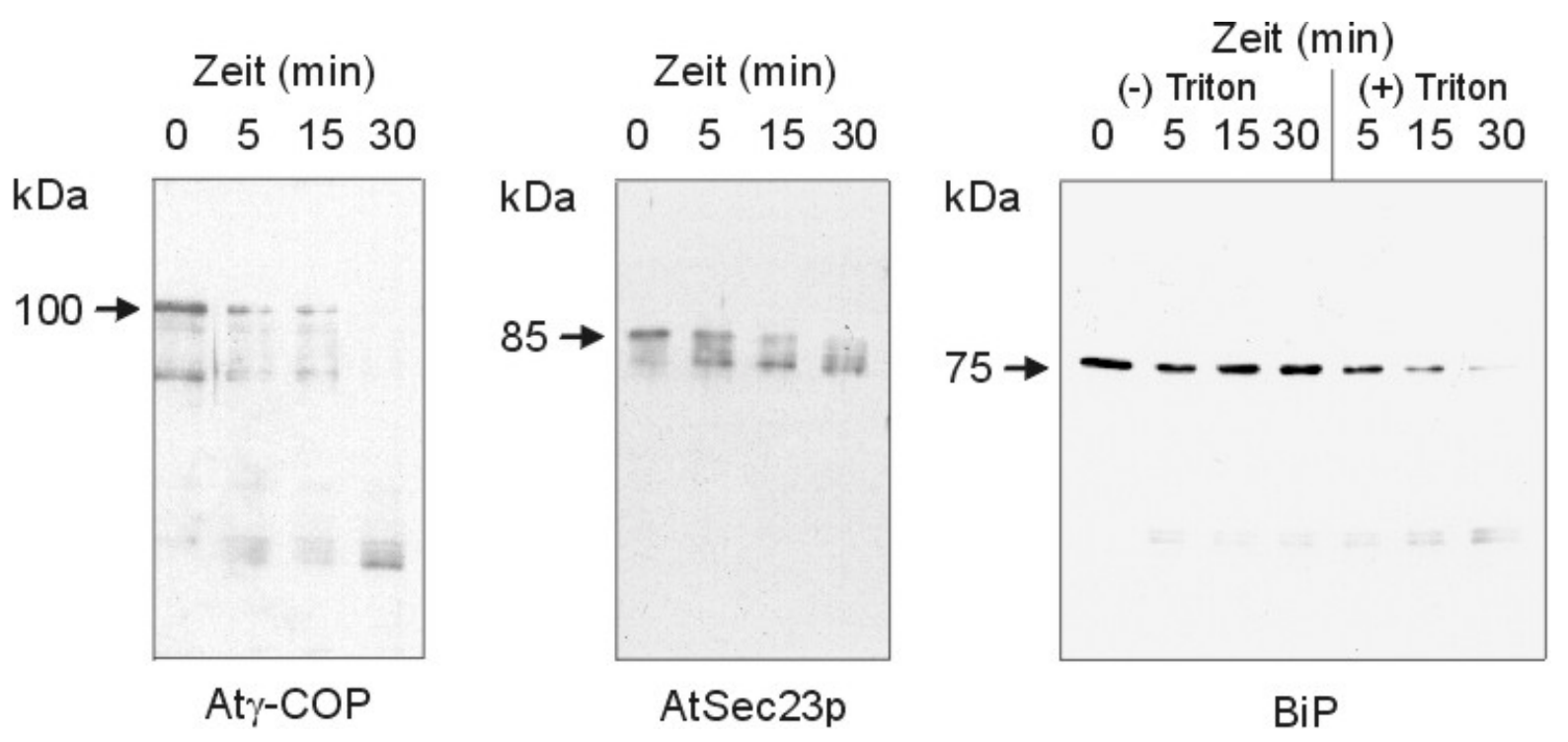

Abb. 3.9: Verdau von At $\gamma$-COP und AtSec23p mit Papain. Das luminale ER-Protein BiP wird nur nach Zugabe von 0,1 \% (v/v) Triton X-100 abgebaut. 
Eine verbreitete Methode, integrale Membranproteine von peripher an Membranen angelagerten Proteinen zu unterscheiden, ist die Behandlung der Membranen mit verschiedenen Reagenzien. Periphere Membranproteine lassen sich im Gegensatz zu integralen Membranproteinen bereits durch hohe Konzentrationen chaotroper Reagenzien wie Harnstoff, Natriumcarbonat und Kochsalz von der Membran ablösen (Hatefi und Hanstein, 1974). Für die Solubilisierung integraler Membranproteine sind dagegen Detergenzien wie Triton X-100 notwendig (Singer, 1974; Helenius et al., 1979). Durch die Behandlung der Membranen mit diesen Reagenzien wurde versucht, das Ergebnis des proteolytischen Verdaus mit Papain zu vervollständigen. Damit konnte aufgeklärt werden, ob At $\gamma$-COP und AtSec23p auf der cytosolischen Seite der Membranen ablösbar sind oder eine integrale Membrandomäne haben. Hierzu wurden mikrosomale Membranfraktionen mit verschiedenen Konzentrationen der oben genannten Reagenzien behandelt und durch eine Zentrifugation von der löslichen Phase getrennt (siehe Kap. 2.2.4.4). Als Kontrolle wurde das Verhalten der PM-ATPase als integrales Membranprotein unter den gleichen Bedingungen untersucht. Dieses Protein konnte nur nach der Behandlung mit Triton X-100 in die lösliche Phase gebracht werden (Abb. 3.10). At $\gamma$-COP und AtSec23p waren in Anwesenheit von 0,1\% und $1 \%$ Triton X-100, 2 M Harnstoff und 0,1 M Natriumcarbonat nicht mehr im Sediment, sondern nur noch im Überstand nachweisbar. Diese Hüllproteine wurden also durch diese Behandlung vollständig von den Membranen abgelöst. Die Behandlung der Membranfraktion mit 0,25, 0,5 und $1 \mathrm{M}$ Natriumchlorid konnte zwar die beiden Proteine zum Teil in die lösliche Phase bringen, aber sie waren auch noch an den Membranen nachweisbar. Das kann mit der schwächeren Wirkung von Natriumchlorid im Vergleich zu Natriumcarbonat und Harnstoff erklärt werden.

Diese Ergebnisse sprechen dafür, dass es sich bei At $\gamma$-COP und AtSec23p nicht um integrale Membranproteine, sondern um peripher an den Membranen angelagerte Proteine handelt. 

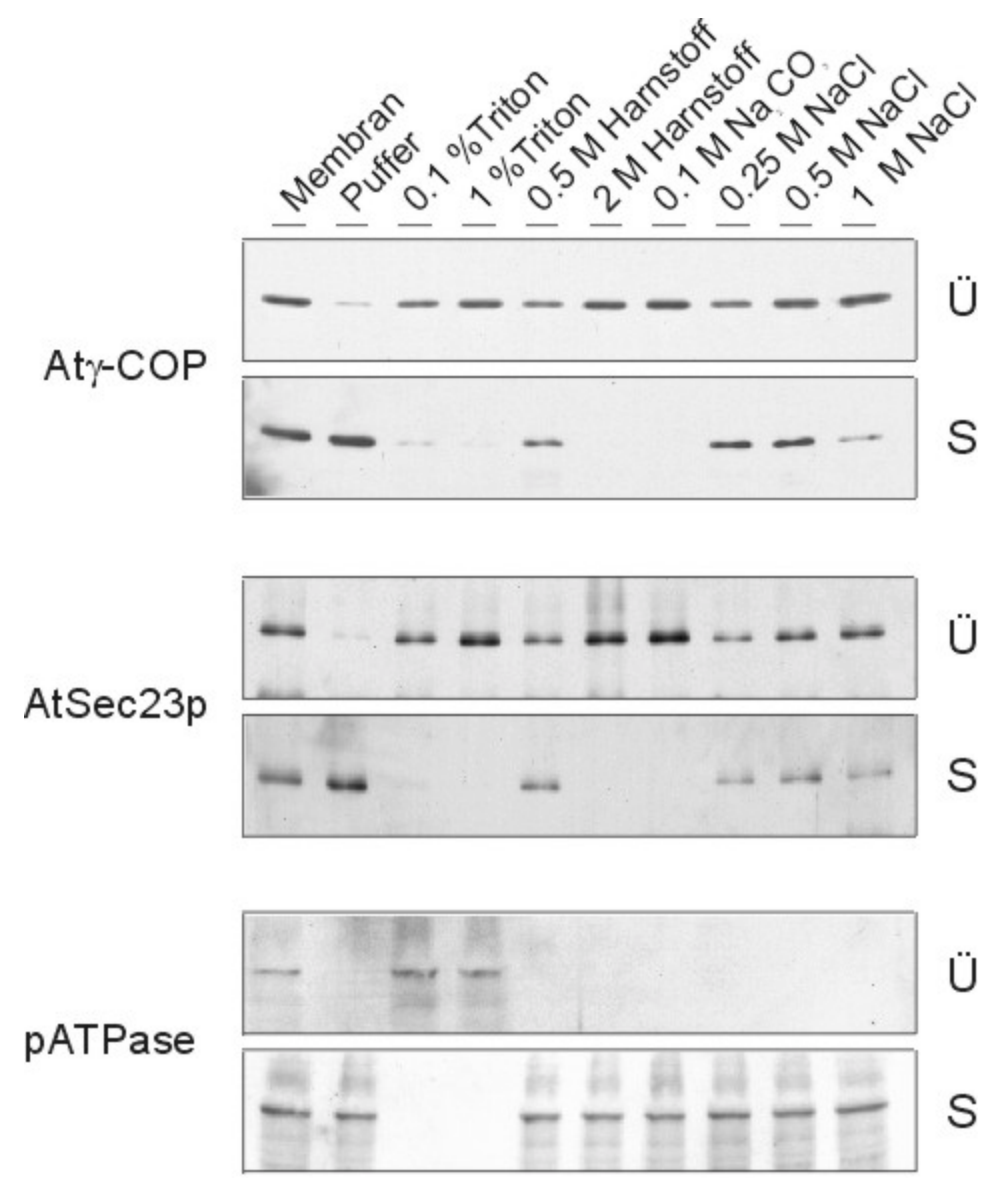

Abb. 3.10: Immunoblots der Sedimente (S) und Überstände (Ü) der Membranfraktionen nach der Behandlung mit verschiedenen Reagenzien und einer anschließenden Zentrifugation. PM-ATPase als ein integrales Protein wird nur mit Triton X-100 solubilisiert. Aty-COP und AtSec23p werden dagegen mit allen Reagenzien von der Membran abgelöst.

\subsubsection{Beeinträchtigung der Membranbindung von At $\gamma$-COP und AtSec23p durch niedrige Temperaturen}

Niedrige Temperaturen haben einen Einfluss auf den intrazellulären Proteintransport (Tartakoff, 1986, 1987). Wie Sauerstoffmangel (Anoxia) führt eine lange Kälte-Phase zur Ansammlung der Hüllproteine der CCVs im Cytosol der Säugetierzellen (Goud et al., 1985; Merisko et. al., 1986a,b). In Pflanzenzellen wurde auch eine Veränderung im Endomembransystem bei niedrigen Temperaturen, möglicherweise als Folge eines verhinderten, vesikelvermittelten Proteintransports, beobachtet (Mollenhauer et al., 1976). Um zu zeigen, dass die Membranbindung von At $\gamma$-COP und AtSec23p durch eine physiologische und nicht durch eine 
unspezifische Wechselwirkung zwischen diesen Proteinen und den Membranen hervorgerufen wird und daher mit einem physiologischen Faktor, wie der Temperatur, beeinflusst werden kann, wurde der Effekt der Kälte auf die Membranbindung von At $\gamma$-COP und AtSec23p untersucht. Dafür wurde eine Blumenkohlpflanze über Nacht für $14 \mathrm{~h}$ in einen Kühlraum bei $4{ }^{\circ} \mathrm{C}$ gestellt. Am nächsten Tag wurden Cytosol- und Membranfraktionen aus Infloreszenzen der Kältebehandelten Pflanze und einer Kontroll-Pflanze, die direkt aus dem Gewächshaus genommen wurde, isoliert (siehe Kap.2.2.2). $20 \mu \mathrm{g}$ Protein jeder Fraktion wurden mit TCA gefällt und später der Analyse durch Western-Blotting unterzogen. Die Kreuzreaktion der Antikörper gegen At $\gamma$-COP und AtSec23p mit der mikrosomalen Membranfraktion der Kälte-behandelten Pflanzen fiel im Vergleich zur Kontrolle schwächer aus (Abb. 3.11). Im Gegensatz dazu waren nach der Kältebehandlung beide Proteine in der Cytosolfraktion stärker angereichert. Die PM-ATPase, ein integrales Membranprotein, konnte als Kontrolle in den mikrosomalen Membranfraktionen in gleicher Stärke nachgewiesen werden. Die Verteilung dieses Proteins wurde also von der Kälte nicht beeinflusst. Mit diesem Versuch konnte gezeigt werden, dass die Membranassoziation von At $\gamma$-COP und AtSec23p durch Kälte als ein physiologischer Faktor verringert wird und es sich daher nicht um eine unspezifische Bindung an die Membranen handelt.

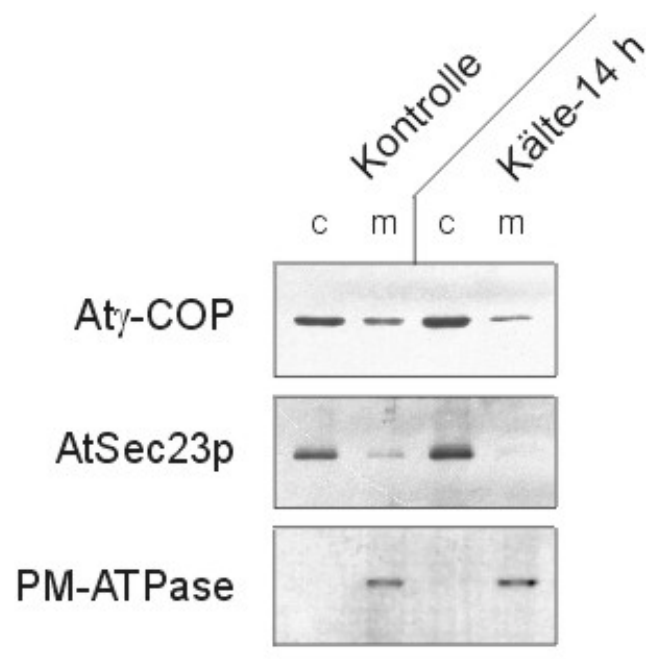

Abb. 3.11: Der Einfluss der Kälte auf die Membranbindung von Aty-COP und AtSec23p. Kälte verschiebt beide Proteine von der Membranfraktion in die Cytosolfraktion. Die Konzentration der PM-ATPase, als integrales Membranprotein, bleibt mit und ohne Kältebehandlung gleich. c: Cytosolfraktion; m: mikrosomale Membranfraktion 


\subsubsection{Einfluss von BFA auf die membrangebundenen At $\gamma$-COP und AtArf1p}

BFA ist ein Alkaloid aus Pilzen, das in Säugetierzellen die Dissoziation des Coatomers von Membranen verursacht (Donaldson et al., 1992; Scheel et al., 1997). Nach dieser Dissoziation werden die angereicherten v-SNAREs in bestimmten Bereichen des GApp zugänglich und treten mit t-SNAREs an den ER-Membranen in Wechselwirkung. Das führt zur Fusion von ER und GApp und zur Mischung ihres Inhalts. In Pflanzenzellen wurde auch ein Transport residenter dictyosomaler Proteine in das ER als ein BFA-Effekt nachgewiesen (Boevink et al., 1998). Mit den Antikörpern gegen Aty-COP und AtArf1p konnte der Einfluss von BFA auf die Bildung der COPI Vesikel am GApp der Pflanzenzellen erforscht werden. Damit konnte festgestellt werden, ob die Dissoziation des pflanzlichen Coatomers von den Membranen als Ursache für den Transport der Proteine aus dem GApp in das ER in Frage kommt. Für die BFA-Behandlungen wurden kultivierte BY2-Tabakzellen ausgewählt, weil mit ihnen die Untersuchung des BFAEffektes in Abhängigkeit von der Zeit durch eine gleichmäßige Aufnahme von BFA in die Zellen möglich war. Außerdem waren die BY2-Tabakzellen für die Beobachtung der intrazellulären, zeitabhängigen Wirkung von BFA mit einem "Confocal Laser Scanning" Mikroskop wegen des niedrig fluoreszierenden Hintergrunds geeignet. Diese wurde parallel zur vorliegenden Arbeit im Labor von Dr. C. Ritzenthaler an der Universität Straßburg (Straßburg, Frankreich) durchgeführt. Für die Behandlung wurden den Tabakzellen pro ml Medium $10 \mu \mathrm{g}$ BFA zugegeben (siehe Kap. 2.2.5). $\mathrm{Zu}$ verschiedenen Zeitpunkten wurden die Zellen aus dem Medium entnommen und eingefroren. Cytosol und mikrosomale Membranen wurden aus den Zellen isoliert und durch Western-Blotting wurde der BFA-Effekt auf die membrangebundenen Aty-COP und AtArf1p analysiert. Wie in Abb. 3.12 zu sehen ist, war At $\gamma$-COP nach einer 5-minütigen Behandlung mit BFA nicht mehr in der Membranfraktion nachweisbar. Dagegen wurde die Konzentration von AtArf1p in der Membranfraktion erst nach der 30-minütigen Behandlung mit BFA schwächer und konnte nach $5 \mathrm{~h}$ Inkubation mit BFA noch in der Membranfraktion nachgewiesen werden. Als Kontrolle diente das luminale ER-Protein BiP, dessen Membranbindung durch BFA nicht beeinflusst wurde. Das bedeutet, dass BFA in Tabakzellen in sehr kurzer Zeit die Dissoziation des Coatomers von dem membrangebundenen AtArf1p verursacht. Durch Untersuchung der

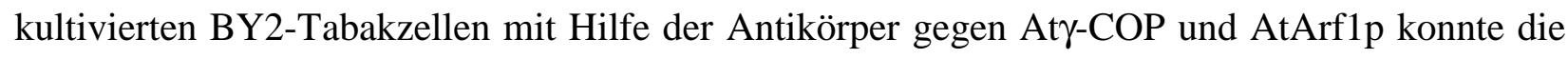
durch die BFA-Behandlung ausgelöste Dissoziation von At $\gamma$-COP von Membranen im "Confocal Laser Scanning" Mikroskop beobachtet werden (Ritzenthaler, persönliche Mitteilung). Dies bestätigte das Ergebnis des oben beschriebenen Experimentes. 


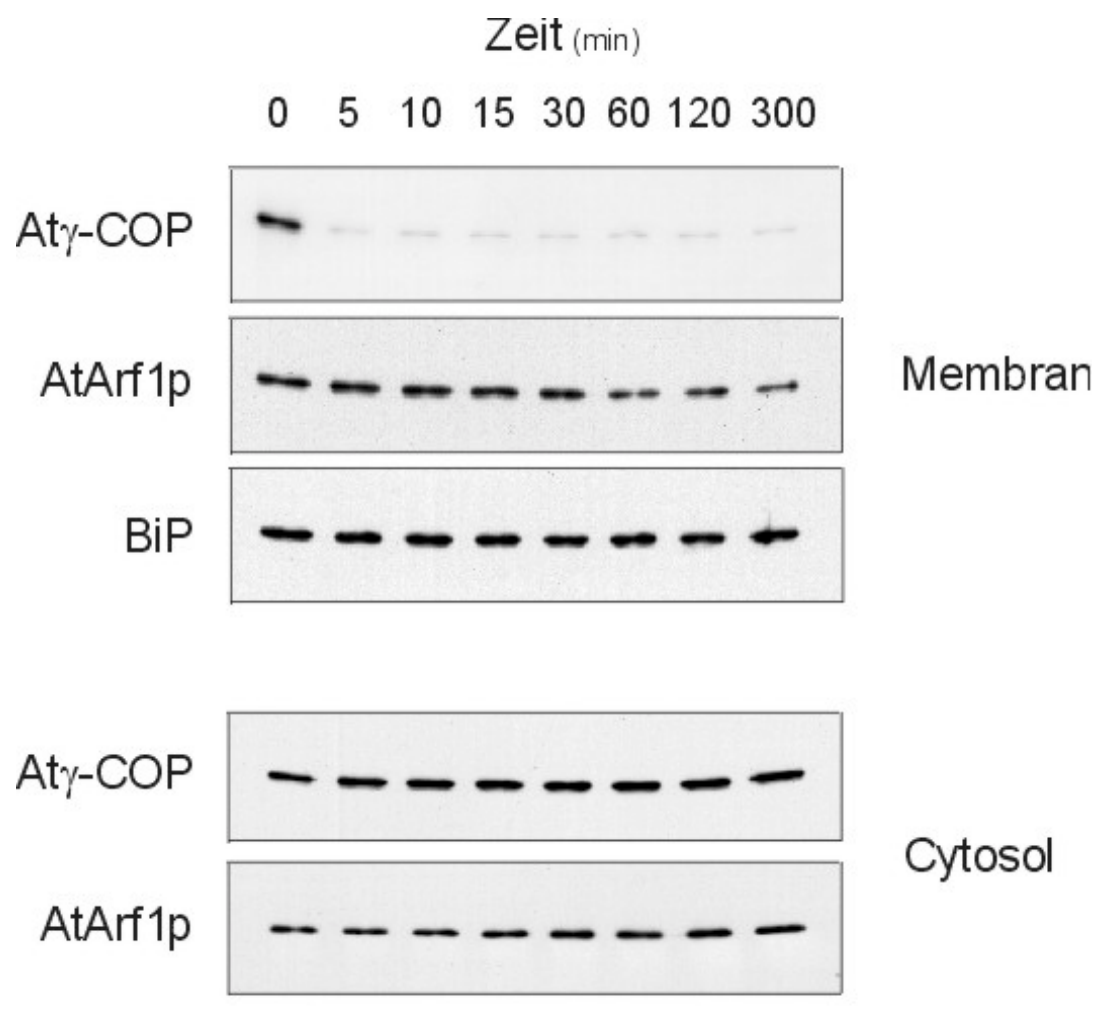

Abb. 3.12: Die Wirkung von BFA auf die membrangebundenen At $\gamma$-COP und AtArf1p. At $\gamma$-COP ist nach einer 5-minütigen Behandlung mit BFA nicht mehr in der Membranfraktion nachweisbar. Die Konzentration des luminalen ER-Proteins BiP wird von BFA nicht beeinflusst.

\subsubsection{Gelfiltrationschromatographie der mikrosomalen Membranen}

Nachdem gezeigt worden war, dass At $\gamma$-COP und AtSec23p in Pflanzenzellen als periphere Membranproteine (siehe Kap. 3.4.1) spezifisch an Membranen binden (siehe Kap. 3.4.2) und ihre Membranbindung eine physiologische Bedeutung hat (siehe Kap. 3.4.3), wurde in einem weiteren Experiment versucht, die mit At $\gamma$-COP und AtSec23p assoziierten Membranen zu identifizieren. Für die Identifizierung dieser Membranen wurde eine Gelfiltrationschromatographie über eine Sephacryl S-1000-Säule mit einem Trennbereich von 500-100.000 kDa durchgeführt. Durch eine solche Gelfiltration konnten bei Hefe mikrosomale Membranen in PM, Endosomen und Organellen aufgetrennt werden (Huang und Chiang, 1997). Die frisch aus Blumenkohl aufgereinigte mikrosomale Membranfraktion wurde auf eine Sephacryl S-1000-Säule aufgetragen und eluiert (siehe Kap. 2.2.4.1). Die Säule wurde mit L- $\alpha$-Lecithin vorgewaschen, um die unspezifische Bindung der Membranen $\mathrm{zu}$ minimieren. $200 \mu \mathrm{l}$ Aliquots von $3 \mathrm{ml}$ großen 
Fraktionen wurden nach der TCA-Fällung durch Western-Blotting analysiert. Zur Identifizierung der Organellen und Vesikel wurden zusätzlich zu den Antikörpern gegen At $\gamma$-COP und AtSec23p, folgende Antikörper verwendet: ein Antikörper gegen BiP als ER-Marker, ein Antikörper gegen RGP für den GApp, ein Antikörper gegen die PM-ATPase für die PM und ein Antikörper gegen $\beta$-Adaptin für die CCVs (siehe Kap. 2.8.5.2). Die Elutionsprofile von At $\gamma$-COP und AtSec23p waren identisch und zeigten zwei Peaks (Abb.3.13). Ein Peak lag bei den Fraktionen 14-18 und der andere bei den Fraktionen 26-33. Ähnliche Profile mit zwei Peaks wurden auch mit den ER- (BiP), GApp- (RGP) und CCV- ( $\beta$-Adaptin) Markern gefunden. Nur die PM-ATPase wurde in einem einzigen Peak in den Fraktionen 15-18 eluiert (Abb. 3.13). Die PM-ATPase kommt als integrales Membranprotein vor und ist daher fest mit der Membran assoziiert. BiP als lösliches, luminales ER-Protein sowie At $\gamma$-COP, AtSec23p, RGP und $\beta$ Adaptin als extrinsische Membranproteine können dagegen beim Homogenisieren der Zellen zum Teil von den Membranen abgelöst werden. Daher kann man davon ausgehen, dass es sich beim zweiten Peak um von Membranen abdissoziierte Proteine handelt. Eine Bestätigung für diese Aussage ist die Elutionsstelle von Thyroglobulin, das als Molekularmassenmarker eingesetzt wurde. Dieses Protein der Molekularmasse 669 kDa wurde in der Fraktion 29 eluiert (Abb. 3.13).

In den Fraktionen 15-18 waren alle untersuchten Proteine erkennbar. Nur BiP als Markerprotein des ER wurde über mehrere Fraktionen eluiert. Das kann damit geklärt werden, dass ERMembranen beim Homogenisieren Mikrosomen von sehr variabler Größe bilden. Diese Organellbruchstücke sind auch in Dichtegradienten wegen ihrer unterschiedlichen Schwebedichte in einem weiten Bereich zu finden (Bar-Peled und Raikhel 1997; Hong et al., 1999; Robinson und Hinz, 2000). Um nachzuweisen, dass beim ersten Peak tatsächlich mikrosomale Membranen eluiert wurden, wurde ein Aliqout der Fraktionen 15-18 für $1 \mathrm{~h}$ bei $100.000 \mathrm{~g}_{\max }$ zentrifugiert. Nach dieser Zentrifugation konnten die sichtbaren Membransedimente von der löslichen Phase getrennt werden. Der Nachweis des nicht dissoziierbaren integralen Membranproteins PMATPase kann als Beweis für die Anwesenheit der Membranen in diesen Fraktionen betrachtet werden. Da die Markerproteine der verschiedenen Blumenkohl-Membranen mit dieser Gelfiltration nicht voneinander getrennt werden konnten, gelang es nicht, die mit At $\gamma$-COP und AtSec23p assoziierten Membranen zu identifizieren. 


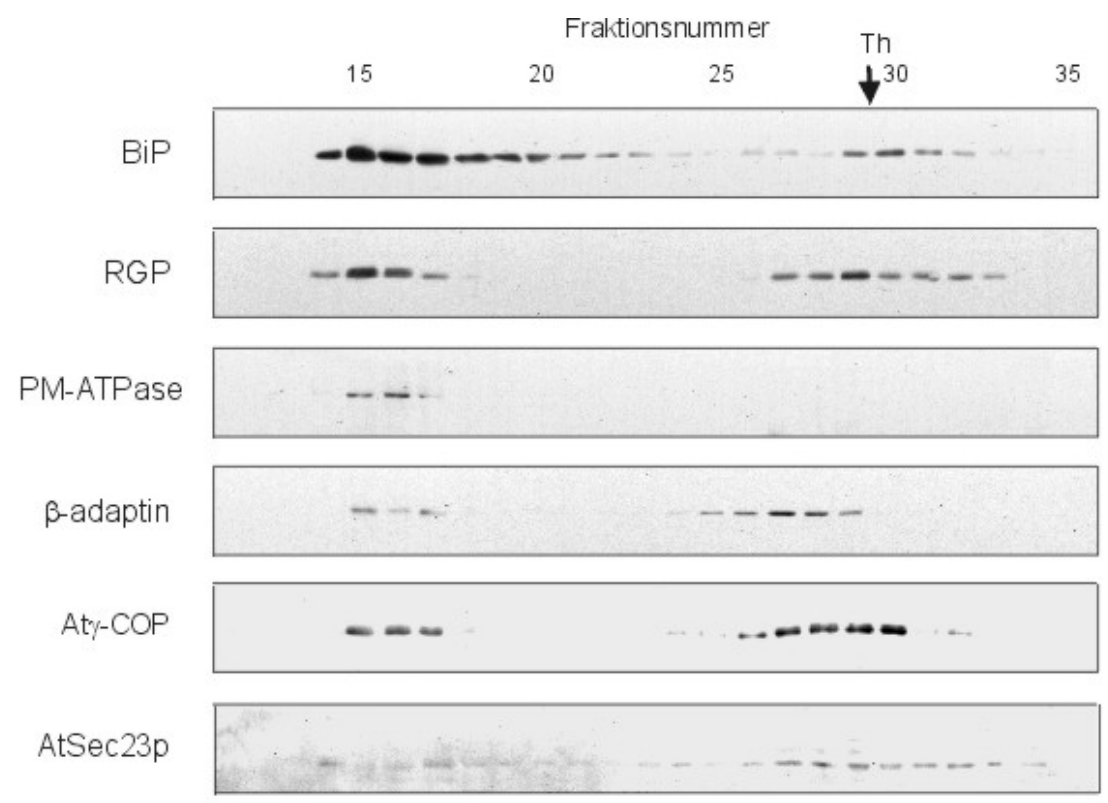

Abb. 3.13: Gelfiltrationschromatographie der mikrosomalen Membranen über die Sephacryl S1000-Säule. Der Molekularmassenmarker Thyroglobulin (Th: 669 kDa) wurde in der Fraktion 29 eluiert.

\subsubsection{Membrangebundene At $\gamma$-COP und AtSec23p in Saccharosedichte- gradienten}

Da die relative Auftrennung der mikrosomalen Membranfraktionen aus Blumenkohl mit der Gelfiltration über die Sephacryl S-1000-Säule nicht möglich war, wurde eine isopyknische Zentrifugation der Membranfraktion im Saccharosedichtegradienten durchgeführt, um sie aufgrund ihrer verschiedenen Dichten aufzutrennen. Die Organellen und ihre Bruchstücke bewegen sich bei der isopyknischen Zentrifugation so lange durch den Gradienten, bis sie einen Punkt erreichen, an dem ihre Dichte mit der des Gradientenmediums übereinstimmt. Dafür muss die Zentrifugation lange genug durchgeführt werden (z. B. 12-16 h bei $100.000 \mathrm{~g}_{\max }$ in einem Ausschwingrotor) (Robinson und Hinz, 2000). Durch Verwendung eines vertikalen Rotors kann diese Zeit, wegen der kürzeren Trennstrecke und der höheren g-Zahl, erheblich verkürzt werden. Da membrangebundene Sec21p und Sec23p im Laufe der Zeit durch die GTP-Hydrolyse von Membranen dissoziiert werden, wurde für die Aufarbeitung der mikrosomalen Membranen der vertikale Rotor mit der kürzeren Zentrifugationszeit ausgewählt. Mikrosomale Membranen wurden zuerst durch eine einstündige Zentrifugation auf einem 55\%-igen (w/w) Saccharosekissen gesammelt, um ihre Konzentration zu erhöhen (siehe Kap. 2.2.4.2). Diese 
Membranfraktion wurde danach auf einem linearen 20-55\% (w/w) Saccharosedichtegradienten unter Plus-Magnesium-Bedingungen aufgetragen und zentrifugiert. Unter diesen Bedingungen zeigen ER-Membranen eine höhere Schwebedichte, weil die Assoziation der Ribosomen mit ERMembranen, die magnesiumabhängig ist, erhalten bleibt. Im Gegensatz dazu werden unter Minus-Magnesium-Bedingung Ribosomen von den ER-Membranen abgelöst. Deshalb haben ERMembranen in Abwesenheit von Magnesium eine niedrigere Dichte. Dadurch kann das ER von anderen Kompartimenten, wie dem GApp, den CCVs und der Plasmamebran besser getrennt werden. Mit der Beobachtung der Verteilung der verschiedenen Proteine unter Plus- und MinusMagnesium-Bedingungen, kann festgestellt werden, ob ein Protein im ER vorkommt.

Nach der isopyknischen Zentrifugation wurde die Verteilung der unter Kap. 3.4.4 beschriebenen Markerproteine durch Western-Blotting untersucht. Unter Plus-Magnesium-Bedingungen zeigten BiP und RGP, die Aufschluss über die ER- und Golgi-Membranen geben, eine breite Verteilung mit einem Peak bei einer Saccharosedichte von $37 \%$ (w/w) (Abb. 3.14). Bei der Kreuzreaktion der beiden Antikörper mit den ersten Fraktionen in einem Saccharosedichtebereich von 20-22 \% (w/w) handelt es sich möglicherweise um die von den Membranen abdissoziierten Proteine, die nun als lösliche Proteine auf dem Gradienten vorkommen. Die PM war in höheren Saccharosedichten im Bereich von 41-43 \% (w/w) nachweisbar. Diese hohe Dichte der PM kann mit der Assoziation von Zellwandbruchstücken erklärt werden. $\beta$-Adaptin-enthaltende Fraktionen traten in Saccharosedichten von 38-45 \% (w/w) auf. Es wurde nachgewiesen, dass dieses Protein sowohl mit CCVs als auch mit der PM assoziiert ist (Robinson 1987; Drucker et al., 1995). Die $\beta$-Adaptin-Verteilung überlappte zum Teil mit der PM-ATPase, war im Vergleich jedoch in einem breiteren Saccharosedichtebereich zu finden. Daher kann man davon ausgehen, dass diese Kreuzreaktion nicht nur die Verteilung der PM, sondern auch die der CCVs widerspiegelt. Es ist auch möglich, dass mit Clathrin assoziierte Golgielemente bei der Homogenisation von anderen Zisternen abgetrennt werden und in diesen Fraktionen neben den CCVs vorkommen (siehe Kap. 1.2) (Robinson, 1985). Die Verteilungsprofile von At $\gamma$-COP und AtSec23p zeigten drei Peaks (Abb. 3.14), wobei der Nachweis von AtSec23p in dem Saccharosedichtegradienten sehr schwierig war. Hier hatten sich vermutlich die membrangebundenen COPII-Hüllproteine durch die Aufarbeitung der Membranen unter Verwendung verschiedener Saccharoselösungen (für Saccharosekissen und Saccharosedichtegradienten) von den Membranen abgelöst. Bei dem ersten Peak von At $\gamma$-COP und AtSec23p auf dem Gradienten handelte es sich um von Membranen abdissoziierte Proteine, die nun als lösliche Proteine vorkamen. Der zweite Peak war mit den ER/Golgi-Fraktionen kolokalisiert und der dritte lag mit einer Saccharosedichte von 43-46\% in einem Bereich, der typisch für Transportvesikel ist (Robinson und Hinz, 2000). 


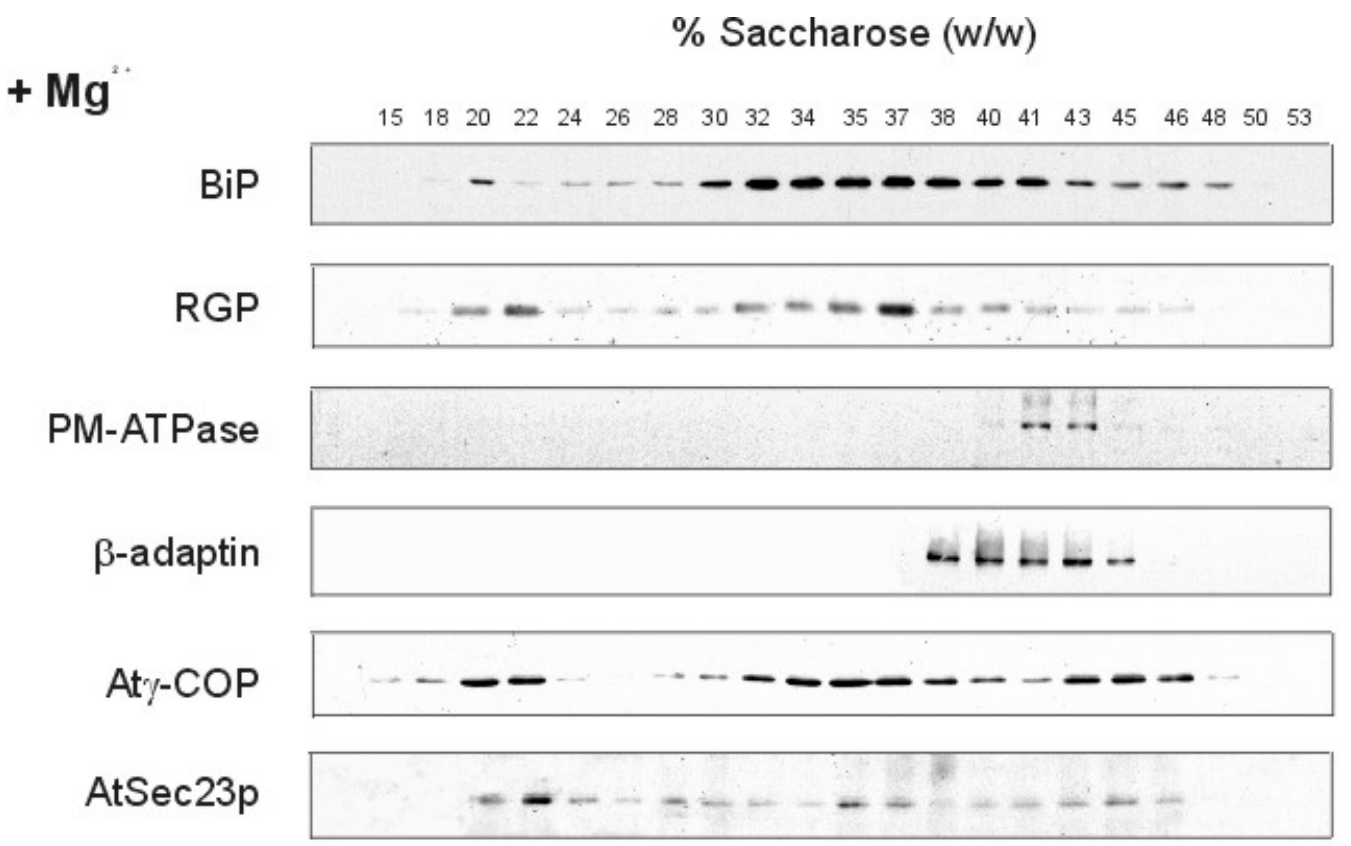

Abb. 3.14: Verteilung der mikrosomalen Membranen in einem Saccharosedichtegradienten unter Plus-Magnesium-Bedingungen.

Um eine Auftrennung von ER und GApp im Saccharosedichtegradienten zu erreichen, wurden die Verteilung der mikrosomalen Membranen von Blumenkohl unter Minus-MagnesiumBedingungen untersucht (siehe Kap. 2.2.4.2). Dabei sollte festgestellt werden, ob Aty-COP und AtSec23p mit ER oder GApp assoziiert sind. Unter diesen Bedingungen zeigte der ER-Marker BiP eine klassische Verschiebung zu niedrigeren Saccharosedichten mit einem Peak bei $29 \%$ (w/w) Saccharose (Abb. 3.15). Eine kleinere, aber auffällige Verschiebung (von einem Peak bei $37 \%$ zu einem Peak bei $34 \%$ (w/w) Saccharose) wurde auch mit dem GApp-Marker RGP beobachtet. Das wurde durch die in Abb. 3.15 dargestellte Verteilung der Aktivität der latenten IDPase, die ein Markerenzym für den GApp ist, bestätigt. Die Verteilungsprofile der PM-ATPase und von $\beta$-Adaptin entsprachen den Plus-Magnesium-Bedingungen und blieben unbeeinflusst von der Magnesiumkonzentration. Die At $\gamma$-COP und AtSec23p enthaltenden Fraktionen traten bei diesem Versuch auch in drei distinkten Proteinpeaks auf, wobei bei beiden Proteinen nur der zweite Peak eine Verschiebung zu einer niedrigeren Saccharosedichte zeigte. Während die Verschiebung von AtSec23p vergleichbar mit der von BiP war, überlappte der zweite Proteinpeak von At $\gamma$-COP mit BiP und RGP. Der Vergleich der Gradienten unter Plus- und Minus-Magnesium-Bedingungen konnte zeigen, dass Atsec23p mit den ER-Membranen und At $\gamma$ - 
COP mit den Membranen des GApp und/oder des ER assoziiert sind. Darüber hinaus sind diese Proteine auch in den Fraktionen mit hoher Saccharosedichte nachweisbar. Es ist möglich, dass in diesen Fraktionen COP Vesikel vorkommen, deren Proteinhülle noch nicht dissoziiert ist.

$\%$ Saccharose $(w / w)$
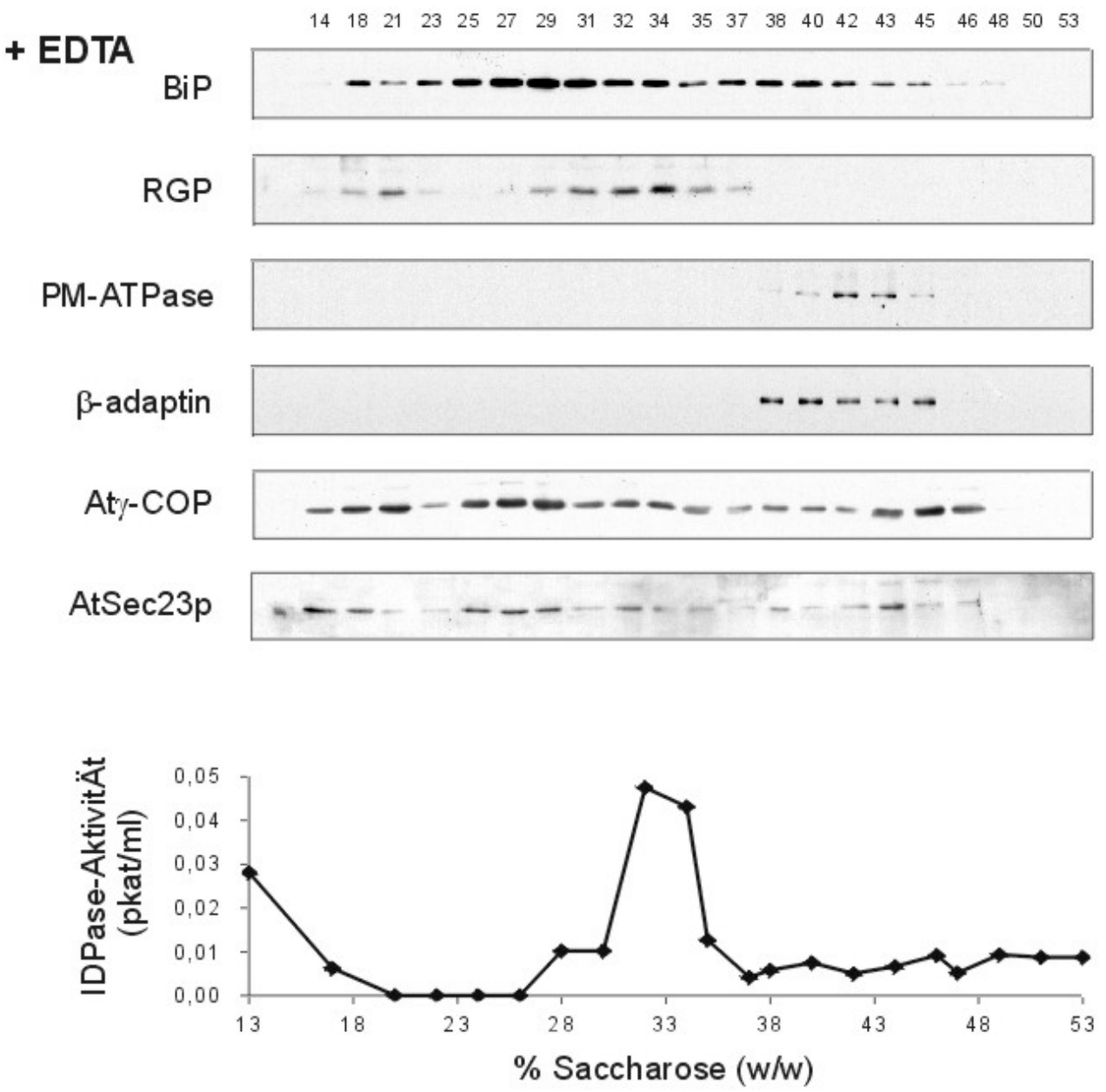

Abb. 3.15: Verteilung der mikrosomalen Membranen in einem Saccharosedichtegradienten unter Minus-Magnesium-Bedingungen. Die Aktivität der latenten IDPase als Markerenzym für den GApp und die Verteilung von RGP sind vergleichbar und bestätigen sich gegenseitig. 


\subsection{Lokalisierung der COPI-Hüllproteine in Wurzelspitzenzellen}

Mit der Saccharosedichtegradientenzentrifugation wurde nachgewiesen, dass die Hüllproteine der pflanzlichen COP Vesikel sowohl in der ER/GApp-Fraktion als auch in einer Membranfraktion von hoher Dichte angereichert werden. Nun sollte mit Hilfe der Immunlokalisierung von COPIProteinen geklärt werden, mit welchen intrazellulären Strukturen diese Proteine assoziiert sind. Dafür wurde zunächst versucht, COPI-Hüllproteine in den Zellen von Blumenkohlinfloreszenzen $\mathrm{zu}$ lokalisieren. Diese Zellen wurden nach einer Aldehyd-/Osmiumfixierung in Kunststoff (London Resin White) eingebettet und mit einem Ultramikrotom geschnitten. Mit keinem der Antikörper gegen Hüllproteine der pflanzlichen COPI Vesikel konnte eine signifikante Markierung innerhalb der Zellen beobachtet werden. Daher wurde mit Hilfe der TokuyasuTechnik (Tokuyasu, 1980, 1986) versucht, eine bessere Lokalisierung der relevanten Proteine zu erreichen (siehe Kap.2.9.2). Die Zellen werden hierbei lediglich nach einer leichten Aldehydfixierung mit einer Saccharoselösung infiltriert und anschließend eingefroren. Sie werden dann bei niedrigen Temperaturen, meist zwischen -95 und $-120{ }^{\circ} \mathrm{C}$ geschnitten (siehe Kap. 2.9.3). Das heißt, es wird keine Entwässerung, die die Antigenizität vieler Proteine schwächen kann, und keine Einbettung in Kunststoff, die die Antigene teilweise maskiert, durchgeführt. Da die Antigene geschont werden, kann mit dieser Methode bei der Immunlokalisierung von Proteinen oft eine größere Markierungsdichte erreicht werden (van Bergen en Henegouwen, 1989). Für die Durchführung der Tokuyasu-Technik bei Pflanzenzellen sind die großen Unterschiede bezüglich der mechanischen Eigenschaften der gefrorenen, zellulären Kompartimente problematisch. Insbesondere Stärkekörner in Amyloplasten, Zellwände und Vakuolen beeinträchtigen die Herstellung von guten Kryoschnitten. Erste Immunmarkierungen der Blumenkohlinfloreszenzen wiesen zudem einen erheblichen unspezifischen Hintergrund auf. Mit dem Ausweichen auf Arabidopsis- bzw. Maiswurzelspitzen wurde das verhindert, da diese Gewebe vermutlich weniger glykolisierte Proteine enthalten. Zudem erwies es sich als Vorteil, die Pflanzen zu bearbeiten, gegen deren Proteine die COPIAntikörper gerichtet waren.

$\mathrm{Zu}$ Beginn der Immunogoldmarkierung der Kryoschnitte wurden die gewonnenen Antiseren gegen Hüllproteine der pflanzlichen COPI Vesikel verwendet. Dabei wurden zwar Dictyosomen markiert, allerdings wiesen auch Zellwände und Stärkekörner in Amyloplasten eine Markierung auf. Daher wurden Immunglobuline aller vorhandenen Antiseren über eine Protein A-Sepharose Säule aufgereinigt (siehe Kap.2.7). Nach Immunogoldmarkierung der Kryoschnitte von Arabidopsis- und Maiswurzelspitzen mit den so gewonnenen Antikörpern war sowohl an den seitlichen Enden der Zisternen als auch in unmittelbarer Nähe am cis-, median- und trans-Bereich der Dictyosomen eine Markierung zu sehen (siehe Abb. 3.16, 3.17 und 3.18). Im Lumen der 
Zisternen und im Cytoplasma konnten jedoch kaum Goldpartikel gefunden werden. Die Markierung in der Nähe der Zisternen fand sich oft an kleinen Vesikeln mit einem Durchmesser von etwa $60 \mathrm{~nm}$, deren 10-15 nm dicke cytoplasmatische Proteinhülle im Elektronenmikroskop auffiel (siehe Abb. 3.16, 3.17 und 3.18). Die markierten Vesikel hatten eine sehr große Ähnlichkeit mit COP Vesikeln auf Kryoschnitten von Säugetierzellen (siehe z. B. Orci et al., 1997). Diese Vesikel waren eindeutig keine CCVs, die mit ihrer 25-30 nm dicken Proteinhülle im trans-Bereich der Dictyosomen $\mathrm{zu}$ sehen waren (Abb. 3.17B). Sowohl CCVs als auch Schleimvesikel, die besonders in den Zellen der Maiswurzelhaube vorkommen (Mollenhauer und Morré, 1994), wurden mit den COP-Antikörpern nicht markiert (Abb. 3.16B und 3.17B). Das bestätigt die Vermutung, dass die mit den COP-Antikörpern markierten Vesikel pflanzliche COPI Vesikel sind, die somit in der vorliegenden Arbeit zum ersten Mal nachgewiesen werden konnten. Die Lokalisierung von AtArf1p in Zellen der Maiswurzelspitzen führte zu einem vergleichbarem Ergebnis. Mit dem Antikörper gegen AtArf1p wurden Dictyosomen und die $60 \mathrm{~nm}$ großen COPI Vesikel markiert (Abb.3.17C,D). Damit konnten eindeutig zwei intrazelluläre Strukturen (GApp und COPI Vesikel) identifiziert werden, mit denen Hüllproteine der COPI Vesikel assoziiert sind. Deshalb kann angenommen werden, dass es sich bei dem zweiten Peak von At $\gamma$-COP im Saccharosegradienten um die Membranen des GApp und beim dritten Peak um COPI Vesikel handelt.

Um eine genaue Zuordnung der pflanzlichen COPI-Hüllproteine bzw. COPI Vesikel zu den verschiedenen Bereichen des GApp treffen zu können, wurde eine statistische Analyse der Immunogoldmarkierungen durchgeführt. Dafür wurde die Verteilung der Goldpartikel anhand von 25 Dictyosomen für jede Markierung mit dem jeweiligen COPI-Antikörper ausgewertet. Dabei wurden die Goldpartikel an den Zisternen und an den Vesikeln gezählt. Um eine Zuordnung der COPI Vesikel zum GApp zu gewährleisten, wurden ausschließlich Vesikel in die Statistik aufgenommen, die nicht weiter als $250 \mathrm{~nm}$ von einem Dictyosom entfernt waren. Cisund trans-Bereich der Golgistapel wurden aufgrund der zisternalen und der interzisternalen Breite unterschieden (siehe Kap. 1.2). Die Auszählung, deren Ergebnis in Tabelle 3.1 dargestellt ist, ergab eine ungleichmäßige Verteilung der Goldpartikel an den Zisternen sowie an den Vesikeln. Beim Vergleich der Markierung der Zisternen und Vesikel konnte festgestellt werden, dass durchschnittlich mehr als $80 \%$ der Goldpartikel an COP Vesikeln in der Nähe der Zisternen zu finden waren. Die Markierung der Vesikel fand sich überwiegend in der Nähe des cis-Bereichs der Dictyosomen. Alle Zisternen der Dictyosomen zeigten eine Immunogoldmarkierung. In diesem Fall waren auch die cis-Zisternen stärker als andere Zisternen und das TGN markiert. Die Hüllproteine der COPI Vesikel waren also in den untersuchten Pflanzenzellen sowie in Säugetierzellen (Oprins et al., 1993) hauptsächlich im cis-Bereich der Dictyosomen lokalisiert. 

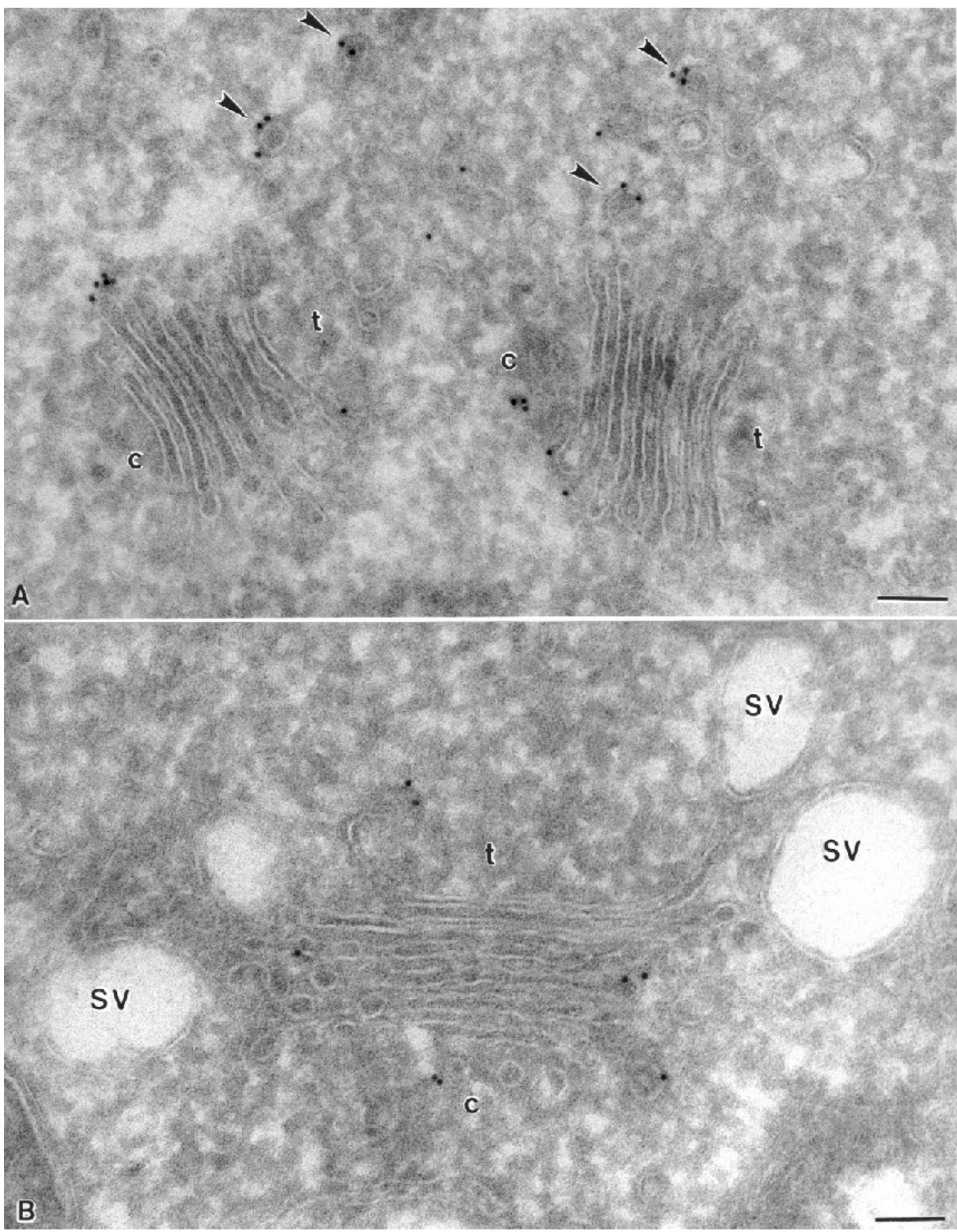

Abb. 3.16: Immunogoldmarkierung auf Kryoschnitten von Maiswurzelspitzen mit dem Antikörper gegen Aty-COP. A) Markierung der Dictyosomen und der COPI Vesikel. Pfeilspitzen deuten auf markierte COPI Vesikel. B) Schleimvesikel (SV) sind im Gegensatz zu den COPI Vesikeln nicht markiert. c, $\mathrm{t}=$ cis- und trans-Bereich der Golgistapel; Strichlänge $100 \mathrm{~nm}$. 


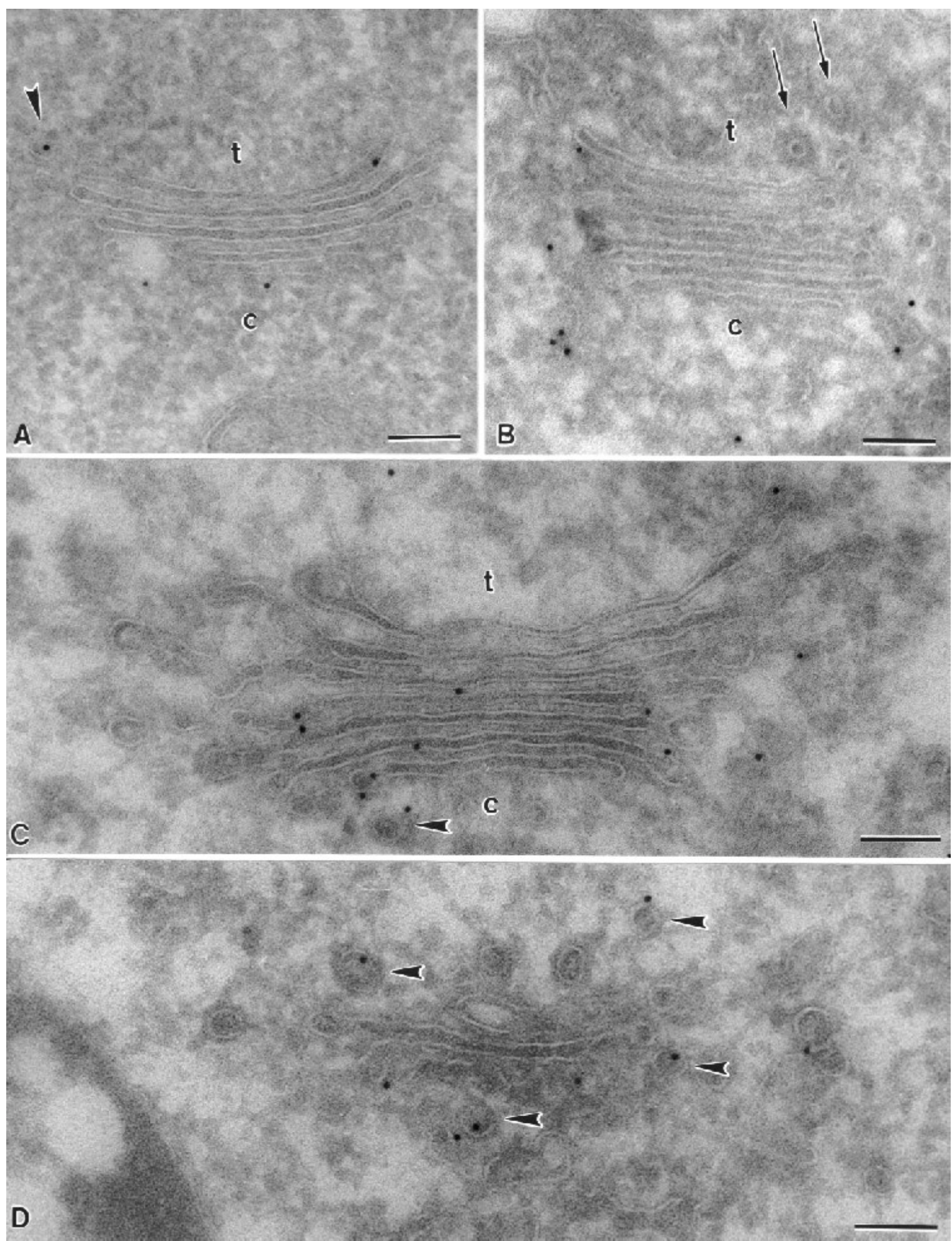

Abb. 3.17: Immunogoldmarkierung auf Kryoschnitten von Maiswurzelspitzen mit den Antikörpern gegen Zm- $\delta$-COP (A), Zm- $\varepsilon$-COP (B) und AtArf1p (C und D). Pfeilspitzen deuten auf markierte COPI Vesikel, Pfeile auf CCVs. c, $\mathrm{t}=$ cis- und trans-Bereich der Golgistapel. Strichlänge $100 \mathrm{~nm}$. 

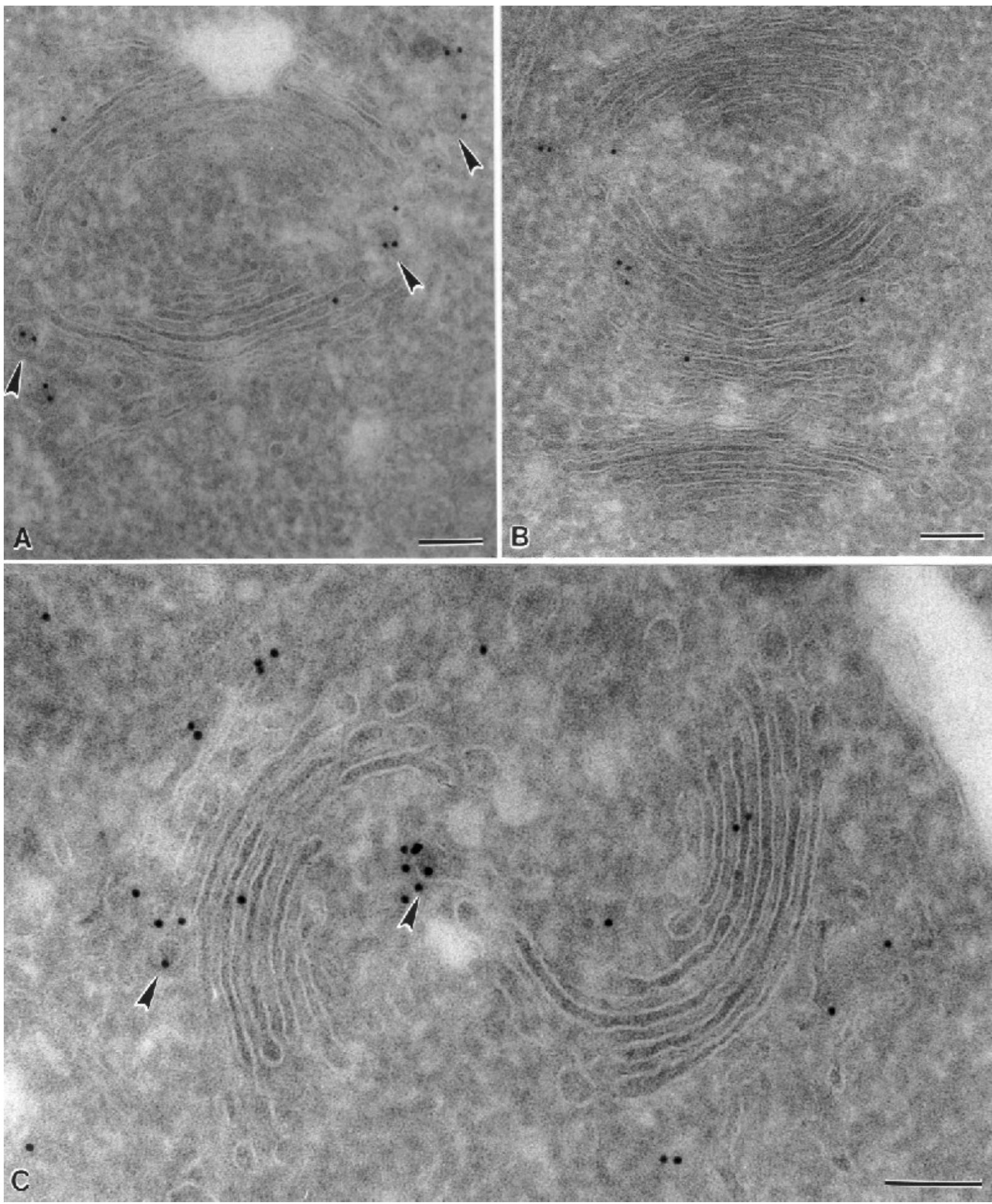

Abb. 3.18: Immunogoldmarkierung auf Kryoschnitten von Arabidopsiswurzelspitzen mit den Antikörpern gegen At $\gamma$-COP (A), Zm- $\delta$-COP (B) und Zm- $\varepsilon$-COP (C). Pfeilspitzen deuten auf markierte COPI Vesikel. c, $\mathrm{t}=$ cis- und trans-Bereich der Golgistapel. Strichlänge $100 \mathrm{~nm}$. 
Tabelle 3.1: Verteilung der Immunogoldmarkierung mit Antikörpern gegen pflanzliche COPI Vesikel an Dictyosomen auf Kryoschnitten von Arabidopsis- und Maiswurzelspitzen. Für jeden Antikörper wurde die Verteilung der Goldpartikel an 25 Dictyosomen ausgezählt.

\begin{tabular}{|c|c|c|c|c|c|c|c|c|c|c|}
\hline \multirow[t]{2}{*}{ Pflanze } & \multirow[t]{2}{*}{ Antikörper } & \multicolumn{5}{|c|}{ Goldpartikel an Zisternen } & \multicolumn{2}{|c|}{$\begin{array}{c}\text { Goldpartikel an } \\
\text { Vesikeln }\end{array}$} & \multirow{2}{*}{$\begin{array}{c}\text { Gesamtzahl } \\
\text { der } \\
\text { Goldpartikel }\end{array}$} & \multirow{2}{*}{$\begin{array}{c}\text { Goldpartikel } \\
\text { pro } \\
\text { Dictyosom }\end{array}$} \\
\hline & & $\begin{array}{l}\text { cis- } \\
\text { most }\end{array}$ & cis & median & trans & TGN & $\begin{array}{l}\text { cis- } \\
\text { Hälfte }\end{array}$ & $\begin{array}{l}\text { trans- } \\
\text { Hälfte }\end{array}$ & & \\
\hline \multirow{3}{*}{ Mais } & At $\gamma$-COP & $\begin{array}{c}9 \\
(5,2 \%)\end{array}$ & $\begin{array}{c}8 \\
(4,7 \%)\end{array}$ & $\begin{array}{c}6 \\
(3,5 \%)\end{array}$ & $\begin{array}{c}6 \\
(3,5 \%)\end{array}$ & $\begin{array}{c}3 \\
(1,8 \%)\end{array}$ & $\begin{array}{c}78 \\
(45,3 \%)\end{array}$ & $\begin{array}{c}62 \\
(36,0 \%)\end{array}$ & 172 & 6,88 \\
\hline & $\mathrm{Zm} \delta-\mathrm{COP}$ & $\begin{array}{c}8 \\
(8,2 \%)\end{array}$ & $\begin{array}{c}5 \\
(5,1 \%)\end{array}$ & $\begin{array}{c}4 \\
(4,1 \%)\end{array}$ & $\begin{array}{c}4 \\
(4,1 \%)\end{array}$ & $\begin{array}{c}2 \\
(2,0 \%)\end{array}$ & $\begin{array}{c}42 \\
(42,8 \%)\end{array}$ & $\begin{array}{c}33 \\
(33,7 \%)\end{array}$ & 98 & 3,92 \\
\hline & $\mathrm{Zm \varepsilon}-\mathrm{COP}$ & $\begin{array}{c}9 \\
(6,0 \%)\end{array}$ & $\begin{array}{c}4 \\
(2,7 \%)\end{array}$ & $\begin{array}{c}4 \\
(2,7 \%)\end{array}$ & $\begin{array}{c}3 \\
(2,0 \%)\end{array}$ & $\begin{array}{c}3 \\
(2,0 \%)\end{array}$ & $\begin{array}{c}68 \\
(45,3 \%)\end{array}$ & $\begin{array}{c}59 \\
(33,3 \%)\end{array}$ & 150 & 6,00 \\
\hline \multirow{3}{*}{$\begin{array}{l}\text { Arabi- } \\
\text { dopsis }\end{array}$} & At $\gamma-\mathrm{COP}$ & $\begin{array}{c}6 \\
(3,3 \%)\end{array}$ & $\begin{array}{c}3 \\
(2,2 \%)\end{array}$ & $\begin{array}{c}1 \\
(0,6 \%)\end{array}$ & $\begin{array}{c}2 \\
(1,1 \%)\end{array}$ & $\begin{array}{c}1 \\
(0,6 \%)\end{array}$ & $\begin{array}{c}95 \\
(52,8 \%)\end{array}$ & $\begin{array}{c}71 \\
(39,4 \%)\end{array}$ & 180 & 7,20 \\
\hline & $\mathrm{Zm} \delta-\mathrm{COP}$ & $\begin{array}{c}5 \\
(6,3 \%)\end{array}$ & $\begin{array}{c}3 \\
(3,8 \%)\end{array}$ & $\begin{array}{c}1 \\
(1,2 \%)\end{array}$ & $\begin{array}{c}1 \\
(1,2 \%)\end{array}$ & $\begin{array}{c}0 \\
(0,0 \%)\end{array}$ & $\begin{array}{c}44 \\
(55,0 \%)\end{array}$ & $\begin{array}{c}26 \\
(32,5 \%)\end{array}$ & 80 & 3,20 \\
\hline & $\mathrm{Zm \varepsilon}-\mathrm{COP}$ & $\begin{array}{c}10 \\
(5,8 \%)\end{array}$ & $\begin{array}{c}5 \\
(2,9 \%)\end{array}$ & $\begin{array}{c}3 \\
(1,8 \%)\end{array}$ & $\begin{array}{c}3 \\
(1,8 \%)\end{array}$ & $\begin{array}{c}1 \\
(0,6 \%)\end{array}$ & $\begin{array}{c}95 \\
(55,6 \%)\end{array}$ & $\begin{array}{c}54 \\
(31,5 \%)\end{array}$ & 171 & 6,84 \\
\hline
\end{tabular}

\subsection{Lokalisierung von AtSec21p in Zellen von Erbsenkotyledonen}

In Kotyledonenzellen von Erbsen gibt es neben lytischen Vakuolen Proteinspeichervakuolen (PSV), in denen Speicherproteine wie Legumin und Vicilin gelagert werden (Hoh et al., 1995; Robinson et al., 1995; Müntz, 1998). Am Transport der Speicherproteine vom GApp zur PSV sind elektronendichte Vesikel mit einem Durchmesser von ca. 130-150 nm, jedoch keine CCVs, beteiligt (Hohl et al., 1996; Robinson et al., 1997; Robinson und Hinz, 1999). Diese Vesikel, die auch in Samen von anderen Pflanzen nachgewiesen wurden (zur Nieden et al., 1984; Levanony et al., 1992; Hara-Nishimura et al., 1993, 1995; Herman, 1994), werden wegen ihres elektronendichten Inhalts als "Dense Vesicles" (DVs) bezeichnet (Hohl et al., 1996). DVs sind gleichmäßig am cis-, median- und trans-Bereich des GApp sowie am TGN verteilt und oft ist ihre Verbindung mit Zisternen zu erkennen (Hohl et al., 1996). Sie scheinen an cis-Zisternen gebildet, aber erst im trans-Bereich freigesetzt $\mathrm{zu}$ werden. Speicherproteine werden hauptsächlich im cis-Bereich in die DVs sortiert (Hillmer et al., 2001). Bei elektronenmikroskopischen Untersuchungen wurde festgestellt, dass CCVs im trans-Bereich des GApp direkt von DVs abknospen können (Hohl et al., 1996; Robinson et al., 1997, 1998). Größere elektronendurchlässige glatte Vesikel, die am Transport von Zellwandpolymeren zum Extrazellulärraum beteiligt sind, wurden auch im trans-Bereich des GApp nachgewiesen 
(Staehelin et al., 1991; Zhang und Staehelin, 1992). Bislang wurde die Existenz der COPI Vesikel in Erbsenkotyledonen nicht nachgewiesen und auch ihre mögliche Beziehung zu DVs war nicht bekannt. Daher sollte gezeigt werden, ob es sich bei DVs um einen anderen Vesikeltyp als COPI Vesikel handelt. Für dieses Zweck wurden Erbsenkotyledonen mit der TokuyasuTechnik aufgearbeitet (siehe Kap. 2.9.2) und mit dem Antikörper gegen At $\gamma$-COP markiert. Da Erbsenkotyledonen aus extrem großen und stark vakuolisierten Zellen bestehen und zudem stärkehaltige Plastiden besitzen, war der Strukturerhalt der Zellen in Gefrierschnitten nicht optimal. Trotzdem waren Zellorganellen wie ER und GApp gut erkennbar. Wie Abb. 3.19 zeigt, konnten mit dem Antikörper gegen At $\gamma$-COP kleine $60 \mathrm{~nm}$ große Vesikel an Dictyosomen markiert werden. DVs, die eindeutig in den Kryoschnitten zu erkennen waren, zeigten dagegen keine Markierung. Auf Kryoschnitten konnten auch von DVs abknospende CCVs im transBereich der Dictyosomen gesehen werden (Abb. 3.19). So konnte gezeigt werden, dass COPI Vesikel einen grundlegend anderen Vesikeltyp als DVs darstellen. Daraus folgt, dass am GApp der Erbsenkotyledonen mindestens vier verschiedene Vesikeltypen (COPI Vesikel, DVs, CCVs und glatte Vesikel) vorkommen.

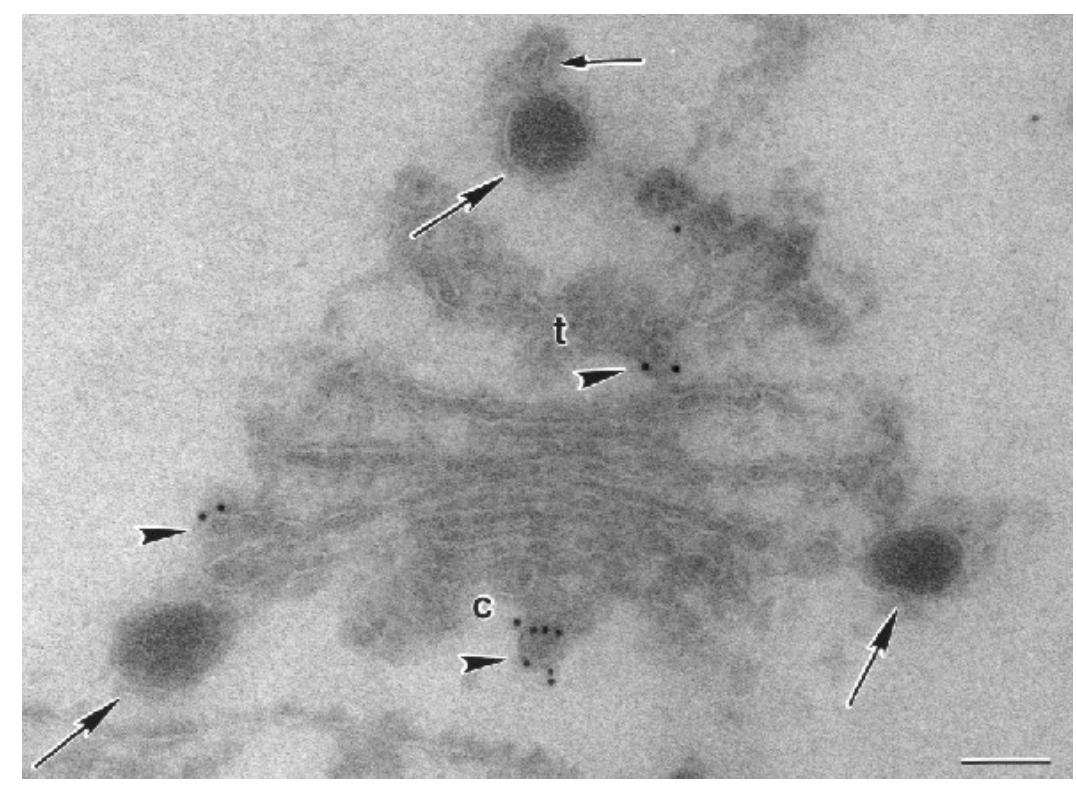

Abb. 3.19: Immunogoldmarkierung des GApp von Erbsenkotyledonen mit dem Antikörper gegen At $\gamma$-COP. Im trans-Bereich des Dictyosoms ist ein abknospender CCV an einem DV zu sehen. Pfeilspitzen deuten auf markierte COPI Vesikel, kleine Pfeile auf CCV und große Pfeile auf DVs. $\mathrm{c}, \mathrm{t}=$ cis- und trans-Bereich der Golgistapel. Strichlänge $100 \mathrm{~nm}$. 


\subsection{Elektronenmikroskopischer Nachweis für den Rücktransport von Proteinen aus dem $c$ is-Bereich des GApp}

COPI Vesikel sind in Hefe und Säugetierzellen am Rücktransport von ER-Proteinen, wie z. B. Calreticulin (siehe Kap. 1.1), aus dem GApp beteiligt (Pelham, 1988; siehe auch Kap. 1.2). In Pflanzenzellen wurde ebenfalls ein Rücktransport von Proteinen aus dem GApp postuliert (Crofts et al., 1999; Gomord et al. 1999; Pagny et al., 1999). Nach der Identifizierung und Charakterisierung der Hüllproteine der COPI Vesikel und deren Lokalisierung am cis-Bereich des GApp in Pflanzenzellen wurde versucht, die Funktion dieser Vesikel durch Identifizierung ihrer putativen Frachtmoleküle zu untersuchen. Dafür wurde zunächst auf den Kryoschnitten der Maiswurzelspitzen eine Markierung mit dem Antikörper gegen Calreticulin durchgeführt. Dieser Antikörper markierte Kernhüllen und ER-Membranen sehr spezifisch und stark (Abb. 3.20). Im Vergleich dazu konnten keine Goldpartikel an Dictyosomen oder an kleinen Vesikeln gesehen werden. Das bedeutet, dass dieses molekulare Chaperon in Pflanzenzellen entweder nicht vom ER zum GApp transportiert wird, oder die Konzentration der transportierten Moleküle sehr gering und somit nicht nachweisbar ist. Aus diesem Grund wurden in einem weiteren Versuch die Wurzelspitzen von transformierten Tabakpflanzen untersucht. Diese Pflanzen synthetisieren $\alpha$ Amylase mit einer am Carboxyterminus angefügten HDEL-Sequenz (Phillipson et al., 2001). Nicht transformierte und mit $\alpha$-Amylase (ohne HDEL-Sequenz) transformierte Tabakpflanzen dienten dabei als Kontrolle. Die transformierten Pflanzen wurden parallel zur vorliegenden Arbeit zur in vitro Induktion der COPI und COPII Vesikel und zur Untersuchung des Frachttransports und der Funktion der HDEL-Sequenz an einem Sekretprotein verwendet (Phillipson et al., 2001). Mit der Messung der $\alpha$-Amylase-Aktivität im Anzuchtmedium (siehe Kap. (2.6) wurde festgestellt, dass dieses Protein von beiden transformierten Pflanzen ins Medium sekretiert wird. Daher war die Funktion der HDEL-Sequenz dieses sekretorischen Proteins beim möglichen Rücktransport der $\alpha$-Amylase-HDEL aus dem GApp nicht klar. Wurzelspitzen der Tabakpflanzen wurden genauso wie Wurzelspitzen von Arabidopsis (siehe Kap. 3.5) mit der Tokuyasu-Technik aufgearbeitet (siehe Kap. 2.9.2) und einer Markierung mit einem Antikörper gegen $\alpha$-Amylase unterzogen. Bei beiden transformierten Pflanzen konnte eine dichte $\alpha$-Amylase Markierung im ER (inklusive Kernhülle), im GApp und in der Zellwand festgestellt werden (siehe Abb. 3.21 und 3.22). Die Spezifität des Antikörpers wurde an Wildtyppflanzen überprüft. Diese zeigten keine Markierung der jeweiligen Kompartimente (siehe Abb. 3.21 C). Bei der Markierung der Dictyosomen fiel ein wichtiger Unterschied zwischen beiden transformierten Pflanzen auf. Während bei den mit $\alpha$-Amylase transformierten Pflanzen alle Zisternen markiert waren, war die Markierung im GApp der mit $\alpha$-Amylase-HDEL transformierten Pflanzen oft nur 
in den cis-Zisternen zu finden (siehe Abb.3.22A). Die statistische Auswertung der Immunogoldmarkierung anhand von jeweils 20 Dictyosomen ergab bei den mit der $\alpha$-Amylase transformierten Pflanzen eine gleichmäßige Verteilung der Goldpartikel in allen Zisternen des GApp (Tabelle 3.2). Die mit der $\alpha$-Amylase-HDEL transformierten Pflanzen zeigten jedoch eine intensive Markierung des cis-Bereiches des GApp (Tabelle 3.2). In mit der $\alpha$-Amylase-HDEL transformierten Pflanzenzellen waren $72,1 \%$ der Goldpartikel in der cis-most-Zisterne und $16,1 \%$ in der cis-Zisterne zu finden. Die weiteren Zisternen wiesen lediglich rund $10 \%$ der Markierung auf. Die Markierung der Zellwand und die Tatsache, dass außer cis-Zisternen auch andere Zisternen leicht markiert wurden, war ein Hinweis darauf, dass die $\alpha$-Amylase-HDEL wie $\alpha$-Amylase ohne HDEL-Sequenz von den transformierten Tabakpflanzen sekretiert wird. Dieses Enzym konnte deshalb im Anzuchtmedium der beiden Pflanzen nachgewiesen werden. Die statistischen Daten zeigten aber eine größere Konzentration der $\alpha$-Amylase-HDEL im cisBereich des GApp. Da die $\alpha$-Amylase ohne HDEL-Sequenz gleichmäßig in allen Zisternen des GApp verteilt war, kann die hohe Konzentration der $\alpha$-Amylase-HDEL auf die HDEL-Sequenz zurückgeführt werden. Diese Sequenz, die in Hefe sowie in Pflanzenzellen als Retentionssignal für viele ER-Proteine fungiert (Pelham, 1988; Denecke et al., 1992), führt mit großer Wahrscheinlichkeit zum Rücktransport der HDEL- $\alpha$-Amylasemoleküle in COPI Vesikeln zum ER und verhindert in Tabakzellen den Weitertransport eines großen Anteils der $\alpha$ Amylasemoleküle zum trans-Bereich des GApp. Diese Sequenz kann aber die Sekretion der $\alpha$ Amylase in transformierten Tabakpflanzen nicht vollständig verhindern.

Tabelle 3.2: Quantifizierung der Immunogoldmarkierung mit dem Antikörper gegen $\alpha$-Amylase auf Kryoschnitten von Wurzelspitzen der mit $\alpha$-Amylase und $\alpha$-Amylase-HDEL transformierten Tabakpflanzen.

\begin{tabular}{|c|c|c|c|c|c|c|c|c|}
\hline \multirow{2}{*}{$\begin{array}{c}\text { Transformierte } \\
\text { Pflanzen }\end{array}$} & $\begin{array}{c}\text { Zahl der } \\
\text { Dictyosomen }\end{array}$ & \multicolumn{4}{|c|}{ Goldpartikel in Zisternen } & $\begin{array}{c}\text { Gesamtzahl } \\
\text { der } \\
\text { Goldpartikel }\end{array}$ & $\begin{array}{c}\text { Goldpartikel } \\
\text { pro } \\
\text { Dictyosom }\end{array}$ \\
\cline { 2 - 9 } & cis-most & cis & median & trans & TGN & & \\
\hline$\alpha$-Amylase & 20 & $\begin{array}{c}19 \\
(22,1 \%)\end{array}$ & $\begin{array}{c}17 \\
(19,8 \%)\end{array}$ & $\begin{array}{c}16 \\
(18,6 \%)\end{array}$ & $\begin{array}{c}16 \\
(18,6 \%)\end{array}$ & $\begin{array}{c}18 \\
(20,9 \%)\end{array}$ & 86 & 4,3 \\
\hline $\begin{array}{c}\alpha \text {-Amylase- } \\
\text { HDEL }\end{array}$ & 20 & $\begin{array}{c}48 \\
(72,1 \%)\end{array}$ & $\begin{array}{c}11 \\
(16,1 \%)\end{array}$ & $\begin{array}{c}3 \\
(4,4 \%)\end{array}$ & $\begin{array}{c}2 \\
(2,9 \%)\end{array}$ & $\begin{array}{c}3 \\
(4,4 \%)\end{array}$ & 68 & 3,4 \\
\hline
\end{tabular}



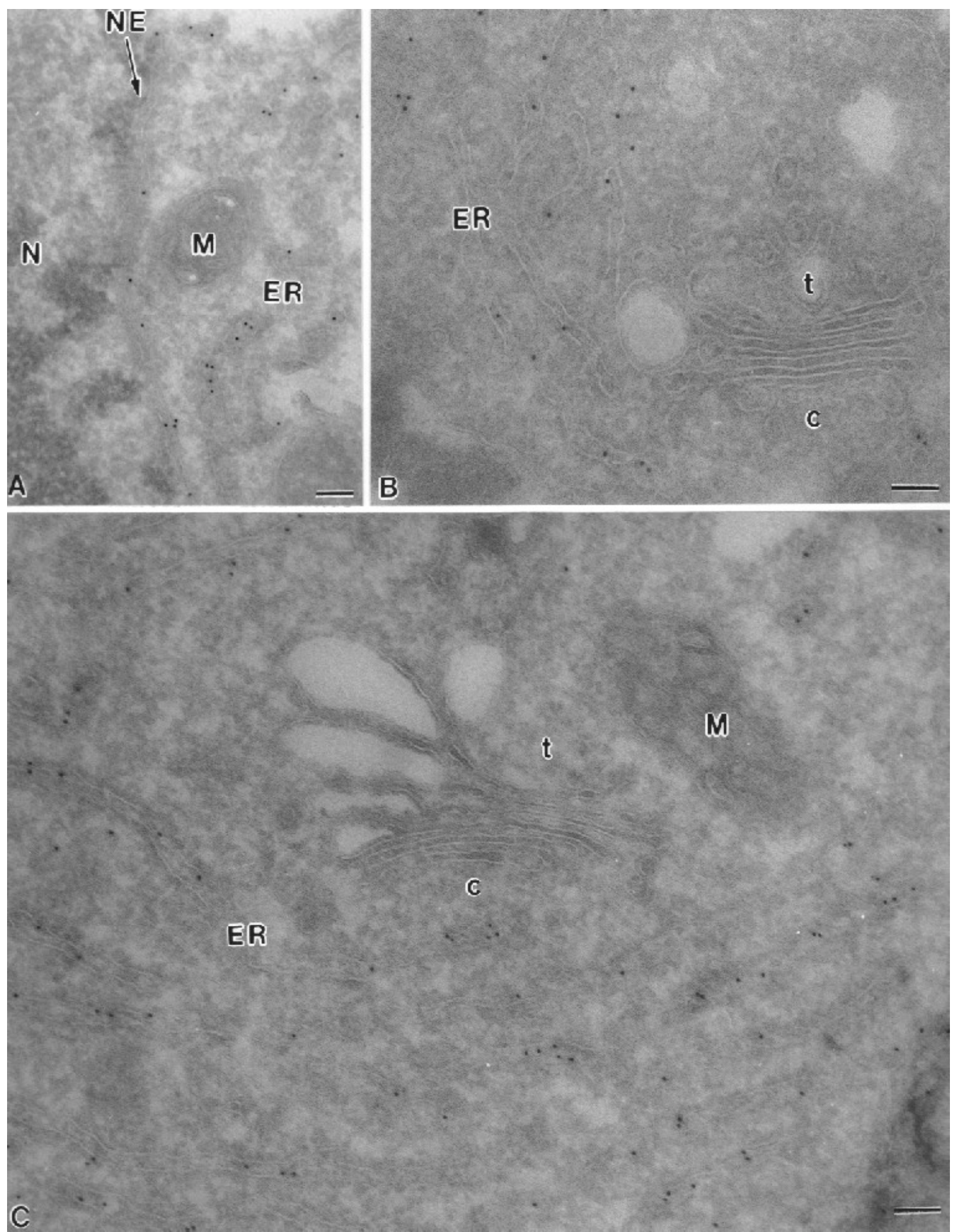

Abb. 3.20: Immunogoldmarkierung auf Kryoschnitten von Maiswurzelspitzen mit dem Antikörper gegen Calreticulin. Das ER und die Kernhülle (A-C) sind im Gegensatz zu den Dictyosomen (B und C) markiert. $\mathrm{M}=$ Mitochondrion; $\mathrm{N}=$ Zellkern; NE = Kernhülle; $\mathrm{c}, \mathrm{t}=$ cisund trans-Bereich der Golgistapel. Strichlänge $100 \mathrm{~nm}$. 


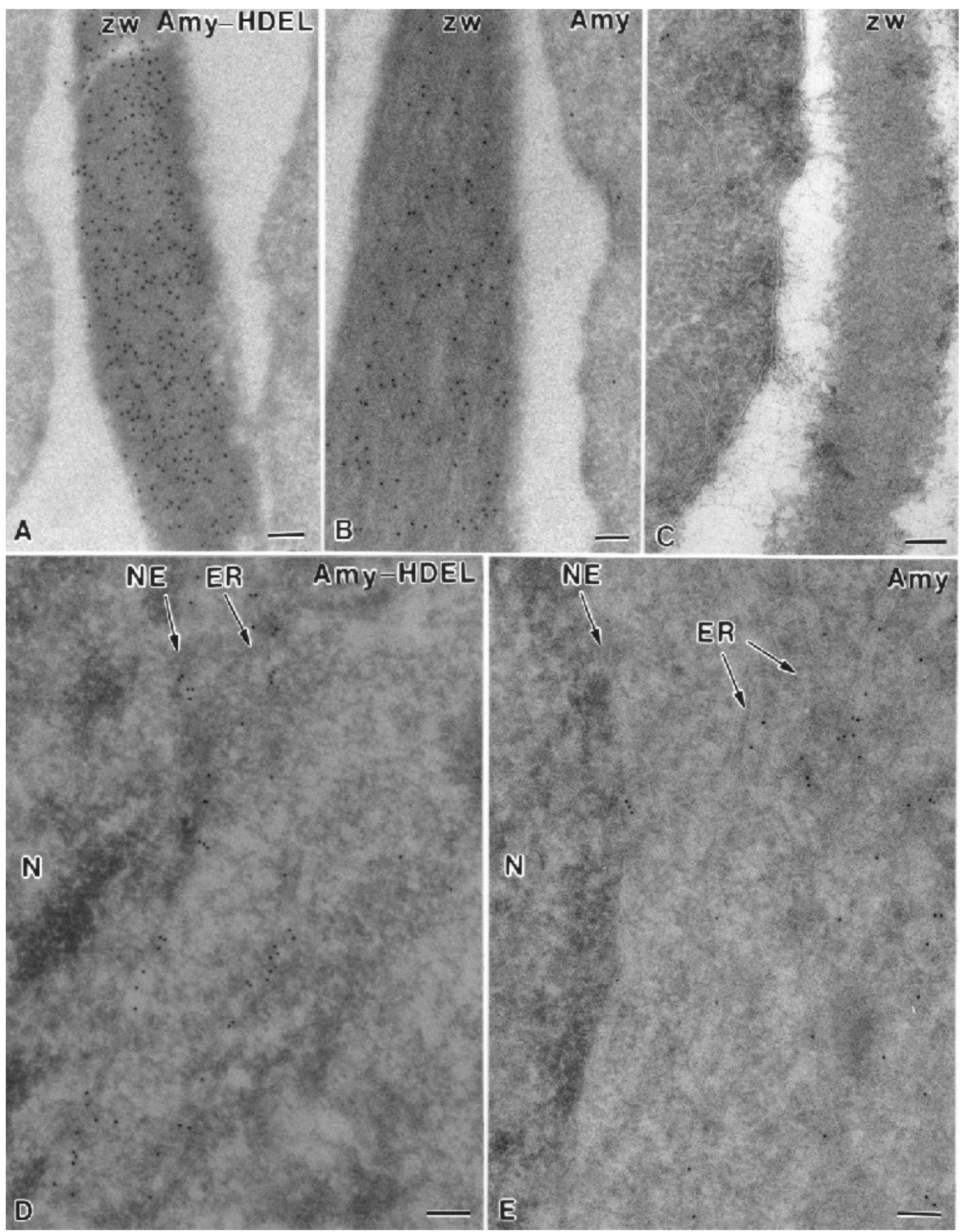

Abb. 3.21: Immunogoldmarkierung auf Kryoschnitten von Tabakwurzelspitzen mit dem Antikörper gegen $\alpha$-Amylase. Die Zellwand (A und B) sowie das ER und die Kernhülle (D und E) der transformierten Pflanzen sind markiert. Dagegen wurden diese Kompartimente in nicht transformierten Pflanzen (Wildtyp), die als Kontrolle dienten, nicht markiert (C). ZW = Zellwand, N = Zellkern; NE = Kernhülle, Strichlänge $100 \mathrm{~nm}$. 

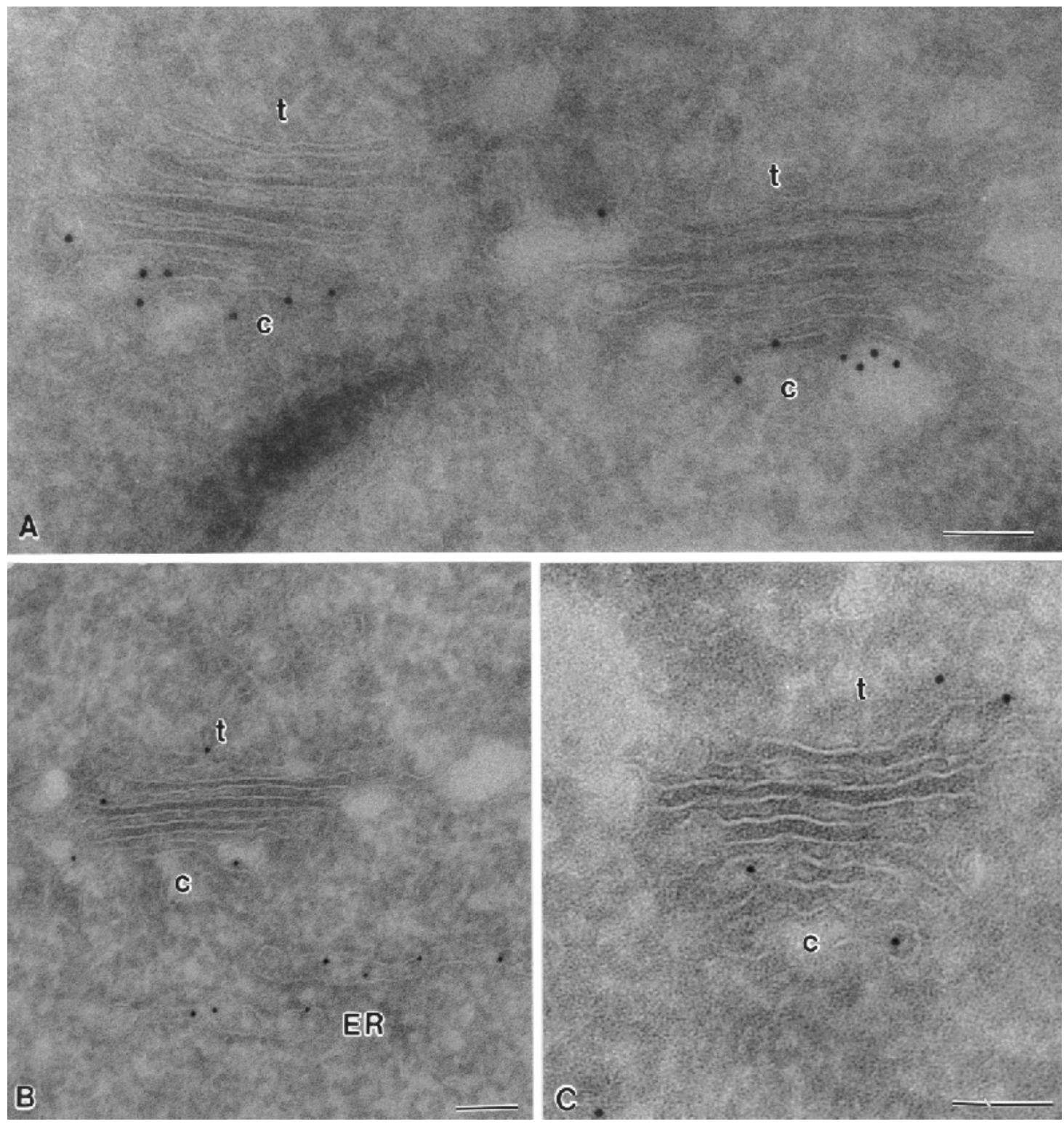

Abb. 3.22: Immunogoldmarkierung des GApp auf Kryoschnitten der transformierten Tabakwurzelspitzen mit dem Antikörper gegen $\alpha$-Amylase. A) Bei den mit $\alpha$-Amylase-HDEL transformierten Pflanzen wurden Dictyosomen überwiegend im cis-Bereich markiert. B, C) Die Markierung der mit $\alpha$-Amylase transformierten Pflanzen ist auf allen Zisternen der Dictyosomen gleichmässig verteilt. c, $\mathrm{t}=$ cis- und trans-Bereich der Golgistapel, Strichlänge $100 \mathrm{~nm}$. 


\section{Diskussion}

Der Proteintransport zwischen verschiedenen Organellen der eukaryotischen Zellen ist mit der Sortierung von Proteinen in verschiedene Vesikel verbunden, die meist eine Proteinhülle besitzen. Clathrin ist das erste Hüllprotein von "coated" Vesikeln, das in verschiedenen Organismen als Hüllprotein von CCVs identifiziert und charakterisiert wurde (Pearse und Robinson, 1990). In den letzten fünfzehn Jahren wurden weitere Transportvesikel nachgewiesen, die als COPI und COPII Vesikel bezeichnet werden (Schekman und Orci, 1996). Seit der Entdeckung der COPI (Orci et al., 1986) und COPII Vesikel (Barlowe et al., 1994) haben viele Arbeitsgruppen versucht, ihre strukturellen Bestandteile bzw. ihre Frachtmoleküle in Hefe und Säugetieren zu identifizieren und zu charakterisieren. Hingegen blieb ihre Existenz und Funktion in Pflanzenzellen bis zu Beginn der vorliegenden Arbeit ungewiss. Da in Arabidopsis thaliana Nukleotidsequenzen gefunden wurden (Newman et al., 1994), die denen ähnlich sind, die in Hefe und Säugetieren die Hüllproteine der COP Vesikel kodieren, nahm man an, dass der Proteintransport zwischen ER und GApp und innerhalb des GApp in Pflanzenzellen nach einem analogen Prinzip wie in Hefe und Säugetierzellen verläuft. Mit Antikörpern, die gegen Hüllproteine von COP Vesikeln von Hefe gerichtet waren, konnten keine spezifischen Kreuzreaktionen mit pflanzlichen Cytosolfraktionen beobachtet werden. Daher waren spezifische Antikörper gegen ihre Bestandteile notwendig, um die Bedeutung pflanzlicher COP Vesikel für den Proteintransport $\mathrm{zu}$ untersuchen. In der vorliegenden Arbeit wurden mit molekularbiologischen Methoden Antikörper gegen $\gamma$-COP und Sec23p aus Arabidopsis hergestellt, mit deren Hilfe die Eigenschaften und Funktionen der COP Vesikel in Pflanzenzellen untersucht werden konnten. Mit den Antikörpern gegen At $\gamma$-COP und AtSec23p wurden in Pflanzenzellen sowohl lösliche als auch membrangebundene Proteine nachgewiesen (siehe Kap. 3.2), die ähnliche Molekularmassen wie ihre Homologe in Hefe (Hosobuchi et al., 1992; Barlowe et al., 1994) und Säugetieren (Stenbeck et al., 1992; Paccaud et al., 1996) aufweisen.

\subsection{Eigenschaften der löslichen At $\gamma$-COP und AtSec23p}

Mit den gegen Aty-COP und AtSec23p gerichteten Antikörpern und mit den Antikörpern gegen

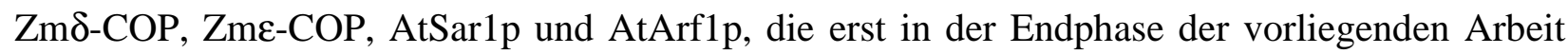
verfügbar waren, wurde die Verteilung putativer Bestandteile der Proteinhülle der pflanzlichen COP Vesikel zwischen dem Cytosol und den Membranen der verschiedenen Pflanzen untersucht. At $\gamma$-COP, AtSec23p, Zm $\delta$-COP und Zme-COP konnten im Cytosol stärker als in der Membranfraktion nachgewiesen werden. Das spricht dafür, dass diese Proteine in Pflanzenzellen überwiegend in löslicher und weniger in membrangebundener Form vorliegen. Das traf nicht auf 
die GTPasen AtSarlp und AtArf1p zu. Während AtArf1p gleichmässig auf Cytosol und Membranen verteilt zu sein scheint, liegt AtSar1p vor allem an Membranen gebunden vor. Diese Verteilung von Sar1p wurde auch von anderen Arbeitsgruppen in verschiedenen Geweben von Arabidopsis (siehe Abb. 2 in Bar-Peled und Raikhel, 1997) und ebenfalls in Hefezellen (Barlowe et al., 1993) nachgewiesen. In Hefe ist mehr als $80 \%$ von Sar1p membrangebunden. Durch eine Überexpression von AtSar1p in Arabidopsis wurde nur die Konzentration des cytosolischen und nicht die des membrangebundenen Proteins erhöht (Bar-Peled und Raikhel, 1997). Das bedeutet, dass in vivo die maximale Membranbindung von AtSar1p in Pflanzenzellen erreicht wird.

Für die proteinbiochemische Charakterisierung von Aty-COP und AtSec23p wurden die Zellen von Blumenkohlinfloreszenzen verwendet. Diese Zellen sind meristematisch und zeichnen sich daher durch einen aktiven Proteintransport aus. Außerdem sind Blumenkohl und Arabidopsis systematisch verwand und gehören zu der Familie der Cruciferen. Da die gewonnenen COPAntikörper gegen Proteine aus Arabidopsis gerichtet waren, konnte diese Verwandtschaft vorteilhaft sein. Ein anderer Vorteil von Blumenkohlinfloreszenzen liegt in ihren geringen endogenen proteolytischen Aktivität. Untersuchungen zur Isolation von Hüllproteinen der CCVs hatten gezeigt, dass die Hüllproteine dieser Vesikel in verschiedenen Pflanzen während der Aufarbeitung unterschiedlich stark proteolytisch abgebaut werden (Drucker, 1995). Da die proteolytische Aktivität in der Cytosolfraktion aus Blumenkohlinfloreszenzen im Vergleich zu anderen pflanzlichen Geweben wie Erbsenkotyledonen und Zucchinihypokotylen niedriger ist (Drucker, 1995), ist die Isolierung und Charakterisierung der Proteine aus diesem Gewebe im Hinblick auf den proteolytischen Abbau weniger problematisch. Die Ammoniumsulfatfraktionierung des Blumenkohlcytosols wurde dazu benutzt, die Konzentration von At $\gamma$-COP und AtSec23p zu erhöhen und einen Teil der endogenen Proteasen abzutrennen (siehe Kap. 3.3.1). Aus dem Blumenkohlcytosol konnte AtSec23p mit 30\% Ammoniumsulfat und At $\gamma$-COP mit $40 \%$ Ammoniumsulfat gefällt werden. Ähnliche Ammoniumsulfatkonzentrationen wurden für die Aufreinigung des Coatomers aus Säugetierzellen (Waters et al., 1991, 1992; Sheff et al., 1996) und des Sec23-Komplexs aus Hefe (Barlowe et al., 1994) beschrieben. Mit $40 \%$ Ammoniumsulfat konnte AtSar1p vollständig und AtArf1p zu einem großen Teil präzipitiert werden. Da die endogenen Proteasen meist erst mit mehr als $50 \%$ Ammoniumsulfat gefällt wurden, konnte mit einer 40\%-igen Ammoniumsulfatfällung eine Cytosolfraktion gewonnen werden, in der die Hüllproteine von pflanzlichen COP Vesikeln angereichert und die proteolytische Aktivität reduziert war. Diese letzte Eigenschaft dieser Cytosolfraktion ist besonders wichtig für die in vitro Untersuchungen der Struktur und Funktion von COP Vesikeln. Für die in vitro Induktion von COP Vesikeln werden ER- und/oder GApp-Fraktionen mit einer Cytosolfraktion bei $37^{\circ} \mathrm{C}$ (Malhotra et al., 1989) für Säugetierzellen oder bei $20-37^{\circ} \mathrm{C}$ für Pflanzenzellen (Pimpl, 1997; Pimpl et al., 2000) inkubiert. Bei diesen Temperaturen ist die Aktivität der endogenen Proteasen erheblich höher als bei $4{ }^{\circ} \mathrm{C}$ (Demmer, 1991; Drucker, 1995). 
Für die in vitro Induktion der pflanzlichen COP Vesikel wurde bisher eine mit 80 \% (Pimpl, 1997) oder $65 \%$ (Pimpl et al., 2000) Ammoniumsulfat gewonnene Cytosolfraktion von Blumenkohl verwendet. Das Ergebnis der Ammoniumsulfatfraktionierung spricht jedoch dafür, dass es viel günstiger ist, diese Versuche mit einer mit $40 \%$ Ammoniumsulfat gewonnenen Cytosolfraktion durchzuführen. Damit kann möglicherweise die Ausbeute der induzierten COP Vesikel erhöht und der Abbau der Hüllproteine reduziert werden.

Außer Arf1p und Sar1p kommen andere Hüllproteine von COP Vesikeln in Proteinkomplexen vor (siehe Kap. 1.3.2 und Kap. 1.3.3). Alle diese Komplexe wurden aus Säugetieren und Hefe isoliert und aufgereinigt (Waters et al., 1991, 1992). Mit den aufgereinigten Proteinkomplexen konnten dann in vitro COPI oder COPII Vesikel induziert werden. Das ermöglichte die Untersuchung der Struktur dieser Vesikel sowie der Funktion ihrer strukturellen Bestandteile von Vesikeln bei der Sortierung der Frachtmoleküle. Neben der Charakterisierung der löslichen At $\gamma$ COP und AtSec23p wurde in der vorliegenden Arbeit versucht, diese Proteine mit biochemischen Methoden aufzutrennen. Damit wäre auch eine gezielte in vitro Induktion von pflanzlichen COPI bzw. COPII Vesikeln ermöglicht. Durch Gelfiltrationschromatographie der mit $40 \%$ Ammoniumsulfat gewonnenen Cytosolfraktion wurden At $\gamma$-COP und AtSec23p als Bestandteile der verschiedenen Proteinkomplexe nachgewiesen (siehe Kap. 3.3.2). Das Elutionsprofil von At $\gamma$ COP stimmte mit dem des Coatomers der Säugetierzellen überein (Waters et al., 1991, 1992). Damit wurde gezeigt, dass Aty-COP Bestandteil eines ca. 700 kDa großen Proteinkomplexes ist, der als pflanzliches Coatomer betrachtet werden kann. Im Vergleich dazu konnte AtSec23p, wie bei Hefe und Säugetieren (Hicke et al., 1992; Paccaud et al., 1996) in einem kleineren Proteinkomplex mit einer Molekularmasse von ca. $400 \mathrm{kDa}$ nachgewiesen werden. Durch Gelfiltrationschromatographie gelang auch eine partielle Auftrennung der beiden Proteinkomplexen.

Das Ergebnis, dass At $\gamma$-COP und AtSec23p Bestandteile verschiedener Proteinkomplexe sind, wurde durch Behandlung des Cytosols mit Neomycin bestätigt. Es ist bekannt, dass das Coatomer von Hefe und Säugetierzellen an die benachbarten, freien Aminogruppen des di-LysinMotivs der membrangebundenen Frachtmoleküle von COPI Vesikeln bindet (Cosson und Letourneur, 1994; Tisdale et al., 1997). Aufgrund dieser Bindung des Coatomers wurden Experimente mit aminoglykosierten Antibiotika durchgeführt, die in ihrer Struktur eine oder mehrere benachbarte Aminogruppen besitzen. Mit diesen Versuchen wurde die Zahl der Bindungsstellen des Coatomers an das di-Lysin-Motiv der Membranproteine untersucht. Dabei konnte das Coatomer durch Behandlung mit Neomycin, Neamin und Sisomycin, die jeweils mindestens zwei benachbarte, freie Aminogruppen besitzen, aus dem Cytosol gefällt werden (Hudson und Draper, 1997). Das war aber nicht der Fall für Antibiotika wie Geneticin und Gentamycin $\mathrm{C}_{1}$, die nur eine benachbarte Aminogruppe haben. Diese Antibiotika konnten zwar 
an das Coatomer binden und seine Bindung an das di-Lysin-Motiv und Neomycin verhindern, sie konnten aber keine großen Aggregate mit dem Coatomer bilden. Damit wurde nachgewiesen, dass beide Klassen von Antibiotika gemeinsame Bindungsstellen am Coatomer haben. Hudson und Draper (1997) sind davon ausgegangen, dass das Coatomer mehr als zwei Bindungsstellen für benachbarte Aminogruppen, wie die des di-Lysin-Motivs, besitzt. An diesen Stellen tritt es in Wechselwirkung mit verschiedenen Neomycinmolekülen, die drei benachbarte Aminogruppen besitzen und ebenfalls an mehr als einen Coatomerkomplex binden können. Das führt zur Vernetzung des Coatomers und zur Bildung großer Aggregate. Diese Aggregate können dann durch Zentrifugation vom Cytosol entfernt werden. In der vorliegenden Arbeit wurde At $\gamma$-COP als Bestandteil des pflanzlichen Coatomers im Gegensatz zum AtSec23-Komplex nach Behandlung mit Neomycin durch Zentrifugation präzipitiert (siehe Kap. 3.3.3). Diese Komplexe lassen sich also aufgrund ihrer verschiedenen Bindungseigenschaften an Neomycin schnell voneinander trennen.

Diese Cytosolfraktion kann nach einer solchen Behandlung für die spezifische in vitro Induktion der COPII Vesikel verwendet werden, weil das Coatomer für die Bildung der COPI Vesikel nicht mehr im Cytosol vorhanden ist. Da das Coatomer bei der Fällung mit Neomycin sehr stabile Aggregate bildet, die nicht mehr gelöst werden können, können die gefällten Coatomermoleküle nicht für die in vitro Versuche verwendet werden. Für diese sind die gewonnen Fraktionen der Gelfiltrationschromatographie geeignet. Dafür würde nur noch Arf1p benötigt (Spang et al., 1998), das auch durch Gelfiltration partiell aufgereinigt werden kann.

\subsection{Physiologische Bedeutung der Membranbindung von At $\gamma$-COP und}

\section{AtSec23p}

Für die membrangebundenen Proteinkomplexe wurden drei Funktionen beschrieben: 1) Sie erzeugen mit ihrer Polymerisation die mechanische Kraft zur Wölbung der Donormembran, die zur Bildung der Vesikel führt (Harter, 1999; Wieland und Harter, 1999). 2) Sie verhindern die Fusion von Donor- und Zielmembranen und ermöglichen einen regulierten Vesikeltransport (Orci et al. 1991; Scheel et al., 1997; Lowe und Kreis, 1998). 3) Sie sind an der Sortierung der Frachtmoleküle beteiligt (Schekman und Orci, 1996; Barlowe, 1998; Harter, 1999). Nachdem gezeigt worden war, dass At $\gamma$-COP und AtSec23p nicht nur in gelöster Form, sondern auch membrangebunden in Pflanzenzellen vorkommen, konnten neue Erkenntnisse bezüglich ihrer möglichen Funktionen gewonnen werden. 


\subsubsection{At $\gamma$-COP und AtSec23p an Membranen des GApp, des ER und der COP Vesikel}

Es wird im Allgemeinen angenommen, dass COPII Vesikel am anterograden Proteintransport vom ER zum GApp beteiligt sind (Barlowe et al., 1994; Barlowe 1995, 1998). Die Donormembran dieser Vesikel ist also die ER-Membran. Im Gegensatz dazu werden COPI Vesikel an Membranen des GApp und ERGIC gebildet (Malhotra et al., 1989; Griffiths et al., 1995; Schekman und Orci 1996). Sie nehmen anscheinend hauptsächlich am retrograden Proteintransport aus dem GApp und ERGIC zum ER teil (Lowe und Kreis, 1998). Es wurde auch nachgewiesen, dass sie eine zusätzliche Funktion beim sowohl anterograden als auch retrograden Proteintransport innerhalb des GApp haben (Orci et al., 1997; siehe auch Kap. 1.3.2). In Säugetierzellen wurden Coatomer-reiche Bereiche im ER nachgewiesen (Orci et al., 1994). Die Funktion von diesen einzelnen ER-Bereichen konnte aber nicht aufgeklärt werden. Wie Clathrin und AP-Komplexe kommen die Bestandteile der Proteinhüllen von COP Vesikeln sowohl im Cytosol als auch an Membranen gebunden vor. Die gelöst vorliegenden Hüllkomplexe binden en bloc an die Donormembranen und leiten damit die Bildung der Vesikel ein (Barlowe et al., 1994; Hara-Kuge et al., 1994). Nach der Freisetzung der Vesikel dissoziiert die Proteinhülle von der Membran. Um die Funktion von pflanzlichen COP Vesikeln am sekretorischen Transportweg zu untersuchen, musste zuerst aufgeklärt werden, in welcher Form sie an ihre Donormembranen binden und ob diese Bindung eine physiologische Bedeutung hat. Es wurde gezeigt, dass At $\gamma-$ COP und AtSec23p wie ihre homologen Proteine in Hefe und Säugetierzellen (Malhotra et al., 1989; Waters et al., 1991; Barlowe et al., 1994; Schekman und Orci, 1996) peripher auf der cytosolischen Seite der Membranen gebunden sind (siehe Kap. 3.4.1). Es war dabei notwendig zu zeigen, dass die Membranbindung spezifisch ist und nicht durch eine unspezifische Wechselwirkung zwischen Membranen und Hüllproteinen hervorgerufen wird. Manche lösliche Proteine binden während der biochemischen Aufarbeitungen durch unspezifische Wechselwirkungen an Membranen. Das ist z. B. für das Coatomer von Hefe (Spang et al., 1998), im Gegensatz zum Coatomer von Säugetierzellen (Bremser et al., 1999), nachgewiesen. In wieweit die Membranassoziation von Aty-COP und AtSec23p spezifisch ist, konnte mit Hilfe der Veränderung eines physiologischen Faktors, der Temperatur, untersucht werden.

Der Proteintransport im sekretorischen Transportweg wird bei Kälte verlangsamt oder sogar verhindert (Saraste und Kuismanen, 1984; Tartakoff, 1986, 1987; Rexach und Schekman, 1991). Das könnte zum Teil daran liegen, dass die Bildung der Transportvesikel unter diesen Bedingungen gehemmt wird (Mollenhauer et al., 1976; Griffiths et al., 1995). Der Einfluss von Kälte auf die Verteilung von AtSar1p zwischen der Cytosol- und der Membranfraktion einer Arabidopsis-Suspensionskultur wurde bereits nachgewiesen (Bar-Peled und Raikhel, 1997). Während die Menge des integralen Membranproteins AtSec12p nach einer 5-tägigen Kälte- 
Behandlung der Zellen wie bei der von der Kontrolle war, konnte AtSar1p, das sowohl als lösliches als auch als peripheres Membranprotein vorkommt, nach dieser Zeit nur im Cytosol nachgewiesen werden. Um den Effekt von niedrigen Temperaturen auf die Membranbindung von At $\gamma$-COP und AtSec23p zu prüfen, wurden Blumenkohlpflanzen über Nacht in einem Kühlraum gehalten. Im Vergleich $\mathrm{zu}$ den Kontrollpflanzen konnte in kältebehandelten Pflanzen eine Verschiebung der beiden Proteine aus der Membranfraktion zur Cytosolfraktion gezeigt werden (siehe Abb. 3.11). Dieses Ergebnis stimmt mit dem von Bar-Peled und Raikhel (1997) beobachteten Kälte-Effekt auf die Membranbindung von Sar1p überein. Damit wurde gezeigt, dass die Bindung von Hüllproteinen der pflanzlichen COP Vesikel von physiologischen Faktoren, wie z. B. Kälte beeinflusst wird. Diese Bindung ist daher spezifisch und spielt möglicherweise bei der Vesikelbildung eine Rolle.

Die verringerte Membranbindung der untersuchten Proteine kann verschiedene Gründe haben. Bei niedrigen Temperaturen wird in Pflanzen das Expressionsmuster von Genen geändert (Guy et al., 1985; Thomashow, 1999). Eine große Klasse von Proteinen, die dabei de novo gebildet werden, sind Hitzeschockproteine (HSPs), die als molekulare Chaperone viele Proteine vor kälteinduzierter Denaturierung schützen (Neven et. al., 1992; Sabehat et al., 1996; Guy et al., 1998). HSPs kommen in Pflanzenzellen zum großen Teil im Cytosol und ER vor (Lee et al., 1995; Ukaji et al., 1999). Da Frachtmoleküle eine entscheidende Rolle bei der Bildung der COP Vesikel spielen (Aridor et al., 1999), kann eine erhöhte Konzentration solcher Proteine im ER und eine niedrigere Konzentration von Frachtmolekülen als Folge der Änderung der Genexpression den Proteinexport aus dem ER und dadurch die Bildung von COPII und COPI Vesikeln reduzieren. Die Synthese von energiereichen Molekülen wie ATP und GTP, die für den Proteintransport notwendig sind, wird bei niedrigen Temperaturen beeinträchtigt und führt so zusätzlich zu einer Verlangsamung und Hemmung des Proteintransports (Tartakoff, 1987; Gravotta, 1990). Ein Mangel an energiereichen Nukleosidtriphosphaten führt zur Einschränkung der Funktion der GTPasen, wie Arf1p und Sar1p, und verringert dadurch die Membranbindung von Hüllproteinen der "coated" Vesikel. Der direkte Effekt von Kälte auf den Proteintransport durch Verlangsamen vieler enzymatischer Aktivitäten oder Wechselwirkungen zwischen Proteinen kann ebenfalls nicht ausgeschlossen werden.

Falls At $\gamma$-COP und AtSec23p eine physiologische Funktion am sekretorischen Transportweg haben, wäre zu erwarten, dass diese Proteine mit Membranen der Kompartimente, die am Proteintransport beteiligt sind, assoziiert sind. Um diese Membranen zu identifizieren, wurden mikrosomale Membranen aus Blumenkohl durch Gelfiltration über eine Sephacryl S-1000 Säule aufgearbeitet (siehe Kap.3.4.4). Dabei gelang es nicht, verschiedene mikrosomale Membranen voneinander $\mathrm{zu}$ trennen. Mit der gleichen Methode konnten dagegen PM und Endosomen von Hefe von anderen Membranen getrennt werden (Huang und Chiang, 1997). Der Grund dafür könnte in einer unterschiedlichen strukturellen Organisation der Hefe- und Pflanzenzellen liegen. 
Während die relative Auftrennung der mikrosomalen Membranen aus Blumenkohl aufgrund ihrer Größe mit diesem Verfahren nicht möglich war, konnten sie anhand der verschiedenen Schwebedichten durch Dichtegradientenzentrifugation aufgetrennt werden (siehe Kap. 3.4.5). Unter Plus-Magnesium-Bedingungen waren Golgi- und ER-Membranen im mittleren Bereich der Gradienten mit einem Peak bei einer Saccharosedichte von 35-37 \% (w/w) und PM und CCVs in höheren Dichten (bei 41-43 \% (w/w) Saccharose) verteilt. Dies stimmt mit den Dichten, die für ER- und Golgi-Membranen (Robinson und Hinz, 2000) sowie für CCVs (Depta et al., 1991; Demmer et al., 1993) und PM (Sandelius und Morré, 1990) von verschiedenen Pflanzenzellen ermittelt wurden, überein. Sowohl At $\gamma$-COP als auch AtSec23p zeigten zwei Peaks im Gradienten. Ein Peak war im ER-/GApp-Bereich der zweite Peak in höheren Saccharosedichten (bei 43-46\% (w/w) Saccharose). In diesen hohen Dichten der Gradienten kommen normalerweise Transportvesikel, wegen ihres kompakten Inhalts, vor. In vitro induzierte COP Vesikel aus Säugetierzellen (Malhotra et al., 1989) und Pflanzenzellen (Pimpl et al., 2000) wurden nach der Dichtegradientenzentrifugation in hohen Saccharosedichten nachgewiesen. Daher kann man daraus schließen, dass At $\gamma$-COP und AtSec23p mit ER und/oder GApp sowie mit kleinen Vesikeln assoziiert sind, die aufgrund ihrer unterschiedlichen Dichte aufgetrennt werden konnten. In einem weiteren Schritt sollte die Verteilung von At $\gamma$-COP und AtSec23p zwischen ER/GApp-Membranen untersucht werden. Dafür wurden mikrosomale Membranen durch Dichtegradientenzentrifugation unter Minus-Magnesium-Bedingungen aufgetrennt. Unter diesen Bedingungen dissoziieren Ribosomen von ER-Membranen ab, wodurch die Dichte des ER verringert wird. Das ER wird im Gradienten in einem Bereich niedrigerer Saccharosedichte angesammelt. Somit kann die Auftrennung von GApp und ER im Gradienten erreicht werden. Dabei konnte zwar eine klassische Verschiebung des ER in die niedrigeren Saccharosedichten beobachtet werden, aber aufgrund einer schwächeren Verschiebung des GApp war die Auftrennung diese Organellen nicht optimal (siehe Abb. 3.15). Die Ursache für die leichte Verschiebung des GApp, die bei anderen Pflanzenzellen ebenfalls beobachtet worden ist (Robinson und Hinz, 2000), ist bislang nicht bekannt. Da für die Wechselwirkung zwischen Proteinen, wie den Proteinen der Golgimatrix oder der interzisternalen Filamenten und Membranproteinen der Zisternen Ionen wie $\mathrm{Mg}^{++}$notwendig sind (Cluett und Brown, 1992; Staehelin und Moore, 1995), kann diese Verschiebung möglicherweise mit der Beeinträchtigung dieser Wechselwirkung durch EDTA und einer daraus resultierten Auflösung der Golgimatrix und/oder Auftrennung der einzelnen Zisternen zu tun haben. Der Proteinpeak von PM und CCVs sowie die Peaks von At $\gamma$-COP und AtSec23p in höheren Saccharosedichten, bei denen es sich um die COP Vesikel handelte, waren dagegen unbeeinflusst von der Abwesenheit von $\mathrm{Mg}^{2+}$. Im Vergleich dazu konnte eine Verschiebung des mittleren Proteinpeaks von At $\gamma$-COP und AtSec23p beobachtet werden. Hiernach schienen AtSec23p mit ER und At $\gamma$-COP mit Golgi- 
und/oder ER-Membranen von Pflanzenzellen assoziiert zu sein. Da die Auftrennung von GApp und ER unter diesen Bedingungen nicht optimal war, konnte nicht genau gezeigt werden, ob At $\gamma$ COP mit dem GApp und/oder ER assoziiert ist. Aus diesem Grund wurden die Hüllproteine der pflanzlichen COPI Vesikel mit Hilfe der Tokuyasu-Technik (siehe Kap. 2.9.2) innerhalb der Wurzelspitzenzellen von Mais und Arabidopsis immunlokalisiert (siehe Kap. 3.5). Die Immunogoldmarkierung mit COPI-Antikörpern war sowohl an den Dictyosomen als auch an den kleinen COPI Vesikeln mit einer erkennbaren Proteinhülle zu sehen. Die Markierung des ER war hingegen nicht signifikant. Die pflanzlichen COPI Vesikel weisen zwar in Kryoschnitten eine ähnliche Struktur wie COPI Vesikel aus Säugetieren auf (siehe Abb.3.16-3.18), sind aber mit einem Durchmesser von 50-60 nm etwa $20 \mathrm{~nm}$ kleiner als COPI Vesikel in Säugetieren (Orci et al., 1993, 1997). Die Markierungen an Dictyosomen waren meist an den seitlichen Enden der Zisternen zu beobachten (siehe Abb.3.16-3.18), wo auch in Säugetierzellen COPI Vesikel gebildet werden (Schekman und Orci, 1996; Orci et al., 1997). Mit diesen Daten konnten die Unklarheiten der Saccharosedichtegradienten aufgeklärt werden. So wurde gezeigt, dass es sich bei dem At $\gamma$-COP im mittleren Bereich der Saccharosegradienten um Dictyosomen und im höheren Bereich um COPI Vesikel handelt. Nach diesem Ergebnis binden sowohl At $\gamma$-COP als auch AtSec23p an die Donormembranen der COP Vesikel und nehmen an der Bildung der COP Vesikel teil.

\subsubsection{Verhinderung der Fusion von ER und GApp durch das Coatomer}

In Säugetierzellen fusionieren nach einer BFA-Behandlung Membranen verschiedener Kompartimente miteinander und verlieren ihre typische Struktur (Lippincott-Schwartz et al., 1989, 1991; Wood et al., 1991). Der BFA-Effekt ist besonders bei Golgistapeln auffällig, die mit ER-Membranen fusionieren und aufgelöst werden (Misumi et al., 1986; Lippincott-Schwartz et al., 1989; Ulmer und Palade, 1991). Auf molekularer Ebene verhindert BFA durch seine Wechselwirkung mit GEFs den Austausch von GDP gegen GTP an Arf-Proteinen (Peyroche et al., 1999; Mansour et al., 1999; siehe auch Kap. 1.3.2). Die Anlagerung des Coatomers (sowie der AP-Komplexe) an die Membran des GApp wird dadurch gestört (Donaldson et al., 1992; Helms und Rothman, 1992; Robinson und Kreis, 1992). Eine schnelle Dissoziation des Coatomers von Membranen wurde auch bei der BFA-Behandlung in Säugetierzellen beobachtet (Donaldson et al., 1992; Scheel et al., 1997). Sowohl die Verhinderung der Bindung des Coatomers als auch dessen schnelle Dissoziation von Membranen des GApp führt zur verfrühten Freilegung von v-SNAREs (Orci et al. 1991; Donaldson et al., 1992; Scheel et al., 1997). Diese sind normalerweise in den Golgi-Membranen von dem Coatomer bedeckt (Schekman und Orci, 1996). Das Coatomer blockiert damit eine unregulierte Wechselwirkung zwischen v-SNAREs der Golgi-Membran und t-SNAREs der ER-Membran und eine daraus resultierende Fusion von ER 
und GApp (Orci et al., 1991; Söllner et al., 1993; Rothman und Warren, 1994; Lowe und Kreis, 1998). Erst nach dem Abknospen der COPI Vesikel werden die v-SNAREs in der Membran der Vesikel durch die Dissoziation der Proteinhülle frei zugänglich und können spezifisch mit t-SNAREs der ER-Mmembran in Wechselwirkung treten (Söllner et al., 1993; Weber et al., 1998). Durch die verfrühte v-SNAREs-Freilegung in "coated buds" der Golgi-Membran in Folge der BFA-Behandlung kommt es zur Fusion von ER und GApp (Donaldson et al., 1992; Scheel et al., 1997).

In Pflanzenzellen bewirkt BFA die Vesikulierung des GApp. Diese kann sowohl bei cis- und median- (Dairman et al., 1995) als auch bei trans-Zisternen beginnen (Satiat-Jeunemaitre und Hawes, 1992; Robinson et al., 1997), wobei letzteres häufiger der Fall zu sein scheint (SatiatJeunemaitre et al., 1996). Die Vesikel werden vermutlich von der Golgi-Matrix zusammengehalten und verbleiben dadurch im Bereich der ehemaligen Dictyosomen (Staehelin und Moore, 1995). Eine Akkumulation von Glykoproteinen und komplexen Polysacchariden am trans-Bereich des GApp - vermutlich als Folge einer Beeinträchtigung der Transportvorgänge wurde ebenfalls als BFA-Wirkung in Pflanzenzellen beschrieben (Satiat-Jeunemaitre und Hawes, 1993). BFA kann ebenfalls zur Schwellung (Driouich et al., 1993; Schindler et al., 1994) oder intrazellulären Umverteilung (Henderson et al., 1994) des ER in Pflanzenzellen führen. Kürzlich wurde in Epidermis- und Mesophyll-Zellen von Tabakpflanzen, die mit der GFPSialyltransferase als fluoreszierendem GApp-Protein transformiert worden waren, gezeigt, dass nach einer BFA-Behandlung fluoreszierende Golgistapel verschwinden und statt dessen das polygonale Netzwerk des ER fluoresziert (Boevink et al., 1998). Bei diesen Experimenten konnte jedoch keine Veränderung der Morphologie des ER festgestellt werden. Dagegen wurde als BFAWirkung in Wurzelzellen von Mais neben einer Kolokalisierung von ER- und GApp-Proteinen eine Reorganization des ER beschrieben (Satiat-Jeunemaitre et al., 1996). Daher scheint der Effekt von BFA in verschiedenen Pflanzengeweben unterschiedlich zu sein. Das kann einerseits mit der unterschiedlichen Schnelligkeit der BFA-Aufnahme in die Zellen verschiedener Gewebe und andererseits mit unterschiedlichen Konzentration von BFA, die für Untersuchungen eingesetzt wurden, zu tun haben.

In der vorliegenden Arbeit wurde der Einfluss von BFA auf membrangebundenes AtArf1p und At $\gamma$-COP aus kultivierten BY2-Tabakzellen biochemisch untersucht. Zahlreiche Vorteile dieser Zellen wurden unter Kap. 3.4.3 beschrieben. Es konnte gezeigt werden, dass eine niedrige Konzentration von BFA im Anzuchtmedium $(10 \mu \mathrm{g} / \mathrm{ml})$ in sehr kurzer Zeit das Ablösen des Coatomers von dem membrangebundenen AtArf1p verursacht (siehe Abb. 3.12). Die Lokalisierungen von Aty-COP und AtArf1p in BY2-Tabak-Suspensionskultur mit Hilfe des "Confocal Laser Scanning" Mikroskops zeigten, dass At $\gamma$-COP durch die BFA-Behandlung schnell von den Golgi-Membranen dissoziiert (Ritzenthaler, persönliche Mitteilung). Dies bestätigte das Ergebnis des oben beschriebenen Experimentes. Damit konnte die BFA-induzierte 
Dissoziation des Coatomers von Membranen in Säugetierzellen (Donaldson et al., 1992; Scheel et al., 1997) auch für Pflanzenzellen nachgewiesen werden. Außerdem wurde hier gezeigt, dass diese BFA-Wirkung in Pflanzenzellen nicht durch die Dissoziation von Arf1p von Membranen verursacht wird. Da die Freisetzung von AtArf1p von Membranen erst längere Zeit nach der BFA-Behandlung geschieht, wirkt BFA vermutlich auf die Bindung des Coatomers an AtArf1p. Dies steht im Gegenteil zu den Ergebnissen von Donaldson et al. (1992), die in Säugetierzellen durch BFA-Behandlung eine parallele, schnelle Freisetzung des Coatomers und die Dissoziation von Arf1p von Membranen ins Cytosol beobachtet haben. Die Ursache für diesen Unterschied ist nicht klar. Denkbar wäre, dass es zwei unterschiedliche Populationen von Arf1p mit verschiedenen Bindungseigenschaften an Membranen gibt. Tatsächlich wurden in Säugetierzellen schon zwei Populationen von Arf1p identifiziert (Helms et al., 1993). Während eine Klasse sehr leicht von Membranen abgetrennt werden konnte, zeigte die andere Klasse eine starke Bindung an Membranen.

Die Dissoziation des Coatomers von Arf1p kann auch in Pflanzenzellen zur Freilegung von v-SNAREs des GApp führen und dadurch die Fusion von GApp und ER ermöglichen. Dies konnte trotz vieler Arbeiten (z. B. Rutten und Knuimann, 1993; Satiat-Jeunemaitre et al., 1996) bislang nicht eindeutig auf der ultrastrukturellen Ebene belegt werden. Pflanzenzellen eignen sich zur Beobachtung der ER/GApp-Fusion sogar besser als Säugetierzellen, da bei ersteren die Golgistapel im ganzen Cytoplasma verteilt sind und eine eindeutige Struktur zeigen. Für solche Untersuchungen sind Tabak-Suspensionskulturen wegen der schnellen und gleichmäßigen Aufnahme von BFA sehr geeignet.

\subsubsection{COPI Vesikel im cis-Bereich des GApp von Pflanzenzellen}

Zahlreiche morphologische und biochemische Eigenschaften unterscheiden den GApp in Pflanzenzellen von dem in Säugetieren und Hefe (Andreeva et al., 1998; Dupree und Sherrier, 1998; Robinson und Hinz, 1999). Viele dieser Unterschiede können darauf zurückgeführt werden, dass die Hauptfunktion des GApp tierischer Zellen in der Sortierung und Prozessierung von Proteinen besteht, während diese Vorgänge in den Dictyosomen der meisten Pflanzenzellen im Vergleich zu der Synthese komplexer Polysaccharide mengenmäßig in den Hintergrund rücken. Darüber hinaus sind im Gegensatz zu den Säugetierzellen, deren GApp einen festen Platz in der Nähe vom Zellkern hat, die Golgistapel von Pflanzenzellen im ganzen Cytoplasma verteilt und entlang eines verzweigten Actin-Netzwerkes, das am ER anliegt, in Bewegung (Boevink et al., 1998; Nebenführ et al., 1999). Trotz dieser Unterschiede wird im Grunde angenommen, dass der Proteintransport zwischen ER und GApp und innerhalb des GApp in Pflanzen und Säugetieren nach dem gleichen Prinzip funktioniert. 
Durch eine statistische Auswertung der Immunogoldmarkierung mit den COPI-Antikörpern konnte in der vorliegenden Arbeit festgestellt werden, dass COPI Vesikel in den Pflanzenzellen überwiegend im cis-Bereich des GApp vorkommen (siehe Tabelle 3.1). Eine vergleichbare Lokalisierung von COPI Vesikeln wurde auch in Säugetierzellen beobachtet (Oprins et al., 1993; Orci et al., 1997). In diesen Zellen wurde jedoch das Coatomer auch am ERGIC (siehe Kap. 1.2) lokalisiert (Oprins et al., 1993; Griffiths et al., 1995; Martinez-Menarguez et al., 1999). Ein Rücktransport der ER-Proteine aus dem ERGIC unter Beteiligung von COPI Vesikeln wird angenommen (Pelham, 1988; Lowe und Kreis, 1998). Morphologisch gesehen enthält dieses post-ER/pre-Golgi Kompartiment vesikuläre und tubuläre Fortsätze (Bannykh und Balch, 1997), die wahrscheinlich durch die Fusion von COPII Vesikeln zustande kommen (Aridor et al., 1995; Scales et al., 1997). Bisher wurde in Pflanzenzellen kein homologes Kompartiment zu ERGIC von Säugetierzellen nachgewiesen. Die cis-most-Zisterne des GApp in Pflanzenzellen weist wie ERGIC eine breite, diskontinuierliche Struktur auf (siehe Abb. 3.22 A und 3.22 C). Dies kann möglicherweise eine Folge der Fusion der COPII Vesikel mit dieser Zisterne sein und als strukturelle Homologie zum ERGIC betrachtet werden.

Einen Hinweis auf die besondere Funktion der cis-most-Zisterne und eine mögliche Funktion der COPI Vesikel ergab die Immunlokalisierung der $\alpha$-Amylase-HDEL und $\alpha$-Amylase in den transgenen Tabakpflanzen (siehe Kap. 3.7). Diese Pflanzen wurden für die Untersuchung der Funktion der carboxyterminalen HDEL-Sequenz bei dem Rücktransport der $\alpha$-Amylase-HDEL vom GApp zum ER hergestellt (Phillipson et al., 2001). Es ist bekannt, dass die H/KDELSequenz am carboxyterminalen Ende der sekretorischen Proteine die Sekretion dieser Proteine in allen eukaryotischen Zellen beeinträchtigt und ihre Konzentration im ER erheblich erhöht (Denecke et al., 1992; Wandelt et al., 1992; Gomord et al., 1997). Es konnte auch nachgewiesen werden, dass eine H/KDEL-Sequenz die Golgi-spezifische Modifikation der N-Glykan-Reste bestimmter Glykoproteine in Säugetierzellen nicht verhindert (Pelham, 1988; Dean und Pelham, 1990). Das bedeutet, dass in Hefe und Säugetierzellen Proteine, die aufgrund ihrer H/KDELSequenz ER-resident sind, nicht kontinuierlich im ER verbleiben, sondern das ERGIC durchlaufen und bis zum GApp gelangen, von wo aus sie zum ER zurücktransportiert werden. Der Rücktransport dieser Proteine geschieht überwiegend aus dem cis-Bereich des GApp (Connolly et al., 1994), aber im Prinzip kann er aus jeder Zisterne und sogar aus dem TGN erfolgen (Miesenböck und Rothman, 1995). Aufgrund der Entdeckung des H/KDEL-Signals und dessen putativen Rezeptors in Pflanzenzellen (siehe unten) wird ihnen auch hier eine Funktion beim Recycling bestimmter Proteine zwischen GApp und ER zugeschrieben (Gomord und Faye, 1996; Gomord et al., 1997, 1999; Pagny et al., 1999). Kürzlich wurde mit der strukturellen Analyse der N-Glykan-Reste der ER-Glykoproteine gezeigt, dass ein sehr effektiver Rücktransport aus dem cis- und median-Bereich des GApp von Pflanzenzellen stattfindet (Pagny et al., 2000). Dieser Rücktransport sorgt angeblich für die Rückhaltung der künstlich mit HDEL 
verknüpften Proteine, wie z. B. bei der Zellwandinvertase-HDEL, die normalerweise keine ERresidenten Proteine darstellen. $\alpha$-Amylase wird wie andere sekretorische Proteine im ER der transformierten Pflanzen gebildet und nach dem Transport durch den GApp sekretiert (Phillipson et al., 2001). In der vorliegenden Arbeit konnte eindeutig gezeigt werden, dass $\alpha$-Amylase ohne HDEL-Signal gleichmäßig in allen Zisternen des GApp der transformierten Pflanzen vorkommt, während $\alpha$-Amylase-HDEL überwiegend im cis-Bereich des GApp, wo COPI Vesikel hauptsächlich vorkommen, und besonders in der cis-most-Zisterne nachgewiesen wurde (siehe Abb. 3.22 und Tabelle 3.2). Die statistische Analyse ergab, dass nur etwa $10 \%$ der Immunogoldmarkierung im median- und trans-Bereich des GApp vorkommen. Daher kann man davon ausgehen, dass durch die HDEL-Sequenz hauptsächlich in der cis-Zisterne aber auch in anderen Zisternen der Rücktransport der $\alpha$-Amylase-HDEL veranlaßt wird. Diese Daten ergänzen die Resultate von Pagny und Mitarbeitern (2000), die einen Rücktransport der Invertase-HDEL aus allen Zisternen des pflanzlichen GApp nachgewiesen haben. Sie deuten zusätzlich auf die wichtige Funktion der cis-most-Zisterne des GApp in Pflanzenzellen bei der Sortierung und bei dem vermutlich durch COPI Vesikel vermittelten Rücktransport von Proteinen zum ER hin.

Es konnte auch gezeigt werden, dass die HDEL-Sequenz die Sekretion der $\alpha$-Amylase nicht vollständig verhindert (siehe Kap. 3.7). In Hefe wurde mit Hilfe von Mutanten, die einen Defekt beim Protein-Rücktransport vom GApp zum ER aufweisen, ein Rezeptor für die HDEL-Sequenz identifiziert, der Erd2p (von "ER retention defective 2") genannt wird (siehe Kap. 1.1) (Semenza et al., 1990). Zu diesem Rezeptor homologe Proteine wurden in Säugetieren (Lewis und Pelham, 1992; Hsu et al., 1992) und Pflanzen (Lee et al., 1993) entdeckt. Interessanterweise wurde dieses Protein in Säugetierzellen im cis-Bereich des GApp lokalisiert (Griffiths et al., 1994). Erd2p bindet im GApp an das H/KDEL-Signal löslicher ER-Proteine, die das ER verlassen, und sorgt für ihren Rücktransport in COPI Vesikeln zum ER (Wilson et al., 1993; Townsley et al., 1993; Orci et al., 1997). Dieser Rezeptor ist möglicherweise auch in den transgenen Tabakpflanzen für den Rücktransport der $\alpha$-Amylase-HDEL aus dem GApp zum ER zuständig. Die Sekretion der $\alpha$-Amylase-HDEL kann so erklärt werden, dass die hohe Syntheserate dieses Proteins zur Sättigung der Rezeptormoleküle führt. Dadurch können die $\alpha$-Amylase-HDEL-Moleküle, die das ER verlassen, nicht mehr vollständig vom GApp zum ER zurückgebracht werden und werden zum Teil sekretiert.

Für Untersuchungen des Proteinrücktransports aus dem GApp werden oft H/KDELFusionsproteine hergestellt, die normalerweise nicht ER-resident sind (Herman et al., 1990; Pueyo et al., 1995; Gomord et al., 1997; Pagny et al., 2000). Diese Proteine werden aufgrund von starken Promotoren, die ihren Genen vorgeschaltet sind, in hohen Konzentrationen in den transformierten Organismen synthetisiert. Die hohe Proteinkonzentration im ER führt 
möglicherweise durch Sättigung der ER-Retentions-Maschinerie zu einem nicht kontrollierbaren Export von Proteinen, welche dann zum großen Teil zum ER zurückgebracht werden. Auf Basis der Experimente mit transformierten Organismen können daher zwar Erkenntnisse über den Proteintransport im sekretorischen Weg gewonnen werden, jedoch ist nicht klar, ob diese die natürlichen Mechanismen widerspiegeln. Das gilt auch für die mit der $\alpha$-Amylase-HDEL oder der Invertase-HDEL transformierten Pflanzen.

Für die Retention der ER-Proteine scheint es außer dem Recycling andere Mechanismen zu geben. Das am Besten untersuchte Chaperon des ER, BiP, konnte in COPII Vesikeln nicht nachgewiesen werden (Barlowe et al., 1994; Kuehn et al., 1998). Wenn das HDEL-Motiv von BiP entfernt wird, wird BiP nur in sehr geringen Mengen sekretiert (Munro und Pelham, 1987; Crofts et al., 1999). Die Retention von Calreticulin ist im Vergleich damit mehr vom HDELSignal abhängig, da es ohne HDEL-Peptid stark sekretiert wird (Crofts et al., 1999). Calreticulin von Mais und Tabak besitzt zwei N-Glykan-Reste, die im GApp prozessiert werden Können (Pagny et al., 2000). Da nach der Behandlung mit BFA, die zur Mischung von ER- und GAppEnzymen führt (siehe Kap.4.2.2), die Struktur dieser N-Glykan-Resten anders prozessiert wird als in den Kontrollpflanzen, kann man davon ausgehen, dass dieses Protein in Pflanzenzellen entweder das ER nie verlässt oder nur in sehr kleinen, nicht detektierbaren Mengen den GApp erreicht (Pagny et al., 2000). Mit dem Antikörper gegen Calreticulin konnte in der vorliegenden Arbeit eine sehr starke Immunogoldmarkierung des ER auf Kryoschnitten von Maiswurzelspitzen festgestellt werden (siehe Abb. 3.20). Im Gegensatz dazu wurde dieses molekulare Chaperon im GApp nicht detektiert. Dieses Ergebnis bestätigt somit die biochemischen Befunde von Pagny et al. (2000) über die Retention von Calreticulin im ER der Pflanzenzellen.

Der Grund für die sehr effektive Retention von ER-Chaperonen wie BiP und Calreticulin ist noch nicht aufgeklärt. Sie kann aber mit der Protein-Protein-Wechselwirkung zwischen Chaperonen untereinander oder zwischen Chaperonen und anderen Proteinen zu tun haben. Die Bildung von stabilen Proteinkomplexen zwischen verschiedenen ER-Chaperonen, z. B. zwischen BiP und Calreticulin, wurde bereits nachgewiesen (Tatu und Helenius, 1997; Crofts et al., 1998). Daher kann nicht ausgeschlossen werden, dass bestimmte ER-Proteine durch die Bildung von großen Proteinkomplexen oder einem Protein-Netzwerk für eine gegenseitige Retention sorgen.

\subsection{COPI Vesikel in Erbsenkotyledonen}

Leguminosensamen eignen sich besonders gut zur Aufklärung des sekretorischen Proteintransportes bei Pflanzen, weil bei ihnen in einer relativ kurzen Zeit der Samenentwicklung große Mengen von Speicherproteinen synthetisiert und in spezialisierte Vakuolen transportiert werden (siehe Kap. 3.6). In Erbsensamen kommt es nach einer Phase intensiver Zellteilung in der zweiten Phase der Samenreifung zu einer deutlichen Zunahme von Größe und Trockengewicht. 
Diese Zunahme beruht neben der Bildung von Stärkekörnern vor allem auf der Speicherung großer Mengen der Speicherproteine Legumin und Vicilin in PSV der Parenchymzellen von Erbsenkotyledonen. Diese Proteine werden am ER als Proproteine synthetisiert (Müntz, 1989) und in den GApp transportiert (Chrispeels et al., 1982), in dem die weitere Sortierung sekretorischer Proteine in verschiedene Vesikel stattfindet (Robinson et al., 1998). Daneben ist der GApp in dieser Wachstumsphase an der Synthese großer Mengen von Zellwandmaterial sowie der Sortierung der Polysaccharide und Exoproteine zur Zelloberfläche beteiligt (Gardiner und Chrispeels, 1975; Ray et al., 1976; Moore und Staehelin, 1988; Staehelin und Moore, 1995). $\mathrm{Da}$ in dieser Phase der Samenentwicklung PSV und lytische Vakuole nebeneinander existieren (Hoh et al., 1995), erfolgt am GApp eine Sortierung $\mathrm{zu}$ mindestens drei verschiedenen Zielkompartimenten. Speicherproteine und vermutlich auch andere lösliche Proteine der PSV verlassen den GApp in DVs (Hohl et al., 1996). In diesen Vesikeln werden sie zur PSV oder einem möglichen Zwischenkompartiment, dem sogenannten "multivesicular body", transportiert (Robinson und Hinz, 1999). Der Transport anderer löslicher Proteine, wie z. B. sauren Hydrolasen, zur lytischen Vakuole wird dagegen von CCVs vermittelt. Ferner könnten größere glatte elektronendurchlässige Vesikel am Transport von Zellwandpolymeren zum Extrazellulärraum beteiligt sein.

Speicherproteine scheinen, nachdem sie den GApp erreicht haben, sehr schnell im cis-Bereich an die Peripherie der Zisternen verlagert $\mathrm{zu}$ werden, wo sie anfangen, sich in elektronendichten Aggregaten zusammenzulagern (Hinz et al., 1997; Robinson und Hinz, 1999; Hillmer et al., 2001). So werden im cis-Bereich des GApp DVs gebildet, die vermutlich mit den reifenden Zisternen bis zur Freisetzung im trans-Breich der Dictyosomen verbunden bleiben. Daher sind sie an allen Zisternen des GApp zu finden. Es scheint, dass DVs mit den Zisternen verbunden bleiben, gemeinsam mit ihnen zum trans-GApp gelangen und einer Reifung unterliegen (Robinson und Hinz, 1999; Hillmer et al., 2001). Während dieser Reifung wird die Sortierung der Speicherproteine in DVs, die hauptsächlich im cis-Bereich des GApp stattfindet, fortgesetzt. Deswegen sind die DVs des cis-Bereiches kleiner als die des trans-Bereiches und ihr Inhalt ist im Vergleich weniger kondensiert (Robinson et al., 1997). Zu Beginn der vorliegenden Arbeit war die Existenz von COPI Vesikeln am GApp der Parenchymzellen von Erbsenkotyledonen nicht nachgewiesen. Der Nachweis dieser Vesikel in diesen Zellen war aus verschiedenen Gründen wichtig. Erstens war unklar, ob DVs eine spezifische Art von COPI Vesikeln sind, die an der Sortierung und dem Transport der Speicherproteine teilnehmen. Zweitens stellte sich die Frage, wenn es sich bei den DVs um einen anderen Vesikeltyp handelt, ob sie die Rolle von COPI Vesikeln beim Intra-Golgi-Transport ersetzen. Drittens war es wichtig zu wissen, ob neben der sehr wahrscheinlichen zisternalen Reifung im GApp der Zellen von Erbsenkotyledonen ein Proteintransport durch COPI Vesikel stattfindet. Diese Fragen konnten nun mit dem gewonnenen Antikörper gegen At $\gamma$-COP beantwortet werden. Durch Immunogoldmarkierung wurden COPI 
Vesikel am GApp der Parenchymzellen von Erbsenkotyledonen als ein weiterer Vesikeltyp identifiziert (siehe Kap. 3.6). Im Gegensatz zu COPI Vesikeln, die mit dem Antikörper gegen At $\gamma$-COP eindeutig markiert worden waren, zeigten DVs keine Markierung. Wie in Abb. 3.19 zu sehen ist, unterscheiden sich immunogoldmarkierte COPI Vesikel durch ihren kleineren Durchmesser und ihre sichtbare Proteinhülle in Kryoschnitten von DVs. Die elektronenmikroskopischen Aufnahmen nach klassischen Aldehyd/Osmium Fixierungen, die keine Proteinhülle an Membranen von DVs sichtbar machen konnten (Hohl et al., 1996; Robinson et al., 1998), wurden mit diesen Daten bestätigt. Da COPI Vesikel an der Sortierung und an dem Transport von Proteinen im GApp und/oder zwischen GApp und ER teilnehmen, kann für den GApp der Parenchymzellen von Erbsenkotyledonen ein paralleler Proteintransport sowohl durch zisternale Reifung als auch durch COPI Vesikel angenommen werden. Dies stimmt mit dem Transportmodell, das für Säugetierzellen vorgeschlagen wird, überein (siehe Kap. 1.2). Mit weiteren Untersuchungen kann nun herausgefunden werden, welche Moleküle als Fracht in COPI Vesikeln von Erbsenkotyledonen transportiert werden.

\subsection{Ausblick}

In der vorliegenden Arbeit wurden durch die partielle Charakterisierung der Hüllproteine von pflanzlichen COP Vesikeln, ihre Lokalisation und den Nachweis ihrer Bedeutung am Proteintransport die Grundlagen für weitergehende Studien des sekretorischen Weges in Pflanzen geschaffen. Die neuesten Ergebnisse verschiedener Arbeitsgruppen zeigen zahlreiche Unterschiede zwischen pflanzlichen und tierischen Zellen bezogen auf die Retentions- und Exportmechanismen der Proteine im ER und GApp (Pagny et al., 1999, 2000; Hillmer et al., 2001; Phillipson et al., 2001). Darüber hinaus sind wahrscheinlich die Frachtmoleküle der COP Vesikel von Pflanzenzellen andere als die von Hefe und Säugetierzellen. Zunächst kann untersucht werden, welche Frachtmoleküle von COP Vesikeln innerhalb des GApp oder zwischen GApp und ER in Pflanzenzellen transportiert werden. Damit können neue Erkenntnisse über die Retentionsmechanismen von ER-Proteinen und ein eventuelles Recycling dieser Proteine durch COPI Vesikel in Pflanzenzellen gewonnen werden. Des weiteren kann die Funktion der Proteinhülle von COP Vesikeln bei der Aufnahme der Fracht erforscht werden. Für die Sortierung der Frachtmoleküle ist die Funktion der Proteine der p24-Familie in Hefe und Säugetierzellen zum Teil nachgewiesen worden (siehe Kap. 1.3.2 und 1.3.3). Ihre Rolle beim Proteintransport durch COP Vesikel scheint in Säugetieren mehr als in Hefe notwendig zu sein (Denzel et al., 2000; Springer et al., 2000). Die Identifizierung und Charakterisierung dieser Proteine in Pflanzenzellen wird es ermöglichen, die Wechselwirkungen zwischen p24-Proteinen und den Untereinheiten von Proteinhüllen der COP Vesikel bzw. ihren löslichen Frachtmolekülen in Pflanzenzellen zu untersuchen. Interessant ist dabei, welche Bedeutung die Funktion der p24- 
Proteine für die Proteinsortierung in Pflanzenzellen hat. Kürzlich konnte nachgewiesen werden, dass die Aufnahme von Frachtmolekülen in in vitro induzierte COP Vesikel durch die Verwendung von GTP $\gamma$ S zum großen Teil verhindert wird (Nickel et al., 1998). Aussagekräftiger ist jedoch immer eine in situ Untersuchung. Wie in dieser Arbeit und auch für Säugetierzellen (Orci et al., 1997) gezeigt wurde, ist die Tokuyasu-Technik für solche Untersuchungen sehr geeignet. 


\section{Zusammenfassung}

1) In der vorliegenden Arbeit wurden zwei Antikörper gegen Proteine aus Pflanzen hergestellt, die homolog zu $\gamma$-COP und Sec23p - die Bestandteile der Proteinhülle der COPI bzw. COPII Vesikel von Hefe und Säugetierzellen - sind. Mit diesen Antikörpern wurden in Pflanzenzellen At $\gamma$-COP mit einer Molekularmasse von 100 kDa und AtSec23p mit einer Molekularmasse von $85 \mathrm{kDa}$ identifiziert. Beide Proteine kommen sowohl löslich als auch membrangebunden in Pflanzenzellen vor.

2) Es ist gelungen, diese Proteine durch Ammoniumsulfatfraktionierung der Cytosolfraktion aus Blumenkohlinfloreszenzen aufzukonzentrieren und sie von einem großen Teil der endogenen Proteasen zu trennen.

3) Durch Gelfiltrationschromatographie cytosolischer Proteine wurde nachgewiesen, dass At $\gamma$ COP und AtSec23p Bestandteile verschiedener Proteinkomplexe sind. At $\gamma$-COP kam dabei in einem Komplex mit einer Molekularmasse von 700 kDa und AtSec23p in einem Komplex mit einer Molekularmasse von 400 kDa vor. Durch eine Behandlung mit Neomycin konnten diese Proteinkomplexe aufgrund ihrer verschiedenen Bindungseigenschaften einfach voneinander getrennt werden.

4) Es wurde gezeigt, dass At $\gamma$-COP und AtSec23p spezifisch als periphere Proteine an die cytoplasmatische Seite von Membranen binden. At $\gamma$-COP wurde an Membranen des GApp und AtSec23p an ER-Membranen nachgewiesen. Beide Proteine wurden ebenfalls als Bestandteile der pflanzlichen COP Vesikel nachgewiesen. Die Beeinträchtigung ihrer Membranbindung durch niedrige Temperatur, welche die Vesikelbildung beeinflusst, wies auf die physiologische Bedeutung ihrer Membranassoziation am vesikelvermittelten Proteintransport hin. Durch BFA-Behandlung konnte Aty-COP sehr schnell von Membranen abdissoziiert werden. Die Dissoziation des pflanzlichen Coatomers von Membranen führt möglicherweise zur Freilegung der v-SNAREs des GApp, die so mit t-SNAREs der ERMembranen in Wechselwirkung treten und dadurch die Fusion von GApp und ER ermöglichen.

5) Mit Hilfe der Immunlokalisierung wurden COPI Vesikel erstmals in pflanzlichen Zellen identifiziert. Diese Vesikel weisen eine Größe von 50-60 nm auf und sind kleiner als COPI Vesikel der Säugetierzellen. Die statistische Analyse der Immunmarkierungen mit den COPIAntikörpern ergab, dass diese Vesikel überwiegend im cis-Bereich des GApp vorkommen. Das weist auf eine besondere Funktion der cis-Zisternen des GApp in Pflanzenzellen hin. In mit der $\alpha$-Amylase-HDEL transformierten Tabakpflanzen wurde dieses Enzym als mögliches Frachtmolekül von COPI Vesikeln in der äußersten cis-Zisterne des GApp lokalisiert. Die cis- 
most Zisterne scheint deshalb in Pflanzenzellen eine ähnliche Funktion zu erfühlen wie das ERGIC in Säugetierzellen.

6) Durch Immunogoldmarkierung wurden COPI Vesikel am GApp der Parenchymzellen von Erbsenkotyledonen als ein weiterer Vesikeltyp nachgewiesen, der nicht mit DVs identisch ist. Es wurde postuliert, dass neben der angenommenen Zisternenreifung in diesen Zellen ein Proteintransport durch COPI Vesikel am GApp stattfindet. 


\section{Literaturverzeichnis}

Ahle S., Mann A., Eichelsbacher U., Ungewickell E. (1988)

Structural relationships between clathrin assembly proteins from the Golgi and the plasma membrane. EMBO J. 7, 919-929

Ahmed S.U., Bar-Peled M., Raikhel N.V. (1997)

Cloning and subcellular location of an Arabidopsis receptor-like protein that shares common features with protein-sorting receptors of eukaryotic cells. Plant Physiol. 114, 325-336

Andreeva A.V., Kutuzov M.A., Evans D.E., Haws C.R. (1998)

The structure and function of the Golgi apparatus: a hundred years of questions. J. Exp. Bot. 49, 1281-1291

Andrews D.W., Johnson A.E. (1996)

The translocon: more than a hole in the ER membrane? Trends Biochem. Sci. 21, 365-369

Aridor M., Bannykh S.I., Rowe T., Balch W.E. (1995)

Sequential coupling between COPII and COPI vesicle coats in endoplasmic reticulum to

Golgi transport. J. Cell Biol. 131, 875-893

Aridor M., Bannykh S.I., Rowe T., Balch W.E. (1999)

Cargo can modulate COPII vesicle formation from the endoplasmic reticulum. J. Biol. Chem. 274, 4389-4399

Aridor M., Weissman J., Bannykh S.I., Nuoffer C., Balch W.E. (1998)

Cargo selection by the COPII budding machinery during export from the ER. J. Cell. Biol. 141, 61-70

Arondel V., Lemieux B., Hwang I., Gibson S., Goodman H.M., Somerville C.R. (1992)

Map-based cloning of a gene controlling omega-3 fatty acid desaturation in Arabidopsis.

Science 258, 1353-1335

Balch W.E., Dunphy W.G., Braell W.A., Rothman J.E. (1984)

Reconstitution of the transport of protein between successive compartments of the Golgi measured by coupled incorporation of N-acetylglucosamine. Cell 39, 405-416

Balch W.E., McCaffery M., Plutner H., Farquhar M.G. (1994)

Vesicular stomatitis virus glycoprotein is sorted and concentrated during export from the endoplasmic reticulum. Cell 76, 841-852

Bannykh S.I., Balch W.E. (1997)

Membrane dynamics at the endoplasmic reticulum-Golgi interface. J. Cell Biol. 138, 1-4 Bannykh S.I., Balch W.E. (1998)

Selective transport of cargo between the endoplasmic reticulum and Golgi compartments. Histochem. Cell Biol. 109, 463-475 
Barlowe C., d'Enfert C., Schekman R. (1993)

Purification and characterization of SAR1p, a small GTP-binding protein required for transport vesicle formation from the endoplasmic reticulum. J. Biol. Chem. 268, 873-879

Barlowe C. (1995)

COPII: a membrane coat that forms endoplasmic reticulum-derived vesicles. FEBS Lett. 369, 93-96

Barlowe C. (1998)

COPII and selective export from the endoplasmic reticulum. Biochim. Biophys. Acta. 1404, 67-86

Barlowe C., Orci L., Yeung T., Hosobuchi M., Hamamoto S., Salama N., Rexach M.F., Ravazzola M., Amherdt M., Schekman R. (1994)

COPII: a membrane coat formed by Sec proteins that drive vesicle budding from the endoplasmic reticulum. Cell 77, 895-907

Barlowe C., Schekman R. (1993)

SEC12 encodes a guanine-nucleotide-exchange factor essential for transport vesicle budding from the ER. Nature 365, 347-349

Bar-Peled M., Raikhel N.V. (1997)

Characterization of AtSec12 and AtSAR1. Proteins likely involved in endoplasmic reticulum and Golgi transport. Plant Physiol. 114, 315-324

Bassham D.C., Gal S., Conceição A.S., Raikhel N.V. (1995)

An Arabidopsis syntaxin homologue isolated by functional complementation of a yeast pep12 mutant. Proc. Natl. Acad. Sci. USA 92, 7262-7266

Baydoun E.A.H., Brett C.T. (1997)

Distribution of xylosyltransferases and glucuronyltransferase within the Golgi apparatus in etiolated pea (Pisum sativum L.) epicotyls. J. Exp. Bot. 48, 1209-1214

Becker B., Bolinger B., Melkonian M. (1995)

Anterograde transport of algal scales through the Golgi complex is not mediated by vesicles.

Trends Cell Biol. 5, 305-307

Becker B., Melkonian M. (1996)

The secretory pathway of protists: spatial and functional organization and evolution.

Microbiol. Rev. 60, 697-721

Bednarek S.Y., Ravazzola M., Hosobuchi M., Amherdt M., Perrelet A., Schekman R., Orci L. (1995)

COPI- and COPII-coated vesicles bud directly from the endoplasmic reticulum in yeast. Cell 83, 1183-1196 
Belden W.J., Barlowe C. (1996)

Erv25p, a component of COPII-coated vesicles, forms a complex with Emp24p that is required for efficient endoplasmic reticulum to Golgi transport. J. Biol Chem. 271, 26939-26946

Blum H., Beier H., Gross H.J. (1987)

Improved silver staining of plant proteins, RNA and DNA in polyacrylamide gels. Electrophoresis 8, 93-99

Blum R., Pfeiffer F., Feick P., Nastainczyk W., Kohler B., Schäfer K.H., Schulz I. (1999) Intracellular localization and in vivo trafficking of p24A and p23. J. Cell Sci. 112, $537-548$

Boevink P., Oparka K., Santa Cruz S., Martin B., Betteridge A., Hawes C. (1998)

Stacks on tracks: the plant Golgi apparatus traffics on an actin/ER network. Plant J. 15, 441-447

Bonfanti L., Mironov A.A. Jr., Martinez-Menarguez J.A., Martella O., Fusella A., Baldassarre M., Buccione R., Geuze H.J., Mironov A.A., Luini A. (1998)

Procollagen traverses the Golgi stack without leaving the lumen of cisternae: evidence for cisternal maturation. Cell 95, 993-1003

Bradford M.M. (1976)

A rapid sensitive method for the quantitation of microgram quantities of protein utilizing the principle of protein-dye binding. Anal. Biochem. 72, 248-254

Braulke T. (1996)

Origin of lysosomal proteins. In: J.B. Lloyd, R.W. Mason; Subcellular Biochemistry.

Biology of the lysosome. Plenum Press, New York, USA, 27, 15-49

Bremser M., Nickel W., Schweikert M., Ravazzola M., Amherdt M., Hughes C.A., Söllner T.H., Rothman J.E., Wieland F.T. (1999)

Coupling of coat assembly and vesicle budding to packaging of putative cargo receptors. Cell 96, 495-506

Brown H.A., Gutowski S., Moomaw C.R., Slaughter C., Sternweis P.C. (1993) ADP-ribosylation factor, a small GTP-dependent regulatory protein, stimulates phospholipase D activity. Cell 75, 1137-1144

Bruyant-Vannier M.P., Gaudient-Schaumann A., Bourlard T., Morvan C. (1996)

Solubilization and partial characterization of pectin methyltransferase from flax cells.

Plant Physiol. Biochem. 34, 489-499 
Campbell I. (1988)

Standard media for cultivation yeast. In: I. Campbell, J.H. Duffus; Yeast: a practical approach. IRL Press, Oxford, UK, 277

Campbell J.L., Schekman R. (1997)

Selective packaging of cargo molecules into endoplasmic reticulum-derived COPII vesicles. Proc. Natl. Acad. Sci. USA 94, 837-842

Cao X., Rogers S.W., Butler J., Beevers L., Rogers J.C. (2000)

Structural Requirements for Ligand Binding by a Probable Plant Vacuolar Sorting

Receptor. Plant Cell 12, 493-506

Chen P.S., Toribara T.Y., Warner H. (1956)

Microdetermination of phosphorus. Anal. Chem. 28, 1756-1758

Chrispeels M.J. (1991)

Sorting of proteins in the secretory system. Annu. Rev. Plant Physiol. Plant Mol. Biol. 42, 21-53

Chrispeels M.J., Higgins T.J.V., Spencer H. (1982)

assembly of storage protein oligomers in the endoplasmic reticulum and processing of the polypeptides in the protein bodies of developing pea cotyledons. J. Cell Biol. 93, 306-313

Chu D.S., Pishvaee B., Payne G.S. (1996)

The light chain subunit is required for clathrin function in Saccharomyces cerevisiae. $J$. Biol. Chem. 271, 33123-33130

Chu D.S., Pishvaee B., Payne G.S. (1999)

A modulatory role for clathrin light chain phosphorylation in Golgi membrane protein localization during vegetative growth and during the mating response of Saccharomyces cerevisiae. Mol. Biol. Cell 10, 713-726

Ciufo L.F., Boyd A. (2000)

Identification of a lumenal sequence specifying the assembly of Emp24p into p24 complexes in the yeast secretory pathway. J. Biol. Chem. 275, 8382-8388

Cluett E.B., Brown W.J. (1992)

Adhesion of Golgi cisternae by proteinaceous interactions: intercisternal bridges as putative adhesive structures. J. Cell Sci. 103, 773-784

Cohen S.N., Chang A.C., Hsu L. (1972)

Non chromosomal antibiotic resistance in bacteria: genetic transformation of Escherichia coli by R-factor-DNA. Proc. Natl. Acad. Sci. USA 69, 2110-2114 
Colley K.J. (1997)

Golgi localization of glycosyltransferases: more questions than answers. Glycobiology 7, $1-13$

Conceição A.S., Marty-Mazars D., Bassham D.C., Sanderfoot A.A., Marty F., Raikhel N.V. (1997)

The syntaxin homologue AtPEP12p resides on a late post-Golgi compartment in plants. Plant Cell 9, 571-582

Connolly C.N., Futter C.E., Gibson A., Hopkins C.R., Cutler D.F. (1994)

Transport into and out of the Golgi-complex studied by transfecting cells with cDNAs encoding horseradish peroxidase. J. Cell Biol. 127, 641-652

Cooper T.G. (1980)

Biochemische Arbeitsmethoden. Walter de Gruyter, Berlin, BRD, 348-352

Cosson P., Letourneur F. (1994)

Coatomer interaction with dilysin endoplasmic reticulum retention motifs. Science 263, $1629-1631$

Coughlan S.J., Hastings C, Winfrey R Jr. (1997)

Cloning and characterization of the calreticulin gene from Ricinus communis L. Plant Mol. Biol. 34, 897-911

Crofts A.J., Leborgne-Castel N., Hillmer S., Robinson D.G., Phillipson B., Carlsson L.E., Ashford D.A., Denecke J. (1999)

Saturation of the endoplasmic reticulum retention machinery reveals anterograde bulk flow. Plant Cell 11, 2233-2247

Crofts A.J., Leborgne-Castel N., Pesca M., Vitale A., Denecke J. (1998)

$\mathrm{BiP}$ and calreticulin form an abundant complex that is independent of endoplasmic reticulum stress. Plant Cell 10, 813-823

Dairman M., Donofrio N., Domozych D.S. (1995)

The effect of brefeldin A upon the Golgi apparatus of green algal flagellate, Gloemonas kupfferi. J. Exp. Bot. 46, 181-186

Dean N., Pelham H.R.B. (1990)

Recycling of proteins from the Golgi compartment to the endoplasmic reticulum in yeast. J. Cell Biol. 111, 369-377

Dell'Angelica E.C., Klumperman J., Stoorvogel W., Bonifacino J.S. (1998)

Association of the AP-3 adaptor complex with clathrin. Science 280, 431-434

Dell'Angelica E.C., Mullins C., Bonifacino J.S. (1999)

AP-4, a novel protein complex related to clathrin adaptors. J. Biol. Chem. 274, 7278-7285 
Dell'Angelica E.C., Ohno H., Ooi C.E., Rabinovich E., Roche K.W., Bonifacino J.S. (1997) AP-3: an adaptor-like protein complex with ubiquitous expression. EMBO J. 16, 917-928 Demmer A. (1991)

Versuche zur Verbesserung von coated Vesikel Isolierung aus Pflanzen. Diplomarbeit, Abteilung für strukturelle Zellbiologie, Universität Göttingen

Demmer A., Holstein S.E.H., Hinz G., Schauermann G., Robinson D.G. (1993)

Improved coated vesicle isolation allows better characterisation of clathrin polypeptides. J. Exp. Botany 44, 23-33

Denecke J., Botterman J., Deblaere R. (1990)

Protein secretion in plant cells can occur via a default pathway. Plant Cell. 2, 51-59

Denecke J., De Rycke R., Botterman J. (1992)

Plant and mammalian sorting for protein retention in the endoplasmic reticulum contain a conserved epitope. EMBO J. 11, 2345-2355

Denecke J., Goldman M.H.S., Demolder J., Seurinck J., Botterman, J. (1991)

The tobacco luminal binding protein is encoded by a multigene family. Plant Cell $\mathbf{3}$, $1025-1035$

Denecke J. (1996)

Soluble endoplasmic reticulum resident proteins and their function in protein synthesis and transport. Plant Physiol. Biochem. 34, 197-205

d'Enfert C., Barlowe C., Nishikawa S., Nakano A., Schekman R. (1991)

Structural and functional dissection of a membrane glycoprotein required for vesicle budding from the endoplasmic reticulum. Mol. Cell Biol. 11, 5727-5734

Denzel A., Otto F., Girod A., Pepperkok R., Watson R., Rosewell I., Bergeron J.J., Solari R.C., Owen M.J. (2000)

The p24 family member p23 is required for early embryonic development. Curr. Biol. 10, $55-58$

Depta H., Holstein S.E.H., Robinson D.G., Lützelschwalb M., Michalke, W. (1991)

Membrane markers in highly purified clathrin-coated vesicles from Cucurbita hypocotyles. Planta 183, 434-442

Dhugga K.S., Tiwari S.C., Ray P.M. (1997)

A reversibly glycosylated polypeptide (RGP1) possibly involved in plant cell wall synthesis: purification, gene cloning and trans Golgi localization. Proc. Natl. Acad. Sci. USA 94, 7679-7684 
Dominguez M., Dejgaard K., Füllekrug J., Dahan S., Fazel A., Paccaud J.P., Thomas D.Y., Bergeron J.J.M., Nilsson T. (1998)

gp25L/emp24/p24 protein family members of the cis-Golgi network bind both COP I and II coatomer. J. Cell Biol. 140, 751-765

Donaldson J.G., Finazzi, D., Klausner R.D. (1992)

Brefeldin A inhibits Golgi membrane-catalysed exchange of guanine nucleotide onto ARF protein. Nature 360, 350-352

Donaldson J.G., Klausner R.D. (1994)

ARF: a key regulatory switch in membrane traffic and organelle structure. Curr. Opin. Cell Biol. 6, 527-532

Dower W.J., Miller J.F., Ragsdale C.W. (1988)

High efficiency transformation of E. coli by high voltage electroporation. Nucleic Acids Res. 16, 6127-6145

Driouich A., Staehelin L.A. (1997)

The plant Golgi apparatus: structural organization and functional properties. In: E.G. Berger,

J. Roth; The Golgi apparatus. Birkhäuser Verlag, Basel, Schweiz, 275-301

Driouich A., Zhang G.F., Staehelin L.A. (1993)

Effect of brefeldin A on the structure of the Golgi apparatus and on the synthesis and secretion of proteins and polysaccharides in sycamore maple (Acer pseudoplatanus) suspension-cultured cells. Plant Physiol. 101, 1363-1373

Drucker M. (1995)

ATP-hydrolysierende Enzyme in pflanzlichen "Clathrin-Coated Vesicles". Dissertation, Universität Göttingen, Cuvillier Verlag, Göttingen

Drucker M.; Herkt B.; Robinson D.G. (1995)

Demonstration of a beta-type adaptin at the plant plasma membrane. Cell Biol. Int. 19, 191-201

Duden R., Hosobuchi M., Hamamoto S., Winey M., Byers B., Schekman R. (1994)

Yeast beta- and beta'-coat proteins (COP). Two coatomer subunits essential for endoplasmic reticulum-to-Golgi protein traffic. J. Biol. Chem. 269, 24486-24495

Dupree P., Sherrier D.J. (1998)

The plant Golgi apparatus. Biochim. Biophys. Acta. 1404, 259-270

Ellis R.J., Hartl F.U. (1999)

Principles of protein folding in the cellular environment. Curr. Opin. Struct. Biol. 9, 102-110

Elrod-Erickson M.J., Kaiser C.A. (1996)

Genes that control the fidelity of endoplasmic reticulum to Golgi transport identified as suppressors of vesicle budding mutations. Mol. Biol. Cell 7, 1043-1058 
Espenshade P., Gimeno R.E., Holzmacher E., Teung P., Kaiser C.A. (1995)

Yeast SEC16 gene encodes a multidomain vesicle coat protein that interacts with Sec23p. J. Cell Biol. 131, 311-324

Evans E.A., Gilmore R., Blobel G. (1986)

Purification of microsomal signal peptidase as a complex. Proc. Natl. Acad. Sci. USA 83, $581-585$

Ey P.L., Prowse S.J., Jenkin, C.R. (1978)

Isolation of pure $\mathrm{IgG}_{1}, \mathrm{IgG}_{2 \mathrm{a}}$, and $\mathrm{IgG}_{2 \mathrm{~b}}$ immunoglobulins from mouse serum using protein A-sepharose. Biochem. 15, 429-436

Farquhar M.G., Hauri H.P. (1997)

Protein sorting and vesicular traffic in the Golgi apparatus. In: E.G. Berger, J. Roth; The Golgi apparatus. Birkhäuser Verlag, Basel, Schweiz, 63-129

Farquhar M.G., Palade G.E. (1981)

The Golgi apparatus (complex) - (1954-1981) - from artifact to center stage. J. Cell Biol. 91, 77-103

Farquhar M.G., Palade G.E. (1998)

The Golgi apparatus: 100 years of progress and controversy. Trends Cell Biol. 8, 2-10

Fichman J., Taiz L., Gallagher S., Leonard R.T., Depta H., Robinson D.G. (1989)

Immunological comparison of the coated vesicle $\mathrm{H}^{+}$-ATPase of plant and animals.

Protoplasma 153, 117-125

Fiedler K., Veit M., Stamnes M.A., Rothman J.E. (1996)

Bimodal interaction of coatomer with the p24 family of putative cargo receptors. Science 273, 1396-1399

Füllekrug J., Nilsson T. (1998)

Protein sorting in the Golgi complex. Biochim. Biophys. Acta 1404, 77-84

Galili G., Sengupta-Gopalan C., Ceriotti A. (1998)

The endoplasmic reticulum of plant cells and its role in protein maturation and biogenesis of oil bodies. Plant Mol. Biol. 38, 1-29

Gardiner M., Chrispeels M.J. (1975)

Involvement of the Golgi apparatus in the synthesis and secretion of hydoxyproline-rich cell wall glycoproteins. Plant Physiol. 5, 536-514

Gaynor E.C., Emr S.D. (1997)

COPI-independent anterograde transport: cargo-selective ER to Golgi protein transport in yeast COPI mutants. J. Cell Biol. 136, 789-802 
Gilmore R. (1993)

Protein translocation across the endoplasmic reticulum: a tunnel with toll booths at entry and exit. Cell 75, 589-592

Gimeno R.E., Espenshade P., Kaiser C.A. (1995)

SED4 encodes a yeast endoplasmic reticulum protein that binds Sec16p and participates in vesicle formation. J. Cell Biol. 131, 325-338

Gimeno R.E., Espenshade P., Kaiser C.A. (1996)

COPII coat subunit interactions: Sec24p and Sec23p bind to adjacent regions of Sec16p. Mol. Biol. Cell. 7, 1815-1823

Glick B.S., Elston T., Oster A. (1997)

A cisternal maturation mechanism can explain the asymmetry of the Golgi stack. FEBS Lett. 414, 177-181

Goda Y., Pfeffer S.R. (1991)

Identification of a novel, $\mathrm{N}$-ethylmaleimide-sensitive cytosolic factor required for vesicular transport from endosomes to the trans-Golgi network in vitro. J. Cell Biol. 112, 823-831

Goffeau A., Barrell B.G., Bussey H., Davis R.W., Dujon B., Feldmann H., Galibert F., Hoheisel J.D., Jacq C., Johnston M., Louis E.J., Mewes H.W., Murakami Y., Philippsen P., Tettelin H., Oliver SG. (1996)

Life with 6000 genes. Science 274, 563-567

Goldberg J. (2000)

Decoding of sorting signals by coatomer through a GTPase switch in the COPI coat complex. Cell 100, 671-679

Gommel D., Orci L., Emig E.M., Hannah M.J., Ravazzola M., Nickel W., Helms J.B., Wieland F.T., Sohn K. (1999)

p24 and p23, the major transmembrane proteins of COPI-coated transport vesicles, form hetero-oligomeric complexes and cycle between the organelles of the early secretory pathway. FEBS Lett. 447, 179-185

Gomord V., Denmat L.-A., Fitchette-Lainé A.-C., Satiat-Jeunemaitre B., Hawes C., Faye L. (1997)

The C-terminal HDEL sequence is sufficient for retention of secretory proteins in the endoplasmic reticulum (ER) but promotes vacuolar targeting of proteins that escape the ER. Plant J. 11, 313-325 
Gomord V., Faye L. (1996)

Signals and mechanisms involved in intracellular transport of secreted proteins in plants. Plant Physiol. Biochem. 34, 165-181

Gomord V., Wee E., Faye L. (1999)

Protein retention and localization in the endoplasmic reticulum and the Golgi apparatus.

Biochimie. 81, 607-618

Goud B., Huet C., Louvard D. (1985)

Assembled and unassembled pools of clathrin: a quantitative study using an enzyme immunoassay. J. Cell Biol. 100, 521-527

Gravotta D., Adesnik M., Sabatini D.D. (1990)

Transport of influenza HA from the trans-Golgi network to the apical surface of MDCK cells permeabilized in their basolateral plasma membranes: energy dependence and involvement of GTP-binding proteins J. Cell Biol. 111, 2893-2908

Griffiths G., Ericsson M., Krijnse-Locker J., Nilsson T., Goud B., Söling H.D., Tang B.L., Wong S.W., and Hong W. (1994)

Localization of the Lys, Asp, Glu, Leu tetrapeptide receptor to the Golgi complex and the intermediate compartment in mammalian cells. J. Cell Biol. 127, 1557-1574

Griffiths G., Pepperkok R., Locker J.K., Kreis T.E. (1995)

Immunocytochemical localization of beta-COP to the ER-Golgi boundary and the TGN.

J. Cell Sci. 108, 2839-2856

Griffiths G., Simons K. (1986)

The trans Golgi network: sorting at the exit site of the Golgi complex. Science 234, 438-443

Gröne T. (1986)

Proteolytische Aktivitäten bei Chorella sorokiniana unter besonderer Berücksichtigung regulatorischer Effekte. Diplomarbeit, Universität Göttingen

Guy C.L., Haskell D., Li Q.-B. (1998)

Association of proteins with the stress 70 molecular chaperones at low temperature: evidence for the existence of cold labile proteins in spinach. Cryobiology 36, 301-314

Guy C.L., Niemi K.J., Brambl R. (1985)

Altered gene expression during cold acclimation of spinach. Proc. Natl. Acad. Sci. USA 82, 3673-3677

Hakes D.J., Dixon J.E. (1992)

New vectors for high level expression of recombinant proteins in bacteria. Anal. Biochem. 202, 293-298 
Hamano T.Y., Oji S., Okamoto Y., Mitsuhashi Y., Matsuki Y. (1983)

A nitrate reductase-inactivating factor in barley (Hordeum distinchum L.) leaves. Plant Cell physiol. 24, 1337-1341

Hamman B.D., Chen J.C., Johnson E.E., Johnson A.E. (1997)

The aqueous pore through the translocon has a diameter of 40-60 A during cotranslational protein translocation at the ER membrane. Cell 89, 535-544.

Hammons C., Helenius A. (1995)

Quality control in the secretory pathway. Curr. Opin. Cell Biol. 7, 523-529

Hanahan D. (1983)

Studies on transformation of Escherichia coli with plasmids. J. Mol. Biol. 166, 557-580

Hanahan D. (1985)

Techniques for transformation of E. coli. In: D. M. Glover; DNA cloning. IRL Press, Oxford, UK

Hanna R., Brummell D.A., Camirand A., Hensel A., Russel E.F., Maclachlan G.A. (1991)

Solubilization and properties of GDP-fucosyltransferases from pea epicotyl membranes.

Arch. Biochem. Biophys. 290, 7-13

Happel N., Robinson D.G., Holstein S.E.H. (1997)

An Arabidopsis thaliana cDNA clone (Accession No. AF009631) is homologous to the micro-adaptins of clathrin coated vesicle adaptor complexes. Plant Physiol. PGR 97-168

Hara-Kuge S., Kuge O., Orci L., Amherdt M., Ravazzola M., Wieland F.T., Rothman J.E. (1994)

En bloc incorporation of coatomer subunits during the assembly of COP-coated vesicles.

J. Cell Biol. 124, 883-892

Hara-Nishimura I., Shimada T., Hiraiwa N., Nishimura M. (1995)

Vacuolar processing enzyme responsible for maturation of seed proteins. J. Plant Physiol. 145, 632-640

Hara-Nishimura I., Takenchi Y., Inoue K., Nishimura M. (1993)

Vesicle transport and processing of the precursor to $2 \mathrm{~S}$ albumin in pumpkin. Plant J. 4, 793-800

Harley S.M., Beevers L. (1989)

Coated vesicles are involved in the transport of storage proteins during seed development in Pisum sativum L.. Plant Physiol. 91, 674-678

Harlow E., Lane D. (1988)

Antibodies. A laboratory manual. Cold Spring Harbour Laboratory, New York, 309-312

Harter C. (1999)

COPI proteins: a model for their role in vesicle budding. Protoplasma 207, 125-132 
Harter C., Pavel J., Coccia F., Draken E., Wegehingel S., Tschochner H., Wieland F.T. (1996) Nonclathrin coat protein gamma, a subunit of coatomer, binds to the cytoplasmic dilysine motif of membrane proteins of the early secretory pathway. Proc. Natl. Acad. Sci. USA 93, 1902-1906

Harter C., Wieland F.T. (1998)

A single binding site for di-lysin retrieval motifs and p23 within the $\gamma$-subunit of coatomer. Proc. Natl. Acad. Sci. USA 95, 11649-11654

Hartl F.U. (1996)

Molecular chaperons in cellular protein folding. Nature 381, 571-580

Hatefi Y., Hanstein W.G. (1974)

Destabilization of membranes with chaotropic ions. Methods Enzymol. 31, 770-790

Hawes C., Crooks K., Coleman J., Satiat-Jeunemaitre B. (1995)

Endocytosis in plants: fact or artefact? Plant Cell Environment 18, 1245-1252

Hawes C., Satiat-Jeunemaitre B. (1996)

Stacks of questions: How does the plant Golgi work? Trends Plant Sci. 1, 395-401

Helenius A., McCaslin D.R., Fries E., Tanford C. (1979)

Properties of Detergents. Methods Enzymol. 56, 734-749

Helms J.B., Palmer D.J., Rothman J.E. (1993)

Two distinct populations of ARF bound to Golgi membranes. J. Cell Biol. 121, 751-760

Helms J.B., Rothman J.E. (1992)

Inhibition by brefeldin A of a Golgi membrane enzyme that catalyses exchange guanine nucleotide bound to ARF. Nature 360, 352-354

Henderson J., Satiat-Jeunemaitre B., Napier R., Hawes C.R. (1994)

Brefeldin A-induced disassembly of Golgi apparatus is followed by disruption of the endoplasmic reticulum in plant cells. J. Exp. Bot. 45, 1347-1351

Herman E.M. (1994)

Multiple origins of intravacuolar protein accumulation of plant cells. Adv. Struct. Biol. 3, 243-283

Herman E.M., Tague B.W., Hoffman L.M., Kjemtrupp S.E., Chrispeels, M.J. (1990)

Retention of phytohemagglutinin with carboxy terminal tetrapeptide KDEL in the nuclear envelope and the endoplasmic reticulum. Planta 182, 305-312

Hicke L., Yoshihisa T., Schekman R. (1992)

Sec23p and a novel 105-kDa protein function as a multimeric complex to promote vesicle budding and protein transport from the endoplasmic reticulum. Mol. Biol. Cell 3, 667-676 
Hillmer S., Freundt H., Robinson D.G. (1988)

The partially coated reticulum and its relationship to the Golgi apparatus in higher plant cells. Eur. J. Cell Biol. 47, 206-212

Hillmer S., Movafeghi A., Robinson D.G., Hinz G. (2001)

Vacuolar storage proteins are sorted in the cis-cisternae of the pea cotyledon Golgi apparatus. J. Cell Biol. in Druck

Hinz G., Hillmer S., Bäumer M., Hohl I. (1999)

Vacuolar storage proteins and the putative sorting receptor BP-80 exit the Golgi apparatus of developing pea cotyledons in different transport vesicles. Plant Cell 11, 1509-1524

Hirst J., Bright N.A., Rous B., Robinson M.S. (1999)

Characterization of a fourth adaptor-related protein complex. Mol. Biol. Cell 10, 2787-2802

Hirst J., Robinson M.S. (1998)

Clathrin and adaptors. Biochem. Biophys. Acta 1404, 173-193

Hoh B., Hinz G., Jeong B.-K., Robinson D.G. (1995)

Protein storage vacuoles form de novo during pea cotyledon development. J. Cell Sci. 108, 299-310

Hohl I., Robinson D.G., Chrispeels M.J., Hinz G. (1996)

Transport of storage proteins to the vacuole is mediated by vesicles without a clathrin coat. J. Cell Sci. 109, 2539-2550

Hong B., Ichida A., Wang Y., Gens J.S., Pickard B.G., Harper J.F. (1999)

Identification of a calmodulin-regulated $\mathrm{Ca}^{2}+$-ATPase in the endoplasmic reticulum. Plant-Physiol. 119, 1165-1176

Hosobuchi M., Kreis T., Schekman R. (1992)

Sec21 is a gene required for ER to Golgi protein transport that encodes a subunit of a yeast coatomer. Nature 360, 603-605

Hsu V.W., Shah N., Klausner R.D. (1992)

A brefeldin A-like phenotype is induced by the overexpression of a human ERD-2-like protein, ELP-1. Cell 69, 625-635

Huang K.M., Gullberg L., Nelson K.K., Stefan C.J., Blumer K., Lemmon S.K. (1997)

Novel functions of clathrin light chains: clathrin heavy chain trimerization is defective in light chain-deficient yeast. J. Cell Sci. 110, 899-910

Huang P.H., Chiang H.L. (1997)

Identification of novel vesicles in the cytosol to vacuole protein degradation pathway.

J. Cell Biol. 136, 803-810 
Hudson R.T., Draper R.K. (1997)

Interaction of coatomer with aminoglycoside Antibiotics: evidence that coatomer has at least two dilysin binding sites. Mol. Biol. Cell 8, 1901-1910

Hugueney P., Bouvier F., Badillo A., d'Harlingue A., Kuntz M., Camara B. (1995)

Identification of a plastid protein involved in vesicle fusion and/or membrane protein translocation. Proc. Natl. Acad. Sci. USA 92, 5630-5634

Jackson M.R., Nilsson T., Peterson P.A. (1993)

Retrieval of transmembrane proteins to the endoplasmic reticulum. J. Cell Biol. 121, 317333

Jiang L., Rogers J.C. (1999)

The Role of BP-80 and Homologs in Sorting Proteins to Vacuoles. Plant Cell 11, 20692071

Kahn R.A., Gilman A.G. (1986)

The protein cofactor necessary for ADP-ribosylation of Gs by cholera toxin is itself a GTP binding protein. J. Biol. Chem. 261, 7906-7911

Kahn R.A., Randazzo P., Serafini T., Weiss O., Rulka C., Clark J., Amherdt M., Roller P., Orci L., Rothman J.E. (1992)

The amino terminus of ADP-ribosylation factor (ARF) is a critical determinant of ARF activities and is a potent and specific inhibitor of protein transport. J. Biol. Chem. 267, 13039-13046

Kahn R.A., Terui T., Randazzo P.A. (1996)

Effects of acid phospholipids on ARF activities: potential roles in membrane traffic.

J. Lipid Mediat. Cell Signal 14, 209-214

Kirsch T., Paris N., Butler J.M., Beevers L., Rogers, J.C. (1994)

Purification and initial characterization of a potential plant vacuolar targeting receptor. Proc. Natl. Acad. Sci. USA 91, 3403-3407

Kirsch T., Saalbach G., Raikhel N.V., Beevers, L. (1996)

Interaction of a potential vacuolar targeting receptor with amino- and carboxyl-terminal targeting determinants. Plant Physiol. 111, 469-474

Klappa P., Zimmermann M., Zimmermann R. (1994)

The membrane proteins TRAMp and sec61 alpha p may be involved in post-translational transport of presecretory proteins into mammalian microsomes. FEBS Lett. 341, 281-287

Kopito R.R. (1997)

ER quality control: the cytoplasmic connection. Cell $\mathbf{8 8}, 427-430$ 
Kornfeld S. (1992)

Structure and function of the mannose 6-phosphate/insulinlike growth factor II receptors. Annu. Rev. Biochem. 61, 307-330

Ktistakis N.T., Brown H.A., Waters M.G., Sternweis P.C., Roth M.G. (1996)

Evidence that phospholipase D mediates ADP ribosylation factor-dependent formation of

Golgi coated vesicles. J. Cell Biol. 134, 295-306

Kuehn M.J., Hermann J.M., Schekman R. (1998)

COPII-cargo interactions direct protein sorting into ER-derived transport vesicles. Nature 391, 187-190

Laemmli U.K. (1970)

Cleavage of structural proteins during assembly of the head of the bacteriophage T4. Nature 227, 680-685

Le Borgne R., Griffiths G., Hoflack B. (1996)

Mannose 6-phosphate receptors and ADP-ribosylation factors cooperate for high affinity interaction of the AP-1 Golgi assembly proteins with membranes. J. Biol. Chem. 271, 2162-2170

Lee G.J., Pokala N., Vierling E. (1995)

Structure and in vitro molecular chaperone activity of cytosolic small heat shock proteins from pea. J. Biol. Chem. 270, 10432-10438

Lee H.I., Gal S., Newman T.C., Raikhel N.V. (1993)

The Arabidopsis endoplasmic reticulum retention receptor functions in yeast. Proc. Natl. Acad. Sci. USA 90, 11433-11437

Lerouge P., Cabanes-Macheteau M., Rayon C., Fischette-Laine A.C., Gomord V., Faye L. (1998)

$\mathrm{N}$-glycoprotein biosynthesis in plants: recent developments and future trends. Plant Mol. Biol. 38, 31-48

Levanony H., Rubin R., Altschuler Y., Galili G. (1992)

Evidence for a novel route of wheat storage proteins to vacuoles. J. Cell Biol. 119, 1117-1128

Lewis M.J., Pelham, H.R.B. (1992)

Ligand-induced redistribution of the human KDEL receptor from the Golgi complex to the endoplasmic reticulum. Cell 68, 353-364

Lin H.-B., Harley B., Butler J.M., Beevers L. (1992)

Multiplicity of clathrin light-chain-like polypeptides from developing pea (Pisum sativum L.) cotyledons. J. Cell Sci. 103, 1127-1137

Liou W., Geuze H.J., Slot J.W. (1996)

Improving structural integrity of cryosections for immunogold labeling. Histochem. Cell Biol. 106, 41-58 
Lippincott-Schwartz J., Yuan L., Tipper C., Amherdt M., Orci L., Klausner R.D. (1991)

Brefeldin A's effects on endosomes, lysosomes, and the TGN suggest a general mechanism for regulating organelle structure and membrane traffic. Cell 67, 601-616

Lippincott-Schwartz J., Yuan L.C., Bonifacino J.S., Klausner R.D. (1989)

Rapid redistribution of Golgi proteins into the ER in cells treated with brefeldin A: evidence for membrane cycling from Golgi to ER. Cell 56, 801-813

Lowe M., Kreis T.E. (1995)

In vitro assembly and disassembly of coatomer. J. Biol. Chem. 270, 31364-31371

Lowe M., Kreis T.E. (1996)

In vivo assembly of coatomer, the COP-I coat precursor. J. Biol. Chem. 271, 30725-30730

Lowe M., Kreis T.E. (1998)

Regulation of membrane traffic in animal cells by COPI. Biochim. Biophys. Acta 1404, 53-66

Lowry O.H., Rosenbrough N.J., Farr L.A., Randell R.J. (1951)

Protein measurement with the folin phenol reagent. J. Biol. Chem. 193, 265-275

Maldonado-Mendoza I.E., Nessler C.L. (1997)

Molecular characterization of the AP19 gene family in Arabidopsis thaliana: components of the Golgi AP-1 clathrin assembly protein complex. Plant Mol. Biol. 35, 865-872

Maldonado-Mendoza I.E., Nessler C.L. (1996)

Cloning and expression of a plant homologue of the small subunit of the Golgi-associated clathrin assembly protein AP19 from Camptotheca acuminata. Plant Mol. Biol. 32, 11491153

Malhotra V., Serafini T., Orci L., Shepherd J.C., Rothman J.E. (1989)

Purification of a novel class of coated vesicles mediating biosynthetic protein transport through the Golgi stack. Cell 58, 329-336

Mansour S.J., Skaug J., Zhao X.H., Giordano J., Scherer S.W., Melancon P. (1999) p200 ARF-GEP1: a Golgi-localized guanine nucleotide exchange protein whose Sec7 domain is targeted by the drug brefeldin A. Proc. Natl. Acad. Sci. USA. 96, 7968-7973

Martinez-Menarguez J.A., Geuze H.J., Slot J.W., Klumperman J. (1999)

Vesicular tubular clusters between the ER and Golgi mediate concentration of soluble secretory proteins by exclusion from COPI-coated vesicles. Cell 98, 81-90

Marzioch M., Henthorn D.C., Herrmann J.M., Wilson R., Thomas D.Y., Bergeron J.J., Solari R.C., Rowley A. (1999)

Erp1p and Erp2p, partners for Emp24p and Erv25p in a yeast p24 complex. Mol. Biol. Cell 10, 1923-1938 
Matsuoka K., Neuhaus J.M. (1999)

Cis-elements of protein transport to plant vacuoles. J. Exp. Bot. 50, 165-174

Matveeva E., Whiteheart S.W. (1998)

The effects of SNAP/SNARE complexes on the ATPase of NSF. FEBS Lett. 435, 211-214

McCleary B.V., Sheehan H. (1987)

Measurement of cereal $\alpha$-amylase : a new assay procedure. J. Cereal Sci. 6, 237-251

Melançon P., Glick B.S., Malhotra V., Weidman P.J., Serafini T., Gleason M.L., Orci L.,

Rothman J.E. (1987)

Involvement of GTP-binding "G" proteins in transport through the Golgi stack. Cell 51, 1053-1062

Melkonian M., Becker B., Becker D. (1991)

Scale formation in algae. J. Electron Microsc. Tech. 17, 165-178

Merisko E.M., Farquhar M.G., Palade G.E. (1986a)

Redistribution of clathrin heavy and light chains in anoxic pancreatic acinar cells.

Pancreas 1, 110-123

Merisko E.M., Fletcher M., Palade G.E. (1986b)

The reorganization of the Golgi complex in anoxic pancreatic acinar cells. Pancreas $\mathbf{1}$, 95-109

Miesenböck G., Rothman J.E. (1995)

The capacity to retrieve escaped ER proteins extends to the trans-most cisternae of the

Golgi stack. J. Cell Biol. 129, 309-319

Miller E.A., Lee M.C.S., Anderson M.A. (1999)

Identification and characterization of a prevacuolar compartment in stigmas of Nicotiana alata. Plant Cell 11, 1499-1508

Mironov A.A., Weidman P., Luini A. (1997)

Variations on the intracellular transport theme: maturing cisternae and trafficking tubules.

J. Cell Biol. 138, 481-484

Misumi Y., Misumi Y., Miki K., Takatsuki A., Tamura G., Ikehara Y. (1986)

Novel blockade by brefeldin A of intracellular transport of secretory proteins in cultured rat hepatocytes. J. Biol. Chem. 261, 11398-11403

Molinari M., Helenius A. (2000)

Chaperone selection during glycoprotein translocation into the endoplasmic reticulum.

Science 288, 331-333

Mollenhauer H.H., Morré D.J. (1991)

Perspectives on Golgi apparatus form and function. J. Electron. Microsc. Tech. 17, 2-14 
Mollenhauer H.H., Morré D.J. (1994)

Structure of Golgi apparatus. Protoplasma 180, 14-28

Mollenhauer H.H., Morré D.J., Vanderwoude W.J. (1976)

Endoplasmic reticulum-Golgi apparatus associations in maize root tips. Mikroskopie. 31, 257-272

Moore P.J., Staehelin L.A. (1988)

Immunogold localization of the cell-wall-matrix polysaccharides rhamnogalacturonan I and xyloglucan during cell expansion and cytokinesis in Trifolium pratense L.;

implications for the secretory pathways. Planta 174, 433-445

Morré D.J. (1987)

The Golgi apparatus. Int. Rev. Cytol. Suppl. 17, 211-253

Movafeghi A., Happel N., Pimpl P., Tai G.-H., Robinson D.G. (1999)

Arabidopsis Sec21p and Sec23p homologs. Probable coat proteins of plant COP-coated vesicles. Plant Physiol. 119, 1437-1445

Mueller S.C., Branton D. (1984)

Identification of coated vesicles in Saccharomyces cerevisiae. J. Cell Biol. 98, 341-346

Munro S., Pelham H.R.B. (1987)

A C-terminal signal prevents secretion of luminal ER proteins. Cell 48, 899-907

Müntz K. (1998)

Deposition of storage proteins. Plant Mol. Biol. 38, 77-99

Müntz K. (1989)

Intracellular protein sorting and the formation of protein reserves in storage tissue cells of plant seeds. Biochem. Physiol. Pflanzen 185, 315-335

Nagahashi J., Nagahashi S.L. (1982)

Triton-stimulated nucleoside diphosphatase: Characterization. Protoplasma 112, 174-180

Nakano A., Brada D., Schekman R. (1988)

A membrane glycoprotein, $S e c 12 p$, is required for transport from the endoplasmic reticulum to the Golgi apparatus in yeast. J. Cell Biol. 107, 851-863

Nakano A., Muramatsu M. (1989)

A novel GTP-binding protein, Sar1p, is involved in transport from the endoplasmic reticulum to the Golgi apparatus. J. Cell Biol. 109, 2677-2691

Nebenführ A., Gallagher L.A., Dunahay T.G., Frohlick J.A., Mazurkiewicz A.M., Meehl J.B., Staehelin L.A. (1999)

Stop-and-go movements of plant Golgi stacks are mediated by the acto-myosin system. Plant Physiol. 121, 1127-1142 
Neer E.J., Schmidt C.J., Nambudripad R., Smith T.F. (1994)

The ancient regulatory-protein family of WD-repeat proteins. Nature 371, 297-300

Neuhaus J.M. (1996)

Protein targeting to the plant vacuole. Plant Physiol. Biochem. 34, 217-221

Neuhaus J.M., Rogers J.C. (1998)

Sorting of proteins to vacuoles in plant cells. Plant Mol. Biol. 38, 127-144

Neuhoff V., Stamm R. und Eibl H. (1985)

Clear background and highly sensitive protein staining with Coomassie Blue dyes in polyacrylamide gels: a systematic analysis. Electrophoresis 6, 427-448

Neven L.G., Haskell D.W., Guy C.L., Denslow N., Klein P.A., Green L.G., Silverman A. (1992)

Association of 70-kilodalton heat-shock cognate proteins with acclimation to cold. Plant

Physiol. 99, 1362-1369

Newman T., de Bruijn F.J., Green P., Keegstra K., Kende H., McIntosh L., Ohlrogge J., Raikhel N., Somerville S., Thomashow M. (1994)

Genes galore: a summary of methods for accessing results from large-scale partial sequencing of anonymous Arabidopsis cDNA clones. Plant Physiol. 106, 1241-1255

Nickel W., Brügger B. (1999)

COPI-mediated protein and lipid sorting in the early secretory pathway. Protoplasma $\mathbf{2 0 7}$, 115-124

Nickel W., Huber L.A., Kahn R.A., Kipper N., Barthel A., Fasshauer D., Söling H.-D. (1994) ADP Ribosylation factor and a 14-kD polypeptide are associated with heparan sulfatecarrying post-trans-Golgi Network secretory vesicles in rat hepatocytes. J. Cell Biol. 125, $721-732$

Nickel W., Malsam J., Gorgas K., Ravazzola M., Jenne N., Helms J.B., Wieland F.T. (1998) Uptake by COPI-coated vesicles of both anterograde and retrograde cargo is inhibited by GTPgammaS in vitro. J. Cell Sci. 111, 3081-3090

Nickel W., Sohn K., Bunning C., Wieland F.T. (1997) p23, a major COPI-vesicle membrane protein, constitutively cycles through the early secretory pathway. Proc. Natl. Acad. Sci. USA 94, 11393-11398

Nishimura N., Balch W.E. (1997)

A di-acidic signal required for selective export from the endoplasmic reticulum. Science 277, 556-558

Oka T., Nakano A. (1994)

Inhibition of GTP hydrolysis by Sar1p causes accumulation of vesicles that are a functional intermediate of the ER-to-Golgi transport in yeast. J. Cell Biol. 124, 425-434

Oprins A., Duden R., Kreis T.E., Geuze H.J., Slot J.W. (1993)

$\beta$-COP localizes mainly to the cis-Golgi side in exocrine pancreas. J. Cell Biol. 121, 49-59 
Orci L., Glick B.S., Rothman J.E. (1986)

A new type of coated vesicular carrier that appears not to contain clathrin: its possible role in protein transport within the Golgi stack. Cell 46, 171-184

Orci L., Malhotra V., Amherdt M., Serafini T., Rothman J.E. (1989)

Dissection of a single round of vesicular transport: sequential intermediates for intercisternal movement in the Golgi stack. Cell 56, 357-368

Orci L., Palmer D.J., Amherdt M., Rothman J.E. (1993)

Coated vesicle assembly in the Golgi requires only coatomer and ARF proteins from the cytosol. Nature 364, 732-734

Orci L., Perrelet A., Ravazzola M., Amherdt M., Rothman J.E., Schekman R. (1994)

Coatomer-rich endoplasmic reticulum. Proc. Natl. Acad. Sci. USA 91, 11924-11928

Orci L., Perrelet A., Rothman J.E. (1998)

Vesicles on strings: morphological evidence for processive transport within the Golgi stack. Proc. Natl. Acad. Sci. USA 95, 2279-2283

Orci L., Stamnes M., Ravazzola M., Amherdt M., Perrelet M., Söllner T.H., Rothman J.E. (1997) Bidirectional transport by distinct populations of COPI-coated vesicles. Cell 90, 335-349

Orci L., Tagaya M., Amherdt M., Perrelet A., Donaldson J.G., Lippincott-Schwartz J., Klausner R.D., Rothman J.E. (1991)

Brefeldin A, a Drug that blocks secretion, prevents the assembly of non-clathrin-coated buds on Golgi cisternae. Cell 22, 1183-1195

Ostermann J., Orci L., Tani K., Amherdt M., Ravazzola M., Elazar Z., Rothman J.E. (1993)

Stepwise assembly of functionally active transport vesicles. Cell 75, 1015-1025

Paccaud J.P., Reith W., Carpentier J.L., Ravazzola M., Amherdt M., Schekman R., Orci L. (1996)

Cloning and functional characterization of mammalian homologues of the COPII component Sec23. Mol. Biol. Cell 7, 1535-1546

Pagano A., Letourneur F., Garcia-Estefania D., Carpentier J.L., Orci L., Paccaud J.P. (1999)

Sec24 proteins and sorting at the endoplasmic reticulum. J. Biol. Chem. 274, 7833-7840

Pagny S., Cabanes-Macheteau M., Gillikin J.W., Leborgne-Castel N., Lerouge P., Boston R.S., Faye

L., Gomord V. (2000)

Protein recycling from the Golgi apparatus to the endoplasmic reticulum in plants and its

minor contribution to calreticulin retention. Plant Cell 12, 739-756

Pagny S., Lerouge P., Faye L., Gomord V. (1999)

Signals and mechanisms for protein retention in the endoplasmic reticulum. J. Exp. Bot. 50, 157-164

Panzner S., Dreier L., Hartmann E., Kostka S., Rapoport T.A. (1995)

Posttranslational protein transport in yeast reconstituted with a purified complex of Sec proteins and Kar2p. Cell 81, 561-570 
Paris N., Rogers J.C. (1996)

The role of receptors in targeting soluble proteins from the secretory pathway to the vacuole. Plant Physiol. Biochem. 34, 223-227

Paris N., Rogers S.W., Jiang L., Kirsch T., Beevers L., Phillips T.E., Rogers J.C. (1997)

Molecular cloning and further characterization of a probable plant vacuolar sorting receptor Plant Physiol. 115, 29-39

Pavel J., Harter C., Wieland F.T. (1998)

Reversible dissociation of coatomer: functional characterization of a $\beta / \delta$-COP subcomplex.

Proc. Natl. Acad. Sci. USA 95, 2140-2145

Payne G.S., Baker D., van Tuinen E., Schekman R. (1988)

Protein transport to the vacuole and receptor-mediated endocytosis by clathrin heavy chaindeficient yeast. J. Cell Biol. 106, 1453-1461

Pearse B.M., Robinson M.S. (1990)

Clathrin, adaptors, and sorting. Annu. Rev. Cell Biol. 6, 151-171

Pelham H.R.B. (1988)

Evidence that luminal ER proteins are sorted from secreted proteins in a post-ER compartment. EMBO J. 4, 913-918

Pelham H.R.B. (1989)

Control of protein exit from the endoplasmic reticulum. Annu. Rev. Cell Biol. 5, 1-23

Pelham H.R.B. (1995)

Sorting and retrieval between the endoplasmic reticulum and Golgi apparatus. Curr. Opin.

Cell Biol. 7, 530-535

Pesacreta T.C., Lucas W.J. (1984)

Plasma membrane coat and a coated vesicle-associated reticulum of membranes: their

structure and possible interrelationship in Chara corallina. J. Cell Biol. 98, 1537-1545

Pesacreta T.C., Lucas W.J. (1985)

Presence of a partially-coated reticulum in angiosperms. Protoplasma 25, 173-185

Peterson G.L. (1977)

A simplification of the protein assay method of Lowry et al. which is more generally applicable. Anal. Biochem. 83, 346-356

Peyroche A., Antonny B., Robineau S., Acker J., Cherfils J., Jackson C.L. (1999)

Brefeldin A acts to stabilize an abortive ARF-GDP-Sec7 domain protein complex:

involvement of specific residues of the Sec7 domain. Mol. Cell 3, 275-285

Peyroche A., Paris S., Jackson C.L. (1996)

Nucleotide exchange on ARF mediated by yeast Gea1 protein. Nature 384, 479-481 
Pfeffer S.R. (1996)

Transport vesicle docking: SNAREs and associates. Annu. Rev. Cell Dev. Biol. 12, $441-461$

Pfeffer S.R. (1999)

Transport-vesicle targeting: tethers before SNAREs. Nat. Cell Biol. 1, 17-22

Pfeffer S.R., Rothman J.E. (1987)

Biosynthetic protein transport and sorting by the endoplasmic reticulum and Golgi. Annu. Rev. Biochem. 56, 829-852

Phillipson B., Pimpl P., Crofts A.J., Taylor J.P., Movafeghi A., Robinson D.G., Denecke J. (2001)

COPII Vesicles support significant bulk flow of soluble proteins. Cell eingereicht

Pimpl P. (1997)

Untersuchungen zur in vitro Induktion von COP-Vesikeln in transgenem Tabak.

Diplomarbeit, Abteilung für strukturelle Zellphysiologie, Universität Göttingen

Pimpl P., Movafeghi A., Coughlan S., Denecke J., Hillmer S., Robinson D.G. (2000)

In situ lokalization and in vitro induction of Plant COPI-coated vesicle. Plant Cell in Druck

Pryer N.K., Salama N.R., Schekman R., Kaiser C.A. (1993)

Cytosolic Sec13p complex is required for vesicle formation from the endoplasmic reticulum in vitro. J. Cell Biol. 120, 865-875

Pueyo J.J., Chrispeels M.J., Herman E.M. (1995)

Degradation of transport-competent destabilized phaseolin with a signal for retention in the endoplasmic-reticulum occurs in the vacuole. Planta 3, 586-596

Rambourg A., Clermont Y. (1997)

Three-dimensional structure of the Golgi apparatus in mammalian cells. In: E.G. Berger,

J. Roth; The Golgi apparatus. Birkhäuser Verlag, Basel, Schweiz, 37-61

Randazzo P.A. (1997)

Functional interaction of ADP-ribosylation factor 1 with phosphatidylinositol 4,5-

bisphosphate. J. Biol. Chem. 272, 7688-7692

Randazzo P.A., Kahn R.A. (1994)

GTP hydrolysis by ADP-ribosylation factor is dependent on both an ADP-ribosylation factor GTPase-activating protein and acid phospholipids. J. Biol. Chem. 269, 10758-10763 
Rapoport T.A., Jungnickel B., Kutay U. (1996)

Protein transport across the eukaryotic endoplasmic reticulum and bacterial inner membranes. Annu. Rev. Biochem. 65, 271-303

Ray P.M., Eisinger W.R., Robinson D.G. (1976)

Organelles involved in cell wall polysaccharide formation and transport in pea cells.

Ber. Dtsch. Bot. Ges. 89, 121-146

Rayon C., Lerouge P., Faye L. (1998)

The protein N-glycosylation in Plants. J. Exp. Biol. 49, 1463-1472

Reinhard C., Harter C., Bremser B., Brügger B., Sohn K., Helms J.B., Wieland F.T. (1999)

Receptor induced polymerization of coatomer. Proc. Natl. Acad. Sci. USA 96, 1224-1228

Rexach M.F., Latterich M., Schekman R.W. (1994)

Characteristics of endoplasmic reticulum-derived transport vesicles. J. Cell Biol. 126, 1133-1148

Rexach M.F., Schekman R.W. (1991)

Distinct biochemical requirements for the budding, targeting, and fusion of ER-derived transport vesicles. J. Cell Biol. 114, 219-229

Robinson D.G. (1985)

Plant membranes: endo- and plasmamembranes of plant cells. John Wiley and Sons, New York, USA

Robinson D.G. (1996)

Clathrin-mediated trafficking. Trends Plant Sci. 1, 349-355

Robinson D.G., Bäumer M., Hinz G., and Hohl I. (1997)

Ultrastructure of the pea cotyledon Golgi apparatus: origin of dense vesicles and the action of brefeldin A. Protoplasma 200, 198-209

Robinson D.G., Braulke T., Denecke J., Happel N., Movafeghi A., Pimpl P. (1998)

New developments in plant coated vesicle research. In: I. Tsekos, M. Moustakas; Progress in botanical research, proceedings of the $1^{\text {st }}$ Balkan botanical congress. Kluwer Academic Publishers, Dordrecht, Niederlande, 399-405

Robinson D.G., Depta H. (1988)

Coated vesicles. Ann. Rev. Plant Physiol. Plant Mol. Biol. 39, 53-99

Robinson D.G., Hinz G. (1997)

Vacuole biogenesis and protein transport to the plant vacuole: a comparison with the yeast vacuole and the mammalian lysosome. Protoplasma 197, 1-25

Robinson D.G., Hinz G. (1999)

Golgi-mediated transport of seed storage proteins. Seed Science Research 9, 267-283 
Robinson D.G., Hinz G. (2000)

Organelle isolation. In: B. Satiat-Jeunemaitre, C. Hawes; Plant cell Biology: A practical approach. IRL Press, Oxford, in Druck

Robinson D.G., Hinz G., Holstein S.E.H. (1998)

The molecular characterization of transport vesicles. Plant Mol. Biol. 38, 49-76

Robinson D.G., Hoh B., Hinz G., Jeong B.-K. (1995)

One vacuole ore two vacuoles: do protein storage vacuoles arise de novo during pea cotyledon development? J. Plant Physiol. 145, 654-664

Robinson D.G., Kristen U. (1982)

Membrane flow via the Golgi apparatus of higher plant cells. Int. Rev. Cytol. 77, 89-127

Robinson M.S. (1987)

$100 \mathrm{kD}$ coated vesicle proteins: molecular heterogeneity and intercellular distribution studied with monoclonal antibodies. J. Cell Biol. 104, 887-895

Robinson M.S. (1994)

The role of clathrin, adaptors and dynamin in endocytosis. Curr. Opin. Cell Biol. 6, 538-544

Robinson M.S. (1997)

Coats and vesicle budding. Trends Cell Biol. 7, 99-102

Robinson M.S., Kreis T.E. (1992)

Recruitment of coat proteins onto Golgi membranes in intact and permeabilized cells: effects of brefeldin A and G protein activators. Cell 69, 129-138

Roca R., Stiefel V., Puigdomenech P. (1998)

Characterization of the sequence coding for the clathrin coat assembly protein AP17 (sigma2) associated with the plasma membrane from Zea mays and constitutive expression of its gene. Gene 208, 67-72

Rothman J.E. (1994)

Mechanisms of intracellular protein transport. Nature 372, 55-63

Rothman J.E., Orci L. (1992)

Molecular dissection of the secretory pathway. Nature 355, 409-415

Rothman J.E., Warren G. (1994)

Implications of the SNARE hypothesis for intracellular membrane topology and dynamics.

Curr. Biol. 4, 220-233

Rothman J.E., Wieland F.T. (1996)

Protein sorting by transport vesicles. Science 272, 227-234

Rutten T.L., Knuiman B. (1993)

Brefeldin A effects on tobacco pollen tubes. Eur. J. Cell Biol. 61, 247-255

Sabehat A., Lurie S., Weiss D. (1998)

Expression of small heat-shock proteins at low temperatures. Plant Physiol. 117, 651-658 
Salama N.R., Chuang J.S., Schekman R.W. (1997)

Sec31 encodes an essential component of the COPII coat required for transport vesicle budding from the endoplasmic reticulum. Mol. Biol. Cell 8, 205-217

Salama N.R., Yeung T., Schekman R.W. (1993)

The Sec13p complex and reconstitution of vesicle budding from the ER with purified cytosolic proteins. EMBO J. 12, 4073-4082

Salinovic O., Montelaro R.C. (1986)

Reversible staining and peptide mapping of proteins transferred to nitrocellulose after separation by sodium dodecylsulfate polyacrylamide gel electrophoresis. Anal. Biochem. 156, 341-347

Sambrook J., Fritsch E.F., Maniatis T. (1989)

Molecular cloning: a laboratory manual. Cold Spring Harbor Laboratory Press, New York, USA

Sandelius A.S., Morré D.G. (1990)

Plasma membrane isolation. In: C. Larsson, I.M. Möller; The plant plasma membrane. Springer Verlag, Berlin, 44-75

Sanderfoot A.A., Ahmed S.U., Marty-Mazars D., Rapoport I., Kirchhausen T., Marty F., Raikhel N.V. (1998)

A putative vacuolar cargo receptor partially colocalizes with AtPEP12p on a prevacuolar compartment in Arabidopsis roots. Proc. Natl. Acad. Sci. USA 95, 9920-9925

Sanderfoot A.A., Kovaleva V., Zheng H., Raikhel N.V. (1999)

The t-SNARE AtVAM3p resides on the prevacuolar compartment in Arabidopsis root cells. Plant Physiol. 121, 929-938

Sanderfoot A.A., Raikhel N.V. (1999)

The specificity of vesicle trafficking: coat proteins and SNAREs. Plant Cell 11, 629-642

Saraste J., Kuismanen E. (1984)

Pre- and post-Golgi vacuoles operate in the transport of Semliki Forest virus membrane glycoproteins to the cell surface. Cell 38, 535-549

Satiat-Jeunemaitre B., Hawes C. (1992)

Redistribution of a Golgi glycoprotein in plant cells treated with brefeldin A. J. Cell Sci. 103, 1153-1166

Satiat-Jeunemaitre B., Hawes C. (1993)

The distribution of secretory products in plant cells is affected by brefeldin A. Cell Biol. Int. 17, 183-193 
Satiat-Jeunemaitre B., Cole L., Bourett T., Howard R., Hawes C. (1996)

Brefeldin A effects in plant and fungal cells: something new about vesicle trafficking?

J. Microsc. 181, 162-177

Sato S., Nakamura Y., Kaneko T., Katoh T., Asamizu E., Tabata S. (2000)

Structural analysis of Arabidopsis thaliana chromosome 3. I. Sequence features of the regions of 4,504,864 bp covered by sixty P1 and TAC clones. DNA Res. 7, 131-135

Scales S.J., Gomez M., Kreis T.E. (2000)

Coat proteins regulating membrane traffic. Int. Rev. Cytol. 195, 67-144

Scales S.J., Pepperkok R., Kreis T.E. (1997)

Visualization of ER to Golgi transport in living cells reveals a sequential mode of action for COPII and COPI. Cell 90, 1137-1148

Scheel J., Pepperkok R., Lowe M., Griffiths G., Kreis T.E. (1997)

Dissociation of coatomer from membranes is required for brefeldin A-induced transfer of

Golgi enzymes to the endoplasmic reticulum. J. Cell Biol. 137, 319-333

Schekman R., Orci L. (1996)

Coat proteins and vesicle budding. Science 271, 1526-1533

Schimmöller F., Simon I., Pfeffer S.R. (1998)

Rab GTPases, directors of vesicle docking. J. Biol. Chem. 273, 22161-22164

Schimmöller F., Singer-Krüger B., Schröder S., Krüger U., Barlowe C., Riezmann H. (1995)

The absence of Emp24p, a component of ER-derived COPII-coated vesicles, causes a defect in transport selected proteins to the Golgi. EMBO J. 14, 1329-1339

Schindler T., Bergfeld R., Hohl M., Schopfer P. (1994)

Inhibition of Golgi apparatus function by brefeldin A in maize coleoptiles and its consequences on auxin mediated growth, cell wall extensibility and secretion of cell wall proteins. Planta 192, 404-413

Schledzewski K., Brinkmann H., Mendel R.R. (1999)

Phylogenetic analysis of components of the eukaryotic vesicle transport system reveals a common origin of adaptor protein complexes 1,2, and 3 and the F subcomplex of the coatomer COPI. J. Mol. Evol. 48, 770-778

Schmid S.L., Braell W.A., Schlossman D.M., Rothman J.E. (1984)

A role for clathrin light chains in the recognition of clathrin cages by 'uncoating ATPase'.

Nature 311, 228-231

Schmid S.L., Damke H. (1995)

Coated vesicles: a diversity of form and function. FASEB J. 9, 1445-1453

Schweizer A., Hauri H.-P. (1992)

The endoplasmic reticulum-Golgi intermediate compartment. Curr. Opin Cell Biol. 4, 600-608 
Seeger M., Payne G.S. (1992)

A role for clathrin in the sorting of vacuolar proteins in the Golgi complex of yeast.

EMBO J. 11, 2811-2818

Semenza J.C., Hardwick K.G., Dean N., Pelham H.R. (1990)

ERD2, a yeast gene required for the receptor-mediated retrieval of luminal ER proteins from the secretory pathway. Cell 61, 1349-1357

Serafini T., Orci L., Amherdt M., Brunner M., Kahn R.A., Rothman J.E. (1991)

ADP-ribosylation factor is a subunit of the coat of Golgi-derived COP-coated vesicles: a novel role for a GTP-binding protein. Cell 67, 239-253

Shaywitz D.A., Espenshade P.J., Gimeno R.E., Kaiser C.A. (1997)

COPII subunit interactions in the assembly of the vesicle coat. J. Biol Chem. 272, 25413-25416

Sheff D., Lowe M., Kreis T.E., Mellman I. (1996)

Biochemical heterogeneity and phosphorylation of coatomer subunits. J. Cell Biol. 271, 7230-7236

Shimada T., Kuroyanagi M., Nishimura M., Hara-Nishimura I. (1997)

A pumpkin $72-\mathrm{kDa}$ membrane protein of precursor-accumulating vesicles has characteristics of a vacuolar sorting receptor. Plant Cell Physiol. 38, 1414-20

Silveira L.A., Wong D.H., Masiart W.R., Schekman R. (1990)

Yeast clathrin has a distinctive light chain that is important for cell growth. J. Cell Biol. 111, 1437-1449

Simpson F., Peden A.A., Christopoulou L., Robinson M.S. (1997)

Characterization of the adaptor-related protein complex, AP-3. J. Cell Biol. 137, 835-845

Singer S.J. (1974)

The molecular organization of membranes. Annu. Rev. Biochem. 43, 805-833

Smith D.B., Johnson K.S. (1988)

Single-step purification of polypeptides expressed in Escherichia coli as fusion with glutathione S-transferase. Gene 67, 31-40

Sohn K., Orci L., Ravazzola M., Amherdt M., Bremser M., Lottspeich F., Fiedler K., Helms J.B., Wieland F.T. (1996)

A major membrane protein of Golgi-derived COPI-coated vesicles involved in coatomer binding. J. Cell Biol. 135, 1239-1248

Söllner T., Whiteheart S.W., Brunner M., Erdjument-Bromage H., Geromanos S., Tempst P., Rothman J.E. (1993)

SNAP receptors implicated in vesicle targeting and fusion. Nature 362, 318-324 
Spang A., Matsuoka K., Hamamoto S., Schekman R., Orci L. (1998)

Coatomer, Arf1p, and nucleotide are required to bud coat protein complex I-coated vesicles from large synthetic liposomes. Proc. Natl. Acad. Sci. USA 95, 11199-11204

Spiess M. (1995)

Heads or tails: what determines the orientation of proteins in the membrane. FEBS Lett. 369, 76-79

Springer S., Chen E., Duden R., Marzioch M., Rowley A., Hamamoto S., Merchant S., Schekman R. (2000)

The p24 proteins are not essential for vesicular transport in Saccharomyces cerevisiae.

Proc. Natl. Acad. Sci. USA 97, 4034-4039

Springer S., Schekman R. (1998)

Nucleation of COPII vesicular coat complex by endoplasmic reticulum to Golgi vesicle

SNAREs. Science 281, 698-700

Staehelin L.A. (1997)

The plant ER: a dynamic organelle composed of a large number of discrete functional domains. Plant J. 11, 1151-1165

Staehelin L.A., Giddings T.H., Levy S., Lynch M.A., Moore P.J., Swords K.M.M. (1991)

Organization of the secretory system of cell wall glycoproteins and complex polysaccharides in plant cells. Sem. Ser. - Soc. Exp. Biol. 45, 183-198

Staehelin L.A., Moore I. (1995)

The plant Golgi apparatus: structure, functional organization and trafficking mechanisms. Ann. Rev. Plant Physiol. Molec. Biol. 46, 261-288

Stamnes M.A., Craighead M.W., Hoe M.H., Lampen N., Geromanos S., Tempst P., Rothman J.E. (1995)

An integral protein component of coatomer-coated transport vesicles defines a family of proteins involved in budding. Proc. Natl. Acad. Sci. USA 92, 8011-8015

Stenbeck G., Schreiner R., Herrmann D., Auerbach S., Lottspeich F., Rothman J.E., Wieland F.T. (1992)

Gamma-COP, a coat subunit of non-clathrin-coated vesicles with homology to Sec21p. FEBS Lett. 314, 195-198

Studier F.W., Moffatt B.A. (1986)

Use of bacteriophage T7 RNA polymerase to direct selective high-level expression of cloned genes. J. Mol. Biol. 189, 113-130

Sturm A., van Kuik J.A., Vliegenthart J.F., Chrispeels M.J. (1987)

Structure, position, and biosynthesis of the high mannose and the complex 
oligosaccharide side chains of the bean storage protein phaseolin. J. Biol. Chem. 262, 13392-13403

Tanigawa G., Orci L., Amherdt M., Ravazzola M., Helms J.B., Rothman J.E. (1993)

Hydrolysis of bound GTP by ARF protein triggers uncoating of Golgi-derived COPcoated vesicles. J. Cell Biol. 123, 1365-1371

Tartakoff A.M. (1986)

Temperature and energy dependence of secretory protein transport in the exocrine pancreas. EMBO J. 5, 1477-1482

Tartakoff A.M. (1987)

The secretory and endocytic paths: mechanisms and specificity of vesicular traffic in the cell cytoplasm. John Wiley \& Sons, New York

Tatu U., Helenius A. (1997)

Interactions between newly synthesized glycoproteins, calnexin and a network of resident chaperones in the endoplasmic reticulum. J. Cell Biol. 136, 555-565

Teasdale R.H., Jackson M.R. (1996)

Signal-mediated sorting of membrane proteins between the endoplasmic reticulum and the Golgi apparatus. Ann. Rev. Cell Biol. 12, 27-54

Thomashow M.F. (1999)

Plant cold acclimation: freezing tolerance genes and regulatory mechanisms. Annu. Rev.

Plant Physiol. Plant Mol. Biol. 50, 571-599

Tisdale E.J., Plutner H., Matteson J., Balch W.E. (1997)

P53/58 binds COPI and is required for selective transport through the early secretory pathway. J. Cell Biol. 137, 581-593

Tokuyasu K.T. (1980)

Immunochemistry on ultrathin frozen sections. Histochem J. 12, 381-403

Tokuyasu K.T. (1986)

Application of cryoultramicrotomy to immunocytochemistry. J. Microsc. 143, 139-149

Towbin H., Staehelin T., Gordon J. (1979)

Electrophoretic transfer of proteins from polyacrylamide gels to nitrocellulose sheets: procedure and some applications. Proc. Natl. Acad. Sci. USA 76, 4350-4354

Townsley F.M., Pelham H.R. (1994)

The KKXX signal mediates retrieval of membrane proteins from the Golgi to the ER in yeast. Eur. J. Cell Biol. 64, 211-216 
Townsley F.M., Wilson D.W., Pelham H.R.B. (1993)

Mutational analysis of the lumen KDEL receptor: Distinct structural requirements for Golgi retention, ligand binding, and retrograde transport. EMBO J. 12, 2821-2829

Traub L.M., Bannykh S.I., Rodel J.E., Aridor M., Balch W.E., Kornfeld S. (1996)

AP-2-containing clathrin coats assemble on mature lysosomes. J. Cell Biol. 135, $1801-1814$

Traub L.M., Kornfeld S. (1997)

The trans-Golgi network: a late secretory sorting station. Curr. Opin. Cell Biol. 9, 527-533

Ukaji N., Kuwabara C., Takezawa D., Arakawa K., Yoshida S., Fujikawa S. (1999)

Accumulation of small heat-shock protein homologs in the endoplasmic reticulum of cortical parenchyma cells in mulberry in association with seasonal cold acclimation. Plant Physiol. 120, $481-490$

Ulmer J.B., Palade G.E. (1991)

Effects of Brefeldin A on the Golgi complex, endoplasmic reticulum and viral envelope glycoproteins in murine erythroleukemia cells. Eur. J. Cell Biol. 54, 38-54

Ungewickell E. (1985)

The $70 \mathrm{kD}$ mammalian heat shock proteins are structurally and functionally related to the uncoating protein that releases clathrin triskelia from coated vesicles. EMBO J. 4, 3385-3391

Ungewickell E, Ungewickell H. (1991)

Bovine brain clathrin light chains impede heavy chain assembly in vitro. J. Biol. Chem. 266, 12710-12714

Ungewickell E., Ungewickell H., Holstein S.E.H., Lindner R., Prasad K., Barouch W., Martin B., Greene L.E., Eisenberg E. (1995)

Role of auxilin in uncoating clathrin-coated vesicles. Nature 378, 632-635

van Bergen en Henegouwen (1989)

Immunogold labeling of ultrathin cryosections. In: M.A. Hayat. Colloidal gold: principals, methods, and applications; vol. 1. Academic Press, London, GB, 191-216

Villalba J.M., Lützelschwalb M., Serrano R. (1991)

Immunolocalization of plasma membrane $\mathrm{H}^{+}$-ATPase in maize coleoptiles and enclosed leaves. Planta 185, 458-461

Vitale A., Denecke J. (1999)

The endoplasmic reticulum - Gateway of the secretory pathway. Plant Cell 11, 615-628 Vowels J.J., Payne G.S. (1998)

A dileucine-like sorting signal directs transport into an AP-3-dependent, clathrinindependent pathway to the yeast vacuole. EMBO J. 17, 2482-2493 
Wahlberg J.M., Spiess M. (1997)

Multiple determinants direct the orientation of signal-anchor proteins: the topogenic role of the hydrophobic signal domain. J. Cell Biol. 137, 555-562

Walter P., Johnson A.E. (1994)

Signal sequence recognition and protein targeting to the endoplasmic reticulum membrane. Ann. Rev. Cell Biol. 10, 87-119

Wandelt C.I., Khan M.R.I., Craig S., Schroeder H.E., Spencer, D., Higgins T.J.V. (1992)

Vicilin with carboxyterminal KDEL is retained in the endoplasmic reticulum and accumulates to high levels in the leaves of transgenic plants. Plant J. 2, 181-192

Waters M.G., Beckers C.J.M., Rothman J. (1992)

Purification of coat protomers. Methods Enzymol. 219, 331-337

Waters M.G., Serafini T., Rothman J.E. (1991)

'Coatomer': a cytosolic protein complex containing subunits of non-clathrin-coated Golgi transport vesicles. Nature 349, 248-251.

Weber T., Zemelman B.V., McNew J.A., Westermann B., Gmachl M., Parlati F., Söllner T.H., Rothman J.E. (1998)

SNAREpins: minimal machinery for membrane fusion. Cell 92, 759-772

Weidler M., Reinhard C., Friedrich G., Wieland F.T., Rosch P. (2000)

Structure of the cytoplasmic domain of p23 in solution: implications for the formation of COPI vesicles. Biochem. Biophys. Res. Commun. 271, 401-418

Wessel D., Flügge U.I. (1984)

A method for the quantitative recovery of protein in dilute solution in the presence of detergents and lipids. Analyt. Biochem. 138, 141-143

West M.A., Bright N.A., Robinson M.S. (1997)

The role of ADP-ribosylation factor and phospholipase D in adaptor recruitment. J. Cell Biol. 138, 1239-1254

Whiteheart S.W., Brunner M., Wilson D.W., Wiedmann M., Rothman J.E. (1992)

Soluble N-ethylmaleimide-sensitive fusion attachment proteins (SNAPs) bind to a multiSNAP receptor complex in Golgi membranes. J. Biol. Chem. 267, 12239-12243

Whiteheart S.W., Rossnagel K., Buhrow S.A., Brunner M., Jaenicke R., Rothman J.E. (1994) N-ethylmaleimide-sensitive fusion protein: a trimeric ATPase whose hydrolysis of ATP is required for membrane fusion. J. Cell Biol. 126, 945-954

Wieland F., Harter C. (1999)

Mechanisms of vesicle formation: insights from the COP system. Curr. Opin. Cell Biol. 11, 440-446 
Wieland F.T., Gleason M.L., Serafini T.A., Rothman J.E. (1987)

The rate of bulk flow from the endoplasmic reticulum to the cell surface. Cell 50, 289-300

Wilson D.W., Lewis M.J., Pelham H.R.B. (1993)

$\mathrm{pH}$-dependent binding of KDEL to its receptor in vitro. J. Biol. Chem. 268, 7465-7468

Wood S.A., Park J.E., Brown W.J. (1991)

Brefeldin A causes a microtubule-mediated fusion of the trans-Golgi network and early endosomes. Cell 67, 591-600

Ybe J.A., Greene B., Liu S.H., Pley U., Parham P., Brodsky F.M. (1998)

Clathrin self-assembly is regulated by three light-chain residues controlling the formation of critical salt bridges. EMBO J. 17, 1297-1303

Yoshihisa T., Barlowe C., Schekman R. (1993)

Requirement for a GTPase-activating protein in vesicle budding from the endoplasmic reticulum. Science 259, 1466-1468

Zhang G.F., Staehelin L.A. (1992)

Functional compartmentalization of the Golgi apparatus of plant cells. An immunocytochemical analysis of high pressure frozen and freeze-substituted sycamore maple suspension culture cells. Plant Physiol. 99, 1070-1083

Zhao L., Helms J.B., Brugger B., Harter C., Martoglio B., Graf R., Brunner J., Wieland F.T. (1997)

Direct and GTP-dependent interaction of ADP ribosylation factor 1 with coatomer subunit B. Proc. Natl. Acad. Sci. USA 94, 4418-4423

zur Nieden U., Manteuffel R., Weber E., Neumann D. (1984)

Dictyosomes participate in the intracellular pathway of storage proteins in developing Vicia faba cotyledons. Eur. J. Cell Biol. 34, 9-17 


\section{Anhang}

At $\gamma-\mathrm{COP}$ ScSec $21 \mathrm{p}$

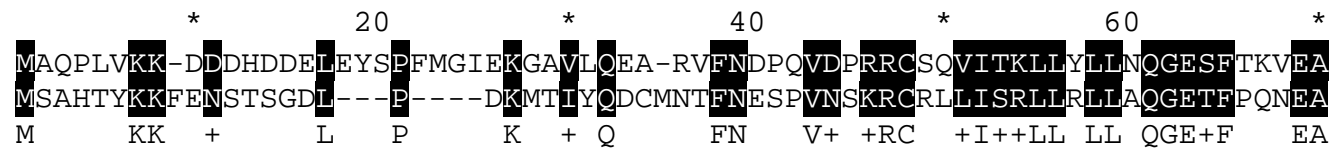

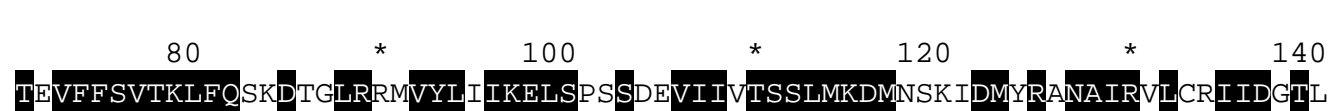

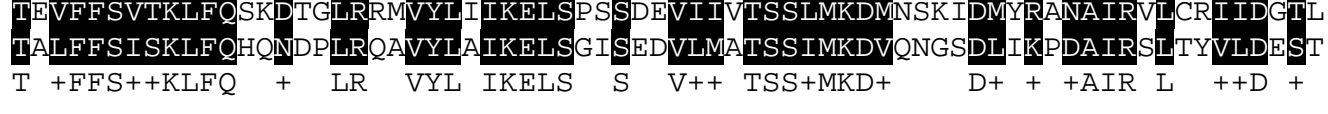

At $\gamma-\mathrm{COP}$

ScSec21p

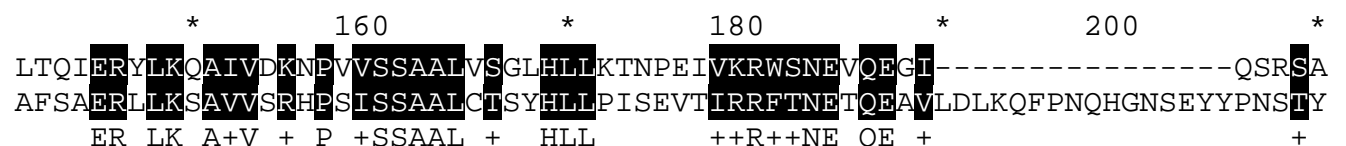

At $\gamma$-COP NTSDPSKYIRYIYNRVHLENATVRAAAVSTLAKFGFMVE--SLKPRITVLLKRCIYDSDDEVRDRATLYL SCSec21p SAPNP SLYVRHIYNRVVLENS I IRSAAVVALSKFALTKNDP TLYESIISLLKRIANDKDDEVRDRATIAI

Anhang 1: Sequenzvergleich von dem putativen $\gamma$-COP aus Arabidopsis thaliana (At) mit dem Sec21p aus Saccharomyces cerevisiae (Sc). Das von der $\gamma$-COP-cDNA abgeleitete Polypeptid (siehe Kap. 3.1.1) ist zu den letzten 417 Aminosäuren im Aminoterminus von At $\gamma$-COP (unterstrichen) homolog. 


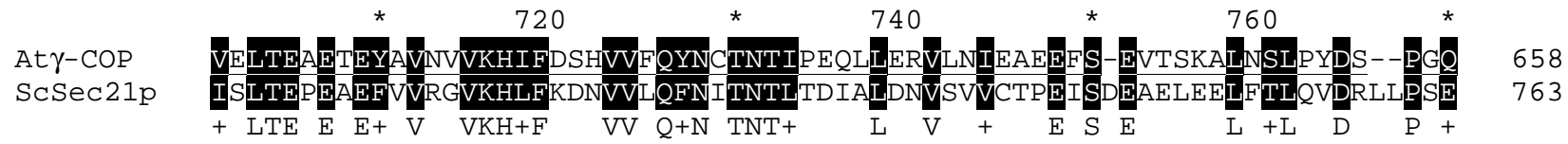

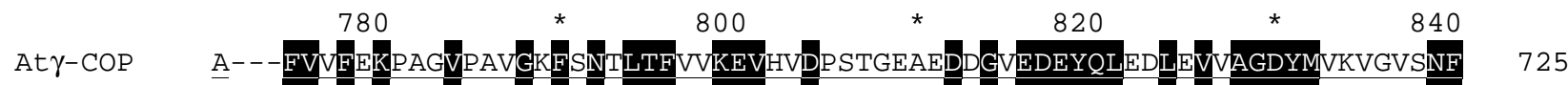

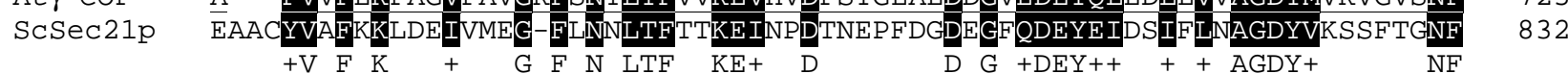

At $\gamma$-COP RNAWESMDEEDERVDEYGLGQRESLGEAVKAVMDLLGMQTCEGTETIPLNARSHTCLISG-VYIGNVKVL

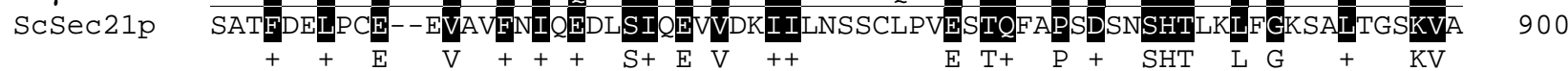

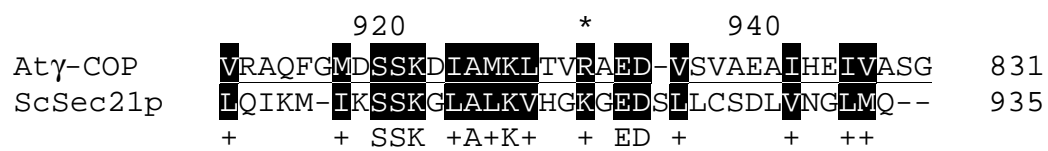

Anhang 1: Fortsetzung.

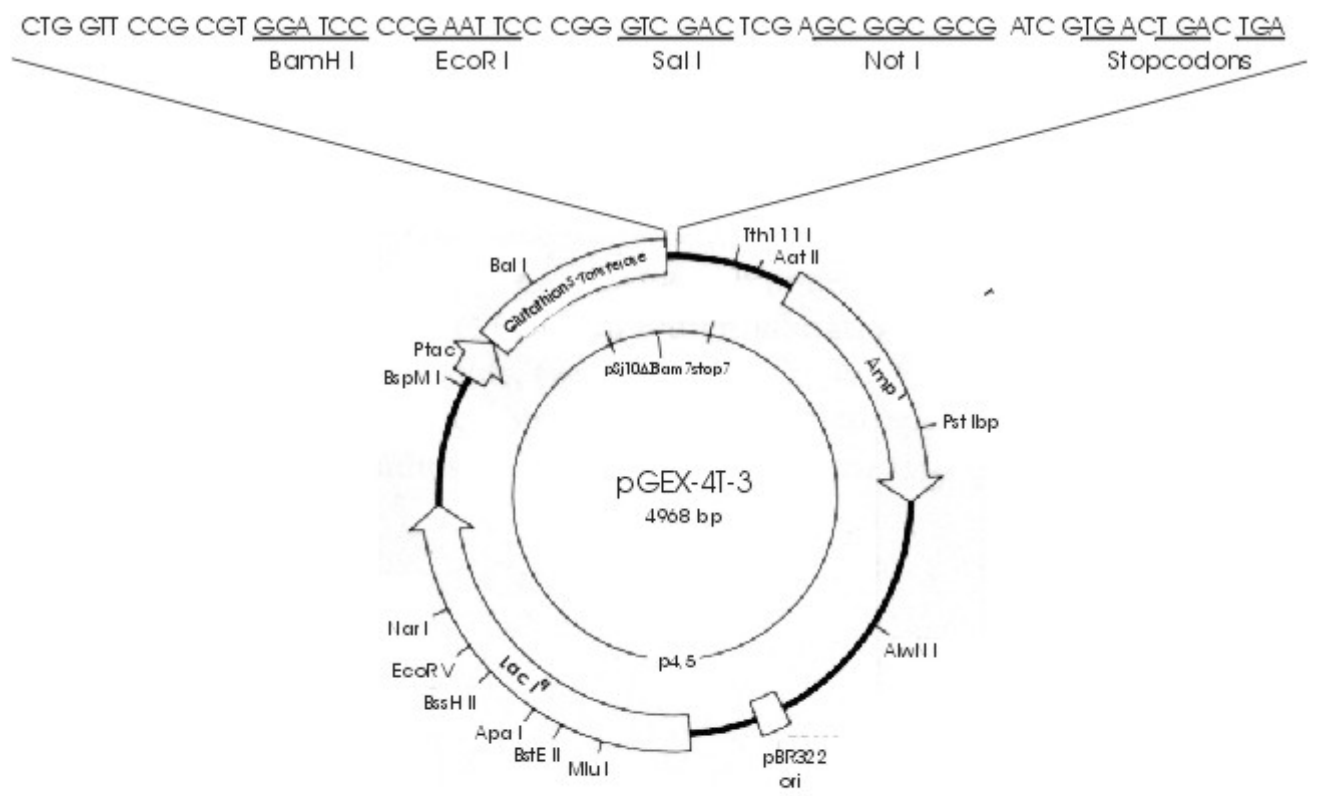

Anhang 2: Die schematische Darstellung des Expressionsvektors pGEX-4T-3 mit den in seiner Struktur vorhandenen Schnittstellen. Dieser Vektor besteht aus 4968 bp. 
At $\operatorname{Sec} 23 p$ ScSec23p

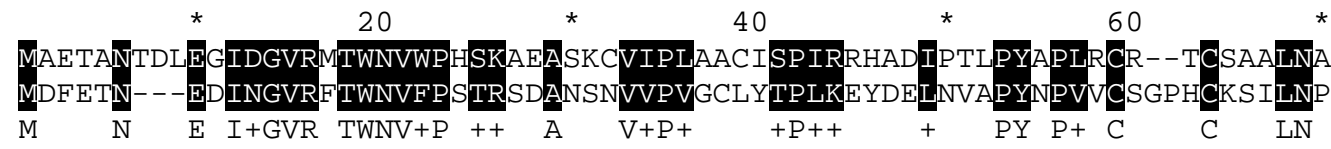

At $\operatorname{Sec} 23 p$ $\mathrm{ScSec} 23 \mathrm{p}$ $\begin{array}{cccccc}80 & * & 100 & * & 120 & *\end{array}$

At $\operatorname{Sec} 23 p$ $\mathrm{ScSec} 23 \mathrm{p}$ * 160

TCMIEEELDFAKSALKQAIGLLPENALVGFVSFGTQAHVHELGF SEMSKVFVFKGDKEISKDQILDQIGL

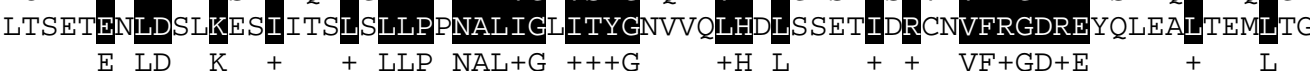

At $\operatorname{Sec} 23 \mathrm{p}$ $\mathrm{ScSec} 23 \mathrm{p}$

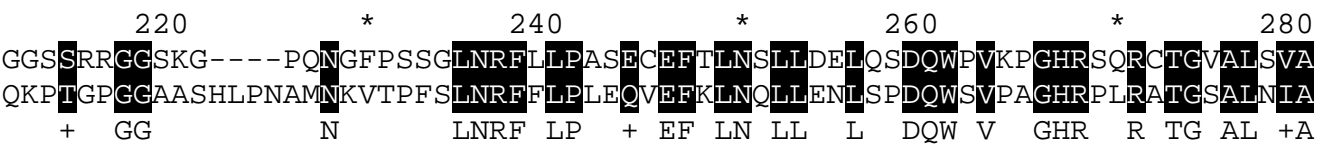

At $\operatorname{Sec} 23 p$

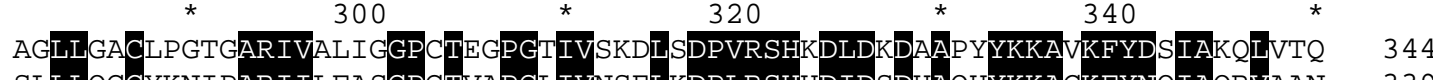
$\mathrm{ScSec} 23 \mathrm{p}$ SLI LL

At $\operatorname{Sec} 23 p$ $\mathrm{ScSec} 23 \mathrm{p}$

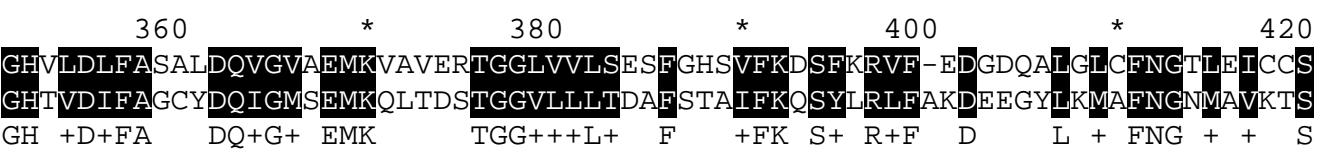

$+460$

At $\operatorname{Sec} 23 \mathrm{p}$ ScSec23p

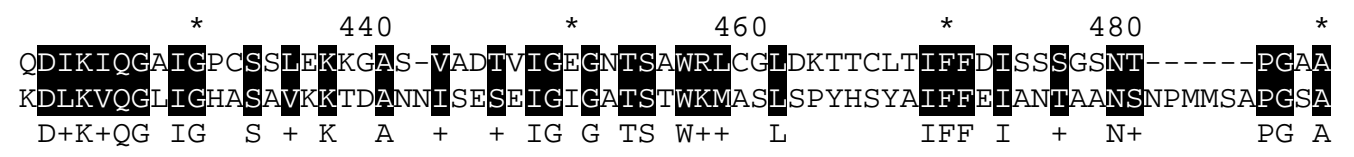

At $\operatorname{Sec} 23 \mathrm{p}$ $\operatorname{ScSec} 23 p$
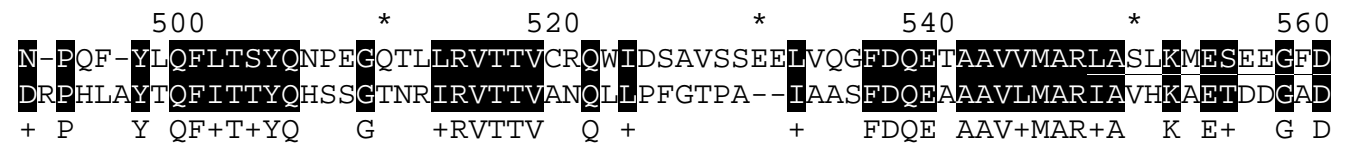

At $\operatorname{Sec} 23 \mathrm{p}$

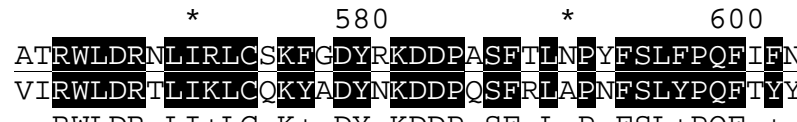

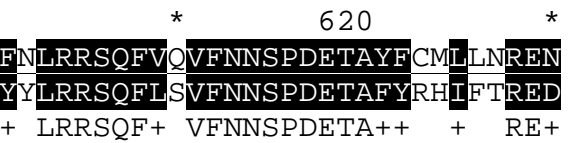

At $\operatorname{Sec} 23 p$ $\operatorname{ScSec} 23 \mathrm{p}$
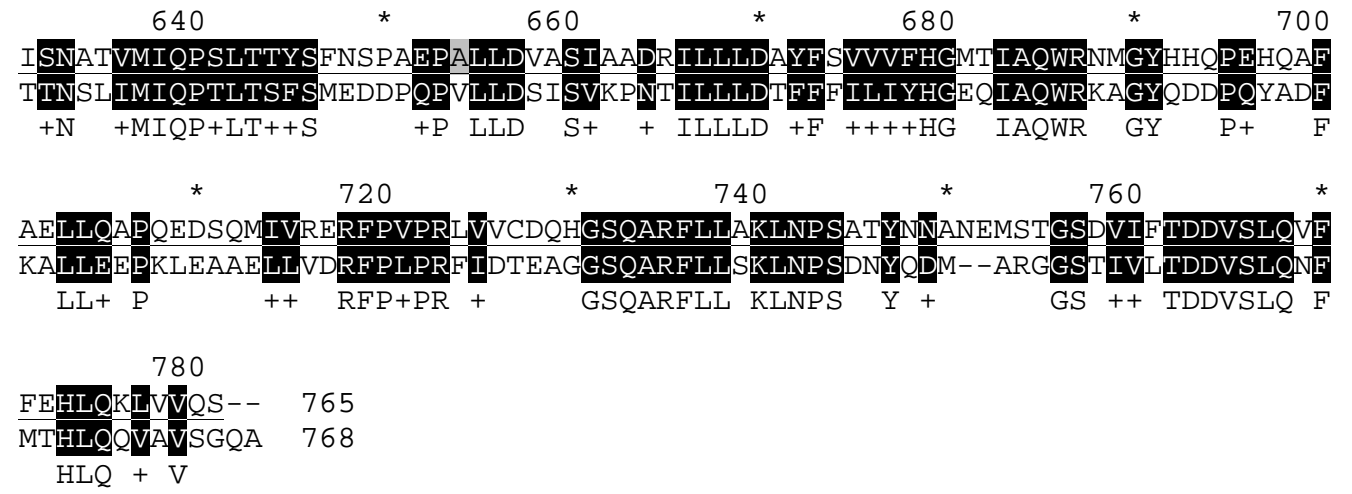

Anhang 3: Sequenzvergleich von Sec23p aus Arabidopsis thaliana (At) und Saccharomyces cerevisiae (Sc). Das von der Sec23-cDNA abgeleitete Polypeptid (siehe Kap. 3.1.2) ist $94 \%$ homolog zu den letzten 234 Aminosäuren am Aminoterminus (unterstrichen) von AtSec23p. 


\section{Danksagung}

Die vorliegende Arbeit wurde unter der Anleitung von Herrn Prof. D.G. Robinson angefertigt. Ihm möchte ich vor allem für seine umfassende Betreuung in allen Phasen dieser Arbeit bedanken.

Herrn Prof. H.-W. Heldt danke ich für die Übernahme des Korreferates.

Mein besonderer Dank gilt Dr. Stefan Hillmer und Dr. Giselbert Hinz, die mir jeder Zeit mit praktischen Ratschlägen und konstruktiver Kritik zur Seite standen.

Aus der Abteilung für strukturelle Zellphysiologie danke ich besonders Dorothee Dasbach, Nicole Happel, Andrea Olbrich, Christel Rühling und Gabriele Schauermann, für ihre Hilfsbereitschaft und das angenehme Arbeitsklima.

Weiterhin bedanke ich mich bei Dr. Jürgen Denecke für die Überlassung der transformierten Tabakpflanzen.

Danken möchte ich nicht zuletzt Dr. Inge Hohl, die durch ihre vielfältige Unterstützung zum gelingen dieser Arbeit beigetragen hat.

Dem Ministerium für Kultur und Ausbildung des Irans danke ich für die Vergabe des Promotionsstipendiums. 


\section{Lebenslauf}

Persönliche Daten:

Staatsangehörigkeit:

Ausbildung:

1972-1980

1980-1984

1984-1989

1989-1993

1993

1993-1995

Aug. 1995 - Feb. 1996

seit Feb. 1996

seit 1996
Ali Movafeghi

geboren am 25.07.1966

in Täbriz, Iran

iranisch

Grund- und Realschule in Täbriz

Gymnasium in Täbriz

Biologiestudium und Abschluss des B.Sc.-Grades im

Fachbereich Biologie an der Universität Täbriz

Biologiestudium und Abschluss des M.Sc.-Grades im

Fachbereich Biologie an der Universität Teheran

Anfertigung der M.Sc.-Arbeit mit dem Thema:

"Quantitative und Qualitative Untersuchungen der

Schleimpolysaccharide von Plantago"

Wissenschaftlicher Mitarbeiter im Fachbereich Biologie

an der Universität Täbriz

Deutschkurs am Goethe Institut, Göttingen

Experimentelle Arbeiten zur Dissertation am Albrecht-von-

Haller Institut für Pflanzenwissenschaften der Georg-

August Universität Göttingen

Mehrfach befristete Tätigkeit als wissenschaftliche

Hilfskraft am Albrecht-von-Haller Institut für

Pflanzenwissenschaften 